\begin{abstract}
SHIN, HYUNMIN. Growth and Characterization of GaN Bulk Crystals via Vapor Phase Transport. (Under the direction of Profs. Robert F. Davis and Zlatko Sitar)
\end{abstract}

Free-standing single crystals of bulk GaN were grown via unseeded vapor phase transport a $1130^{\circ} \mathrm{C}$ on hexagonal $\mathrm{BN}$ surfaces via direct reaction of Ga with ammonia. The temperature and stability of the $\mathrm{Ga}$ source were critical in terms of uniform nucleation and growth. The source temperature was maintained at $1260^{\circ} \mathrm{C}$ to minimize a rapid reaction leading to the formation of $\mathrm{GaN}$ and the subsequent decomposition beneath the surface and consequent spattering of Ga. A maximum crystal growth temperature of $1130^{\circ} \mathrm{C}$ was determined in which the $\mathrm{GaN}$ growth kinetics were much greater than decomposition. The number of nucleation events was reduced and the crystal size increased by a novel nucleation technique wherein $\mathrm{NH}_{3}$ was introduced at high temperatures. The resulting crystals were either needles or platelets depending on the process variables employed. Low V/III ratios achieved via ammonia flow rates $\leq 75 \mathrm{sccm}$ and/or ammonia total pressures $\leq 430$ Torr favored lateral growth. The average lateral growth rate for the platelets was $\sim 50 \mu \mathrm{m} / \mathrm{hr}$; the average vertical growth rate for the needles was $\sim 500 \mu \mathrm{m} / \mathrm{hr}$. Growth rates in all other directions for each of these two morphologies were very low. Seeded growth of both needle and platelet crystals was also achieved; however, the growth rate decreased at longer times and higher pressures due to reaction with $\mathrm{H}_{2}$ from the increased decomposition of ammonia. Nitrogen dilution of ammonia reduced the amount of hydrogen generated as a result of ammonia decomposition and increased the kinetic barrier to desorption of reactants from the $\mathrm{GaN}$ surface and then alleviated the enhanced decomposition of $\mathrm{GaN}$ crystals. A $2 \mathrm{~mm} \mathrm{x}$ 
$1.5 \mathrm{~mm}$ needle and a $2.3 \mathrm{~mm} \times 1.8 \mathrm{~mm} \times 0.3 \mathrm{~mm}$ platelet of GaN were grown with minimal decomposition in a $66.7 \% \mathrm{NH}_{3}+33.3 \% \mathrm{~N}_{2}$ gas mixture. Excellent crystalline quality was confirmed by Raman spectroscopy and Photoluminescence.

Crystal growth using a Ga- 5 at $\% \mathrm{Al}$ source was conducted in an attempt to increase growth rate and inhibit decomposition. No notable change in growth rate was observed and hollow crystals were formed, indicating hat Al promotes vertical growth under otherwise similar conditions for $\mathrm{GaN}$ growth. In addition, fine-grained AlN was formed within the binary $\mathrm{Ga}-\mathrm{Al}$ source, thus, the supply of $\mathrm{Al}$ was progressively reduced. Nucleation control via addition of $\mathrm{Si}$ resulted in a slightly reduced number of larger crystals. X-ray Photoelectron Spectroscopy suggested that amorphous silicon nitride was formed on the $\mathrm{BN}$ substrate and nucleation rate was slightly reduced. Silicon was not detected within the sensitivity of Energy Dispersive Spectroscopy. Raman spectroscopy revealed insignificant amount of Si present in the crystal. Smoother surface morphology of the crystals grown in the presence of $\mathrm{Si}$ was observed by Scanning Electron Microscopy. 


\title{
GROWTH AND CHARACTERIZATION OF GAN BULK CRYSTALS VIA VAPOR PHASE TRANSPORT
}

\author{
by \\ HYUNMIN SHIN
}
A dissertation submitted to the Graduate Faculty of
North Carolina State University
In partial fulfillment of the requirements for the Degree of
Doctor of Philosophy

\section{MATERIALS SCIENCE AND ENGINEERING}

\author{
Raleigh
}

2001

APPROVED BY:

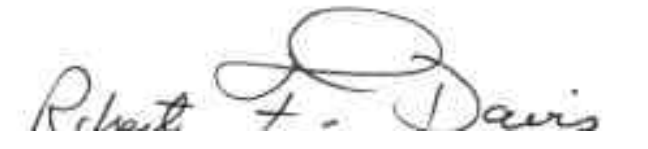

Robert F. Davis

Chair of Advisory Committee

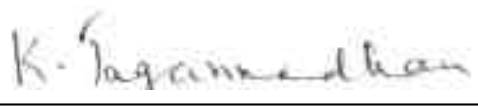

Jagannadham Kasichainula

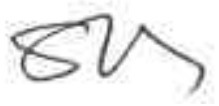

Zlatko Sitar

Co-Chair of Advisory Committee

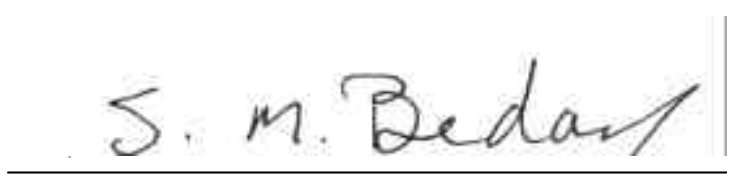

Salah M. Bedair 
Dedicated to my parents

\section{Kwang Gyun and Sang Guem}

and to my wife and son

Sue and William 


\section{Biography}

Hyunmin Shin was born on September 6 ${ }^{\text {th }}, 1964$ to Kwang Gyun and Sang Guem in Seoul, Korea. He received his Bachelor of Science degree in Ceramic Engineering from Yonsei University, Seoul, Korea, in February 1987. He received a Master of Science in Ceramic Engineering from the same institution in August 1989. He then came to study in the U. S. A. and received another Master of Science in Materials Science from the Department of Mechanical Engineering at Northeastern University, Boston, MA in September 1993. Mr. Shin has been pursuing his Doctor of Philosophy degree under advisement from Prof. Robert F. Davis in the Department of Materials Science and Engineering at North Carolina State University, Raleigh, NC, since July 1997. He was inducted to the Phi Kappa Phi Honor Society in April 2001.

Mr. Shin is married to Sue Choi and has a lovely son, William Shin. 


\section{Acknowledgments}

First and foremost, I wish to express my sincere appreciation to Dr. Robert F. Davis, the chairman of my Advisory Committee, for his academic advice, encouragement, stimulating discussion, enormous support during the course of this research, and especially giving me the opportunity to work with the nitride research group. I would also like to extend my thanks to Dr. Zlatko Sitar, the co-chair of my Advisory Committee, for providing invaluable scientific intuition, invaluable suggestions regarding this research and enouragement. My appreciations are also due Dr. Jaqannadham Kasichainula and Dr. Salah Bedair for serving in my Advisory Committee with deep interest.

I would like to acknowledge my appreciation to the Office of Naval Research for providing funding for this research.

It has been my pleasure and privilege to work with a group of nice colleagues. I truly appreciate their assistance, discussion and friendship. I would like to express my special gratitude to Mr. Darren Thomson and Mr. Pete Miraglia for supplying GaN thin films for this research. I would also like to thank Mr. Ed Preble and Dr. Sven Einfeldt for their assistance with X-ray diffraction and Photoluminescnce measurement. I would like to appreciate Dr. Alan D. Batchelor for his assistance in Atomic Force Microscopy. I would like to thank Dr. Robert J. Nemanich for the Raman spectroscopy and Dr. Tsvetangka Zheleva and Dr. O. H. Nam for their valuable discussion.

I am also grateful to Dr. Bob Terrian, Dr. Drew Hanser, Dr. Eric Carlson, Dr. Kevin Linthicum, Dr. Kieran Tracy, Dr. Thomas Gelake, Mr. Tim Smith, Mr. Philip 
Hartlieb, Mr. Brian Coppa for their assistance and friendship. I especially thank Ms. Jan Jackson for her assistance in the research-related problems and warm encouragement. My appreciation also goes to Dr. Raoul Schlesser, Dr. Scott Wolter, Dr. Fuminori Okuzumi, Dr. Wei Liu, Mr. Chuck Draper, Mr. Ramon Collazo, Mr. Gleb Yushin, Mr. Erdem Arkun, Mr. Nirmal Govindaraju in Dr. Sitar group for their discussions and friendship.

I would also like to thank Dr. Lisa Porter and Mrs. Sitar for their warm friendship and kindness every Thanksgiving Day.

I would like to thank my parents for their lifelong sacrifices, consistent encouragement and support. I cannot thank my wife, Sue, and my son, William, enough for their patience and endless support and love.

Thank you again, Dr. Davis and Dr. Sitar for helping me survive. I am forever in your debt. 


\section{Table of Contents}

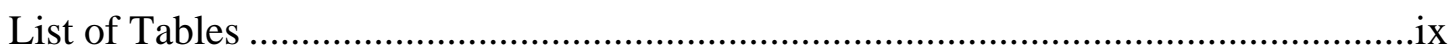

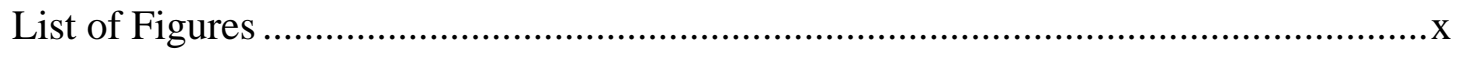

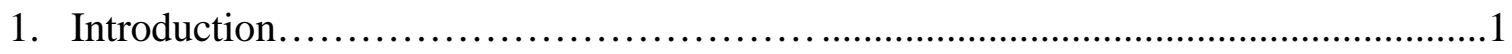

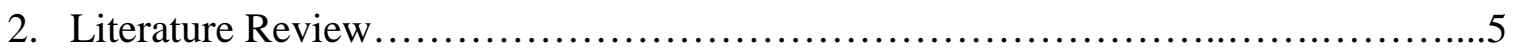

2.1. Growth Methods........................................................ 5

2.1.1. High Pressure-High Temperature Solution Growth........................5

2.1.2. HVPE(Hydride Vapor Phase Epitaxy) ............................. 8

2.1.3. Flux Growth........................................................ 12

2.1.4. Vapor Phase Transport.............................................. 13

2.1.4.1.Gallium Nitride as the Source Material in an Ammonia Atmosphere. 13

2.1.4.2.Gallium as the Source Material in an Ammonia Atmosphere.......... 15

2.1.5. Other Techniques................................................ 18

2.2. Thermodynamics and Surface Kinetics of GaN Growth.......................2 21

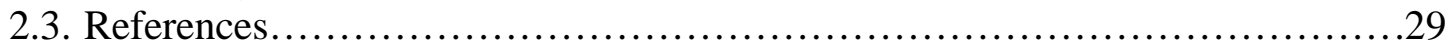

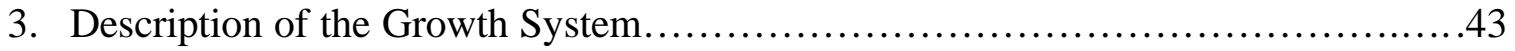

4. High Temperature Nucleation and Growth of GaN Crystals via Vapor Phase

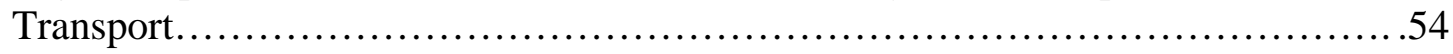

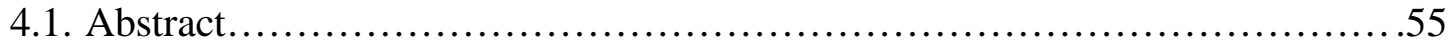

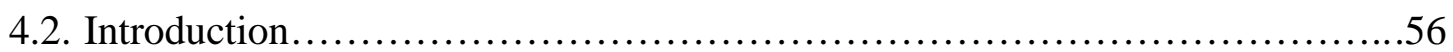

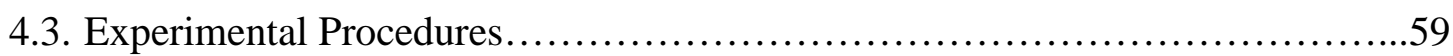

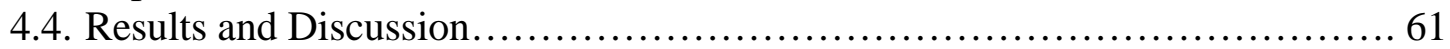

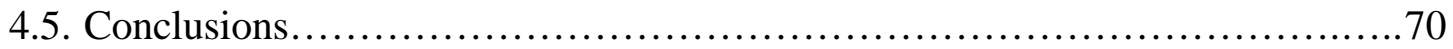

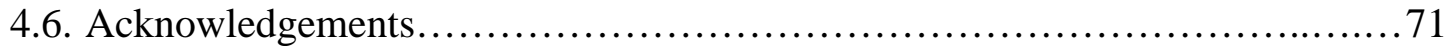

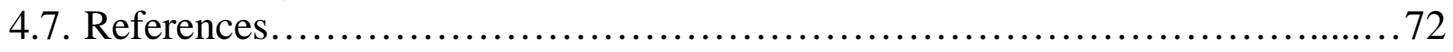

5. A New Processing Route for Growth of Bulk GaN Crystals.........................87

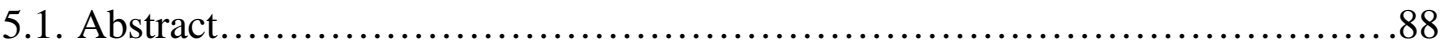

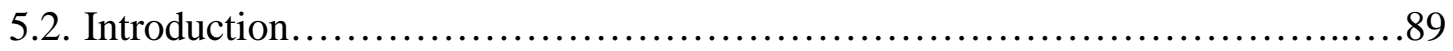

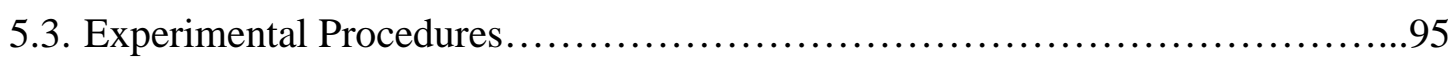

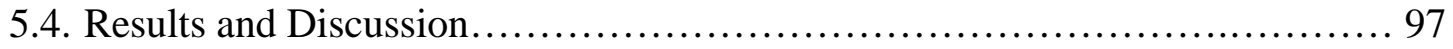

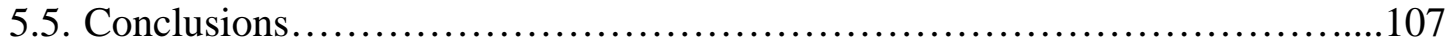

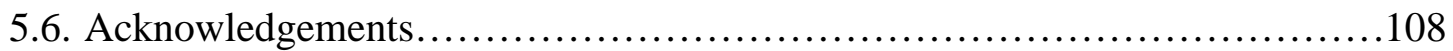

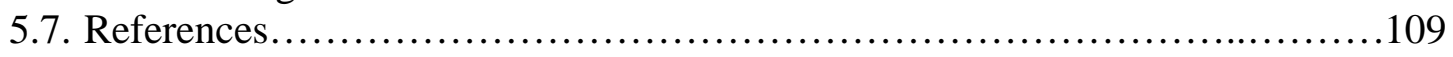

6. Effect of Nitrogen Dilution on the Growth of GaN Crystals....................... 125 


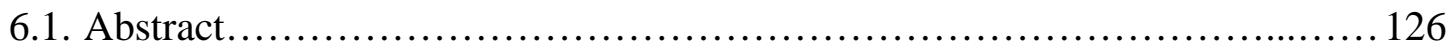

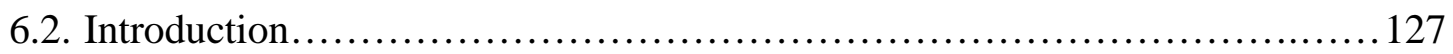

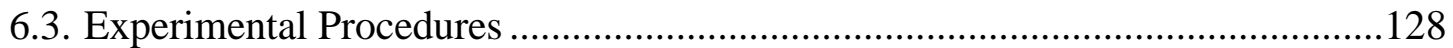

6.4. Results and Discussion....................................................... 129

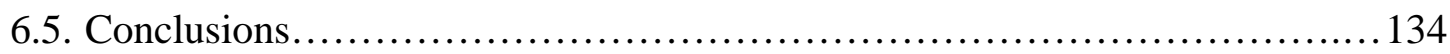

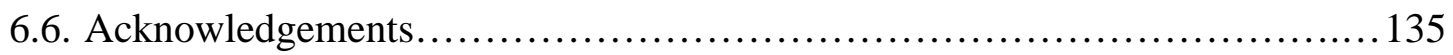

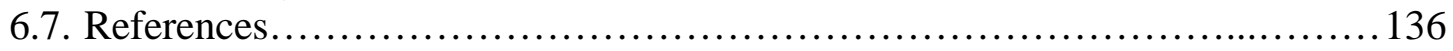

7. Effects of the Presence of Si on the Growth of GaN bulk Crystals................... 144

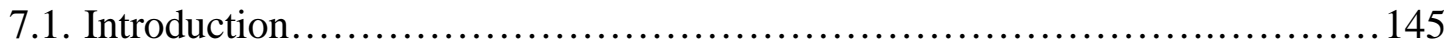

7.2. Experimental Procedures................................................. 150

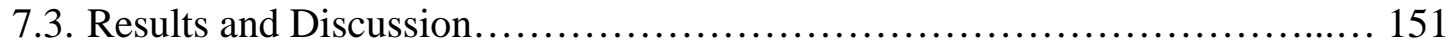

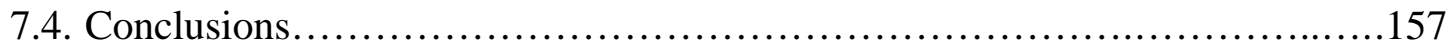

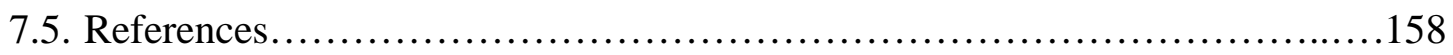

8. Effect of the Presence of $\mathrm{Al}$ on the Growth of GaN Bulk Crystals.................. 167

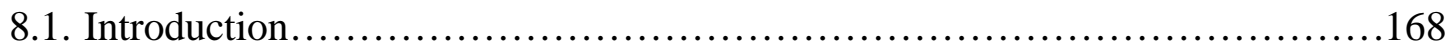

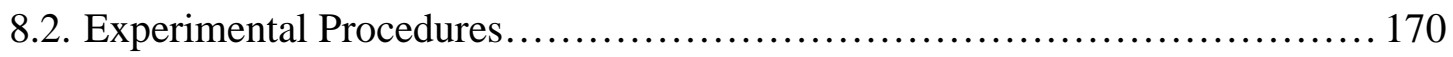

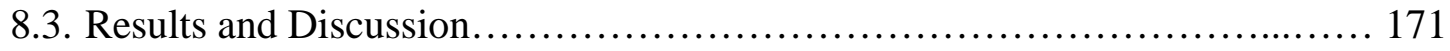

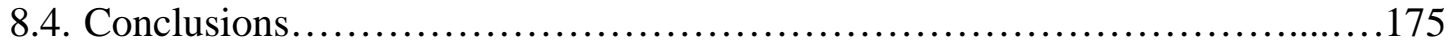

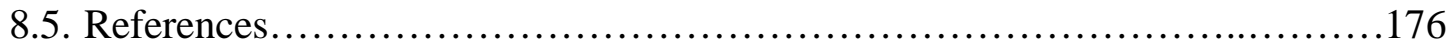

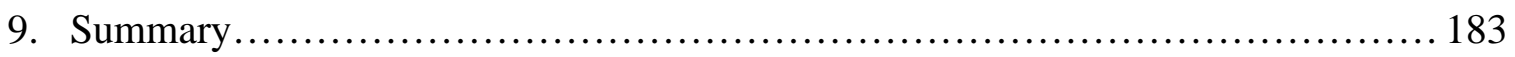

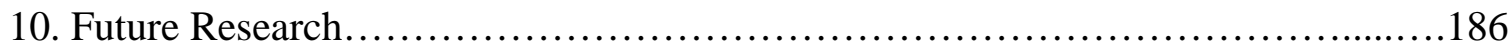

11. Appendix 1: Additional Information in Support of Chapter 4 regarding the High Temperature Nucleation and Growth of GaN Crystals...........................................189

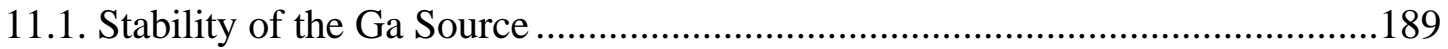

11.2. Ga Source-to-Crystal Distance...................................................................... 190

11.3. High Temperature Nucleation..........................................................................191

11.4. Effect of the Direct Impingement of $\mathrm{NH}_{3}$ on the GaN Growth ........................193

11.5. Effect of $\mathrm{NH}_{3}$ Flow Rate on the Crystal Morphology of GaN.........................194

11.6. In Situ Monitoring of the Seeded Growth..........................................................195

11.7. Growth of GaN Crystals on GaN/AlN/SiC and AlN/SiC Substrates................197

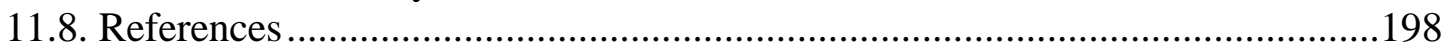

12. Appendix 2: GaN Growth System Operation....................................................210

12.1 Inserting Growth Crucible in Growth Chamber ………………….................2.

12.2 Pump Down the Chamber after Loading the Sam ...........................................210

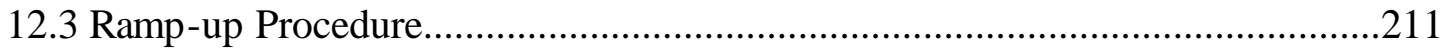


12.4 In situ Monitoring

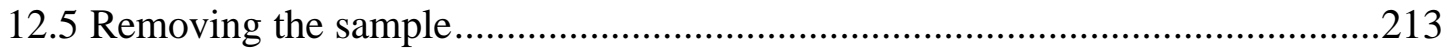

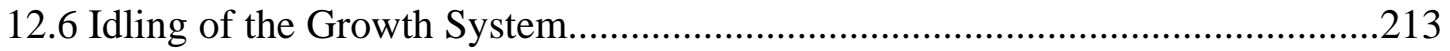

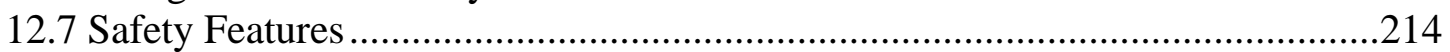




\section{List of Tables}

Table 2.1 Growth techniques for bulk Ga crystals................................41

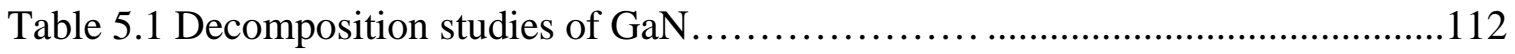




\section{List of Figures}

Figure 2.1 Equilibrium pressure curve for GaN. The equilibrium pressure of $\mathrm{N}_{2}$ over

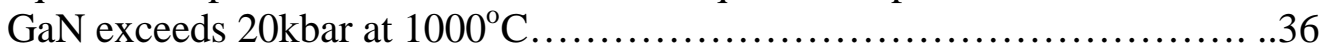

Figure 2.2 Nitrogen solubility in liquid gallium as a function of temperature.............36

Figure 2.3 Gibbs free energy of $\mathrm{GaN}$ and its constituents

Figure 2.4 Equilibrium pressure of $\mathrm{NH}_{3}$ and $\mathrm{N}_{2}$ over $\mathrm{GaN}$; solid line: calculated byThurmond and Logan[75], dashed line: calculated by Karpinski et al. [76], dotted line:calculated using the most recent thermodynamic data.

Figure 2.5 Schematic illustration of $\mathrm{GaN}$ formation on a solid surface starting with

$\mathrm{Ga}$ and $\mathrm{NH}_{3}$ precursors

Figure 2.6 Rates of surface kinetics of $\mathrm{GaN}$ : $\Phi_{\mathrm{Ga}}$ : impingement rate of $\mathrm{Ga}, \Phi_{\mathrm{NH} 3}$ : impingement rate of $\mathrm{NH}_{3}, \mathrm{D}_{\mathrm{Ga}}$ : desorption rate of $\mathrm{Ga}, \mathrm{D}_{\mathrm{N}}$ : desorption rate of nitrogen, $\mathrm{D}_{\text {decom: }}$ decomposition rate of $\mathrm{GaN}[90]$

Figure 3.1 Schematic diagram of the growth system

Figure 3.2 Photograph of the GaN growth system including the electronic control tower.

Figure 3.3 Cutaway view of the growth chamber with dual heater....

Figure 3.4 (a) Stainless steel growth chamber with water jacket in operation and

(b) Growth crucible and support made of $\mathrm{BN}$ prior to loading

Figure 3.5 (a) Long distance microscope with a CCD camera installed on the top flange and (b) the viewport in line of sight with the substrate.

Figure 3.6 Two different cooling configurations for substrate temperature control.

(a) 3/4" cooling tube (b) 3/8" cooling tube with a Mo tip and the BN insert.

Figure 3.7 A typical temperature profile in the growth crucible.

Figure 4.1 (a) Schematic diagram of the BN growth cell and interfacing 3/8" cooling tube. (b) A typical temperature profile in the growth cell at the $\mathrm{BN}$ substrate temperature of $1130^{\circ} \mathrm{C}$

Figure 4.2 Stability field of the Ga source in pure flowing ammonia. Data points indicate the conditions under which eruptions occurred in the molten Ga... .76 
Figure 4.3 Evolution of crystal volume as a function of growth temperature at 760Torr and $150 \mathrm{sccm}$ of $\mathrm{NH}_{3}$ using the high temperature nucleation technique and the conventional growth process

Figure 4.4 Optical micrographs of (a) the surface of the BN substrate prior to growth and (b) the resultant GaN crystals grown using the high temperature nucleation technique and (c) the BN surface and (d) the crystals grown by the conventional growth process at $1130^{\circ} \mathrm{C}$ and 760 Torr for $2 \mathrm{hrs}$ .78

Figure 4.5 Comparison of crystals grown at $1130^{\circ} \mathrm{C}, 430 \mathrm{Torr}$ for $2 \mathrm{hrs}$ (a) without a cover over the Ga source(higher Ga flux) (b) with the use of the cover

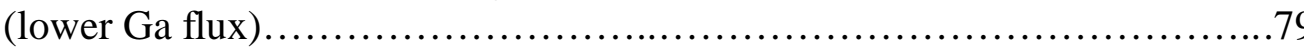

Figure 4.6 (a) Variation in crystal size and (b) the aspect ratio of the GaN crystals as a function of $\mathrm{NH}_{3}$ flow rate at $1130^{\circ} \mathrm{C}$ and $430 \mathrm{Torr}$ for $2 \mathrm{hrs}$

Figure 4.7 SEM micrographs of GaN crystals grown at $1130^{\circ} \mathrm{C}$ and $430 \mathrm{Torr}$ for $2 \mathrm{hrs}$ with different $\mathrm{NH}_{3}$ flow rates:(a) $25 \mathrm{sccm}$, (b) $50 \mathrm{sccm}$, and (c) $60 \mathrm{sccm} . . . . . . .81$

Figure 4.8 SEM micrographs of $\mathrm{GaN}$ crystals grown at $1130^{\circ} \mathrm{C}, 60 \mathrm{sccm}$ of $\mathrm{NH}_{3}$ and total pressures of (a) 430Torr, (b) 595Torr, and (c) 760Torr for 2hrs

Figure 4.9 Three dimensional-surface plot of aspect ratio versus total pressure and $\mathrm{NH}_{3}$ flow rate field for crystals grown at $1130^{\circ} \mathrm{C}$

Figure 4.10 Effect of Ga source temperature on the morphology of crystals grown at the growth temperature of $1130^{\circ} \mathrm{C}, 430$ Torr and $60 \mathrm{sccm}$ of $\mathrm{NH}_{3}$ for $2 \mathrm{hrs}$ for the $\mathrm{Ga}$ source temperature of (a) $1240^{\circ} \mathrm{C}$, (b) $1250^{\circ} \mathrm{C}$, and (c) $1260^{\circ} \mathrm{C}$

Figure 4.11 Optical and SEM micrographs of GaN crystals from cluster of GaN needles grown at $1130^{\circ} \mathrm{C}, 430$ Torr, and $60 \mathrm{sccm}$ of $\mathrm{NH}_{3}$ for $6 \mathrm{hrs:}$ (a) final crystals after seeded growth, (b) a magnified view of a crystal in (a), (c) a SEM micrograph of the surface of the crystal in (b), (d) GaN crystals grown on $\mathrm{BN}$, (e) Raman spectrum of the crystal in (b)....

Figure 4.12 A GaN platelet grown from a GaN seed at $1130^{\circ} \mathrm{C}, 430 \mathrm{Torr}$ and $60 \mathrm{sccm}$ of $\mathrm{NH}_{3}$ for 6hrs: (a) original seed (b) after growth for 6hrs (c)a SEM micrograph of a smooth area of the (0001) surface of (b), (d)a rough area of the (0001) surface of (b), (e) Raman spectrum of the platelet shown in (b)....

Figure 5.1 A schematic diagram of the growth chamber with the quadruple mass spectrometer for gas composition analysis. 
Figure 5.2. Time-dependent evolution of the surface morphologies at $1130^{\circ} \mathrm{C}$, 760Torr of $\mathrm{NH}_{3}$ for (a) $2 \mathrm{hrs}$, (b) $8 \mathrm{hrs}$, and (c) $15 \mathrm{hrs}$

Figure 5.3 Decomposition rate of $\mathrm{GaN}$ at $1130^{\circ} \mathrm{C}, 60 \mathrm{sccm}$ of $\mathrm{NH}_{3}$ in the total pressure range from 100Torr to 760Torr

Figure 5.4 Composition of the gas at $1130^{\circ} \mathrm{C}$ in the growth reactor (a) without the presence of $\mathrm{Ga}$ and (b) in the presence of $\mathrm{NH}_{3}$ and $\mathrm{Ga}$.

Figure 5.5 AFM images of the surfaces of $\mathrm{GaN}$ samples after annealing at $1130^{\circ} \mathrm{C}$, $60 \mathrm{sccm}$ of $\mathrm{NH}_{3}$, and various $\mathrm{NH}_{3}$ total pressures

Figure 5.6 Optical and SEM micrographs of GaN crystals annealed at $1130^{\circ} \mathrm{C}$ and 430Torr for $2 \mathrm{hrs}$ in different ambient gas mixtures: (a) 60sccm $\mathrm{NH}_{3}$ (b) $40 \mathrm{sccm} \mathrm{NH} \mathrm{NH}_{3}+20 \mathrm{sccm} \mathrm{N} \mathrm{N}_{2}$ (c) $20 \mathrm{sccm} \mathrm{NH} \mathrm{NH}_{3}+40 \mathrm{sccm} \mathrm{N}$

Figure 5.7 AFM images of the GaN surfaces annealed at $1130^{\circ} \mathrm{C}, 430 \mathrm{Torr}$ of different gas mixtures: (a)before annealing, (b)60sccm of $\mathrm{NH}_{3}$, (c) $50 \mathrm{sccm} \mathrm{NH} \mathrm{NH}_{3}+10 \mathrm{sccm} \mathrm{N}$, (d) $40 \mathrm{sccm} \mathrm{NH} \mathrm{NH}_{3}+20 \mathrm{sccm} \mathrm{N}$, (e) $30 \mathrm{sccm}$ $\mathrm{NH}_{3}+30 \mathrm{sccm} \mathrm{N}$, and (f) $20 \mathrm{sccm} \mathrm{NH} \mathrm{NH}_{3}+40 \mathrm{sccm} \mathrm{N} \mathrm{N}_{2}$

Figure 5.8 Decomposition rates of $\mathrm{GaN}$ at $1130^{\circ} \mathrm{C}$, 430Torr in $(60-\mathrm{x}) \mathrm{sccm} \mathrm{NH}_{3}+$ $\mathrm{x} \operatorname{sccm} \mathrm{N}_{2}$ gas mixture.

Figure 5.9 Composition of the gas in the growth reactor at $1130^{\circ} \mathrm{C}$ (a) without the Ga source and (b) with the Ga source in (60-x) sccm $\mathrm{NH}_{3}+\mathrm{x} \mathrm{sccm} \mathrm{N}_{2}$ gas mixture

Figure 5.10 Prismatic GaN crystal seeded-grown at $1130^{\circ} \mathrm{C}, 430 \mathrm{Torr}$ and $40 \mathrm{sccm}$ $\mathrm{NH}_{3}+20$ sccm $\mathrm{N}_{2}$; (a) SEM micrograph of the crystal, (b) SEM surface morphology of the c-face (c) SEM surface morphology of the a-face....

Figure 5.11 Raman spectrum of the GaN crystal seeded-grown in Fig. 10. Inset is a magnified view of the $\mathrm{E}_{2}^{(2)}$ peak.

Figure 5.12 Photoluminescence spectrum of the bulk GaN crystal shown in Fig.

10 (a)

Figure 6.1 Effect of nitrogen dilution on the morphology of crystals grown at $1130^{\circ} \mathrm{C}$, 760Torr, for $4 \mathrm{hrs}$ (a) $60 \mathrm{sccm}$ of $\mathrm{NH}_{3}$, (b) $40 \mathrm{sccm}$ of $\mathrm{NH}_{3}+$ $20 \mathrm{sccm}$ of $\mathrm{N}_{2}$ and (c) $20 \mathrm{sccm}$ of $\mathrm{NH}_{3}+40 \mathrm{sccm}$ of $\mathrm{N}_{2}$

Figure 6.2 SEM micrographs of (a) a GaN platelet grown at $1130^{\circ} \mathrm{C}$ and $760 \mathrm{Torr}$ of $20 \mathrm{sccm} \mathrm{NH}_{3}+40 \mathrm{sccm} \mathrm{N}_{2}$ (b) a magnified view of the crystal surface. 
Figure 6.3 SEM micrographs of (a) GaN crystals grown at $1130^{\circ} \mathrm{C}$ and 430Torr of $60 \mathrm{sccm}$ of $\mathrm{NH}_{3}$ and (b) seeded growth on a seed platelet at $1130 \mathrm{oC}$ and 760Torr of $40 \mathrm{sccm} \mathrm{NH}_{3}+20 \mathrm{sccmN}_{2}$ for $8 \mathrm{hrs}$

Figure 6.4 A GaN crystal seeded-grown at $1130^{\circ} \mathrm{C}$, 430Torr and $40 \mathrm{sccm} \mathrm{NH}_{3}+$ $20 \mathrm{sccm} \mathrm{N}_{2}$; (a) SEM micrograph (b) XRD pattern and SEM surface morphology of the c-face (c) XRD pattern and SEM surface morphology of the a-face.

Figure 6.5 AFM images of the smooth area of (a) the a-face and (b) the c-face of the prismatic $\mathrm{GaN}$ crystal seeded-grown at $1130^{\circ} \mathrm{C}, 430$ Torr and $40 \mathrm{sccm}$ $\mathrm{NH}_{3}+20 \mathrm{sccm} \mathrm{N}$, for $36 \mathrm{hrs}$

Figure 6.6 A Raman spectrum of the GaN crystal seeded-grown in Fig. 4. Inset is a magnified view of the $\mathrm{E}_{2}^{(2)}$ peak

Figure 6.7 SEM micrographs of (a) a GaN platelet seeded-grown at $1130^{\circ} \mathrm{C}$, 430Torr and $40 \mathrm{sccmNH}_{3}+20 \mathrm{sccmN}_{2}$, for $48 \mathrm{hrs}$ and (b) the surface morphology of the c-face.

Figure 6.8 AFM images of the smooth area of the surface of the GaN platelet grown at $1130^{\circ} \mathrm{C}, 430$ Torr and $40 \mathrm{sccm} \mathrm{NH}_{3}+20 \mathrm{sccm} \mathrm{N}$, for $48 \mathrm{hrs}$

Figure 6.9 A Raman spectrum of the GaN crystal seeded-grown in Fig. 7. Inset is a magnified view of the $\mathrm{E}_{2}{ }^{(2)}$ peak

Figure 6.10 Photoluminescence spectrum of a bulk GaN crystal seeded grown at $1130^{\circ} \mathrm{C}$ in ammonia diluted with $33 \% \mathrm{~N}_{2}$.....

Figure 7.1 Equilibrium vapor pressures of $\mathrm{Al}, \mathrm{Ga}$, and $\mathrm{Si}$ as a function of temperature[13]

Figure 7.2 SEM micrographs of GaN crystals grown in the presence of $\mathrm{Si}$ in 7 60Torr of $\mathrm{NH}_{3}$ ambient for $10 \mathrm{hrs}$ at $1130^{\circ} \mathrm{C}$ showing the a-face(a), the a-face(b), and the c-face(c), respectively and at $1170^{\circ} \mathrm{C}$ showing the a-face(d), the a-face(e), and the c-face(f) respectively

Figure 7.3 Micrographs of the GaN crystals showing the wider a-face(a)(b) as well as the Raman spectra(c) of $\mathrm{GaN}$ crystals grown in the presence of $\mathrm{Si}$ in the growth chamber at $1130^{\circ} \mathrm{C}$ in $\mathrm{NH}_{3}$ ambient of 760 Torr for $10 \mathrm{hrs}$......

Figure 7.4 Raman spectra from the a-face of $\mathrm{GaN}$ crystals grown at $1130^{\circ} \mathrm{C}$ without the presence of $\mathrm{Si}$ in the growth chamber(a), at $1130^{\circ} \mathrm{C}$ in the presence of $\mathrm{Si}(\mathrm{b})$, at $1170^{\circ} \mathrm{C}$ in the presence of $\mathrm{Si}$ 
Figure 7.5 XPS spectra of GaN crystals grown at $1130^{\circ} \mathrm{C}$ without the presence of $\mathrm{Si}$ in the growth chamber

Figure 7.6 XPS spectra of $\mathrm{GaN}$ crystals grown at $1130^{\circ} \mathrm{C}$ in the presence of $\mathrm{Si}$ in the growth chamber.

Figure 7.7 XPS spectra of the BN surface after $\mathrm{GaN}$ growth in the presence of $\mathrm{Si}$ at $1130^{\circ} \mathrm{C}$

Figure 8.1 AlN crystals grown at (a) $1370^{\circ} \mathrm{C}$, (b) \& (c) $1400^{\circ} \mathrm{C}$ and 430 Torr, $100 \mathrm{sccm}$ of $\mathrm{NH}_{3}$ for $4 \mathrm{hrs}$

Figure 8.2 SEM micrographs of (a)(b) the c-face of an AlN platelet and (c)(d) the a-face of an AlN needle 178

Figure 8.3 AFM images of the c-face of the AlN platelet shown in Fig. 2(a).

Figure 8.4 SEM micrographs of GaN crystals grown (a)at $1130^{\circ} \mathrm{C}$, (b) magnified view of the crystal in (a), (c)at $1170^{\circ} \mathrm{C}$, (d) magnified view of the crystal in (c), (e)at $1200^{\circ} \mathrm{C}$ and (f) pure GaN crystals grown at $1130^{\circ} \mathrm{C}$ and 430Torr for $2 \mathrm{hrs}$

Figure 8.5 X-ray diffraction patterns of (a) Ga-5at\% Al source after 5 runs

(b) pure GaN crystals (c) GaN crystals with $\mathrm{Al}$ addition and

(d) a photograph of the $\mathrm{Ga}-\mathrm{Al}$ mixture source after a growth run

Figure 8.6 Raman spectra of GaN, AlN and GaN crystals grown with Al.

Figure 11.1 SEM micrographs of (a) the surface of a GaN crystal grown at $1130^{\circ} \mathrm{C}$, (b) a magnified view of the area (a), and (c) the surface of a crystal grown at $1170^{\circ} \mathrm{C}$

Figure 11.2 In situ monitoring of the surface of the Ga source at different temperatures and $\mathrm{NH}_{3}$ flow rates at 760Torr

Figure 11.3 Crystal size variation as a function of the source-to-crystal distance. .201

Figure 11.4 Temperature profile used in (a) the conventional process and (b) the high temperature nucleation technique .202

Figure 11.5 Free energy changes associated with nucleation of a spherical particle of radius $r .[6]$. .203

Figure 11.6 Nucleation rate $J$ as a unction of supersaturation, $\mathrm{p} / \mathrm{p}_{\mathrm{o}}[7]$ .203 
Figure 11.7 Effect of direct impingement of $\mathrm{NH}_{3}$ on the crystal growth at $1130^{\circ} \mathrm{C}$,

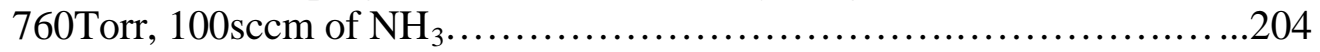

Figure 11.8 Optical micrographs of crystals grown at $1130^{\circ} \mathrm{C}, 430 \mathrm{Torr}$, and $\mathrm{NH}_{3}$ flow rate of (a) $25 \mathrm{sccm}$, (b) $40 \mathrm{sccm}$, (c) $60 \mathrm{sccm}$, (d) $75 \mathrm{sccm}$ for $2 \mathrm{hrs} \mathrm{.......205}$

Figure 11.9 Raman spectra of the $\mathrm{GaN}$ platelets grown at $1130^{\circ} \mathrm{C}$, 430Torr and

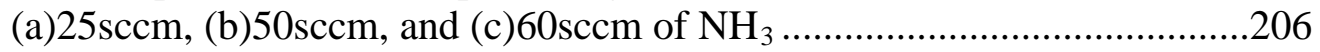

Figure $11.10 \mathrm{In}$ situ monitoring of the seeded growth of GaN needles at $1130^{\circ} \mathrm{C}$, 430Torr and $60 \mathrm{sccm}$ of $\mathrm{NH}_{3}$

Figure $11.11 \mathrm{In}$ situ monitoring of the seeded growth of a GaN platelet at $1130^{\circ} \mathrm{C}$,

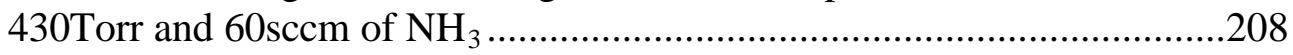

Figure 11.12 SEM micrographs of GaN thick films grown at $1130^{\circ} \mathrm{C}, 430 \mathrm{Torr}$, and $60 \mathrm{sccm}$ of ammonia for $6 \mathrm{hrs}$ on (a)(b)(c)GaN/AlN/SiC and (d)(e)(f) AlN/SiC substrate. 


\section{Introduction}

Gallium nitride, a semiconductor with a direct bandgap of $3.4 \mathrm{eV}$, has considerable realized and future potential for optoelectronic and microelectronic applications. It is currently used in the manufacture of blue and green light-emitting diodes(LEDs) and blue emitting laser diodes(LDs). Considerable research is being conducted to achieve improved high frequency and/or microelectronic devices based on $\mathrm{GaN}$ due to its thermal stability and large direct band gap[1-3]. ${ }^{1}$ Metallorganic vapor phase epitaxy(MOVPE) 35and molecular beam epitaxy(MBE) have been mainly used for the epitaxial growth of GaN device structure on sapphire and silicon carbide substrates. There are no readily available $\mathrm{GaN}$ substrates. However, these foreign substrates are not closely matched to $\mathrm{GaN}$ in terms of atom-atom separation and coefficients of thermal expansion. Thus, residual stresses are introduced into the growing films that are subsequently relieved by the formation of misfit and threading dislocations. This leads to deterioration in the electrical and optical character of the device produced from the III-nitrides. It has been demonstrated that homoepitaxial $\mathrm{GaN}$ films possess better optical properties in comparison to the heteroepitaxially deposited material. State-of-the-art techniques such as lateral epitaxial overgrowth (LEO)[4,5] and pendeo-epitaxy (PE)[6,7] have recently been developed to reduce the number of threading dislocations that originate from the interface with the lattice-mismatched substrates. The dislocation density has been reduced approximately five orders of magnitude via these techniques. The laser diodes fabricated on LEO-GaN substrate by MOVPE were operated with an estimated lifetime

\footnotetext{
${ }^{1}$ References for this Section are located at the end of the Literature Review.
} 
greater than $10,000 \mathrm{hrs}[8]$. However, these techniques involve rather complicated secondary processes including lithography, plasma etching and multiple growths of GaN. Thus, the time and expense of these processes provides a strong impetus for the development of commercially viable bulk GaN boules and wafers.

Bulk GaN crystals have been produced by various techniques. Platelets of $\mathrm{GaN}$ having dimensions exceeding $10 \mathrm{~mm}$ in width have been obtained in high pressure-high temperature solution growth studies[9-19]. Single crystal films of GaN exceeding $100 \mu \mathrm{m}$ have been prepared on sapphire substrates using hydride vapor phase epitaxy[20-21] or sublimation methods[44,51] and released by laser melting of the GaN/sapphire interface[26]. Free standing GaN crystals were also prepared via sublimation of gallium nitride powder[53,56], reaction of gallium vapor with ammonia[62,63], and growth in a sodium flux[37,39]. Each growth technique is reviewed in some detail in Chapter 2. For bulk GaN crystal growers, this review provides descriptions of major technical achievements and problems encountered in each growth technique. The thermodynamics and surface kinetics of the GaN growth are briefly discussed at the end of Chapter 2.

In the research of this dissertation, bulk GaN crystals were grown via a reaction of Ga vapor with ammonia in a dedicated growth system equipped with an in situ monitoring facility, as described in Chapter 3. This system has been described in detail, including growth chamber, cooling mechanism, control system, heating mechanism, and pumping system. The principles underlying the construction of the growth crucible and its modification are also described. 
The first phase of this research involved an evaluation of the effects of different processing parameters on the growth of crystals. To achieve stable growth conditions, the stability of the Ga source was investigated in terms of Ga source temperature, $\mathrm{NH}_{3}$ total pressure and $\mathrm{NH}_{3}$ flow rate. The position of the Ga source was also optimized to obtain maximum growth rates. In an effort to reproducibly grow larger GaN seed crystals, a high temperature nucleation technique was developed, as described in Chapter 4. With the aid of this technique, three-dimensional processing windows for control of the aspect ratio of the GaN crystals were obtained with respect to growth temperature, ammonia total pressure and flow rate. Application of this knowledge fostered the achievement of the seeded growth of $\mathrm{GaN}$ crystals as a preview to the continuous growth of $\mathrm{GaN}$ crystals.

Chapter 5 details the studies regarding the determination of the reasons for the enhanced decomposition of $\mathrm{GaN}$ at higher ammonia total pressures. Cessation of the growth and gradual decomposition of the crystal in a prolonged growth was a major obstacle in the research described in Chapter 4. Mass spectrometry was employed to determine the gas phase composition. On the basis of the results, nitrogen dilution of ammonia was employed to achieve the prolonged growth of the $\mathrm{GaN}$ crystals.

A new processing route developed to overcome the decomposition problem was applied to the growth of seed crystals, as described in Chapter 6. Changes in crystal morphology with nitrogen dilution of ammonia were also investigated. Secondary nucleation problems encountered in the growth of seed crystals prompted the seeded growth combined with the new processing route. The resultant GaN crystals were characterized by Raman spectroscopy and photoluminescence measurements. 
The investigations regarding the growth of larger crystals at higher growth rates without their decomposition led to additional research regarding the effect of the presence of silicon or aluminum in the ambient during on-growth, as described in Chapter 7. The surface morphologies of the crystals grown in the presence of $\mathrm{Si}$ were studied. X-ray photoelectron spectroscopy was employed to determine the reason for the reduced nucleation in the presence of Si. No detectable Al was incorporated into the GaN crystals.

It is to author's belief that, by applying the results obtained in this research, the understanding of the nucleation and growth process of GaN bulk crystals via vapor phase transport using Ga and ammonia have been significantly improved, and the technologies for growing bulk GaN crystals have been advanced to realize the advent of commercial $\mathrm{GaN}$ substrates in near future. 


\section{Literature Review}

\subsection{Growth Methods}

\subsubsection{High Pressure-High Temperature Solution Growth}

Pressure and the equipment that apply pressure have become important tools in the field of crystal growth. The technique that offers the best prospects for the growth of large crystals under pressure is the temperature gradient transport method in which solute is transported from a hotter to a cooler region, where, preferably, a seed is located. Regarding the growth of $\mathrm{GaN}$, the very low solubility of nitrogen in gallium at one atmosphere is a significant handicap that can only be overcome by the use of high pressures that, in turn, allow the use of higher temperatures, increased nitrogen solubility and higher rate of growth. A solubility of the order of a few percent is desired for the growth of crystals having a commercially viable size. Madar et al.[9] attempted to grow GaN crystals by using an internally heated pressure vessel. Platelets and needles with dimensions below $1 \mathrm{~mm}$ were formed at $1200^{\circ} \mathrm{C}$ and at a $\mathrm{N}_{2}$ overpressure of $8 \mathrm{kbar}$. They estimated of the solubility of nitrogen in $\mathrm{Ga}$ under these conditions to be $10^{-3} \mathrm{~mol}$ fraction. As can be seen in Fig. 2.1[10] and Fig. 2.2[11] a nitrogen pressure of about $20 \mathrm{kbar}$ corresponds to a nitrogen solubility in liquid gallium of the order of $1 \%$. Lower temperatures correspond to lower nitrogen solubility, therefore by controlling the temperature difference in the crucible one can control the difference of the nitrogen concentration and accordingly the supersaturation in the growth zone. 
Porowski et al.[12-17] have employed the solubility of nitrogen in liquid Ga to grow $\mathrm{GaN}$, using higher $\mathrm{N}_{2}$ pressures $(<20 \mathrm{kbar})$, higher temperatures $\left(>1500^{\circ} \mathrm{C}\right)$ and larger volume crucibles. Crystallization processes were conducted in large volume gas pressure reactors at $\mathrm{N}_{2}$ overpressures up to $20 \mathrm{kbar}$, which corresponds to a $\mathrm{GaN}$ stability limit at $1650^{\circ} \mathrm{C}$, as shown in Fig. 2.1. The growth times were long to obtain sufficiently large crystals, because the equilibrium $\mathrm{N}$ concentrations were not high. The crystals grown at $1600^{\circ} \mathrm{C}$ under a $\mathrm{N}_{2}$ overpressure of $20 \mathrm{kbar}$ were $10 \mathrm{~mm} \times 10 \mathrm{~mm}$ x $0.05 \mathrm{~mm}$. The growth rate was $\sim 100 \mu \mathrm{m} / \mathrm{hr}$ in the $\{10 \overline{1} 0\}$ directions[13-16]. It is believed that the GaN grows from an atomic nitrogen-supersaturated solution of liquid Ga through adsorption of $\mathrm{N}_{2}$ on the liquid Ga surface, rupture of the triple bond to form atomic nitrogen, and the dissolution the latter nitrogen species and its reaction with Ga in a cooler section of the container. Dissolution of atomic nitrogen into the $\mathrm{Ga}$ is the rate-limiting step when the temperature gradient between the hot and the cold zone is large. Diffusion from the hot to the cold zone of the gallium is the rate-limiting step in the growth when the temperature gradient is small. An examination of the crystal morphology indicated that the resulting crystal shape depends on the pressure, temperature range, and supersaturation during growth. For pressures and temperatures lying deeply inside the GaN stability field (e.g., higher pressure and lower temperature), the crystals are hexagonal prisms elongated in the c-direction. At conditions close to the equilibrium curve, the dominant shape of the crystals is a hexagonal plate.

Atomistic insights regarding the mechanisms of the aforementioned morphological change have not been developed. In general, the crystals grown slowly $(<100 \mu \mathrm{m} / \mathrm{h})$, e.g., under the smaller temperature gradients, exhibited transparency, a 
slightly yellowish color, and flat mirror-like surfaces. Typical reported widths (FWHM) of X-ray rocking curves for (0004) $\mathrm{CuK} \alpha$ reflection were 23-32 arcsec. Note that these curves were significantly more narrow than the corresponding curves for heteroepitaxial GaN films grown by MBE or MOCVD techniques (typically 100 300arcsec). It was observed that the quality of the GaN crystals deteriorated with increasing growth rate (high supersaturation) and with increasing dimensions of the crystals. This was probably due to non-uniform distribution of nitrogen in he solution across growing crystal face. The deterioration of quality of the $5 \sim 10 \mathrm{~mm}$ wide crystals grown with a growth rate of $0.5 \sim 1 \mathrm{~mm} / \mathrm{h}$ was indicated by the broadening of the rocking curves to a FWHM of 50 arcsec. For growth rates above $1 \mathrm{~mm} / \mathrm{h}$, the formation of hollow, skeletal or dendritic crystals was observed.

In conventional solution growth, the solvent is saturated by the solute, and the temperature is decreased to realize supersaturation for the growth of the crystals. This process, however, has the following disadvantages: (1) the growth rate is lowered, since the temperature is lowered, (2) the solubility is lowered and constitutional supercooling easily occurs; (3) crystal growth ceases after a certain period, if the solute is not continuously supplied, and a large part of the solvent is left unused. An attempt to overcome these disadvantages was made by Inoue et al.[18] with the development of the pressure-controlled solution growth (PC-SG) method. In the PC-SG method, supersaturation is realized by applying an overpressure without any temperature decrease. In a manner similar to the Polish research[11-17], an increase in the concentration of nitrogen atoms in the melt was achieved using a pressurized $\mathrm{N}_{2}$ atmosphere. A GaN crystal grown at a growth rate of $\sim 0.8 \mathrm{~mm} / \mathrm{h}$ by the $\mathrm{PC}-\mathrm{SG}$ method at $1450^{\circ} \mathrm{C}$ under a 
nitrogen pressure of $0.98 \mathrm{GPa}$ was about $10 \mathrm{~mm}$ in average and in the [10 $\overline{1} 0]$ direction. The dislocation density of the crystals was estimated to be less than $10^{6} \mathrm{~cm}^{-2}$.

The main disadvantage of the high-temperature high-pressure solution growth technique is that the crystal size is limited by the size of the pressure anvil. The widths of the zones for stable crystallization correspond to the zones of uniform concentration of nitrogen in liquid $\mathrm{Ga}$ in the growth crucibles. The zones with the most uniform concentrations that allow the best growth are located at the central part of the crucibles. Poroski et al.[14] predicted that $17 \mathrm{~mm}$ crystals could be grown in the $24 \mathrm{~mm}$ crucibles. Increasing the size of the crucibles in this technique, however, is not an easy task because of both high cost and difficulty in achieving high pressures over large areas. The hightemperature high-pressure solution method, if suitably scaled up, should yield $\mathrm{cm}$-sized crystals under the approximate conditions used by Karpinski et al.[11] However, the necessary investment for such a scale-up is unlikely unless it is lucrative in terms of sales of crystals.

\subsubsection{HVPE(Hydride Vapor Phase Epitaxy)}

A promising route developed recently for the development of $\mathrm{GaN}$ substrates involves the heteroepitaxial growth of GaN films by a rapid growth technique, such as hydride vapor phase epitaxy (HVPE), followed by the ex situ etch removal of the initial substrate to leave a free-standing GaN film. The HVPE technique has been used to grow layers of $\mathrm{GaN}$ with thickness in the range of 5 to $350 \mu \mathrm{m}[20-30]$. The growth is conducted 
in an atmospheric pressure quartz reactor containing two separate temperature zones. In the first reaction zone, operated at about $900^{\circ} \mathrm{C}$, molten $\mathrm{Ga}$ metal is reacted with flowing $\mathrm{HCl}$ gas to yield $\mathrm{GaCl}$ and $\mathrm{H}_{2}$ reaction products. These reaction products are transported to the second zone, typically maintained at $1000^{\circ} \mathrm{C} \sim 1100^{\circ} \mathrm{C}$ into which are also introduced the $\mathrm{N}_{2}$ diluent and $\mathrm{NH}_{3}$ at a high flow rate which react with the $\mathrm{GaCl}$ to form the GaN. It is well known that growth rates exceeding $1 \mathrm{~mm} / \mathrm{hr}$ can be achieved using HVPE.

However, there are several drawbacks to the HVPE technique. One difference in the growth of GaN by HVPE, as compared with the growth of other III-V compounds, is the strong thermodynamic propensity for $\mathrm{GaN}$ to form, leading to undesirable gas phase reactions and wall deposition problems[24,25]. An additional difficulty results from the use of corrosive $\mathrm{HCl}$ gas, which can quickly destroy reactor equipment if care is not taken to avoid impure gases or leaks to air and the consequent introduction of $\mathrm{H}_{2} \mathrm{O}$ vapor into the chamber. The HVPE process also tends to create copious amounts of $\mathrm{NH}_{3} \mathrm{Cl}$, $\mathrm{GaCl}_{3}$ and $\mathrm{GaCl}_{3}: \mathrm{NH}_{3}$ which will condense on and eventually clog exhaust lines unless they are heated to sufficiently high temperatures $\left(>150^{\circ} \mathrm{C}\right)$ and/or operated at reduced pressures. GaN crystals grown via HVPE are typically 10 200 $\mu$ m thick. Large diameter crystals are also possible if cracking due the mismatch in the thermal expansion coefficients with the substrate material can be ameliorated. Separation of thick films of GaN from the substrate is a separate challenge, that requires additional novel techniques such as reactive ion etching in $\mathrm{SF}_{6}$ containing gas mixture[29] and a laser melting[26]. Despite its simplicity in growth equipment, this post-growth process adds additional cost to the budget. In spite of these limitations, HVPE has recently enjoyed a renaissance, 
because of its typically high growth rate and low cost, suggesting that it may find application as a bulk growth technique for low-defect $\mathrm{GaN}$ thick films for use in subsequent growth of device structures. Recently, crack-free GaN thick films of $250 \sim 350 \mu \mathrm{m}$ in thickness were grown on 2" diameter sapphire wafers by HVPE and separated from the substrates by KrF excimer laser melting[26]. The FWHM of the X-ray rocking curves for the (0002) diffraction of GaN/sapphire and free standing GaN was reduced from 254 to 149 arcsec due to the relaxation of bowing.

Surface treatment of the sapphire substrate by $\mathrm{Ga}$ and $\mathrm{HCl}$ gas just before the growth of $\mathrm{GaN}$ is found to be effective in avoiding the generation of pits and in preparing a high quality crystalline GaN film with a flat surface[24]. It has been found that the lattice strain caused by the difference in the thermal expansion coefficients between the GaN and sapphire was reduced as the thickness of the GaN film was increased[24].

Detchprohm et al.[34] have grown GaN films of several hundred microns thickness on sapphire substrates with a $\mathrm{ZnO}$ buffer layer. They obtained $\mathrm{GaN}$ films that were several millimeters square that could be peeled from the substrate. Recently, Ushi et al.[28, 35] succeeded in the HVPE growth of a few tens of microns thick GaN on a 2" diameter sapphire substrate with crack-free and mirror-like surfaces by coalescence of selectively grown $\mathrm{GaN}$ on patterned $\mathrm{SiO}_{2}$ masks. However, the technique does not provide the fundamental advantages of homoepitaxy, because the $\mathrm{GaN}$ is still on a sapphire substrate. Shibata et al.[27] also adopted the selective area growth technique of GaN using the HVPE method to obtain GaN bulk single crystals. The FWHM (195 arcsec) of the X-ray rocking curve for (0004) diffraction was more narrow than that (348 arcsec) of the sample grown by conventional methods. However, fragmentation of the 
crystal into smaller domains began as either thickness or growth rate was increased. Without a buffer layer, formation of such domains was also observed in the thicker GaN layers $(>30 \mu \mathrm{m})$ grown on sapphire substrates[30].

Melnik et al.[33] has grown high-quality GaN crystal on SiC substrates. After GaN growth, the $\mathrm{SiC}$ substrates were removed by reactive ion etching (RIE) in a gas mixture containing $\mathrm{SF}_{6}$. No cracks were observed on most of the crystals. The fracture of the thick GaN layer was the main factor limiting the size of the bulk crystal. The best FWHM of x-ray rocking curves was about 150 arcsec. This can be ascribed to the advantage of the better lattice-matched substrate.

Most reported values of growth rates are much lower than the $800 \mu \mathrm{m} / \mathrm{hr}$ obtained by Seifert et al.[36] The coaxial arrangement of the gas inlet tubes used by these investors achieved good mixing of the reactant gases prior to deposition. This indicates that the gas flow dynamics in the HVPE system is one of most significant parameters that determine the growth rate and quality of the crystals. Monlar et al.[25] have grown up to 2 in diameter films with a maximum thickness of $74 \mu \mathrm{m}$ and found that uniformity of the $\mathrm{GaN}$ crystals depended on the gas flow pattern and $\mathrm{HCl} / \mathrm{NH}_{3}$ ratio. In $\mathrm{HVPE}$ system, the heaviest $\mathrm{GaN}$ deposits were always observed in regions closest to $\mathrm{GaCl}: \mathrm{NH}_{3}$ mixing zone[21].

It is expected that systematic investigations of the influence of the different growth parameters in the HVPE technique will lead to further improvements in the characteristics of the epitaxial layers as well as to an increased understanding of the chemistry of the formation of GaN from this gaseous chemistry. 


\subsubsection{Flux Growth}

The flux growth method employs lower temperatures and pressures than the high pressure and HVPE techniques. Small GaN bulk crystals have been prepared at reasonably low temperature and pressure by means of the flux method[37-41]. However, both the nucleation sites and the growth orientations of bulk $\mathrm{GaN}$ are still random in this method. The as-grown GaN crystals are currently too small for use in device fabrication due to the very low growth $\operatorname{rate}(\sim 5 \mu \mathrm{m} / \mathrm{h})$. Yano et al.[37] have grown polycrystalline $\mathrm{GaN}$ films on sapphire substrates at $800^{\circ} \mathrm{C}$ and nitrogen pressure of $\sim 100 \mathrm{~atm}$ using a solution of $\mathrm{Ga}$ and $\mathrm{NaN}_{3}$ as starting materials. The mixing of $\mathrm{NaN}_{3}$ and $\mathrm{Ga}$ in the reaction tube was expected to form a Ga-N binary phase as nitrogen decomposed from the $\mathrm{NaN}_{3}$. However, the details regarding the GaN nucleation are still unknown.

Yamane et al.[38,39] grew GaN platelets and prismatic needles at $750^{\circ} \mathrm{C}$ and $70 \mathrm{bar}$ using the method used by Yano et al. by adjusting the $r_{\mathrm{Na}}=\mathrm{Na} /(\mathrm{Na}+\mathrm{Ga})$ molar ratio of the starting materials. The crystal morphology changed with increasing $r_{\mathrm{Na}}$ from $\operatorname{prismatic}(r=0.38)$ to $\operatorname{platelet}(r=0.47)$ and fine grains $(r=0.64)$. It was suggested by the investigators that changes in morphology implied that the supersaturation of $\mathrm{GaN}$ in the melt increased with the $r_{\mathrm{Na}}$ value. It appeared that spontaneous nucleation growth occurred rapidly, and the degree of supersaturation dropped before further grain growth at $r_{\mathrm{Na}}=0.64$. They also grew cubic $\mathrm{GaN}$ single crystals by using a $\mathrm{K}$ metal flux at $750^{\circ} \mathrm{C}$. Recent studies on c-GaN film growth have demonstrated that this phase is stable under nitrogen-deficient conditions[40,41]. Indeed c-GaN films have been prepared at high temperatures $\left(\sim 900^{\circ} \mathrm{C}\right)$ and at low N/Ga ratios via MBE[41]. However, it was not clear 
whether the $\mathrm{K}$ metal flux produced a similar nitrogen deficient condition compared to the solution environment produced with a $\mathrm{Na}$ flux. Flux growth of $\mathrm{GaN}$ crystals is in the early stages of development. Investigations regarding the development of a better understanding of flux growth are necessary. The problems of low growth rates and possible contamination from the stainless steel crucible used for crystal growth must be solved.

\subsubsection{Vapor Phase Transport}

\subsubsection{Gallium Nitride as the Source Material in an Ammonia Atmosphere}

The simplest methods of growing high purity single-crystal group-III nitrides would be those in which these nitrides are themselves used as the starting materials. The process of transport of the nitride and subsequent growth of the single crystals of the selected material, e.g., GaN, involve heating gallium nitride powder in the presence of ammonia at temperatures above $1000^{\circ} \mathrm{C}$. Mass spectrometry results indicate that $\mathrm{GaNH}, \mathrm{GaN}_{2} \mathrm{H}$ or even $\mathrm{GaCH}_{3}, \mathrm{GaO}, \mathrm{GaCN}$ and $\mathrm{GaCO}$ molecules exist in the gas phase[43]. It is generally accepted that the process is called "sublimation" though the mass spectrometry data show that reactions between the $\mathrm{GaN}$ and $\mathrm{NH}_{3}$ are the route by which $\mathrm{GaN}$ is taken into the gas phase when the source material is pre-synthesized $\mathrm{GaN}$ and "evaporationrecondensation" when pure Ga is used[44]. They are sometimes used interchangeably. 
Manchon et al.[46] grew hexagonal needles to $2 \mathrm{~mm}$ in length by heating $\mathrm{GaN}$ powder at $1150-1200^{\circ} \mathrm{C}$ in pure ammonia for $16 \mathrm{hrs}$. Zetterstrom[47] grew rather larger crystals of up to $5 \mathrm{~mm} \times 1 \mathrm{~mm}$ by heating pre-synthesized $\mathrm{GaN}$ above $1100^{\circ} \mathrm{C}$ in an ammonia flow for about 72 hours. The needles were colorless as long as the temperature did not exceed $1200^{\circ} \mathrm{C}$. Conversion of $\mathrm{Ga}_{2} \mathrm{O}_{3}$ to $\mathrm{GaN}$ was accomplished in an ammonia atmosphere between 600 and $1100^{\circ} \mathrm{C}[48]$. However, no advantage of this method was reported. A similar method was used by Ejder[62] except that $\mathrm{NH}_{3} / \mathrm{N}_{2}$ mixtures were used, and the temperature was lower $\left(1000-1150^{\circ} \mathrm{C}\right)$. He obtained prism-shaped crystals on the cooler parts of his furnace.

A more detailed series of studies of the morphology of GaN crystals formed primarily by sublimation was undertaken by Aoki and Ogino[48]. They compared the reaction between ammonia and gallium in an open quartz boat with that in a partly closed quartz ampoule. The crystallite size increased as the temperature was raised to $1160^{\circ} \mathrm{C}$; most of their studies were concentrated in the range $1100-1180^{\circ} \mathrm{C}$. Translucent yellow crystals to $3 \times 0.1 \mathrm{~mm}$ were obtained, mainly on the crucible wall.

Sakai et al.[44] have obtained $\mathrm{GaN}$ needles by sublimation of $\mathrm{GaN}$ powder in 50sccm of flowing $\mathrm{NH}_{3}$ via deposition onto sapphire substrates at a substrate temperature of $1050^{\circ} \mathrm{C}$. However, the crystal size was reported to be limited to small needles. They also investigated the growth mechanism of $\mathrm{GaN}$ by their sublimation technique using quadruple mass analysis (QMA). The saturation of crystal size with growth time was thought to be due to the depletion of the active species in the powder, namely, those consisting of $\mathrm{Ga}, \mathrm{N}$ and $\mathrm{H}$ atoms, including $\mathrm{GaNH}$ and $\mathrm{GaN}_{2} \mathrm{H}$. One way to overcome this problem is to repeat the growth using a new powder in each growth. Indeed the 
crystal increased after 14 repetitions. Balkas et al.[52] was successful in obtaining high quality GaN crystals to $1 \mathrm{~mm}$ in length via sublimation with a growth rate of $0.5 \mathrm{~mm} / \mathrm{hr}$ in the direction perpendicular to the basal plane. They also found that the direction of fastest growth and thus the crystal shape were controlled by changing the $\mathrm{Ga} / \mathrm{NH}_{3}$ flux ratio and the growth temperature. However, systematic investigations were not conducted regarding this issue.

Kamler et al.[55] have also investigated the sublimation technique in a horizontal quartz tube reactor. In heir experiments, the source crystals obtained by the reaction of gallium vapor with ammonia were smaller in comparison to the crystals prepared by the sublimation of gallium nitride powder. When GaN crystals of a few hundred micrometer average diameter were used as the gallium nitride source, the generation of free gallium was not observed. Therefore, the sublimation process was slower but more stable in terms of transport of reactants. However, the reasoning behind this is still not clear. In spite of its high growth rate and simplicity in apparatus, the sublimation technique has an inherent difficulty in that pre-synthesized GaN powder or crystals must be continuously supplied.

\subsubsection{Gallium as the Source Material in an Ammonia Atmosphere}

Single crystal growth of $\mathrm{GaN}$ has been achieved via the direct reaction of $\mathrm{Ga}$ vapor with $\mathrm{NH}_{3}$. Crystals with dimensions of a few microns have been synthesized by reacting $\mathrm{NH}_{3}$ with $\mathrm{Ga}$ or $\mathrm{Ga}$ compounds. Growth of large crystals has been limited by the extensive nucleation of small crystals. In general, only dense, unconnected, small crystals 
are typically obtained. The difference between $\mathrm{Ga}$ and $\mathrm{GaN}$ as a Ga source lies in the way the Ga specie is supplied to the surface of a growing crystal. Ga vapor can be directly obtained from a molten Ga metal and transported to the growing crystal unless gas phase reaction with ammonia occurs. Sublimation of GaN may go through either congruent or incongruent evaporation depending primarily on the reactor pressure; congruent evaporation under MBE conditions and incongruent evaporation under CVD conditions. There is still debate regarding the evaporating species during the sublimation of GaN. Under typical growth conditions (high total pressure) in the sublimation growth technique, it is believed that $\mathrm{GaN}$ undergoes incongruent evaporation, that is, $\mathrm{GaN}$ decomposes and $\mathrm{Ga}$ and $\mathrm{N}$ species evaporate separately. Therefore, the supply of $\mathrm{Ga}$ is similar in both cases except that in the sublimation process $\mathrm{GaN}$ must undergo decomposition on the surface of the source material. More systematic investigations would elucidate the reaction path for each technique and lead to better control of the growth.

Since Johnson et al.[57] synthesized polycrystalline GaN deposits by the reaction of $\mathrm{NH}_{3}$ with molten $\mathrm{Ga}$, several researchers have employed similar methods to prepare this material. The decomposition of a solid gallium tribromide-ammonia complex $\left(\mathrm{GaBr}_{3}: 4 \mathrm{NH}_{3}\right)$ in an ammonia, argon and hydrogen atmosphere was used for the deposition of gallium nitride on $\mathrm{SiC}$ substrates[58]. The deposition rate of gallium nitride in argon was considerably less than in ammonia. Gallium nitride could not be formed in the presence of a large excess of hydrogen gas. Pichugin and Yaskov[59] obtained needles of $5 \times 0.3 \mathrm{~mm}$ by flowing ammonia at 1 atmospheric pressure over the Ga in a quartz boat for several hours at $1150^{\circ} \mathrm{C}$. A more detailed study aimed at determining the 
optimum conditions for the growth of GaN crystals by this last method was conducted by Elwell et al.[60,61] The optimum partial pressure of ammonia and temperature were approximately $1 \times 10^{-3} \mathrm{~atm}$ and $930^{\circ} \mathrm{C}$, respectively. The upper limit of the growth temperature $\left(1010^{\circ} \mathrm{C}\right)$ was set by the decomposition of $\mathrm{GaN}$. The largest crystal, $2.5 \mathrm{~mm}$ long, was nucleated on a silicon carbide rather than on a GaN seed.

A slight modification of sublimation process called the sublimation sandwich technique has been introduced by Vodakov et al.[43,45,54] A Ga and GaN powder mixture was used as the source material and was placed several millimeters below the $6 \mathrm{H}-\mathrm{SiC}(0001)$ or sapphire(0001) substrates. They obtained GaN single crystal thick films of $15 \times 15 \times 0.5 \mathrm{~mm}$ with average growth rates of about $350 \mu \mathrm{m} / \mathrm{hr}$. The maximum thickness of a GaN crystal that can be grown by this technique is unknown at this writing, since major defects originate from the mismatch in lattice constants and thermal expansion coefficients, as in the HVPE technique.

Ejder[62] employed both the open boat method and the ampoule method in the growth of $\mathrm{GaN}$ from the vapor phase by the reaction of $\mathrm{Ga}$ and $\mathrm{NH}_{3}$ at $1100 \sim 1150^{\circ} \mathrm{C}$ to investigate the effect of the Ga vapor concentration on the morphology. In the former method, Ga was contained in an open alumina boat and a mixture of nitrogen and ammonia was passed over the boat. With this method mostly needles were produced, where the maximum growth velocity was in the c-direction. In the latter method, an ampoule of silica glass containing a hole of about $1 \mathrm{~mm}$ at one end was used to achieve a higher Ga vapor concentration. Platelets of about $300 \mu \mathrm{m}$ in width were obtained with a growth rate of $20 \mu \mathrm{m} / \mathrm{hr}$ in the ampoule method. They speculated that the highest concentration of GaN vapor, by evaporation, should be expected once all the starting $\mathrm{Ga}$ 
metal was converted to GaN. However, evaporation of $\mathrm{GaN}$ at one atmosphere has been found to be incongruent, and the growth mechanism of the platelet is still unclear. It is worth mentioning that the $\mathrm{Ga}$ concentration in the vapor phase can be expected to be higher in the ampoule method as compared to that in the open boat method. Callahan et al.[64] observed the formation of high aspect ratio crystals on the upper surface of the GaN crust, where the Ga vapor concentration presumably is low. Beneath the crust, growth was preferentially along the basal plane of the GaN. This observation is similar to the results obtained in another vapor transport system[63].

Reaction of gallium with ammonia to form GaN has always suffered from the problem of massive nucleation of very small crystals, usually smaller than $0.5 \mathrm{~mm}$ in diameter. Callahan et al.[64] grew GaN platelets as large as 2 x 9 x $0.1 \mathrm{~mm}$ at near atmospheric pressures using $\mathrm{NH}_{4} \mathrm{Cl}$ as a nitrogen source with growth rates up to $100 \mu \mathrm{m} / \mathrm{hr}$ in the hexagonal plane. They also reported that uncontrolled nucleation remained a problem to be overcome. With an appropriate processing window for a growth on a seed crystal, continuous growth can be achieved without secondary nucleation on the growing crystal.

\subsubsection{Other Techniques}

The addition of bismuth to the molten gallium was found to be detrimental to the growth of larger crystals since crystal growth of $\mathrm{GaN}$ from $\mathrm{Ga} / \mathrm{Bi}$ alloys resulted in more copious nucleation than $\mathrm{Ga}$ alone[60]. This is in contrast to the observations of Logan 
and Thurmond[67] who found that bismuth additions reduced the nucleation of $\mathrm{GaN}$ in their liquid phase epitaxy experiments, and the crystal size was increased by imposing a thermal gradient across the growth melt. In this way dissolved nitrogen was presumably transported to regions of lower temperature where growth occurred. The growth mechanism is not clear, since the nitrogen solubility at atmospheric pressure is negligible under their growth conditions. Crystal growth from $\mathrm{Ga} / \mathrm{Sn}$ alloys using nitrogen in place of the ammonia was also attempted, since tin reacts with molecular nitrogen to provide atomic nitrogen in solution. The preliminary results with $\mathrm{Ga} / \mathrm{Sn}$ solutions were not encouraging. Plate-like and needle-shaped crystals were observed under relatively extreme conditions. The crystals were of hexagonal form, dominated by $\{10 \overline{1} 0\}$ faces with flat $\{0001\}$ end faces or by caps having both $\{10 \overline{1} 1\}$ and $\{10 \overline{1} 2\}$ faces. Crystals grown from gallium solutions in a flowing ambient containing ammonia appear to form by an unusual mechanism. Once small crystals have formed at the gallium surface, continued growth occurs by the propagation of $\{10 \overline{1} 0\}$ layers across these dominant faces. If this layer growth is slow, the end faces cap over to form the planar $\{0001\}$ facets. Faster growth results in the formation of a depression in the center of the $\{0001\}$ end face as the layers spreading over from the adjacent $\{10 \overline{1} 0\}$ faces fail to reach the center of this end face. When the supersaturation is raised so that growth is even faster, the crystals become hollow.

Chen et al.[65] also used molten $\mathrm{Ga}$ and $\mathrm{NH}_{4} \mathrm{Cl}$ as a nitrogen source. The resultant crystals grown at $350 \sim 500^{\circ} \mathrm{C}$ were nanocrystals of about $10 \mathrm{~nm}$ in average diameter. Injection of atomic nitrogen into a Ga liquid pool was attempted to grow thick films of polycrystalline GaN[71,72]. The nitrogen plasma used in this synthesis was generated 
from an electron cyclotron resonance (ECR) source. A polycrystalline GaN dome completely covered the liquid gallium and thin platelets of $\mathrm{GaN}$ aligned normal to the surface of the dome, showing a strong [11 $\overline{2} 0]$ texturing. The average growth rate was approximately $8 \mu \mathrm{m} / \mathrm{hr}$. Though the use of atomic nitrogen circumvents the high equilibrium pressures required for the synthesis of bulk $\mathrm{GaN}$ from molecular nitrogen and gallium, the growth rate is too low to be commercially viable.

It is possible to grow GaN crystals by current crystal growing techniques, though their sizes are not sufficient to build devices on them. Among the GaN crystal growth techniques discussed above, the direct reaction of Ga vapor with ammonia seems to be the simplest and most commercially viable technique. High-pressure growth requires complicated equipment and high temperature which increases the cost of production. In the sublimation technique, one has to continually replenish the system with externally pre-synthesized GaN powder; otherwise, the crystal size is limited by the amount of initial powder input. The HVPE approach achieves a higher growth rate; however, latticemismatched substrates are currently used with resultant stresses and cracking on cooling. Cracking and nonuniformity problems can be eliminated by utilizing an already-grown GaN film as a substrate. The vapor phase transport technique has several potential advantages. High purity GaN crystals can be fabricated from the electronic grade $\mathrm{Ga}$ and ammonia since both water and oxygen level have recently been reduced to $<1 \mathrm{ppm}$ in the ammonia. In addition, preliminary experiments in this research have shown that a high growth $\operatorname{rate}(\sim 500 \mu \mathrm{m} / \mathrm{hr})$ could be achieved and the aspect ratio could be controlled by adjusting the growth parameters. Moreover, the growth system is simpler and rather easier to scale up for mass production than other systems. A summary of the various 
growth techniques, their material sources, process conditions, crystal growth rates and the largest crystals sizes obtained to date are presented in Table 2.1 in tandem with their associated reference(s).

\subsection{Thermodynamics and Surface Kinetics of GaN Growth}

Gallium nitride has the calculated bonding energy of $2.2 \mathrm{eV} / \mathrm{bond}[73]$. A consequence of this high value is its high melting temperature ( 2790K) and moderate thermal stability. Studies of the thermodynamics of GaN have mainly been concerned with the decomposition reaction:

$$
\mathrm{GaN}=\mathrm{Ga}+1 / 2 \mathrm{~N}_{2}
$$

The strong triple bond in the nitrogen molecule $(4.38 \mathrm{eV})$ lowers the thermodynamic potential of the nitride constituents, namely, Ga and $1 / 2 \mathrm{~N}_{2}$. Since the free energy of each of its constituents decreases with temperature faster than the free energy of the crystal, gallium nitride loses its stability at high temperatures. At atmospheric pressure, GaN becomes unstable at about $1200^{\circ} \mathrm{K}[74]$. Conversely, the application of pressure allows an increase in the free energy of the constituents, $\mathrm{Ga}$ and $\mathrm{N}$, much more than that of the crystal, shifting the equilibrium point to higher temperatures and extending the stability range of $\mathrm{GaN}$, as shown in Fig. 2.3. Application of $11 \mathrm{kbar}$ of $\mathrm{N}_{2}$ moved the equilibrium point from $\sim 1200 \mathrm{~K}$ to $\sim 1750 \mathrm{~K}$. This concept is utilized in the high-temperature highpressure solution growth of GaN[74]. 
The above irreversible reaction is clearly important for synthesis and crystal growth, since the growth process is controlled by competition between the reverse reaction, which critically depends on the arrival of activated nitrogen species at the growing surface, and the forward reaction whose rate limiting step is the unusually large kinetic barrier of decomposition of GaN. Thurmond and Logan[75] calculated the equilibrium pressure of $\mathrm{N}_{2}$ above GaN. More recently, Karpinski et al.[76] used the partial decomposition of GaN in a high pressure apparatus to measure the equilibrium pressure of $\mathrm{N}_{2}$ over GaN, over a wide range of temperature. The results are shown in Fig. 2.4. The high values of the equilibrium pressure of $\mathrm{N}_{2}$ are apparent from this plot, for example $\sim 100$ atm at $1100^{\circ} \mathrm{C}$. Because of these very high equilibrium nitrogen pressures, most crystal growth experiments have used ammonia as the source of nitrogen both for synthesis and crystallization. Since the ammonia molecule is much less stable than $\mathrm{N}_{2}, 100 \mathrm{~atm}$ of nitrogen is equivalent to $0.1 \mathrm{~atm}$ of ammonia at $1000^{\circ} \mathrm{C}$. Thurmond and Logan[75] also calculated the equilibrium vapor pressure of $\mathrm{NH}_{3}$ over GaN. However, all the thermodynamic values for $\mathrm{GaN}$ were assumed to have the same values as $\mathrm{ZnO}$; namely, $\Delta \mathrm{H}_{298}{ }^{\circ}=-26.4 \mathrm{kcal}$ and $\mathrm{S}_{298}{ }^{\circ}=10.43 \mathrm{cal} / \mathrm{mol} \cdot \mathrm{K}$. With the latest thermodynamic data $\left(\Delta \mathrm{H}_{298}{ }^{\circ}=-27.9 \mathrm{kcal} / \mathrm{mol}[77], \mathrm{S}_{298}{ }^{\circ}=8.8 \mathrm{cal} / \mathrm{mol} \cdot \mathrm{K}[77], \mathrm{C}_{\mathrm{p}}=9.06+2.14 \times 10^{-3} \mathrm{~T}(\mathrm{~J} / \mathrm{mol} \cdot \mathrm{K})\right.$ [78]), higher equilibrium pressures of $\mathrm{NH}_{3}$ over $\mathrm{GaN}$ were calculated, as shown in Fig. 2.4. Therefore, growth of $\mathrm{GaN}$ is possible at sub-atmospheric pressures using ammonia. Calculation of the free energy of the reaction $\left(\Delta \mathrm{G}_{900 \mathrm{C}}=-48.4 \mathrm{kcal} / \mathrm{mol}\right)$ showed the formation of gallium nitride to be favored over the temperature region of interest. Contrary to these thermodynamic calculations, however, the growth rate of GaN crystals is negligible to $900^{\circ} \mathrm{C}$, showing that the chemical reaction is kinetically controlled. 
The nitrogen molecule with its highly stable $\mathrm{N}-\mathrm{N}$ triple bond $(9.8 \mathrm{eV})$ is extremely difficult to break into its atomic $\mathrm{N}$ free radical constituents that are necessary for GaNbased compound growth. While this is not a barrier to growth of GaN crystals in hightemperature high-pressure solution growth, it makes the growth of $\mathrm{GaN}$ almost impossible at pressures below atmospheric pressure. Such stability results in the necessity to dissociate the molecule using various processes such as those utilized in plasma assisted molecular beam epitaxy (MBE), electron cyclotron resonance plasma assisted $\mathrm{MBE}$, and radio frequency plasma MBE. Unfortunately, all these approaches require modifications to the growth reactor and necessitate a significant monetary investment. Even with the use of highly energetic nitrogen species, the thermal energy on the growing surface is important for the uptake of both $\mathrm{N}$ and $\mathrm{Ga}[79]$. While all of the above techniques have demonstrated the growth of GaN materials, they are inadequate for bulk growth of $\mathrm{GaN}$ because of the low growth rates. In contrast, the dissociation of ammonia molecules has three steps, namely[80]

$$
\begin{array}{ll}
\mathrm{NH}_{3}=\mathrm{NH}_{2}+\mathrm{H} & \left(\mathrm{E}_{\mathrm{a}}=4.8 \mathrm{eV}\right) \\
\mathrm{NH}_{2}=\mathrm{NH}+\mathrm{H} & \left(\mathrm{E}_{\mathrm{a}}=3.9 \mathrm{eV}\right) \\
\mathrm{NH}=\mathrm{N}+\mathrm{H} & \left(\mathrm{E}_{\mathrm{a}}=3.4 \mathrm{eV}\right)
\end{array}
$$

The overall energy for dissociation $(12.1 \mathrm{eV})$ is greater than that for dissociation of nitrogen $(9.8 \mathrm{eV})$; however, the reaction is kinetically favorable due to the lower activation energy for each step. Thermodynamically, almost all the $\mathrm{NH}_{3}$ is decomposed into $\mathrm{N}_{2}$ and $\mathrm{H}_{2}$ at temperatures higher than $300^{\circ} \mathrm{C}$. However, it is well known that the decomposition rate of $\mathrm{NH}_{3}$ under typical growth conditions is slow without a catalyst, and the extent of the decomposition strongly depends on the growth conditions and 
equipment. Decomposition of $\mathrm{NH}_{3}$ in the presence of $\mathrm{Ga}$ and $\mathrm{GaN}$ was reported by Liu et al.[81], where dissociation of ammonia was easily achieved upon impact with a thermally activated GaN surface. The successful use of ammonia as a nitrogen precursor in the growth of GaN films has been reported by many researchers (see, e.g., Refs. 82-85).

A growth model has been proposed for the formation of $\mathrm{GaN}$ from $\mathrm{Ga}$ and $\mathrm{NH}_{3}$ and is illustrated in Fig. 2.5 [83]. As a first step, and in order to form the GaN molecule, the reaction barrier must to be reduced either by an increase in the energy of the reactant molecules or thorough a feasible chemical reaction path. The first step of the proposed reaction sequence includes the adsorption of $\mathrm{NH}_{3}$ on a $\mathrm{Ga}$ site, either within the $\mathrm{GaN}$ surface or an adsorbed $\mathrm{Ga}$ atom on the substrate surface. The bonding between $\mathrm{Ga}$ and $\mathrm{N}$ is through the lone pair electrons of the $\mathrm{NH}_{3}$. The second and third steps involve the formation of Ga-ammonia intermediate molecules coupled with the migration of $\mathrm{H}$ from the adsorbed ammonia to the surface and further reaction of the Ga with the ammonia to replace the $\mathrm{H}$ with the $\mathrm{Ga}$. The final step involves the formation of $\mathrm{GaN}$ and the liberation of $\mathrm{H}_{2}$ from the surface. The concept of on surface cracking (OSC) of ammonia has also introduced by Kamp and co-workers[84,85].

Thon and Kuech[86] studied high temperature gas phase reactions between trimethylgalliium (TMG) and ammonia in a MOCVD reactor using mass spectrometry. The main gas phase species was $\left[\left(\mathrm{CH}_{3}\right)_{2} \mathrm{Ga}: \mathrm{NH}_{2}\right]_{\mathrm{x}}$, where most probably $\mathrm{x}=3$, resulting from the fast adduct formation followed by the elimination of methane. The adduct formation in the gas phase depletes the reactants, changes the transport rates of the reactants to the surface, and eventually affects the growth rate and uniformity of the GaN 
films. These parasitic gas phase reactions can be reduced by appropriate design of the MOCVD reactor.

Ammonia behaves as a Lewis base (lone pair electron donor), and its decomposition is accelerated through interaction with an electron deficient Lewis acid such as Ga (lone pair electron acceptor). The existence of a Lewis acid on the surface lowers the activation energy, which increases significantly the surface residence time and permits the reaction intermediates to be formed. Once the Lewis complex has been formed, Ga atoms replace the $\mathrm{H}$ atoms either sequentially or simultaneously in the complex. The $\mathrm{H}$ atoms react on the surface to form $\mathrm{H}_{2}$, which desorbs and is pumped away.

Several other studies reveal that $\mathrm{NH}_{3}$, after physisorption to the surface, instantaneously chemisorbs under release of a hydrogen atom at temperature above $200 \mathrm{~K}$. At moderate temperatures $\mathrm{NH}_{2}$ and $\mathrm{NH}$ are formed, and $\mathrm{H}_{2}$ is released from the surface. With increasing temperatures the remaining $\mathrm{H}$ is stripped off and the nitrogen forms a nitride with the surface[87-89]. However, surface reaction depends on many variables including growth temperature, total pressure, and incoming flux of each reactant. Therefore, information regarding the rates of the surface kinetics is useful in determining experimental parameters. For example, a V/III ratio for the growth of $\mathrm{GaN}$ can be estimated based upon desorption rates of $\mathrm{Ga}$ and $\mathrm{N}$, as shown in Fig. 2.6. At $780^{\circ} \mathrm{C}$, the desorption rate of $\mathrm{Ga}, \mathrm{D}_{\mathrm{Ga}}$, is the same as that of $\mathrm{N}, \mathrm{D}_{\mathrm{N}}$, and $\mathrm{D}_{\mathrm{Ga}}>\mathrm{D}_{\mathrm{N}}$ at $\mathrm{T}<780^{\circ} \mathrm{C}$ and $\mathrm{D}_{\mathrm{Ga}}<\mathrm{D}_{\mathrm{N}}$ at $\mathrm{T}>780^{\circ} \mathrm{C}[90]$. GaN crystals with better structural quality were obtained in the Ga-rich regime of $\mathrm{MBE}$, where the growth temperature is usually low $\left(<700^{\circ} \mathrm{C}, \mathrm{D}_{\mathrm{Ga}}\right\rangle$ $\mathrm{D}_{\mathrm{N}}$ ) due to the use of an activated nitrogen plasma source. This growth condition shifts to N-rich regime in case of the CVD grown GaN films, where the growth temperature is 
$\sim 1000^{\circ} \mathrm{C}\left(\mathrm{D}_{\mathrm{Ga}}<\mathrm{D}_{\mathrm{N}}\right)$ and sufficient to efficiently crack ammonia molecules. All the growth parameters are closely related to each other and, in turn, to surface kinetics and should be controlled with precision.

GaN crystals have been grown as whiskers, needles, and platelets. Correlations between the morphology and growth conditions have not been established. It is, however, generally believed that the morphology is a consequence of the interplay among the V/III ratio, the growth pressure, and the growth temperature. One of the difficulties in the investigation of this matter is the lack of available data, since most of the work regarding the surface kinetics has been limited to the basal plane of $\mathrm{GaN}$ thin films. Control of the morphology of the growing crystal is essential in terms of a large-scale production.

Previous research[63] showed that the aspect ratio of GaN crystals could possibly be controlled by adjusting the V/III ratio and the growth temperature. In addition, GaN crystals were grown without any disturbance for a short period of time; however, prolonged growth did not lead to larger crystals. In most cases, the crystals either ceased to grow or tended to decompose after several hours under the same growth conditions. This implies that one or more growth variables changed during the growth. In situ monitoring would allow one to grow crystals while changing the variables simultaneously.

Nucleation of numerous GaN crystals from the reaction of Ga with ammonia has been reported[64]. A constant reflux of growth could be one of the reasons why a large number of nucleation sites and crystallographic orientations of $\mathrm{GaN}$ results from vapor reactions. Even though the maximum growth rate can be achieved at a minimal decomposition rate, secondary nucleation is detrimental to growth of larger single 
crystals. If there is any local fluctuation in the concentration of the vapor species, nucleation of another nuclei on the growing crystal will be inevitable. This implies that the processing window is very narrow and that the growth parameters should be controlled with precision. Unlike the case of nucleation from the melt, which increases rather slowly with decreasing temperature, after reaching the critical supercooling; nucleation from the vapor begins rapidly at a certain critical supercooling. The physical explanation is that both nucleation and growth from the melt are strongly influenced by diffusion which takes place through a medium much more viscous than in the case of a vapor. Ideal conditions for the growth of large single crystals are encountered if, as a result of nucleation control, only one nucleus of the solid can be formed in the system. Without the competition of other nuclei this crystal would then grow as large as growth rate and size of the apparatus would allow. Such conditions can be realized at a value of supersaturation sufficiently low to allow nucleation to occur only on an active site and sufficiently high to allow an appreciable growth rate. Data concerning the critical supersaturation in the case of crystallization from the vapor phase are very few. Very narrow metastable regions imply that control of nucleation in the vapor growth would be very difficult. To increase the reproducibility and also the size of the crystals, single crystal seeds can be used.

The following Chapters describe in detail the research conducted for this dissertation and concerned with the use of vapor phase transport and the reaction between Ga vapor and ammonia to grow increasingly larger single crystals of GaN. A dedicated growth system, constructed and commissioned by this investigator, and equipped with an in situ monitoring facility, as described in Chapter 3, was used for these studies. The use 
of this system at both moderate (conventional) and high substrate temperatures and with respect to the position of the Ga source for nucleation and growth in pure ammonia are described in Chapter 4. This chapter also discusses the very good experimental reproducibility obtained that allowed the construction of three-dimensional diagrams of the processing windows to achieve control of the aspect ratio of the GaN crystals with respect to growth temperature, ammonia total pressure and flow rate. Chapter 5 reports the investigations regarding the enhanced decomposition in ammonia using mass spectrometry. Application of this knowledge by the author fostered the achievement of seeded growth of GaN crystals on GaN seed crystals in an ammonia/nitrogen mixture for a prolonged growth time, as described in Chapter 6. The results of preliminary studies concerned with growth of $\mathrm{GaN}$ crystals in the presence of a $\mathrm{Si}$ wafer and from an $\mathrm{Al} / \mathrm{Ga}$ solution are described in Chapters 7 and 8, respectively. 


\subsection{References}

1. S. Nakamura, T. Mukai, M. Senoh, Appl. Phys. Lett. 64, 1687(1994)

2. S. Nakamura, M. Senoh, S. Nagahama, N. Iwasa, T. Yamada, T. Marsushita, H. Kiyoku, Y. Sugimoto, Jpn. J. Appl. Phys., 35, L74(1996)

3. S. Nakamura, J. Cryst. Growth, 170, 11(1997)

4. O. H. Nam, T. S. Zheleva, M. D. Bremser and R. F. Davis, J. Electron. Mater., 27(4), 233(1998)

5. T. S. Zheleva, W. M. Ashmawi, O. H. Nam and R. F. Davis, Appl. Phys. Lett., 74(15), (1999)

6. K. J. Linthicum, T. Gehrke, D. B. Thomson, K. M. Tracy, E. P. Carson, T. P. Smith, T. S. Zheleva, C. A. Zorman, M. Mehregany, and R. F. Davis, MRS Internet J. Nitride Semicond. Res., 4S1, G4.9(1999)

7. D. B. Thomson, T. Gehrke, K. J. Linthicum, P. Rajagopal, and R. F. Davis, MRS Internet J. Nitride Semicond. Res., 4S1, G3.37(1999)

8. S. Nakamura, M. Senoh, S. Nagahama, N. Iwasa, T. Yamada, T. Marsushita, H. Kiyoku, Y. Sugimoto, T. Kozaki, H. Umemoto, M. Sano and K. Chocho, J. Cryst. Growth, 189/190, 820(1998)

9. R. Madar, G. Jacob, J. Hallais and R. Fruchart, J. Cryst. Growth, 31, 197(1975)

10. J. Karpinski, and S. Porowski, J. Cryst. Growth, 66, 11(1984)

11. I. Grzegory, J. Jun, M. Bockowski, S. Krukowski, M. Wroblewski, B. Lucznik and S. Porowski, J. Phys. Chem. Solids 56, 639 (1995)

12. I. Grzegory, J. J. Jun, M. Bockowski and S. Porowski, Physica B 185, 99(1993) 
13. I. Grzegory, M. Bockowski, B. Lucznik, M. Wroblewski and S. Porowski, MRS Internet J. Nitride Semicond. Res. 1, 20(1996)

14. S. Porowski, M. Bockowski, B. Lucznik, G. Nowak and J. Baranowski, Mat. Res. Soc. Symp. Proc., 449, 35(1997)

15. S. Porowski, J. Cryst. Growth, 189/190, 153(1998)

16. S. Porowski, MRS Internet J. Nitride Semicond. Res. 4, 13(1999)

17. M. Bockowski, Physica B, 265, 1(1999)

18. T. Inoue, Y. Seki, O. Oda, and S. Kurai, Jpn. J. Appl. Phys. 39, 2394(2000)

19. T. Suski, P. Perlin, M. Leszczynski, H. Teisseyre, I. Grzegory, J. Jun, M. Bockowski, S. Porowski, K. Pakura, A. Wysmolek, and J. M. Baranowski, Mat. Res. Soc. Proc. 396, 15(1996)

20. H. P. Maruska and J. J. Tietjen, Appl. Phys. Letters 15, 327(1969)

21. M. Ilegems, J. Cryst. Growth, 13/14, 360(1971)

22. T.L. Chu, K. Lto, R. K. Smeltzer, and S. C. Chu, J. Electrochem. Soc. 121, 159(1974)

23. K. Gillessen, K. H. Schuller, and B. Struck, Mat. Res. Bull.,12(10), 955(1977)

24. K. Naniwae, S. Itoh, H. Amano, K. Itoh, K. Hiramatsu, and I. Akasaki, J. Cryst. Growth, 99, 381(1990)

25. R. J. Molnar, W. Gotz, L. T. Romano, and N. M. Johson, J. Cryst. Growth, 178, 147(1997)

26. S. S. Park, I. W. Park, and S. H. Choh, to be published.

27. T. Shibata, H. Sone, K. Yahashi, M. Yamaguchi, K. Hiramatsu, and N. Itoh, J. Cryst. Growth, 189/190, 67(1998)

28. A. Usui, Mat. Res. Soc. Symp. Proc., 482, 233(1998) 
29. M. Albrecht, I.P. Nikitina, A.E. Nikolaev, and H. P. Strunk, Phys, Stat. Sol., A, 176, 453(1999)

30. 30.T. Paskoba, E. B. Svedberg, L.D. Madsen, R. Yakimova, I. G. Ivanov, A. Henry, and B. Monemar, MRS Internet J. Nitride Semicond. Res. 4S1, G3.16(1999)

31. L.Zang, S. L. Gu, T. F. Kuech, M. P. Boloslawski, J. Cryst. Growth, 213, 1(2000)

32. R. Cadoret, J. Cryst. Growth, 205, 123(1999)

33. Y. Melnik, K. Vassilevski, I. P. Nikitina, A. I. Babanin, V. Y. Davydov, and V. A. Dmitriev, MRS Internet J. Nitride Semicond. Res. 2, 39(1997)

34. T. Detchprohm, K. Hiramatsu, H. Amano, and I. Akasaki, Appl. Phys. Lett., 61, 2688(1992)

35. A. Ushi, H. Sunakawa, A. Sakai, and A. A. Yamaguchi, Jpn. J. Appl. Phys., 36, L899(1997)

36. W. Seifert, G. Fitzl, E. Butter, J. Crystal Growth, 52, 257(1981)

37. M. Yano, M. Okamoto, Y. K. Yap, M. Yoshimura, Jpn. J. Appl. Phys. 38, L1121(1999)

38. H. Yamane, T. Kajiwara, T. Sekiguchi, and M. Shiamda, Jpn. J. Appl. Phys. 39, L146(2000)

39. H. Yamane, T. Sekiguchi, and M. Shimada, and F. Disalvo, J. Cryst. Growth, 186, 8(1998)

40. S. Oktyabrsky, K. Dovidenko, A. K. Sharma, J. Narayan and V. Joshkin, Appl. Phys. Lett., 59, 944(1991)

41. J. Wu, H. Yaguchi, K. Onabe, Y. Shiraki, and R. Ito, Jpn. J. Appl. Phys., 37, $1440(1998)$ 
42. R. Dwilinski, J. M. Baranowski, M. Kaminska, and R. Doradzinski, Acta Physica Polonica A, 90, 763(1996)

43. P. G. Baranov, E. N. Mokhov, A. O. Ostroumov, M. G. Ramm, M. S. Ramm, V. V. Ratnikov, A. D. Roenkov, Yu. A. Vodakov, A. A. Wolfson, G. V. Saparin, S. Yu. Karpov, D. V. Zimina, Yu. N. Makarov, Holger Juergensen, MRS Internet J. Nitride Semicond. Res. 3, 50(1998)

44. S. Sakai, S. Kurai, K. Nishino, K. Wada, H. Sato, and Y. Naoi, Mat. Res. Soc. Proc. 449, 15(1997)

45. Y. A. Vodakov, E. N. Mokhov, A. D. Roenkov, M.E. Boiko, and P. G. Baranov, J. Cryst. Growth, 183, 10(1998)

46. D. D. Manchon, A. S. Barker, P. J. Dean, and R. B. Zetterstrom, Solid State Comm., 8, 1227(1970)

47. R. B. Zetterstorm, J. Mat. Sci., 5, 1102(1970)

48. M. Aoki, M. Sano, and T. Ogino, Sago Shikenso Nempo, 34, 125(1975)

49. B. J. I. Sherwood and D. K. Wickenden, J. Mat. Sci., 5, 869(1970)

50. A. Addamiano, J. Electrochem. Soc.,108, 1072(1962)

51. J. Wang, R. S. Q. Fareed, M. Hao, S. Mahanty, M. Osinski, and S. Sakai, J. Appl. Phys., 85(3), 1895(1999)

52. C. M. Balkas, Z. Sitar, T. Zheleva, L. Bergman, I. K. Shmagin, J. F. Muth, R. Kolbas, R. Nemanish, and R. F. Davis, Mat. Res. Soc. Symp. Proc., 449, 41(1997)

53. M. Aoki, M. Sano, and T. Ogino, Sago Shikenso Nempo, 34, 125(1975) 
54. Y. A. Vodakov, E. N. Mokhov, M. G. Ramm, A. D. Roenkov, A. G. Ostroumov, A. A. Wolfson, S. Yu, N. Markov, and H. Jurgensen, Mat. Res. Soc. Symp. Proc., 482, 27(1998)

55. G. Kamler, J. Zachara, S. Podsiadlo, L. Adamowicz, and W. Gebicki, J. Cryst. Growth, 212, 39(2000)

56. J. Wang, S. Sakai, J. Appl. Phys., 85.3, 1895 (1999)

57. W. C. Johnson, J. P. Parsons, and M. C. Crew, J. Phys. Chem., 36, 2651(1932)

58. T. L. Chu, J. Electrochem. Soc. 118, 1200(1971)

59. I.G.Pichugin and D.A.Yaskov, Neorg. Mat., 6, 1973(1970)

60. D. Elwell, R. S. Feigelson, M. M. Simkins, and W. A. Tiller, J. Cryst. Growth, 66, 45(1984)

61. D. Elwell and M. M. Elwell, Prog. Crystal Growth and Charact., 17, 53(1988)

62. E. Ejder, J. Crystal Growth, 22, 44 (1974)

63. C. M. Balkas, Z. Sitar, T. Zheleva, L. Bergman, I. K. Shmagin, J. F. Muth, R. Kolbas, R. Nemanich, and R. F. Davis, J. Cryst. Growth, 208, 100(2000)

64. M. Callahan, M. Harris, M. Suscavage, D. Bliss and J. Baily, MRS Internet J. Nitride Semicond. Res. 4, 10(1999)

65. X. L. Chen, Y. G. Cao, Y. C. Lan, X. P. Xu, J. Q. Li, K. Q. Lu, P. Z. Jiang, T. Xu, Z. G. Bai, and J. K. Liang, J. Cryst. Growth, 209, 208(2000)

66. M. Shibata, T. Furuya, H. Sakaguchi, and S. Kuma, J. Cryst. Growth, 196, 47(1999)

67. R. A. Logan and C. D. Thurmond, J. Electrochem. Soc. 119, 1727(1972)

68. M. Aoki and T. Orgino, J. J. Appl. Phys., 78, 2383(1981) 
69. M. Puchinger, T. Wagner, D. Rodewald, J, Bill, F. Aldinger, and F. F. Lnage, J. Cryst. Growth, 208, 153(2000)

70. A. Agonita, C. C. Hayman, and J. C. Angus, Appl. Phys. Lett., 70, 179(1997)

71. A. Agonita, C. C. Hayman, J. C. Angus, L. Wang, J. S. Dyck, and K. Kash, Mat. Res. Soc. Symp. Proc., 449, 47(1997)

72. J. S. Dyck, Kath, K. Kash, M. T. Grossner, C. C. Hayman, A. Argoitia, N. Yang, M. Hong, M. E. Kordesch, nd J. C. Angus, MRS Internet J. Nitride Semicond. Res. 4S1, G3.23(1999)

73. W. A. Harrison, Electronic Structure and Properties of Solids Ed. Freeman, San Francisco (1980)

74. I. Grzegory, M. Bockowski, B. Lucznik, M. Wroblewski and S. Porowski, MRS Internet J. Nitride Semicond. Res. 1, 20(1996)

75. C. D. Thurmond and R. A. Logan, J. Electrochemical. Soc., 119(5), 622(1972)

76. J. Karpinski, J. Jun and S. Porowski, J. Cryst. Growth, 66, 1(1984)

77. A. V. Davydov and T. J. Anderson, The $194^{\text {th }}$ Meeting of the Electrochemical Society, Nov. 1-6, (1999)

78. O. Kubaschewski, C. B. Alcock, and P. J. Spencer, "Materials Thermochemistry", Pergamon Press, NY (1993)

79. N. Newman, J. Ross, and M. Rubin, Appl. Phys. Lett., 62(11), 1242(1993)

80. F. A. Cotton and G. Wilkinson, "Advanced Inorganic Chemistry", $5^{\text {th }}$ edition, Johns Wiley \& Sons, NY (1988)

81. S.S. Liu et al., J. Electrochem. Soc., 125, 7, 1161(1978) 
82. W. Kim, O. Aktas, E. Botchkarev, A. Salvador, S. N. Mohammad, and H. Morkoc, J. Appl. Phys., 79(10), 7657(1996)

83. E. Kim, I. Berishev, and A. Bensaoula, J. Appl. Phys., 85(2), 1178(1999)

84. M. Kamp, M. Mayer, A. Pelzmann, and K. J. Ebeling, Mat. Res. Soc. Symp. Proc., 449, 161(1997)

85. M. Kamp , M. Mayer, A. Pelzmann, and K. J. Ebeling, MRS Internet J. Nitride Semicond. Res. 2, 26 (1997).

86. A. Thon and T. F. Kuech, Appl. Phys. Lett., 69(1), 55(1996)

87. G. Ertl, M. Huber, J. Catal. 61, 537 (1980).

88. M.Grunze in D.A.King, "The Chemical Physics of Solid Surfaces and Heterogeneous Catalysis, Synthesis and Decomposition of Ammonia”, 4, Elsevier Scientific Publishing Company, Amsterdam (1982)

89. D. F. Davidson, K. Kohse-Hoinghaus, A. Y. Chang, and R. K. Hanson, Int. J. Chem. Kinetics, 22, 513(1990)

90. D. D. Koleske, A. E. Wickenden, R. L. Henry, W. J. Desisto, and R. J. Gorman, J. Appl. Phys., 84(4) 1998(1998) 


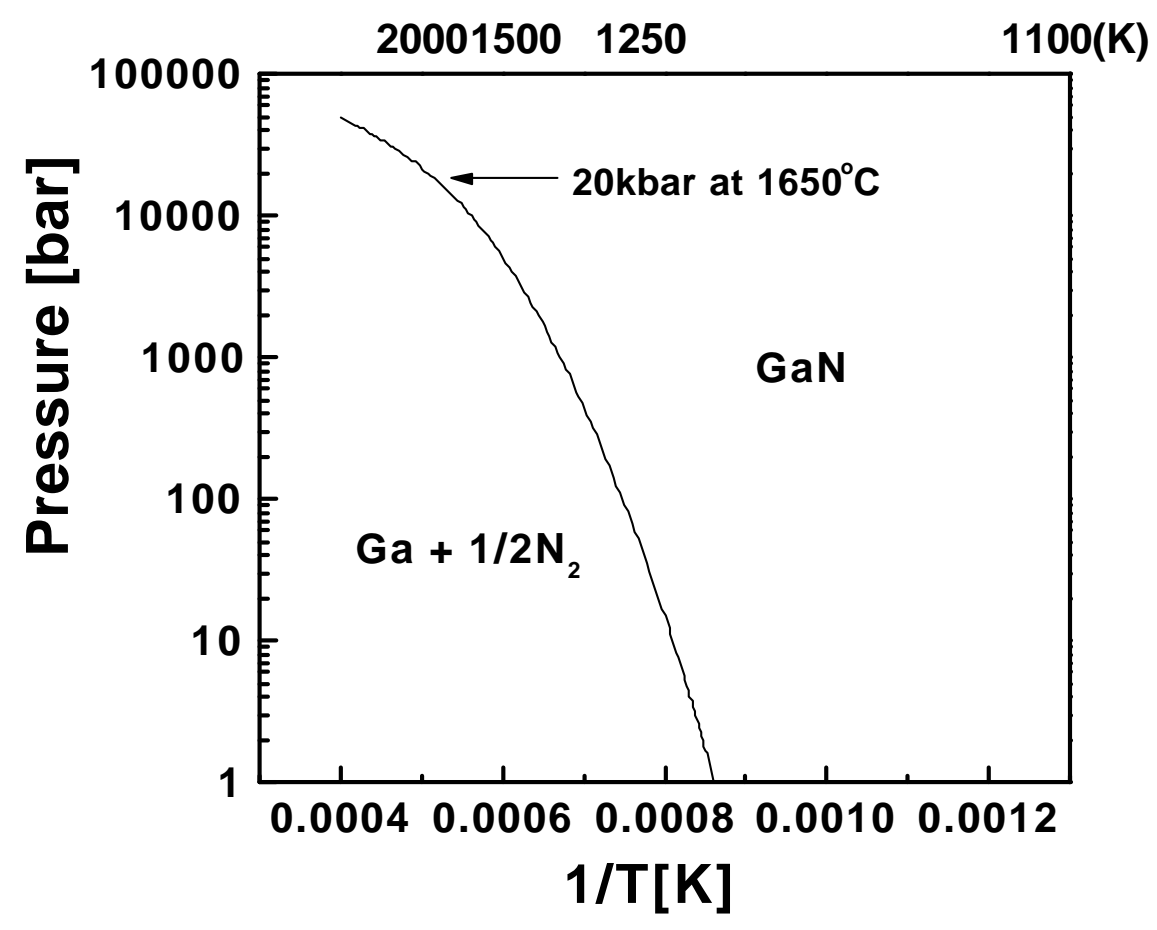

Figure 2.1 Equilibrium pressure curve for GaN. The equilibrium pressure of $\mathrm{N}_{2}$ over $\mathrm{GaN}$ exceeds $20 \mathrm{kbar}$ at $1000^{\circ} \mathrm{C}[10]$.

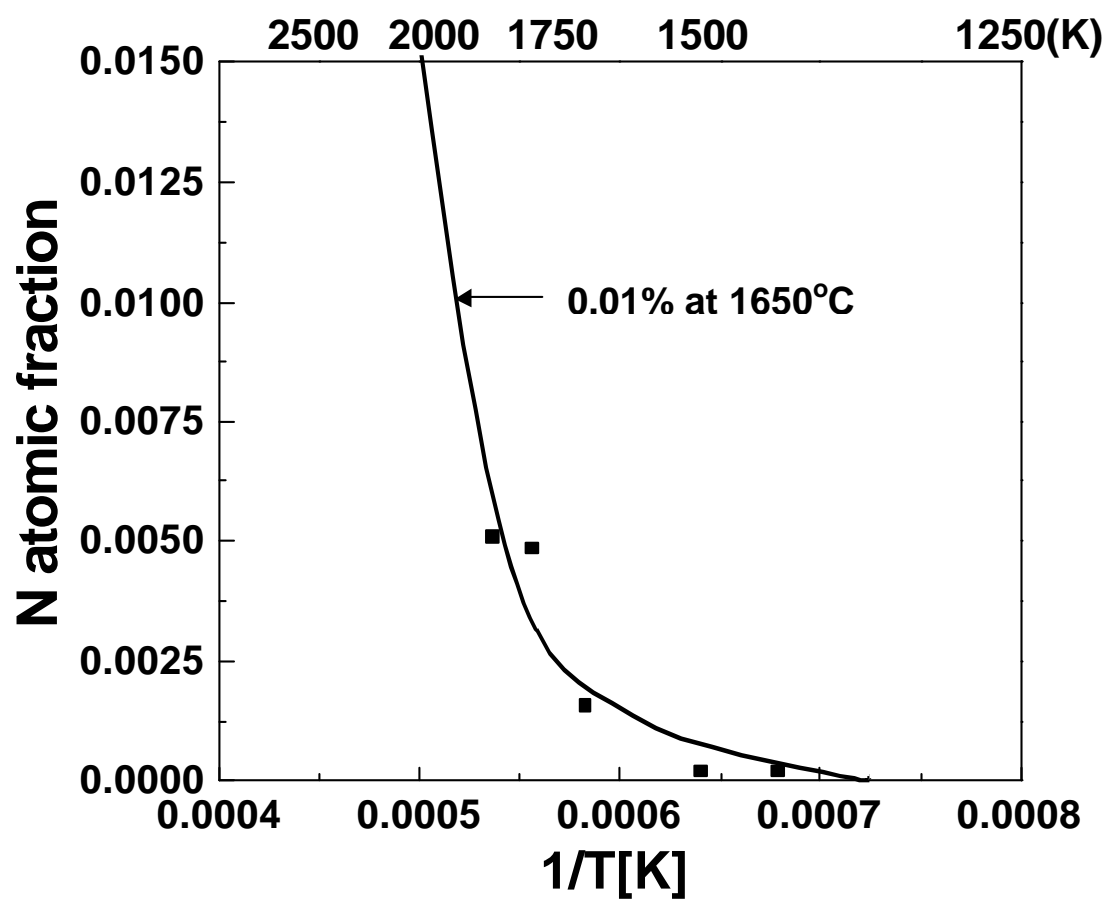

Figure 2.2 Nitrogen solubility in liquid gallium as a function of temperature[11]. 


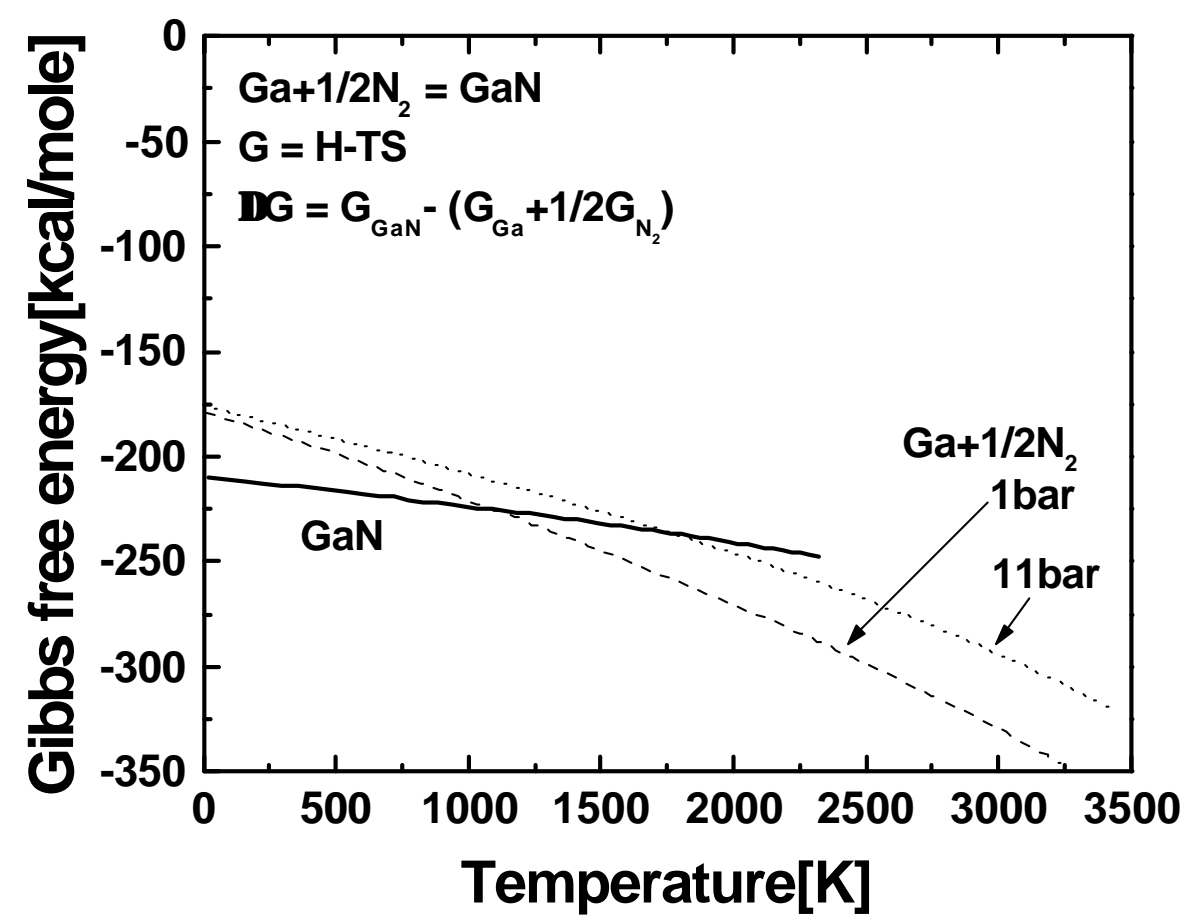

Figure 2.3 Gibbs free energy of GaN and its constituents[74]. 


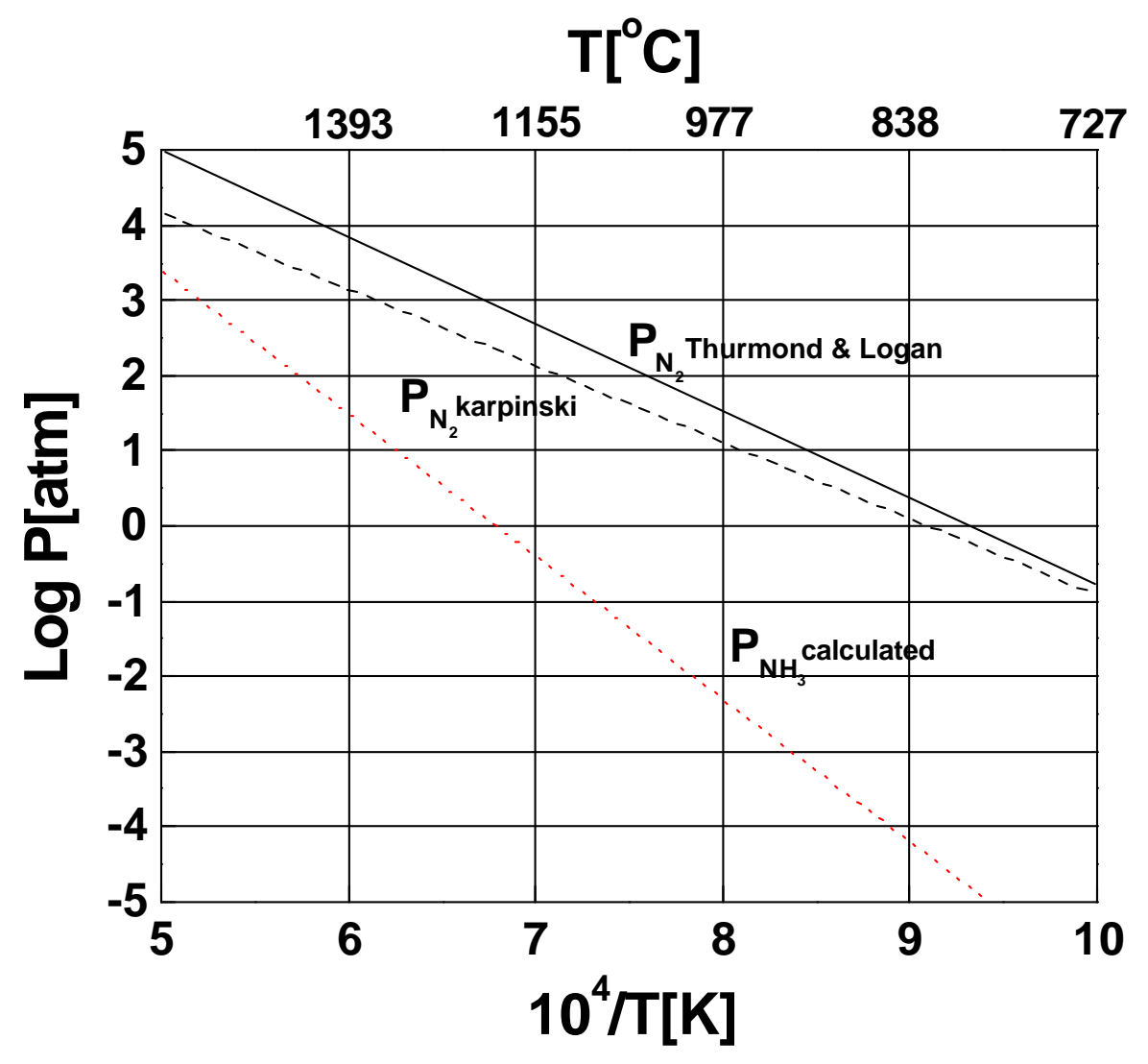

Figure 2.4 Equilibrium pressure of $\mathrm{NH}_{3}$ and $\mathrm{N}_{2}$ over $\mathrm{GaN}$; solid line: calculated by Thurmond and Logan[75], dashed line: calculated by Karpinski et al[76], dotted line: calculated using the most recent thermodynamic data. 


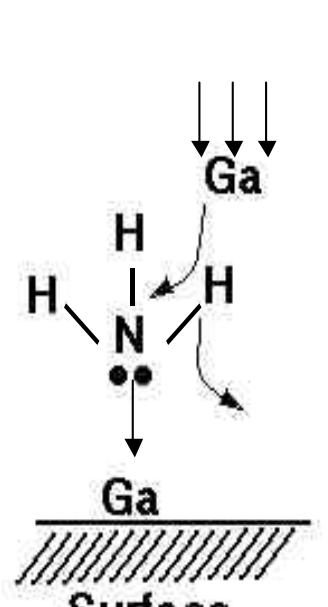

Surface

(1)
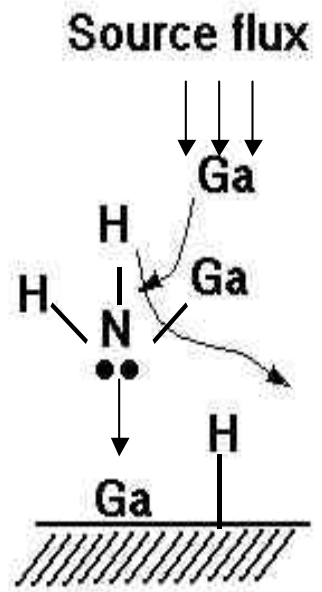

(2)

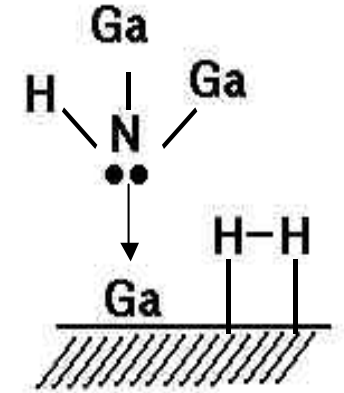

(3)

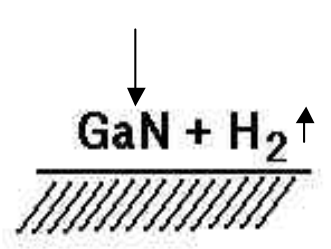

(4)

Figure 2.5 Schematic illustration of $\mathrm{GaN}$ formation on a solid surface starting with $\mathrm{Ga}$ and $\mathrm{NH}_{3}$ precursors. 


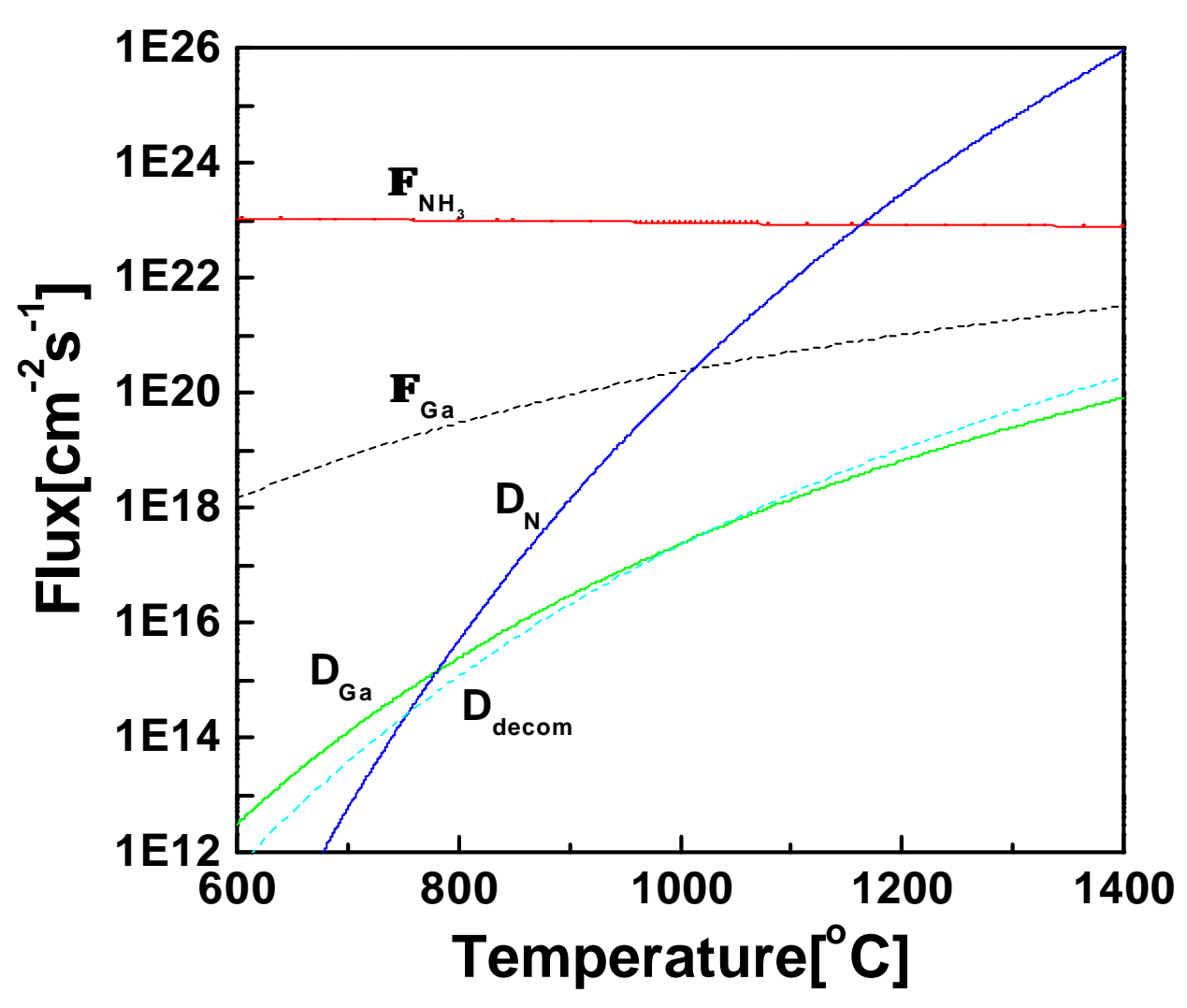

Figure 2.6 Rates of surface kinetics of GaN: $\Phi_{\mathrm{Ga}}$ : impingement rate of Ga, $\Phi_{\mathrm{NH} 3}$ : impingement rate of $\mathrm{NH}_{3}, \mathrm{D}_{\mathrm{Ga}}$ : desorption rate of $\mathrm{Ga}, \mathrm{D}_{\mathrm{N}}$ : desorption rate of nitrogen, $\mathrm{D}_{\mathrm{decom}}$ : decomposition rate of $\mathrm{GaN}[90]$. 


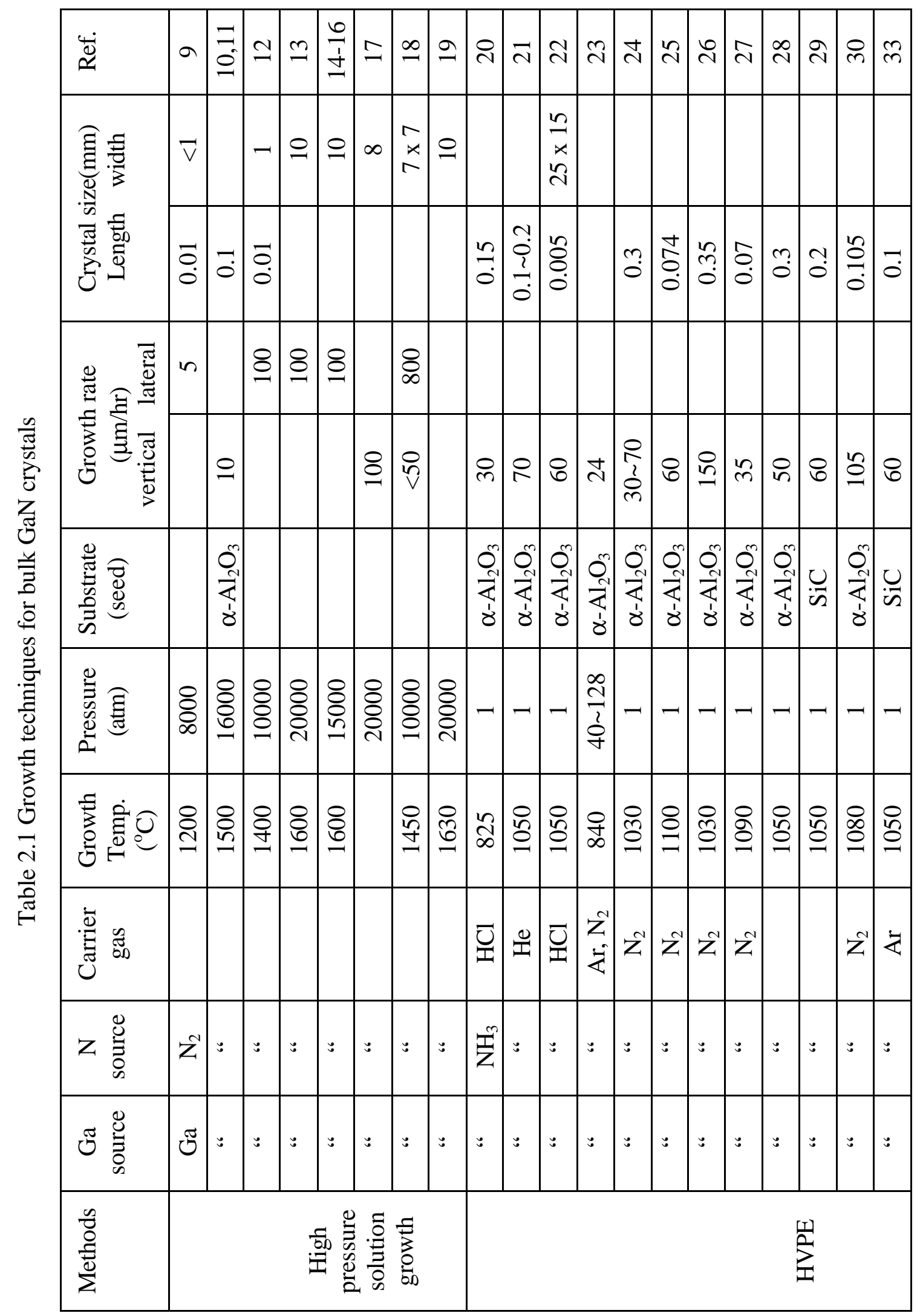




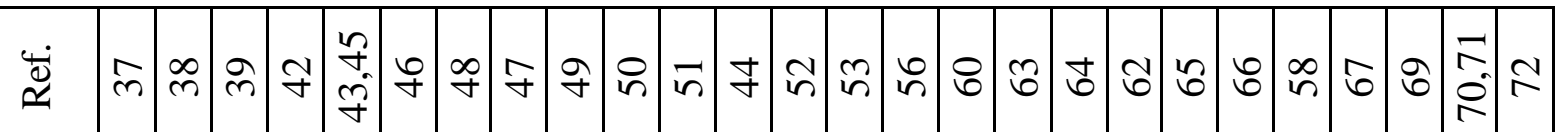

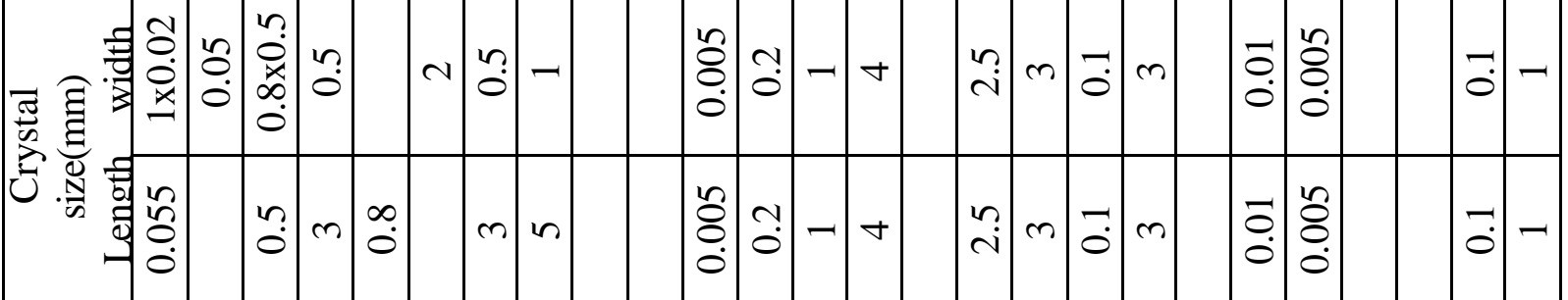

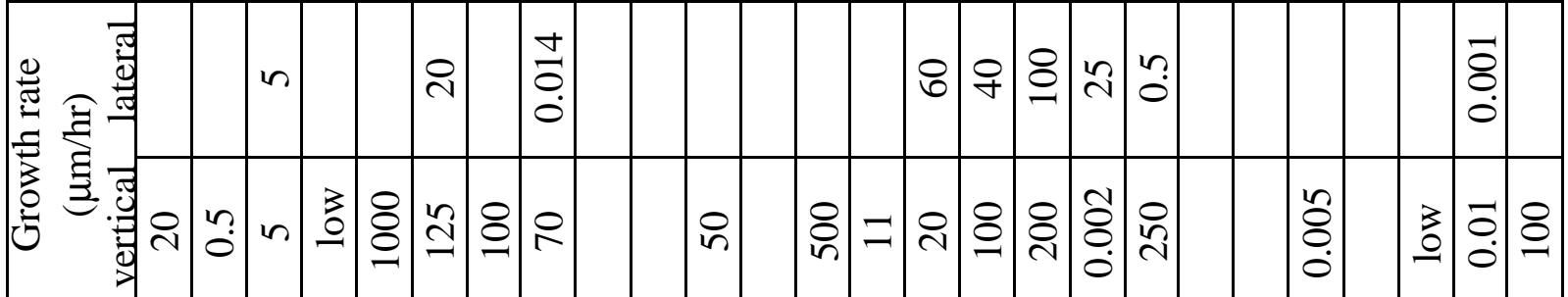

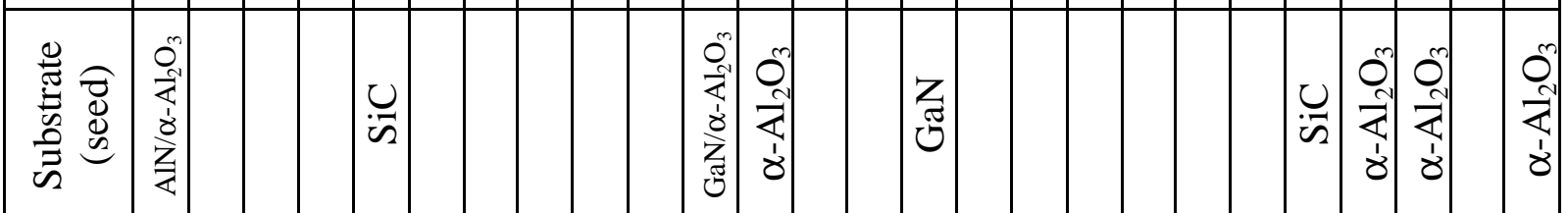

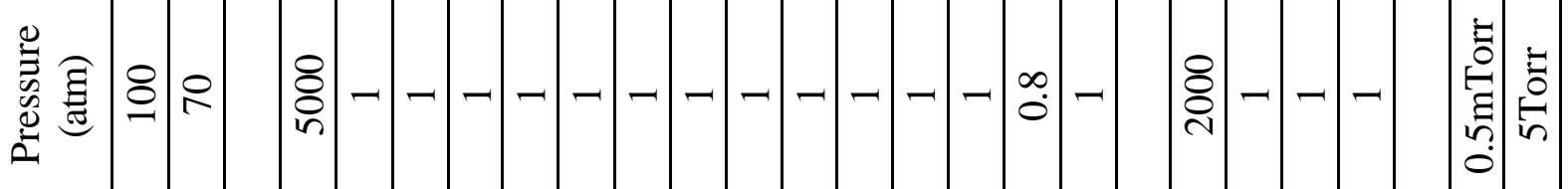

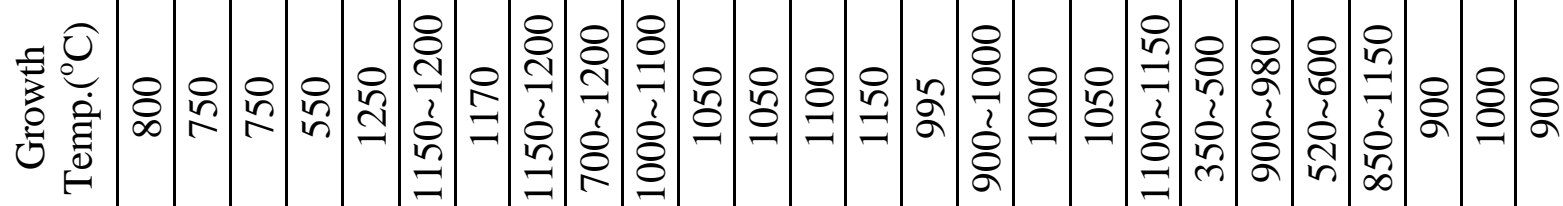
芯

$I^{N}$

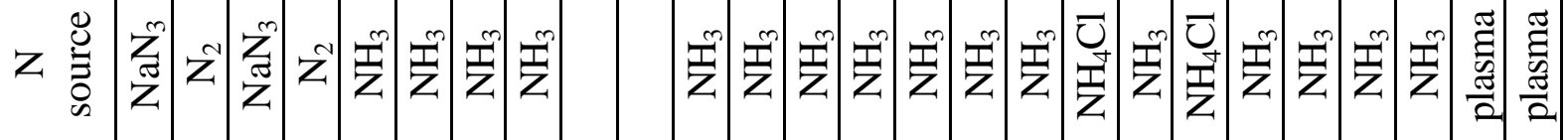

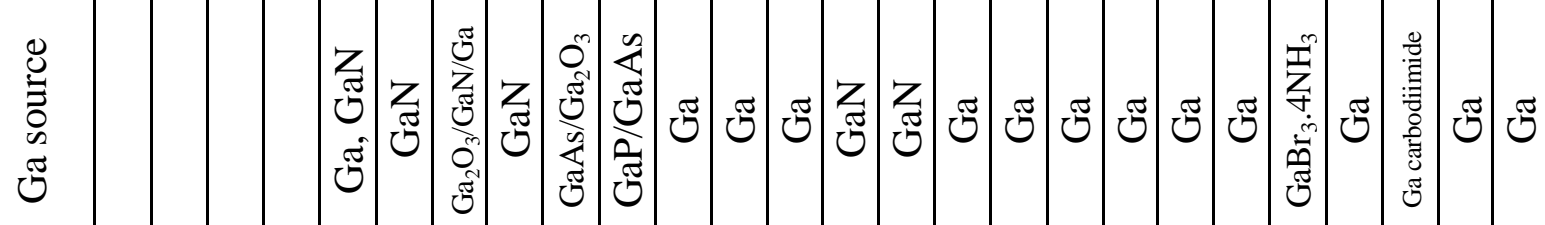

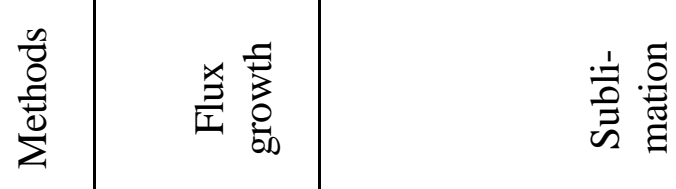

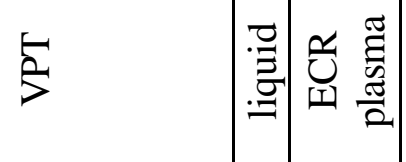




\section{Description of the Growth System}

Crystal growth experiments were conducted in a dedicated growth system especially designed for GaN growth and shown schematically and pictorially in Figs. 3.1 and 3.2, respectively. The complete system consists of a stainless steel growth chamber, a chemical pump to maintain growth pressure in the reactor tube, a mechanical pump to evacuate the outer chamber, a control tower including an in-situ monitoring facility, a gas delivery and control system, and a chiller for the outer chamber. The growth furnace was operated using a PID controller specially programmed with LabView for the growth. All the growth parameters were controlled by the input values from the controller. To ensure safe operation, an interlock system was also programmed to shut down the growth system and the flow of all gases in case of an emergency.

Figure 3.3 shows a cutaway view of the stainless steel chamber. The system consists of a 4" diameter alumina reactor tube and a 16.5" outer stainless steel chamber. The latter accommodates two graphite heaters around the alumina tube. The heaters were designed to have specific resistances at high temperatures to comply with the outputs of the power supply and were fabricated from a high purity grade of graphite $(>99 \%$, Carbone of America). Both graphite heaters are supported by water-cooled electrical feedthroughs. Radiation shields made of tantalum sheets were placed around the two heaters to reflect heat effectively toward the center of the alumina reactor tube. To monitor the temperature, two type-C thermocouples were inserted through small holes in the tantalum radiation shields and placed $2 \mathrm{~mm}$ away from the center of each heater. The thermocouples were not in direct contact with the heaters to avoid an abrupt change in reading in case of detachment of the thermocouple from the heater. 
The outer chamber was continually evacuated by a mechanical pump to minimize oxidation of the graphite heaters to prolong their lifetime during operation. The pressure in the outer chamber was maintained below $2 \times 10^{-3}$ Torr even at the heater temperature of $1600^{\circ} \mathrm{C}$. The outer chamber is equipped with a water jacket around the outside as well as top and bottom flanges, as shown in Fig. 3.4(a). Two viton o-rings were used to seal the gap between the alumina reactor tube and the outer chamber. To avoid deterioration at high temperatures, a water-cooled copper coil separately cooled the o-rings. All the fixtures including the growth crucible inside the alumina reactor tube were manufactured from hot pressed boron nitride $(\mathrm{BN})$ because of its inertness to $\mathrm{NH}_{3}$ and its ease of machining. All the metal parts were located away from the growth zone as far as possible to minimize the possibility of contamination. In addition, all the metal parts were covered by boron nitride. Figure 3.4(b) shows the BN growth assembly and supports prior to loading. A special chemical pump was used in tandem with a butterfly valve to maintain the desired pressure in the alumina reactor tube. A pneumatic cylinder was used to lift either the top flange or the chamber for maintenance. A variety of safety features were employed. The whole system was programmed to shut down in case of overheating, overpressure, and the loss of cooling water.

One of the features of system is the implementation of in situ monitoring capability. A long distance microscope was installed on the top flange of the chamber (Fig. 3.5(a)) to constantly monitor the substrate during the growth through a viewport (Fig. 3.5(b)). An IR reflective lens was inserted between the viewport and the long distance microscope to reduce the radiative heat transfer. In addition, an electric cooling fan was used to cool the viewport, the temperature of which otherwise would increase to about $120^{\circ} \mathrm{C}$ during a 
typical run. Each run was monitored though a $\mathrm{CCD}$ camera attached to the back of the microscope and taped using a VCR. Images were retrieved from the tape and then captured by a frame grabber.

In designing a growth crucible, nucleation and growth of extraneous material on the tube walls and other reactor parts were considered. The severity of these two phenomena depends on the nature of the growth process. Generally, extraneous deposition is not a problem unless it becomes sufficiently extensive so as to deplete the gas stream of reactants prior to reaching the substrate. Resistance-heated, hot-wall systems are usually employed with deposition processes having negative exothermic heats of reaction so that deposition will occur on the cooler parts of the apparatus. With such systems a small temperature minimum between the source and substrate may result in significant deposition at this region. The resulting crystals will undergo further growth and simultaneously deplete the gas stream of reactants or greatly alter its composition prior to reaching the substrate. In such systems this extraneous growth must be eliminated or reduced to a very low value if meaningful kinetic results are to be obtained. With this in mind, a growth cell was designed in such way that all the GaN could be deposited on the coolest part, which is the top surface of the central pedestal of a BN crucible, as shown in Fig. 3.6(a). However, liquid Ga crept over the sidewall of its container during growth.

It is believed that $\mathrm{Ga}$ vapor reacts with $\mathrm{NH}_{3}$ to form a network of small GaN crystallites on the BN surfaces adjacent to the melt. Though liquid Ga does not wet BN, it wets and spreads over the GaN crystals. To eliminate this problem, an extra BN container was introduced. The space between the Ga source container and the substrate provided an insulating layer, so that a larger temperature gradient could be achieved without 
sacrificing the temperature of the Ga source. A schematic diagram of the growth crucible is shown in Fig. 3.6(b). The temperatures of each part of the growth crucible were measured with type-C thermocouples with a precision of $0.1^{\circ} \mathrm{C}$. A typical temperature profile is shown in Fig. 3.7. The temperature of the BN substrate was also calibrated with a pyrometer. 


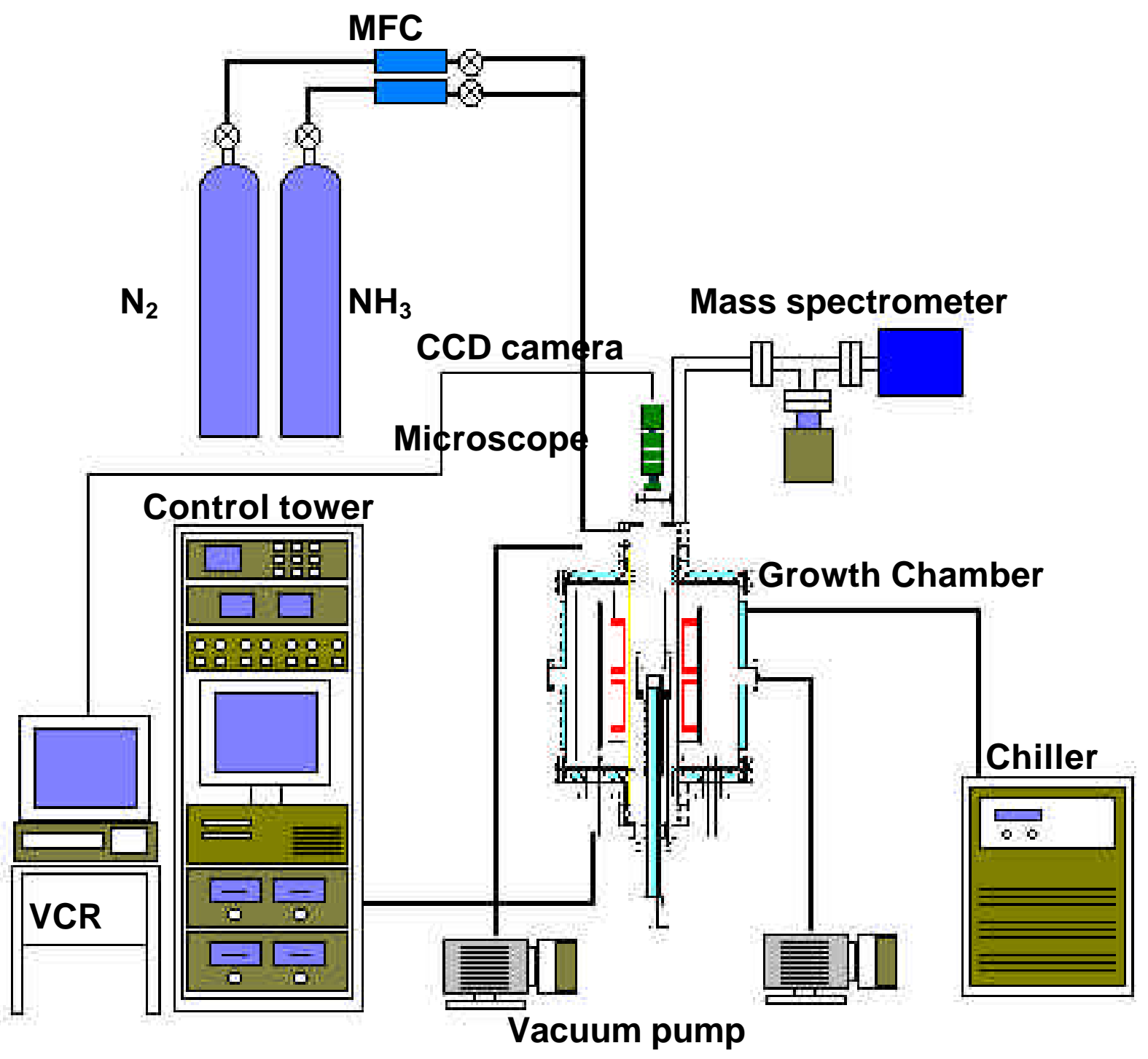

Figure 3.1 Schematic diagram of the growth system. 


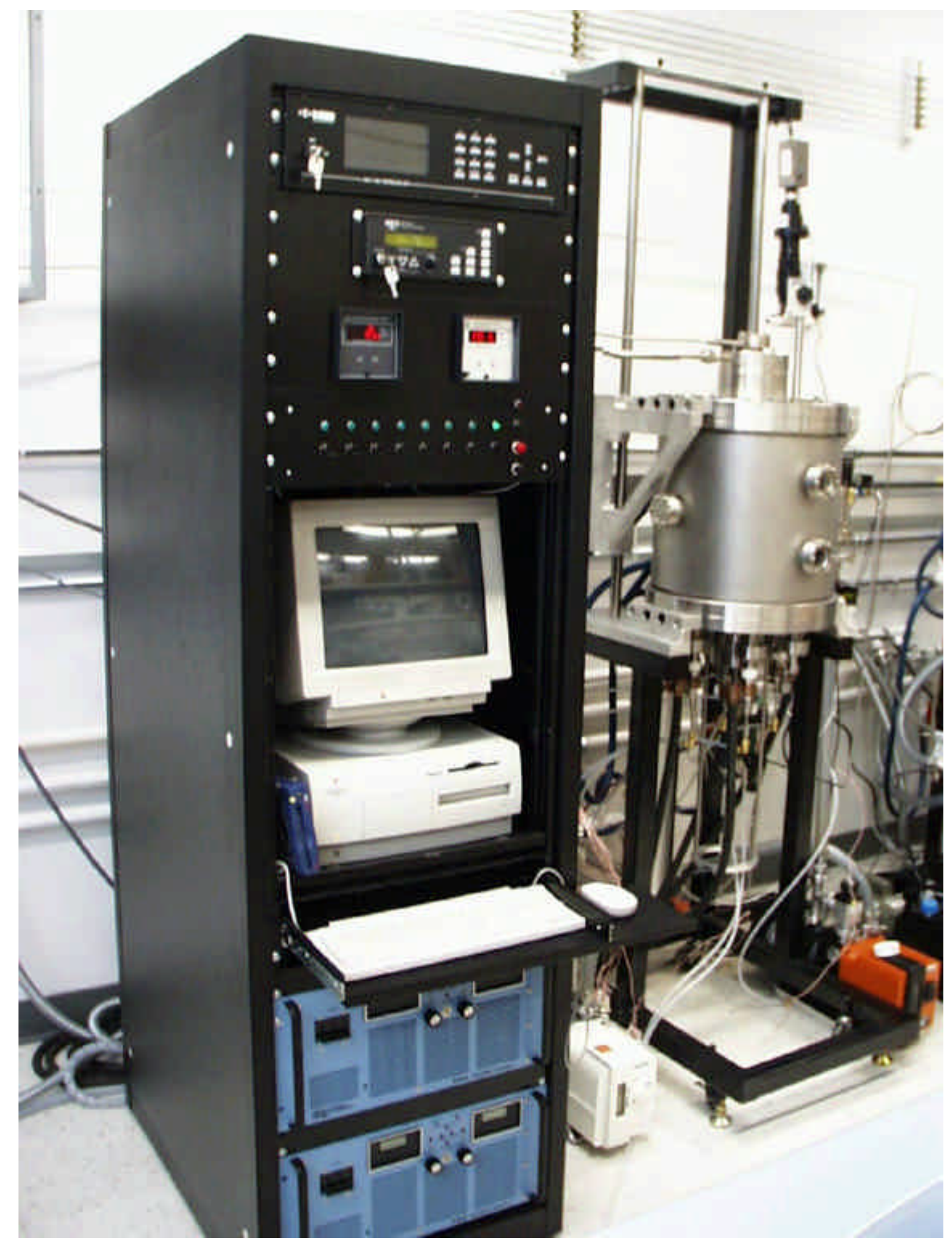

Figure 3.2 Photograph of the GaN growth system including the electronic control tower. 


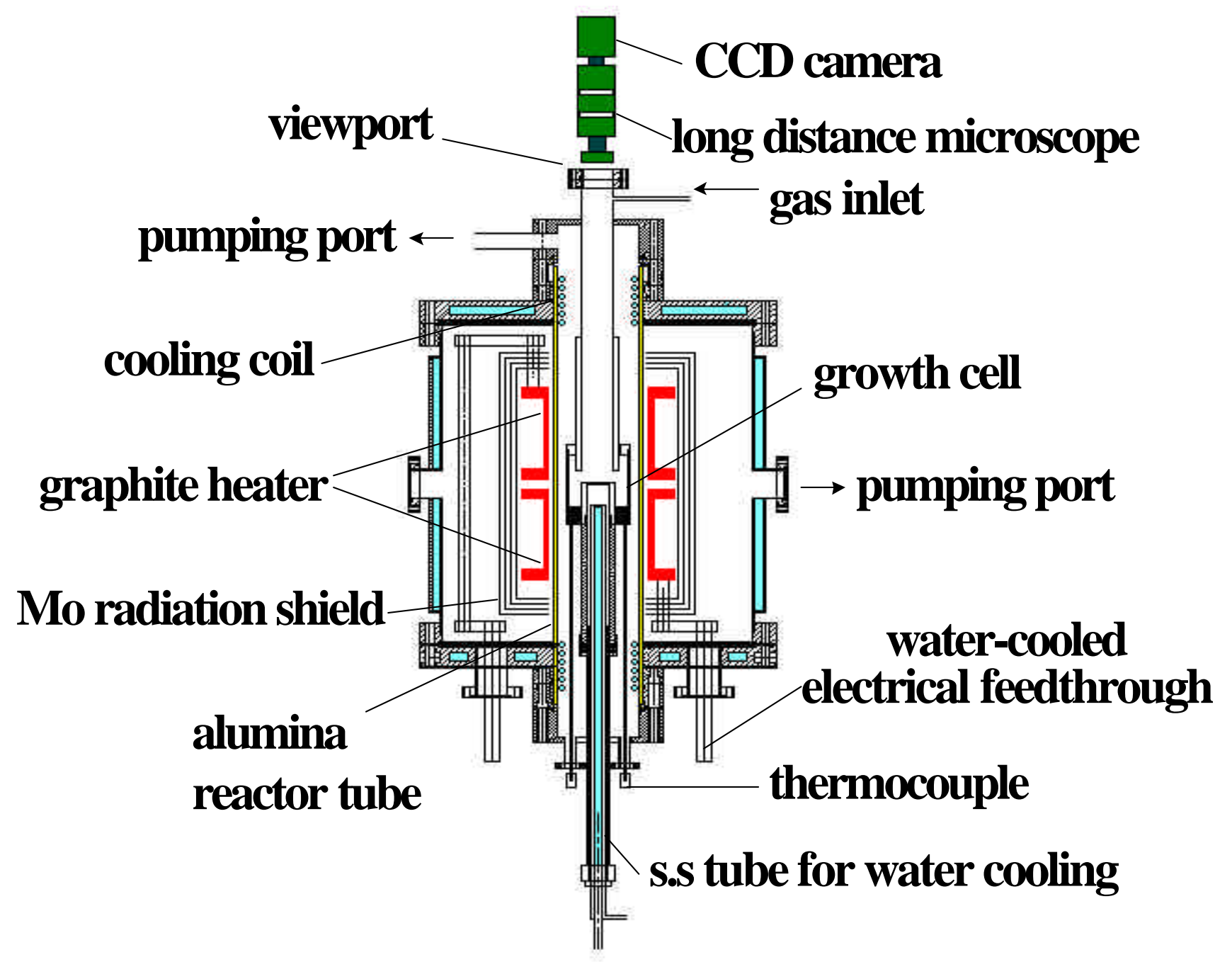

Figure 3.3 Cutaway view of the growth chamber with dual heater. 


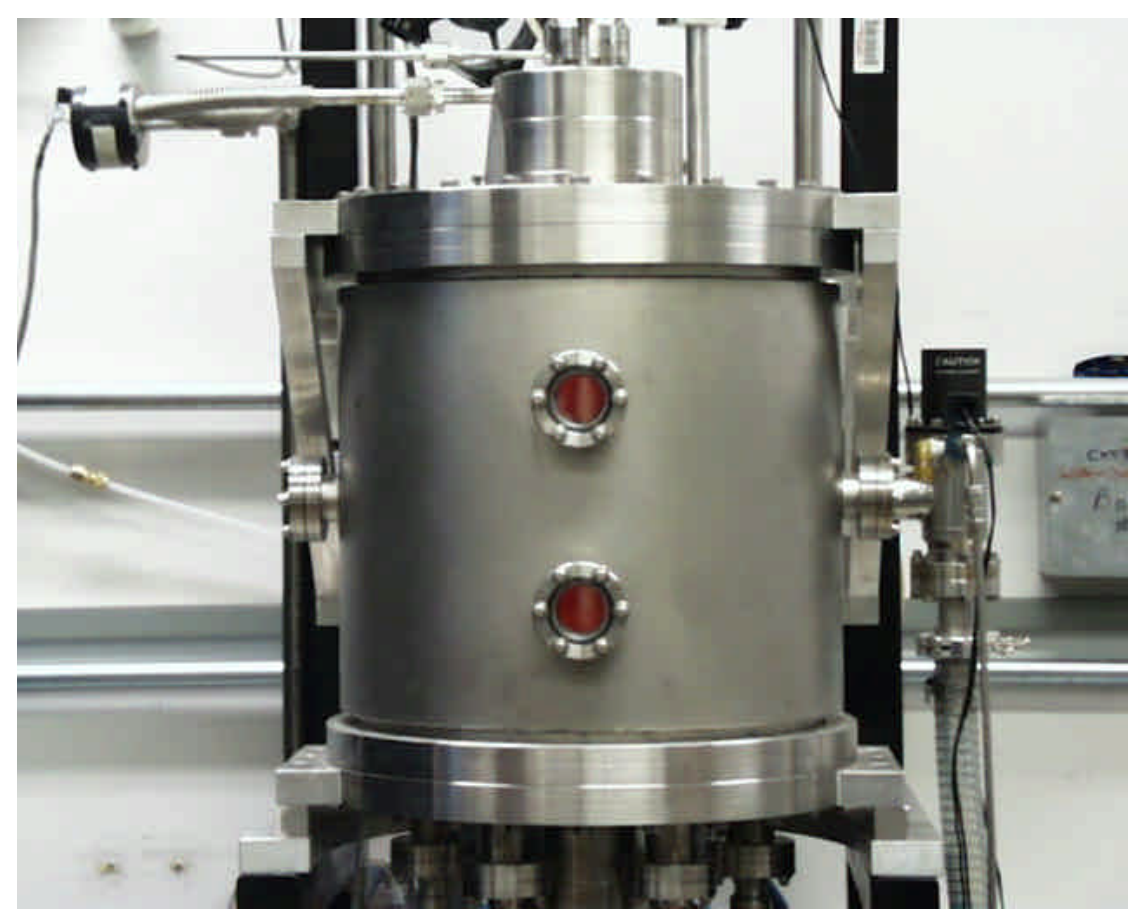

(a)

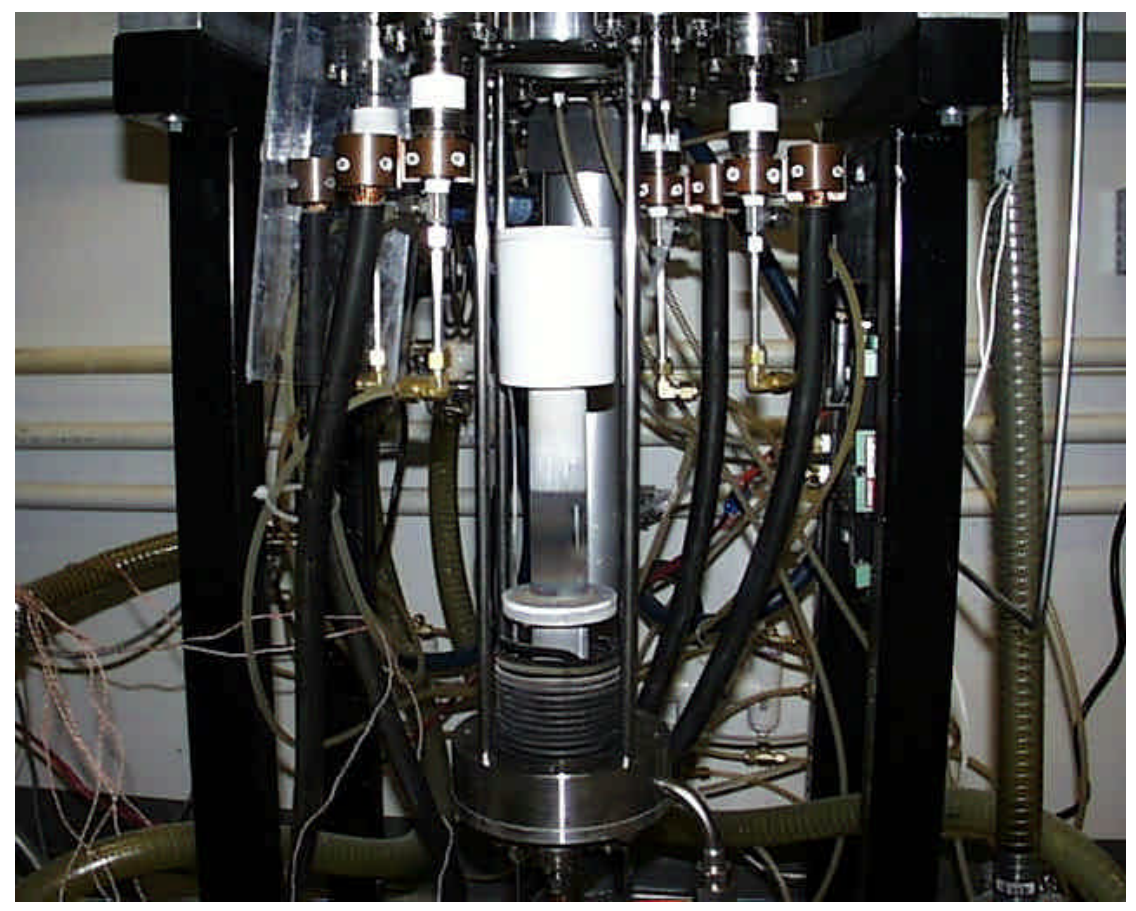

(b)

Figure 3.4 (a) Stainless steel growth chamber with water jacket in operation and (b) growth crucible and support made of $\mathrm{BN}$ prior to loading. 


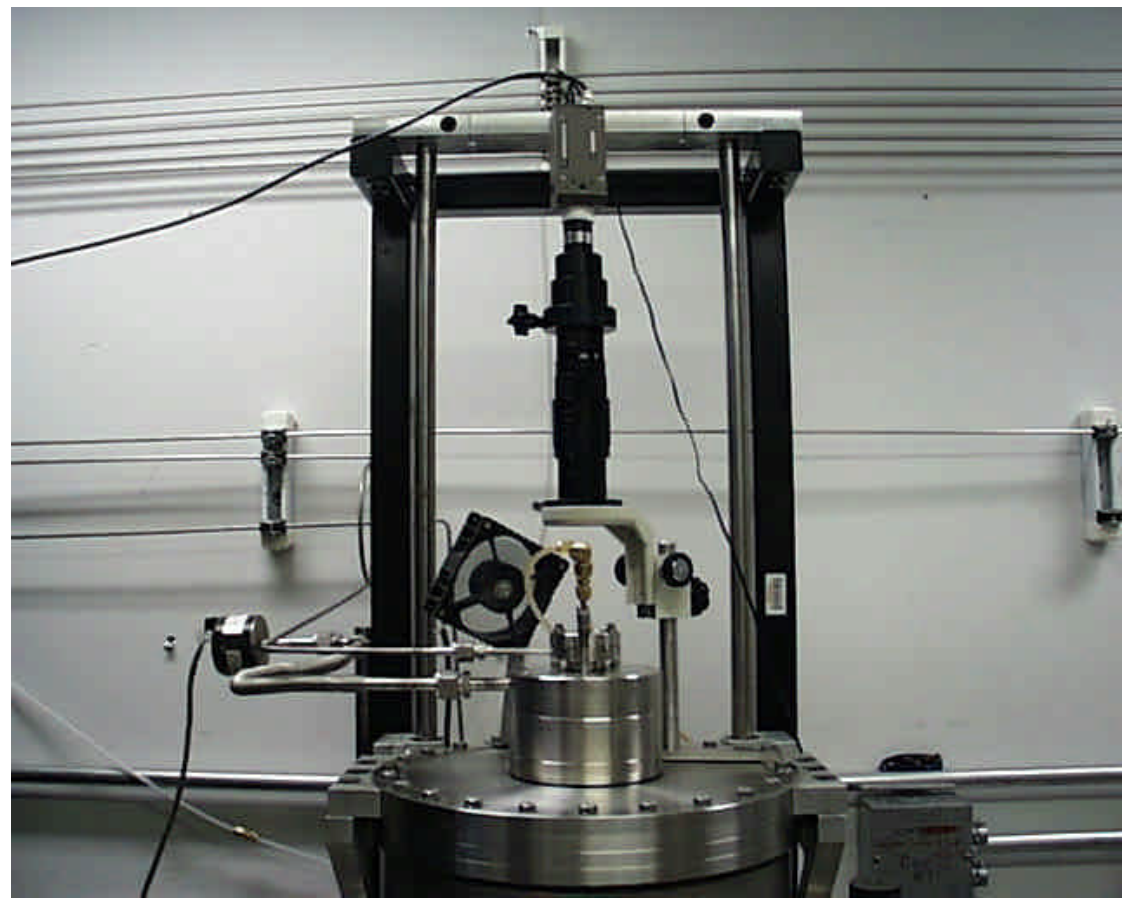

(a)

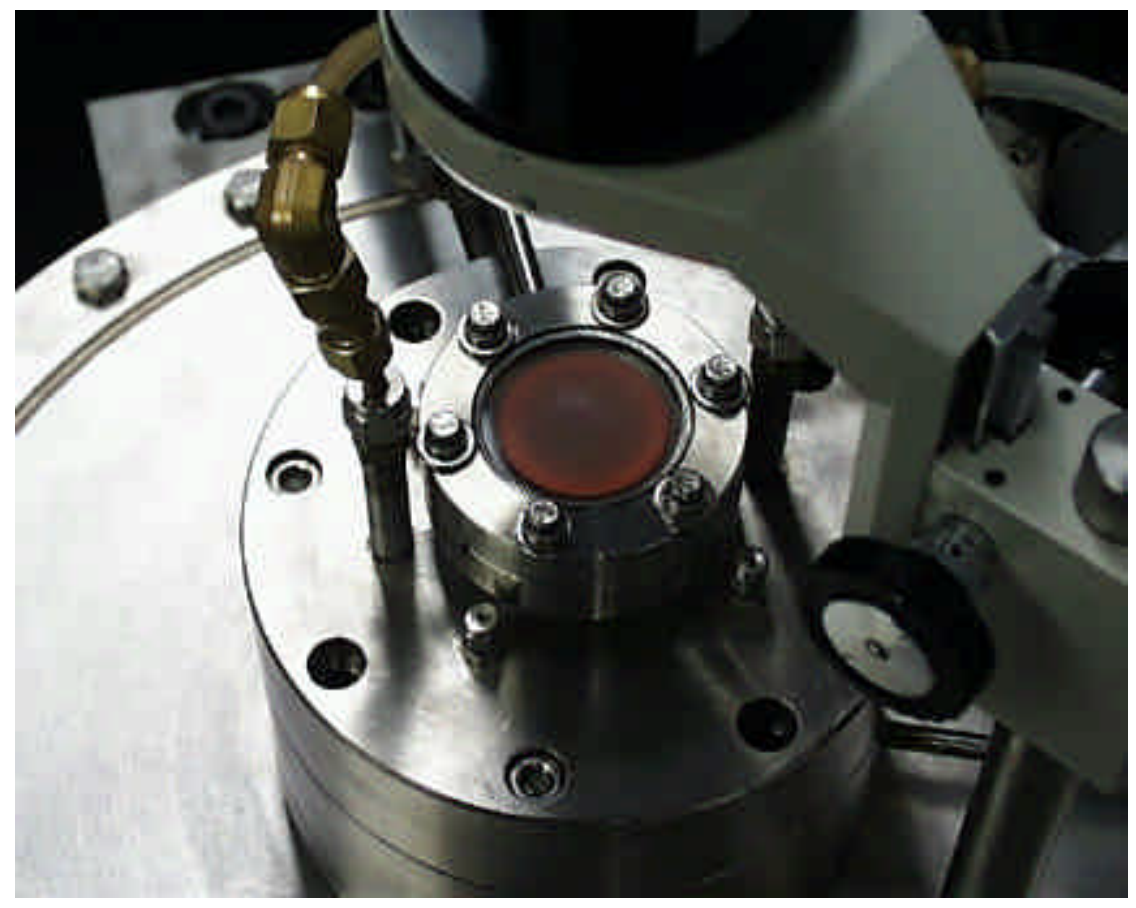

(b)

Figure 3.5 (a) Long distance microscope with a CCD camera installed on the top flange and (b) the viewport in line of sight with the substrate. 

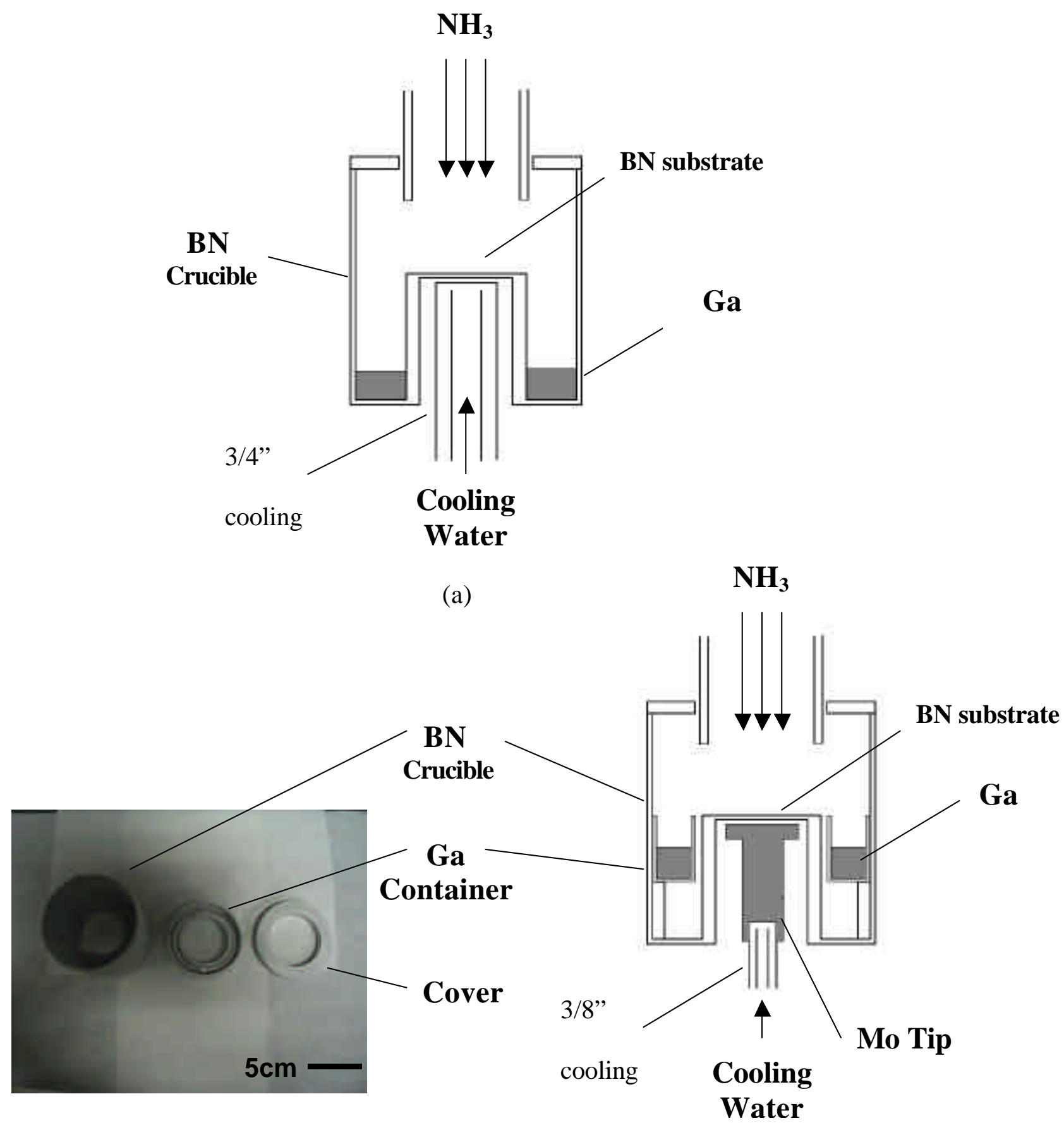

(b)

Figure 3.6 Two different cooling configurations for substrate temperature control:

(a) 3/4" cooling tube and (b) 3/8" cooling tube with a Mo tip and the BN insert. 


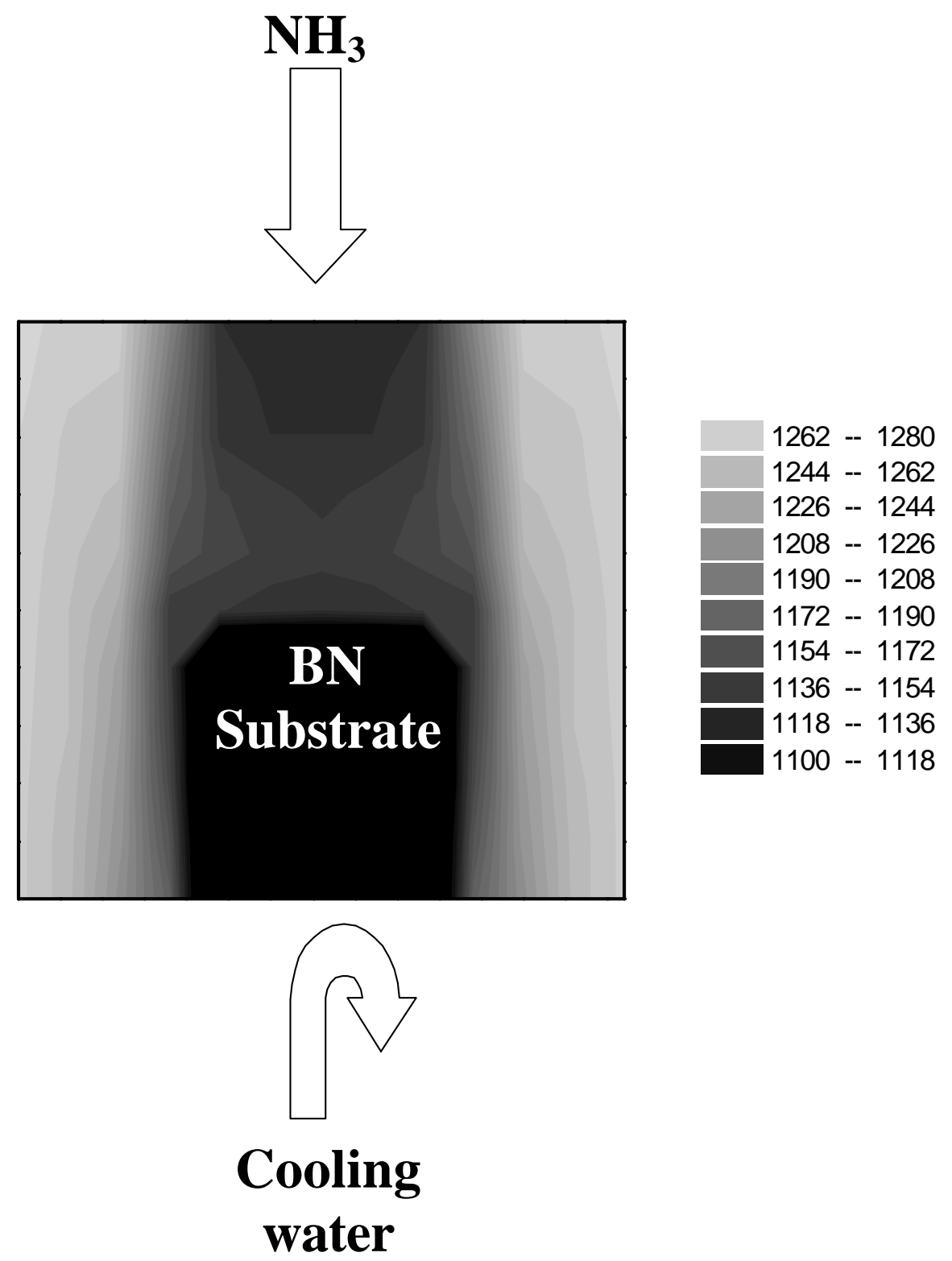

Figure 3.7 A typical temperature profile in the growth crucible. 


\section{High Temperature Nucleation and Growth of GaN Crystals via Vapor Phase Transport}

to be submitted to the Journal of Crystal Growth

by

H. Shin, D. B. Thomson, R. Schlesser, Z. Sitar, and R. F. Davis

Department of Materials Science and Engineering,

North Carolina State University, Raleigh, NC, 27695-7907 


\subsection{Abstract}

Vapor phase transport processes involving the reaction of Ga vapor and ammonia have been used to grow needle- and platelet-shaped single crystals of $\mathrm{GaN}$ at $1130^{\circ} \mathrm{C}$ without secondary nucleation. Introduction of the $\mathrm{NH}_{3}$ only at high temperatures reduced the density of nucleation, minimized the amount of $\mathrm{GaN}$ crust on the Ga source and resulted in larger crystals. A three-dimensional processing map has been constructed with respect to ammonia flow rate and total pressure at $1130^{\circ} \mathrm{C}$ to achieve control of the aspect ratio. Platelet growth of GaN was favored using low ammonia flow rates and/or low total ammonia pressures and low V/III ratios. Crystals with aspect ratios $<1$ were obtained at $1130^{\circ} \mathrm{C}, 430$ Torr and $25 \sim 75 \mathrm{sccm}$ of ammonia. The average lateral growth rate for the GaN platelets was $\sim 50 \mu \mathrm{m} / \mathrm{hr}$ and the average vertical growth rate for the needles was $\sim 500 \mu \mathrm{m} / \mathrm{hr}$. Raman spectroscopy revealed that the best platelets were grown at $1130^{\circ} \mathrm{C}$ using ammonia flow rates of $60 \mathrm{sccm}$ and a Ga source temperature of $1260^{\circ} \mathrm{C}$. Seeded growth from previously grown needles and platelets at lateral and vertical rates of $\sim 25$ and $\sim 10 \mu \mathrm{m} / \mathrm{hr}$, respectively, was achieved at $1130^{\circ} \mathrm{C}, 430 \mathrm{Torr}$ and an ammonia flow rate of $60 \mathrm{sccm}$. 


\subsection{Introduction}

Sapphire and silicon carbide are the primary substrates for the growth of $\mathrm{GaN}$ and other III-Nitride films and device structures, as substrates of, e.g., GaN and AlN, are not yet readily available. The former two substrates are not matched to any III-Nitride in terms of atom-atom separation and coefficients of thermal contraction. Residual stresses introduced into the growing films are relieved by the formation of misfit and threading dislocations. Lateral epitaxial overgrowth (LEO) $[1,2]$ and pendeo-epitaxy[3,4] have been employed to reduce the density of these dislocations by approximately five orders of magnitude in GaN and AlGaN films. Selected laser diodes fabricated on LEO-GaN substrates via MOVPE have an estimated lifetime $>10,000 \mathrm{hrs}[5]$. However, these techniques involve multiple, time consuming and expensive processing steps including lithography, plasma etching and multiple growths of GaN. Additionally, it has been demonstrated that homoepitaxial GaN films possess improved optical and electrical properties relative to films grown on foreign substrates by any technique[6-8]. As such, a strong impetus now exists for the development of commercially viable techniques for producing bulk GaN boules and wafers.

Bulk GaN crystals have been produced by various techniques, including high pressure-high temperature solution growth[9], hydride vapor phase epitaxy[10], sublimation growth[11], flux growth[12], and vapor phase transport (VPT)[13] involving the direct reaction of $\mathrm{Ga}$ vapor with ammonia. The last technique employs continuous supplies of electronic grade $\mathrm{Ga}$ and ammonia having both water and oxygen levels at $<1 \mathrm{ppm}$. However, there are difficulties inherent in this technique that must be surmounted to achieve the growth of boules of $\mathrm{GaN}$. 
Extensive primary and secondary nucleation of small, unconnected crystals are typically obtained within a narrow processing window[14]. Nucleation from the vapor begins rapidly at a certain critical supercooling, unlike that from a melt, which occurs relatively slowly via diffusion through a much more viscous medium. Data concerning critical supersaturation in the case of crystallization from the vapor phase are very few[15]. Formation of a thin Ga crust over the molten Ga source reduces the outgoing Ga flux and changes the V/III ratio in the gas phase. This, in turn, leads to changes in the growth kinetics of previously nucleated or seed crystals and, ultimately, to the cessation of growth. This crust can be avoided via precise control of the Ga-temperature, ammonia flow rate and total pressure such that $\mathrm{GaN}$ decomposition on the molten $\mathrm{Ga}$ is prevalent relative to the formation of this compound.

Aspect ratio control is another critical issue in bulk growth and a subject of the research reported herein. Elwell et al.[16] grew GaN crystals by the unseeded reaction between $\mathrm{Ga}$ and ammonia in an ammonia/hydrogen mixture. Plate-like and needle-like crystal habits were observed when crystals were grown at $\sim 890^{\circ} \mathrm{C}$ and $\sim 960^{\circ} \mathrm{C}$, respectively, at an ammonia partial pressure of $1 \times 10^{-3}$ atm in one atmosphere of an ammonia/hydrogen mixture. Kamler et al.[17] grew needles and platelets via evaporation of small $\mathrm{GaN}$ crystals at $850 \sim 1000^{\circ} \mathrm{C}$ and $1000 \sim 1100^{\circ} \mathrm{C}$, respectively, at $10 \sim 30 \mathrm{sccm}$ and 1atm of ammonia. They also found that needles grew on the part near the ammonia gas inlet and prisms and plates on the free Ga-rich part near the outlet. Edjer[18] obtained $\sim 300 \mu \mathrm{m}$ wide $\mathrm{GaN}$ platelets at $1000 \sim 1150^{\circ} \mathrm{C}$ using a heated silica ampoule containing an 1 $1 \mathrm{~mm}$ hole to achieve a high Ga vapor pressure. Callahan et al.[14] observed the formation of high aspect ratio crystals on the upper surface of a $\mathrm{GaN}$ crust formed on a 
molten Ga source maintained in an ammonia atmosphere. Beneath the crust, growth was preferentially along the basal plane of the GaN. Balkas et al[13] reported that the aspect ratio of GaN crystals grown via vapor phase transport in a manner similar to that used in the present research decreased with decreasing V/III ratio and suggested that a higher Ga flux promoted lateral growth. In the high-pressure, high-temperature solution growth technique employed by Porowski and co-workers[9,19], a needle-like habit has been shown to dominate for large supersaturations; a plate-like habit was prevalent for lower supersaturations. However, there has been no reported systematic investigation regarding the influence of processing variables on the aspect ratio of GaN bulk crystals.

In this paper, bulk GaN crystals have been grown via a reaction of Ga vapor with ammonia. The stability of the Ga source was investigated in terms of temperature and $\mathrm{NH}_{3}$ flow rate, and a high temperature nucleation technique was developed in an effort to reproducibly grow larger GaN crystals under stable growth conditions. With the aid of the latter technique, three-dimensional processing windows for control of the aspect ratio of GaN crystals have been obtained with respect to ammonia pressure and flow rate. Application of this knowledge has fostered the achievement of the seeded growth of GaN crystals without secondary nucleation as a preview to the continuous growth of $\mathrm{GaN}$ crystals. 


\subsection{Experimental Procedures}

A dedicated, computer-controlled growth system, especially designed for GaN growth and consisting of a growth chamber, two mechanical pumps, an in situ monitoring facility, and a gas delivery system were employed for this research. The 16.5" diameter, double walled, water cooled outer stainless steel growth chamber contained a 4" diameter alumina reactor tube surrounded by two graphite heaters supported by water-cooled electrical feedthroughs. Tantalum radiation shields surrounded the two heaters. Two typec thermocouples were inserted through these shields and located $2 \mathrm{~mm}$ from the center of each heater. The outer chamber was continually evacuated to minimize oxidation of the graphite heaters. The pressure in the outer chamber was maintained below $2 \times 10^{-3} \mathrm{Torr}$ even at the heater temperature of $1600^{\circ} \mathrm{C}$. Two viton o-rings, separately cooled using a water-cooled copper coil, were used to seal the gap between the alumina reactor tube and the outer chamber.

All the fixtures inside the alumina reactor tube were manufactured from hot pressed boron ritride $(\mathrm{BN})$ and all the metal parts were covered by boron nitride because of its inertness to $\mathrm{NH}_{3}$ and ease of machining. A chemical pump was used in tandem with a butterfly valve to maintain the desired pressure in the alumina reactor tube. A long distance microscope was installed on the top flange of the chamber to monitor the substrate during the growth.

A growth cell was designed such that all the GaN could be deposited on the cool top surface of the central pedestal of a BN crucible, shown in Fig. 4.1(a), by keeping the temperature of the crucible wall sufficiently high to prevent nucleation of GaN. An initial problem regarding the flow of liquid Ga over the sidewall of its container during growth 
was solved by placing the Ga into a supported open annulus inserted into the original container. The space between the Ga source container and the substrate provided an insulating layer, so that a large temperature gradient could be achieved without sacrificing the temperature of Ga source. The optimum distance between the Ga source and the substrate for the best $\mathrm{Ga}$ transport was $2 \mathrm{~cm}$.

The temperatures of each part of the growth crucible were measured with type-C thermocouples with a precision of $\sim 0.1^{\circ} \mathrm{C}$. A typical temperature profile is shown in Fig. 1(b). The temperature of the substrate was also calibrated by observing the melting point of $\mathrm{Au}$ with a pyrometer. The high purity $\mathrm{Ga}(99.999 \%)$ was heated within the temperature range of 1240 to $1260^{\circ} \mathrm{C}$. Ammonia was introduced from the top and initially reacted with the $\mathrm{Ga}$ vapor on a hexagonal $\mathrm{BN}$ surface to form GaN crystals by spontaneous nucleation. The process variables of growth temperature, total ammonia pressure and ammonia flow rate were varied from 1090 to $1170^{\circ} \mathrm{C}, 430$ to $760 \mathrm{Torr}$, and 25 to $75 \mathrm{sccm}$, respectively, to obtain conditions for vertical and lateral growth. Needles and platelets with smooth surface morphologies were subsequently selected for seeded growth. In the latter process, ammonia was introduced when the substrate temperature reached $\sim 1050^{\circ} \mathrm{C}$ to avoid decomposition of the seed crystals. The GaN crystals were subsequently characterized using optical microscopy, scanning electron microscopy(SEM), Raman spectroscopy, and X-Ray diffraction(XRD). 


\subsection{Results and Discussion}

Preliminary experiments concerned with the spontaneous nucleation and growth of GaN crystals showed that the growth eventually ceased due to the formation of a GaN crust on the molten Ga source. In addition, macro-size Ga droplets formed on the substrate and disturbed the crystal growth.

To determine the optimum operating conditions for the $\mathrm{Ga}$ source in a pure ammonia ambient, the surface was monitored in situ using the long distance microscope. The surface of the liquid gallium remained clean at $1100^{\circ} \mathrm{C}$, under $50 \mathrm{sccm} \mathrm{NH}_{3}$ at a total pressure of 760Torr. Increasing the flow rate to $100 \mathrm{sccm}$ at this pressure and temperature caused small GaN crystals to form and move on the surface of the Ga. At a flow rate of 200sccm, with all other conditions the same, numerous small eruptions occurred on the surface. The data points in Fig. 4.2 indicate the conditions under which the eruptions occurred. This phenomenon can be considered as a dynamic equilibrium between the formation and decomposition of $\mathrm{GaN}$. Further increase in $\mathrm{NH}_{3}$ flow rate above $\sim 325 \mathrm{sccm}$ at $1100^{\circ} \mathrm{C}$ resulted in the formation of a thin crust of $\mathrm{GaN}$ and the cessation of the violent reaction. At higher temperatures, both the violent reaction and the crust formation occurred at higher $\mathrm{NH}_{3}$ flow rates. The ammonia density above the surface of the molten Ga increases as the ammonia flow rate or the total pressure increases. Therefore, the dynamic equilibrium point moved toward higher temperatures at higher ammonia flow rates or total pressures.

The eruptions caused spattering of the Ga. This spattering is attributed to the decomposition of $\mathrm{GaN}$ and the consequent formation of $\mathrm{N}_{2}$-filled bubbles either at the surface or that rose to the surface and burst, causing drops of melt to be propelled from 
the Ga source container. Nitrogen pressures greater than one atmosphere can be produced by the dissociation of $\mathrm{GaN}$ to $\mathrm{Ga}$ and $\mathrm{N}_{2}$ since the equilibrium $\mathrm{N}_{2}$ pressure is $\sim 100$ atm at $1025^{\circ} \mathrm{C}$. If the spattering occurred during the early stage of the growth cycle, the Ga droplets reacted with the $\mathrm{NH}_{3}$ to form GaN seeds on which further growth occurred. In addition, contact of a Ga droplet with an already formed GaN crystal accelerated the decomposition rate of the latter and, in turn, changed the growth kinetics. These processes may result in a false interpretation of the data for growth of GaN crystals. Logan and Thurmond[20] also observed the spattering of $\mathrm{Ga}$ in the attempt of deposition of $\mathrm{GaN}$ layer on sapphire. At lower pressures, this spattering occurred at higher $\mathrm{NH}_{3}$ flow rates, since $\mathrm{GaN}$ is less stable at reduced pressures. To avoid the spattering of Ga, the temperature of the $\mathrm{Ga}$ source and the $\mathrm{NH}_{3}$ flow rate were maintained above $1200^{\circ} \mathrm{C}$ and below 200sccm, respectively. The Ga source temperature used in this research was $1260^{\circ} \mathrm{C}$ unless otherwise specified.

During the ramp-up to the growth temperature in a conventional GaN bulk crystal growth process, Ga vapor always exists over the substrate and reacts with ammonia introduced at room temperature to form $\mathrm{GaN}$ nuclei on the $\mathrm{BN}$ substrate. As the system temperature increases, the explosive reactions described above begin to occur and reaction between $\mathrm{Ga}$ and $\mathrm{NH}_{3}$ to form nuclei on a substrate becomes favorable; however, at less than the desired growth temperature. The incoming reactants, $\mathrm{Ga}$ and $\mathrm{NH}_{3}$, are now in competition among those nuclei before incorporation into the crystals. The more nuclei that form, the smaller will be the individual crystal size. One way to avoid this problem is to maintain the substrate surface free of any nucleation by placing a shutter over the substrate until the system reaches the growth temperature so that Ga vapor 
cannot get onto the substrate surface. However, this could not be readily accommodated in the system used in this research. A second way of avoiding the problem is to initiate nucleation at a higher temperature where the number of nuclei will be much smaller. Since the Ga flux is fixed at a given temperature of the Ga source, more material would be incorporated into a nucleus if the number of nuclei for the incoming vapor species becomes smaller. In this component of the research the Ga source and the substrate were heated to $1260^{\circ} \mathrm{C}$ in a nitrogen ambient at a ramping rate of about $20^{\circ} \mathrm{C} / \mathrm{min}$. After soaking at $1260^{\circ} \mathrm{C}$ for $20 \mathrm{~min}$, the ambient gas was switched from nitrogen to ammonia. Crystal growth was initiated by lowering the temperature of the substrate to the desired value. The increased crystal volume obtained with this processing route as compared to the conventional process are indicated in Fig. 4.3. The crystal volume increased to $1170^{\circ} \mathrm{C}$ and decreased at $1200^{\circ} \mathrm{C}$ due to decomposition. The optimum growth temperature, however, was determined to be $1130^{\circ} \mathrm{C}$ because crystals grown at $1170^{\circ} \mathrm{C}$ showed partially decomposed surface morphologies.

The maximum growth temperature in the conventional process was $1150^{\circ} \mathrm{C}$. This is believed to be due to the free Ga that existed on the substrate prior to growth as a result of the spattering due, as noted above, to the decomposition of the GaN. Pisch[21] and Schoonmaker[22] observed the enhanced decomposition of $\mathrm{GaN}$ in the presence of $\mathrm{Ga}$ at $720^{\circ} \mathrm{C}$ and $916^{\circ} \mathrm{C}$, respectively. This process would be accelerated at the elevated temperatures used in this research. Therefore, free Ga may decrease the growth rate of the crystals due to enhanced decomposition at $1170^{\circ} \mathrm{C}$.

The high temperature nucleation technique also produces, prior to nucleation, a clean substrate surface(Fig. 4.4(a)) in contrast to the formation of free liquid Ga that 
accompanied the conventional nucleation process (Fig. 4.4(c)) during ramp-up. The nucleation density was reduced appreciably with this process, and larger crystals resulted, as shown in Fig. 4.4(b), in comparison to those that formed in the conventional process (Fig. 4.4(d)). Once Ga droplets formed on the surface, they tended to stay on the substrate surface throughout the run, especially at the higher pressures. As noted above, the excess liquid $\mathrm{Ga}$ is detrimental to the growth of $\mathrm{GaN}$ in that it enhances the decomposition by lowering the activation energy for the decomposition; the Ga droplets are also sources for multiple nucleation as shown in Fig. 4.4(d). The prevention of the formation of GaN crust on the surface of the molten Ga during ramp-up was another advantage of the high temperature nucleation technique in that it allows a continuous supply of Ga vapor possible during growth. All process procedures and samples described hereafter in this paper were determined within and grown using the high temperature nucleation technique. From the standpoint of morphology and aspect ratio, platelets were not obtained under any growth conditions when the distance from the gas inlet to the substrate was 1". However, the aspect ratio of the needle-like crystals decreased with decreasing V/III ratio. To clarify this point, crystal growth was conducted using different Ga fluxes under otherwise identical growth conditions by placing an adjustable cover over the Ga source, as shown in Fig. 4.5. Crystals grown with higher Ga fluxes (Fig. 4.5(a)) showed a smooth surface morphology on the a-face and growth hillocks on the cface. The different surface morphologies are due to the different growth kinetics on the different crystallographic planes. For the lower Ga fluxes(Fig. 4.5(b)), the lengths of the crystals did not change appreciably, but the widths of the crystals decreased from $\sim 85 \mu \mathrm{m}$ to $\sim 15 \mu \mathrm{m}$. This result supports the previous observation that a higher Ga flux promotes 
lateral growth along the $\langle 11 \overline{2} 0\rangle$ directions. Callahan, et al.[14] reported that $\mathrm{GaN}$ platelets were grown inside the Ga crust formed over the Ga melt where the Ga flux was higher. Both the a-face and the c-face of the crystals grown with the lower Ga flux in the present research were very rough, as shown in Fig. 4.5(b) and are the apparent result of decomposition.

One way of achieving a higher Ga flux in the substrate area is to reduce the $\mathrm{NH}_{3}$ flow rate near the substrate to decrease the contribution of the forced convection and to allow more Ga atoms to diffuse toward the substrate. This approach is different from raising the emperature of the Ga source; the latter is accompanied by an increase in the temperature of the other portions of the growth assembly. To achieve a lower ammonia flow rate, the gas inlet was raised to 2" from the substrate in addition to using lower ammonia flow rates. Figure 4.6(a) shows the variation of crystal size grown at $1130^{\circ} \mathrm{C}$ and 430Torr as a function of ammonia flow rate. As the flow rate was increased, the vertical growth rate increased and the lateral growth decreased and became almost constant at the flow rate of 50sccm. Though the aspect ratios of the crystals (Fig. 4.6(b)) increased with the ammonia flow rate, it is worth noting that all the crystals grown under these conditions were platelets with an aspect ratio less than unity. Free Ga was observed up to the ammonia flow rates of $50 \mathrm{sccm}$, indicating that there was insufficient ammonia. At this point, crystal growth in the vertical direction began to increase. It is evident that GaN platelets are preferred at low V/III ratios under these conditions. It should also be noted that the nucleation density increased with increasing ammonia flow rate. The color of the crystal varied from black through dark amber to bright amber with increasing ammonia flow rate. 
The SEM micrographs shown in Fig. 4.7 reveal that crystals grown at $1130^{\circ} \mathrm{C}$, 430Torr and ammonia flow rates less than 50sccm had very rough surfaces. It is apparent that the excess Ga hindered diffusion of the reactant species on the (0001) plane of GaN and gave rise to the nucleation of new crystals. As the ammonia flow rate was increased, this excess Ga was incorporated into the crystal and allowed the length of the crystal (along the c-direction) to increase and the surface morphologies to become significantly more smooth. Raman spectroscopy showed that crystals grown using ammonia flow rates $>50 \mathrm{sccm}$ exhibited only allowed modes for wurtzite structure than those grown at lower flow rates. As the ammonia flow rate was increased above $75 \mathrm{sccm}$, polycrystalline $\mathrm{GaN}$ powder began to appear and covered the entire substrate at $100 \mathrm{sccm}$.

Another way of adjusting the available ammonia density around a growing crystal is via total pressure. Micrographs of crystals grown at the substrate temperature of $1130^{\circ} \mathrm{C}$, the $\mathrm{NH}_{3}$ flow rate of $60 \mathrm{sccm}$ and different total ammonia pressures are shown in Fig. 4.8. Platelets of GaN were obtained at 430Torr and needles at 760Torr. As the V/III ratio is decreased with decreasing total pressure of ammonia, these changes in crystal morphology agree with the arguments given above. The use of total pressures below 430Torr resulted, in general, in excessive condensation of $\mathrm{Ga}$ due to the lack of $\mathrm{NH}_{3}$ molecules available for the formation reaction of GaN. This implies that the processing window is rather narrow and the processing variables must be carefully controlled.

The processing windows for vertical growth and lateral growth of the GaN crystals were determined by constructing the three-dimensional plot shown in Fig. 4.9 of the aspect ratios of crystals versus the total pressure and the ammonia flow rate. The average lateral growth rate for the GaN platelets was $\sim 50 \mu \mathrm{m} / \mathrm{hr}$; the average vertical 
growth rate for the needles was $\sim 500 \mu \mathrm{m} / \mathrm{hr}$; growth rates in all other directions for these two morphologies were very low. Ammonia flow rates $\leq 75 \mathrm{sccm}$ and/or total pressures $\leq 430$ Torr and therefore lower V/III ratios favored lateral growth. The use of flow rates $\geq 75 \mathrm{sccm}$ initiated the formation of $\mathrm{GaN}$ powder. The Ga flux increased (1) with decreasing ammonia flow rate due to reduced forced convection above the growing crystals and (2) with decreasing total pressure due to increased mean free path of the $\mathrm{Ga}$ vapor. Lower ammonia flow rates and/or lower total pressures favor lateral growth and vice versa.

The mechanism by which lower V/III ratios promote lateral growth of GaN bulk crystals is unclear at present. Crawford et al.[23] reported that excess Ga reduced the growth rate of $\mathrm{GaN}(0001)$. They proposed that $\mathrm{NH}_{3}$ reacted only with the strongly bound $\mathrm{Ga}$, and that the excess $\mathrm{Ga}$ in the weakly bound sites reduced the growth rate by blocking the underlying reactive Ga sites. Although wurtzite GaN has two polarities, it has been shown by Smith et al.[24,25] that both the Ga- and the $\mathrm{N}$-faces can possess $\mathrm{Ga}$ termination. Smith et al. [24] have also shown that the $(1 \times 1)$ surface structure of $\mathrm{GaN}(000 \overline{1})$ grown via molecular beam epitaxy consists of a Ga adlayer bonded atop N atoms of the N-terminated bilayer. Recently, they have reported a $(1 \times 1)$ surface reconstruction on the Ga face consisting of one or more Ga adlayers on top of the Gaterminated bilayer[25]. They also noted that at temperatures greater than $350^{\circ} \mathrm{C}$ these $\mathrm{Ga}$ layers are likely to be fluid. First-principles total energy calculations indicate that a surface consisting of a laterally contracted bilayer of $\mathrm{Ga}$ is (under Ga-rich conditions) the most stable structure that has been obtained to date[26]. The trend towards Ga-stabilized surfaces can be understood in terms of the unique properties of $\mathrm{GaN}$ : the pronounced 
ionicity, the large mismatch in the covalent radii and the very different chemical properties of $\mathrm{Ga}$ and $\mathrm{N}$. Due to the small radius of the $\mathrm{N}$ atoms, the spacing between $\mathrm{Ga}$ atoms in $\mathrm{GaN}$ is only slightly larger than in Ga metal. Therefore, the Ga atoms in the surface layer can form metallic bonds even without relaxation, and the strength of these bonds is only slightly weaker than those formed in metallic Ga. This behavior has not been observed on traditional semiconductor surfaces where dimers or trimers between surface atoms are commonly formed. An analysis of the electron density for the $\mathrm{GaN}(000 \overline{1}) \mathrm{Ga}-$ adlayer structure shows an accumulation of charge between the surface $\mathrm{Ga}$ atoms. The p-orbitals of the surface $\mathrm{Ga}$ atoms overlap strongly with their neighbors and give rise to a highly disperse metallic band of surface states in the band gap [24,25]. The additional metallic bonds stabilize excess $\mathrm{Ga}$ on the surface and explain why $\mathrm{Ga}$ terminated surfaces are so stable. Ga-terminated surfaces are also stabilized by the fact that $\mathrm{N}_{2}$ molecules (which limit the chemical potential of $\mathrm{N}$ ) exhibit one of the strongest chemical bonds in nature. Though there is no evidence whether excess Ga stabilizes the (10̄10) plane, it is unlikely that a Ga layer stabilizes this surface because this plane already contains GaN dimmers on the surface. Therefore, this plane may be able to grow under Ga-rich conditions.

If the V/III ratio controls the aspect ratio of the GaN crystal at a given growth temperature, as observed by changes in the ammonia flow rate and the total pressure, changes in the Ga source temperature will produce a similar trend. Therefore, another set of experiments was conducted at the substrate temperatures of $1130^{\circ} \mathrm{C}, 430 \mathrm{Torr}$ and $60 \mathrm{sccm}$. The Ga source temperature was varied while all other experimental parameters were kept invariant. At the $\mathrm{Ga}$ source temperature of $1240^{\circ} \mathrm{C}, \mathrm{GaN}$ needles were formed. 
The aspect ratio of the crystal decreased with increasing $\mathrm{Ga}$ source temperature to $1260^{\circ} \mathrm{C}$, as expected. The morphological changes are shown in Fig. 4.10. Since the evaporation rate of $\mathrm{Ga}$ is an exponential function of temperature, the difference of $10^{\circ} \mathrm{C}$ results in a large difference in the Ga vapor pressure; e.g., $210 \mathrm{mTorr}\left(2.26 \times 10^{19} \mathrm{~cm}^{-2} \mathrm{~s}^{-1}\right)$ at $1250^{\circ} \mathrm{C}$ and $240 \mathrm{mTorr}\left(2.58 \times 10^{19} \mathrm{~cm}^{-2} \mathrm{~s}^{-1}\right)$ at $1260^{\circ} \mathrm{C}$. At Ga source temperatures above $1260^{\circ} \mathrm{C}$, excessive $\mathrm{Ga}$ condensation occurred, since there was a limited amount of $\mathrm{NH}_{3}$ available for the reaction. Increasing the $\mathrm{NH}_{3}$ flow rate again resulted in the formation of fine $\mathrm{GaN}$ powder. This may have been due to a combined effect of increased thermal convection and forced convection, that give rise to higher supply rate of Ga vapor and ammonia to the substrate than that required for the growth of single crystal material.

Increasing the growth time resulted in an increase in the average crystal size; however, secondary nucleation occurred. To overcome this problem, seeded growth was conducted on carefully selected GaN needles and platelets(Fig. 4.11(a)). In these experiments, ammonia was introduced at the substrate temperature of $1050^{\circ} \mathrm{C}$ to prevent decomposition of the seed crystal. A cluster of $\mathrm{GaN}$ needles rather than a single needle was used as a seed, because it was not easy to separate the latter from the cluster or maintain it on the $\mathrm{BN}$ substrate during evacuation. Growth was conducted under conditions conducive to lateral growth, namely, $1130^{\circ} \mathrm{C}, 430 \mathrm{Torr}$ and $60 \mathrm{sccm}$ of ammonia. Upon initiation of growth, a nucleation exclusion zone was formed around the seed crystals. As larger seed crystals are employed, the smaller crystals that form around it tend to re-evaporate into the gas phase because of the large, exothermic latent heat of formation of GaN. This nucleation exclusion zone remained throughout each growth run and did not change in size, as shown in Fig. 4.11(a). This indicates that incoming Ga and 
$\mathrm{NH}_{3}$ fluxes to the seed crystals did not change appreciably during the growth. No secondary nucleation was observed on the seed crystals (Fig. 4.11(b), 4.12(b)), while numerous randomly oriented $\mathrm{GaN}$ platelets were formed on the $\mathrm{BN}$ surface as shown in Fig. 4.11(d). The surface morphologies of the GaN crystals were smooth (Fig. 4.11(c) and Fig. 4.12(c)), and Raman spectra showed the only allowed modes of the wurtzite structure(Fig. 4.11(e) and Fig. 4.12(e)). Under the conditions of $1130^{\circ} \mathrm{C}, 430 \mathrm{Torr}$, and 60 sccm of $\mathrm{NH}_{3}$, both the $\mathrm{GaN}$ needle and platelet seed crystals grew laterally at a rate of $\sim 25 \mu \mathrm{m} / \mathrm{hr}$. The growth rate in the c-direction was $<10 \mu \mathrm{m} / \mathrm{hr}$. The surface of the GaN platelet after seeded growth was partly covered by very small GaN particles in a swirling pattern, as shown in Fig. 4.12(d). This appears to be a post-growth feature that may have formed during cool-down, as the excess free $\mathrm{Ga}$ on the c-face reacts with the ammonia at a lower temperature to form powder-like GaN that is weakly bonded to the surface.

\subsection{Conclusions}

Needle- and platelet-shaped single crystals of $\mathrm{GaN}$ have been grown via vapor phase transport (VPT) without secondary nucleation. The optimum growth temperature was determined to be $1130^{\circ} \mathrm{C}$. A novel nucleation technique wherein $\mathrm{NH}_{3}$ was introduced only at high temperatures resulted in 1) a cleaner template prior to growth, 2) a reduction in the nucleation density, 3) minimization of a GaN crust on the surface of the Ga source, and 4) larger crystals. A continuous supply of Ga vapor was achieved using the source temperature of $\sim 1240^{\circ} \mathrm{C}$ and ammonia flow rates $\leq 200 \mathrm{sccm}$. A three-dimensional processing map for aspect ratio control was constructed with respect to ammonia flow 
rate and total pressure at $1130^{\circ} \mathrm{C}$. Low V/III ratios, achieved using lower ammonia flow rates and/or lower total ammonia pressures, favored platelet growth of $\mathrm{GaN}$ at $1130^{\circ} \mathrm{C}$. Ammonia flow rates $>60 \mathrm{sccm}$ were required for growth of platelets with excellent Raman characteristics at the Ga source temperature of $1260^{\circ} \mathrm{C}$. Larger needles and platelets were also successfully achieved via seeded growth at $1130^{\circ} \mathrm{C}, 430 \mathrm{Torr}$ and an ammonia flow rate of $60 \mathrm{sccm}$.

\subsection{Acknowledgements}

The authors acknowledge support of the Office of Naval Research under contract N00014-00-1-0192 (Colin Wood, monitor). 


\subsection{References}

1. O. H. Nam, T. S. Zheleva, M. D. Bremser and R. F. Davis, J. Electron. Mater., 27(4), 233(1998)

2. T. S. Zheleva, W. M. Ashmawi, O. H. Nam and R. F. Davis, Appl. Phys. Lett., 74(15), (1999)

3. K. J. Linthicum, T. Gehrke, D. B. Thomson, K. M. Tracy, E. P. Carson, T. P. Smith, T. S. Zheleva, C. A. Zorman, M. Mehregany, and R. F. Davis, MRS Internet J. Nitride Semicond. Res., 4, 9(1999)

4. D. B. Thomson, T. Gehrke, K. J. Linthicum, P. Rajagopal, and R. F. Davis, MRS Internet J. Nitride Semicond. Res., 4, 37(1999)

5. S. Nakamura, M. Senoh, S. Nagahama, N. Iwasa, T. Yamada, T. Marsushita, H. Kiyoku, Y. Sugimoto, T. Kozaki, H. Umemoto, M. Sano and K. Chocho, J. Cryst. Growth, 189/190, 820(1998)

6. F. A. Ponce, D. P. Bour, W. Gotz, N. M. Johnson, H. I. Helava, I. Grzegory, J. Jun, and S. Poroski, Appl. Phys. Lett. 68(7), 917(1996).

7. M. Kamp, C. Kirchner, V. Schwegler, A. Pelzmann, E.J. Ebeling, M. Lesczczynski, I. Grzegory, T. Suski, S. Porowski. MRS Internet J. Nitride Semicond. Res. 4S1, G10.2 (1999).

8. R.A. Zauner, J. J. Schermer, W. J.P. van Enckevort, V. Kirilyuk, J. L. Weyher, I. Grzegory, P.R. Hageman, and P. K. Larsen, MRS Internet J. Nitride Semicond. Res. 5S1, W6.3 (2000).

9. S. Porowski, MRS Internet J. Nitride Semicond. Res. 4, 13(1999) 
10. T. Shibata, H. Sone, K. Yahashi, M. Yamaguchi, K. Hiramatsu, and N. Itoh, J. Cryst. Growth, 189/190, 67(1998)

11. M. Balkas, Z. Sitar, T. Zheleva, L. Bergman, I. K. Shmagin, J. F. Muth, R. Kolbas, R. Nemanish, and R. F. Davis, Mat. Res. Soc. Symp. Proc., 449, 41(1997)

12. H. Yamane, T. Kajiwara, T. Sekiguchi, and M. Shiamda, Jpn. J. Appl. Phys. 39, L146(2000)

13. C. M. Balkas, Z. Sitar, T. Zheleva, L. Bergman, I. K. Shmagin, J. F. Muth, R. Kolbas, R. Nemanich, and R. F. Davis, J. Cryst. Growth, 208, 100(2000)

14. M. Callahan, M. Harris, M. Suscavage, D. Bliss and J. Baily, MRS Internet J. Nitride Semicond. Res. 4, 10(1999)

15. J. J. Gilman ed., "The Art and Science of Growing Crystals", J. Wiley, New York (1963)

16. D. Elwell, R. S. Feigelson, M. M. Simkins, and W. A. Tiller, J. Cryst. Growth, 66, 45(1984)

17. G. Kamler, J. Zachara, S. Podsiadlo, L. Adamowicz, W. Gebicki, J. Cryst. Growth, 212, 39(2000)

18. E. Ejder, J. Crystal Growth, 22, 44(1974)

19. S. Porowski, I. Grzegory, J. Cryst. Growth, 178, 174(1997)

20. R. A. Logan and C. D. Thurmond, J. Electrochem. Soc., 119(12), 1727(1972)

21. Pisch, R. Schmid-Fetzer, J. Crystal Growth, 187, 329(1998)

22. R. C. Schoonmaker, A. Buhl and J. Lemley, J. Phys. Chem., 69, 3455(1965)

23. D. E. Crawford, R. Held, A. M. Johnston, A. M. Dabiran, P. I. Cohen, MRS Internet J. Nitride Semicond. Res. 1, 12(1996) 
24. A.R. Smith, R.M. Feenstra, D.W. Greve, J. Neugebauer, J.E. Northrup, Phys. Rev. Lett. 79 3934(1997)

25. A.R. Smith, R.M. Feenstra, D.W. Greve, M. S. Shin, M. Skowronski, J. Neugebauer, J.E. Northrup, Appl. Phys. Lett. 72, 2114(1998)

26. J. E. Northrup, J. Neugebauer, R. M. Feenstra, A. R. Smith, Phys. Rev. B, 61(15), 9932(2000) 


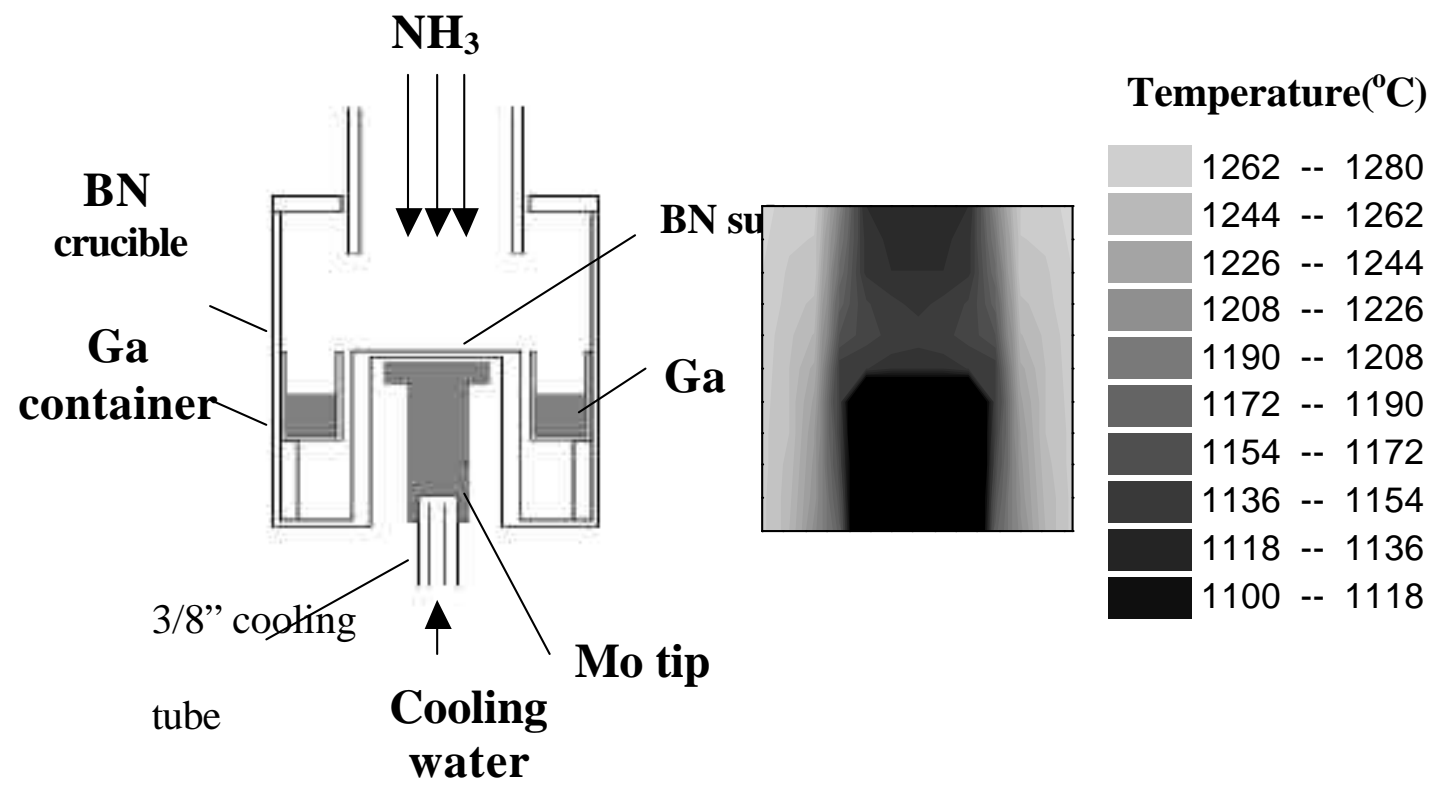

(a)

(b)

Figure 4.1 (a) Schematic diagram of the BN growth cell and interfacing 3/8" cooling tube. (b) A typical temperature profile in the growth cell at the $\mathrm{BN}$ substrate temperature of $1130^{\circ} \mathrm{C}$. 


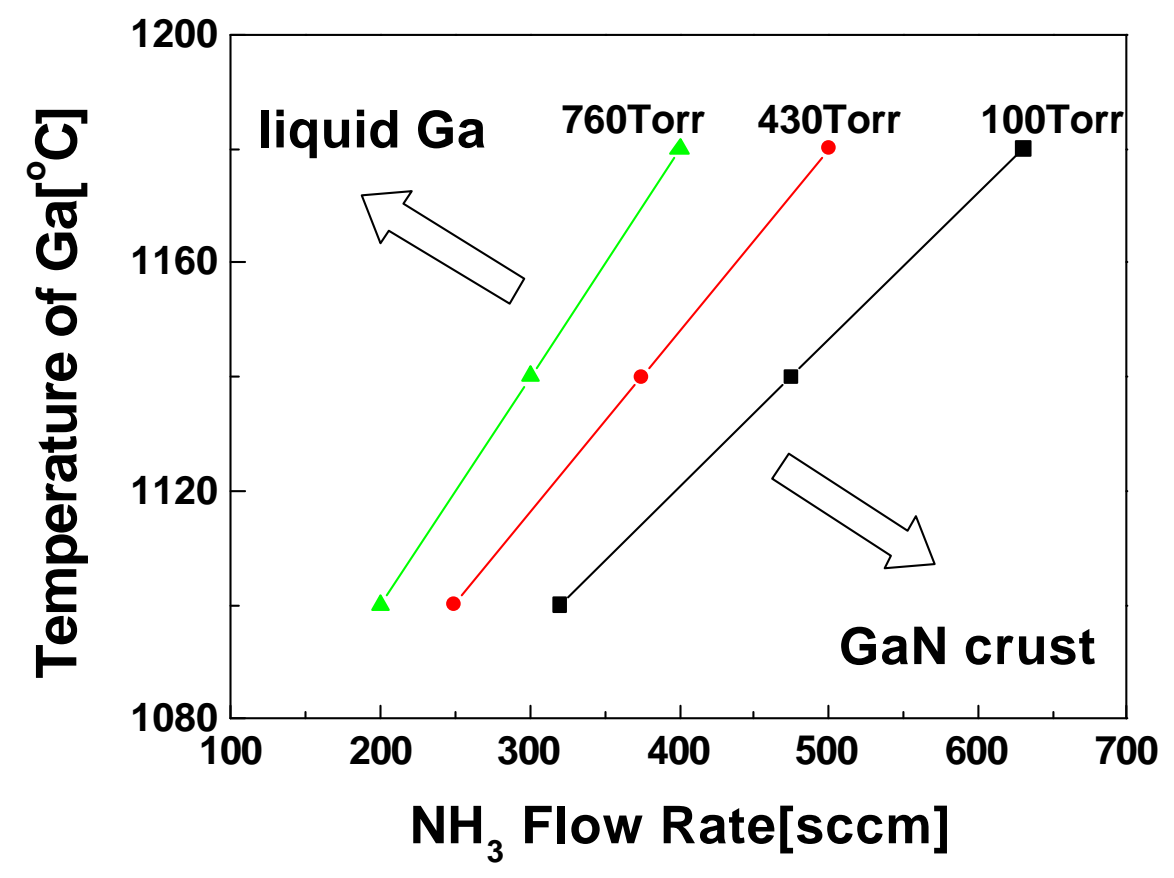

Figure 4.2 Stability field of the Ga source in pure flowing ammonia. Data points indicate the conditions under which eruptions occurred in the molten Ga. 


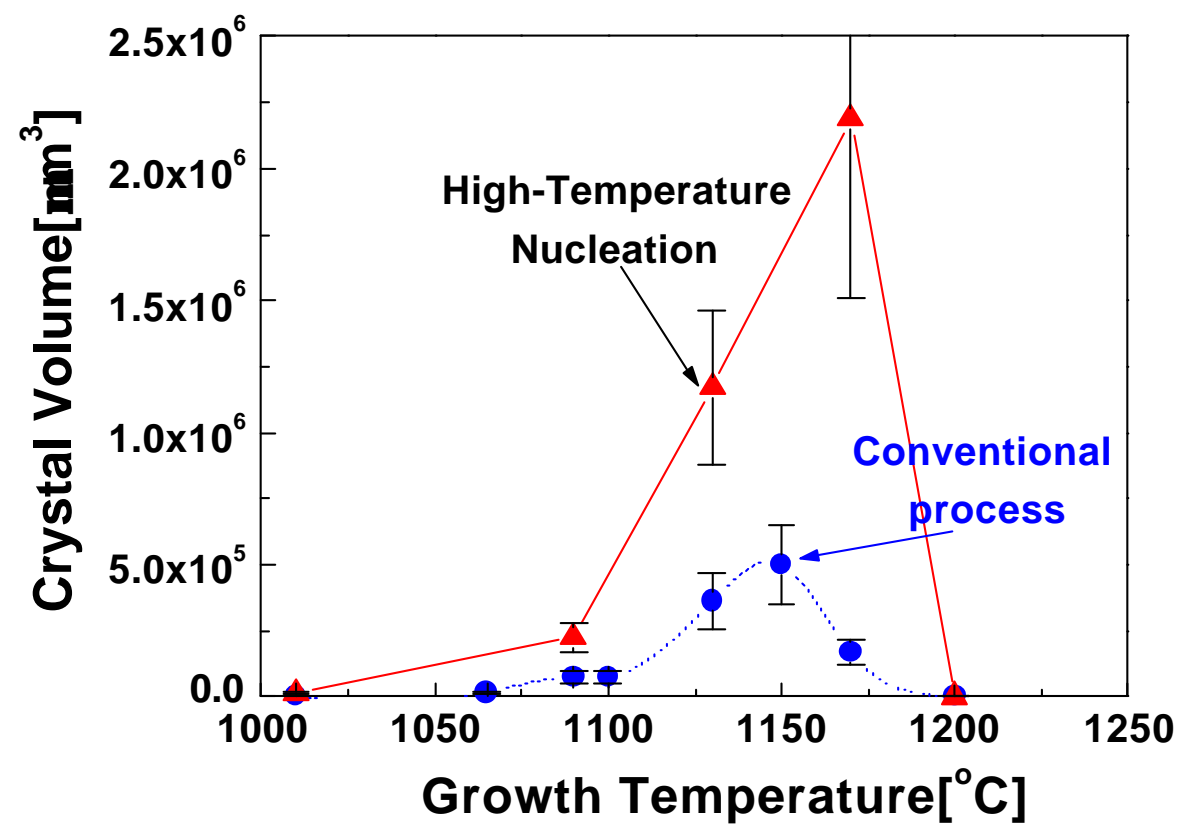

Figure 4.3 Evolution of crystal volume as a function of growth temperature at 760Torr and $150 \mathrm{sccm}$ of $\mathrm{NH}_{3}$ using the high temperature nucleation technique and the conventional growth process. 

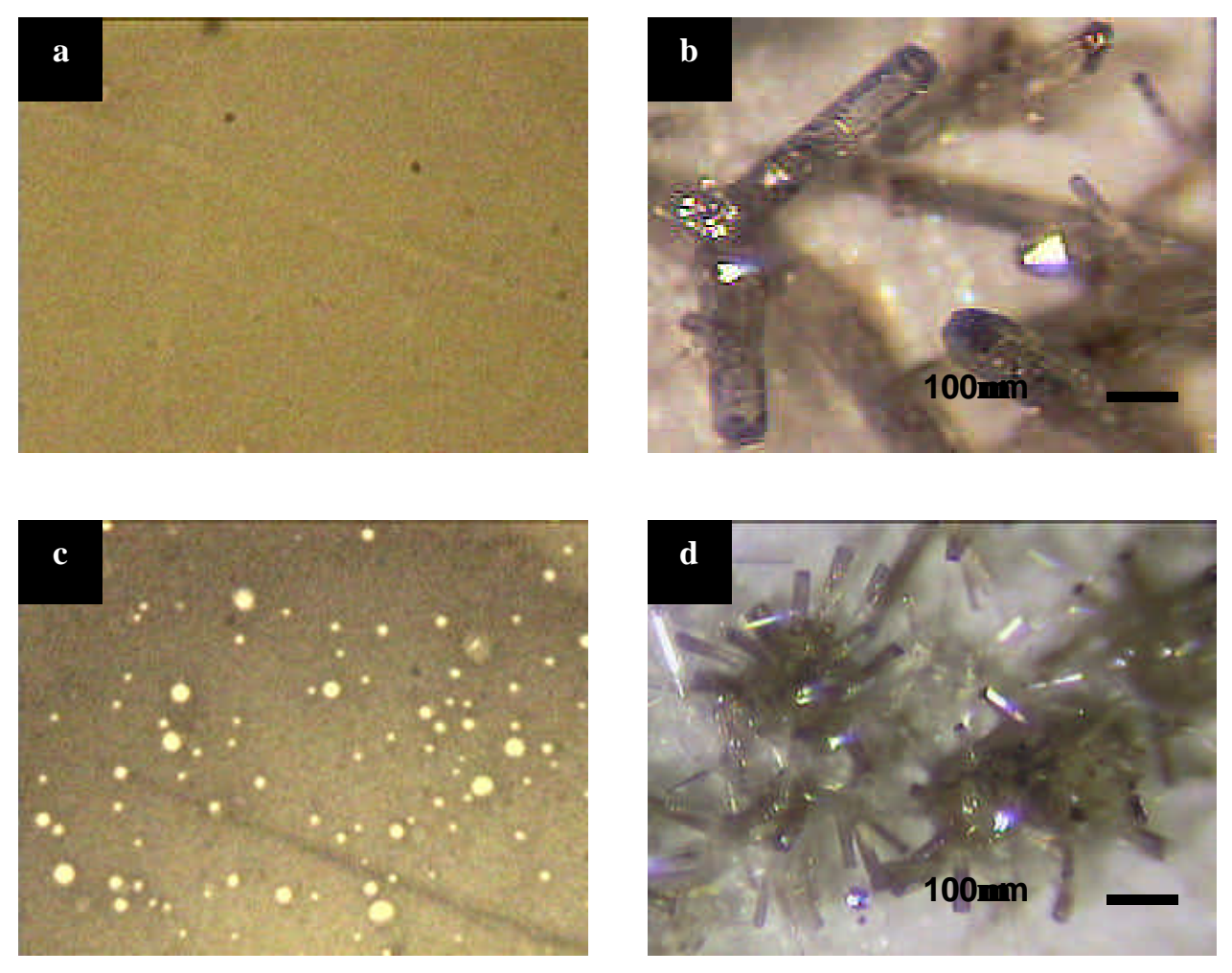

Figure 4.4 Optical micrographs of (a) the surface of the BN substrate prior to growth and (b) the resultant GaN crystals grown using the high temperature nucleation technique and (c) the BN surface and (d) the crystals grown by the conventional growth process at $1130^{\circ} \mathrm{C}$ and 760Torr for $2 \mathrm{hrs}$. 

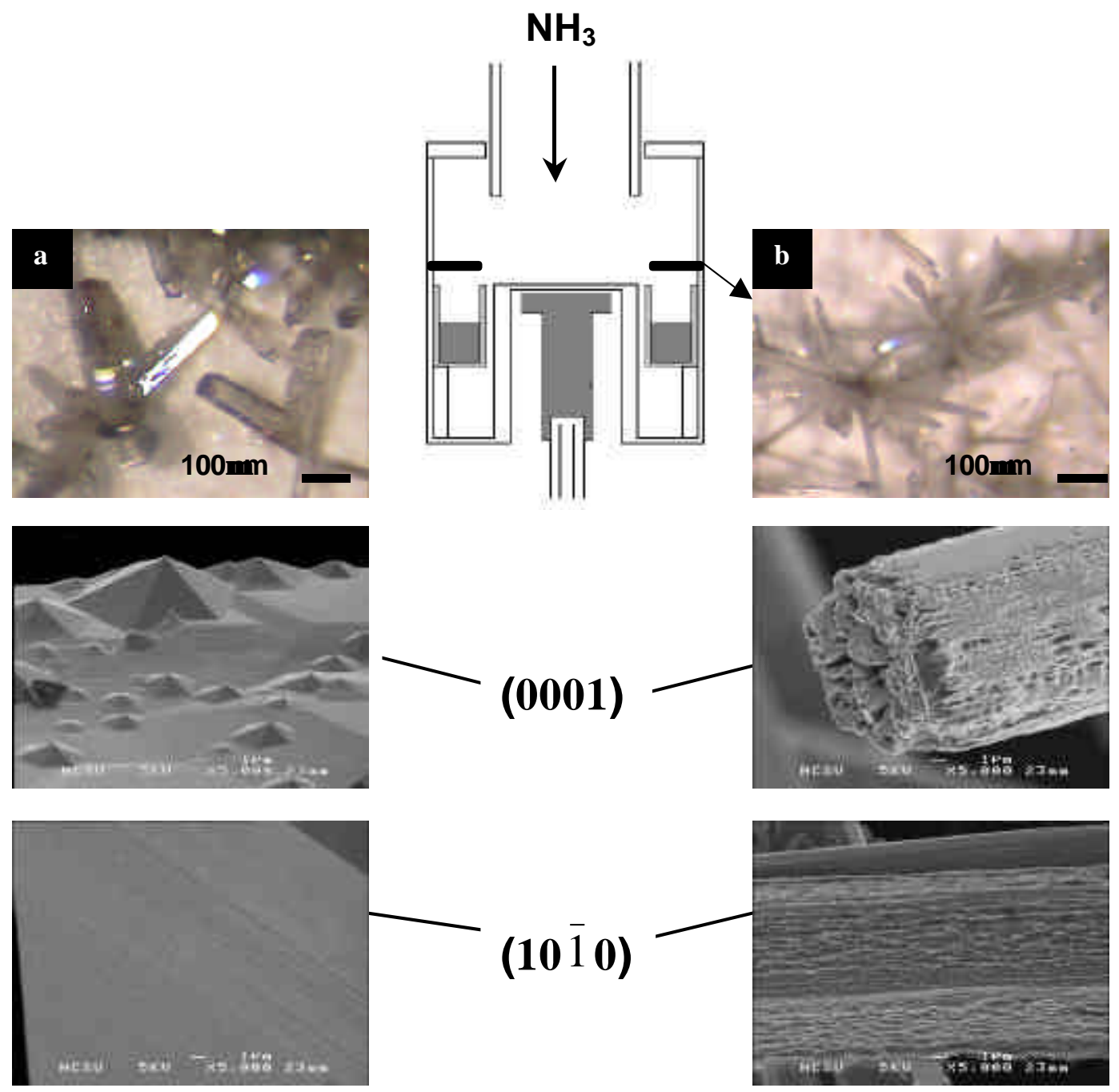

Figure 4.5 Comparison of crystals grown at $1130^{\circ} \mathrm{C}, 430$ Torr for $2 \mathrm{hrs}$ (a) without a cover over the Ga source(higher Ga flux) (b) with the use of the cover(lower Ga flux). 

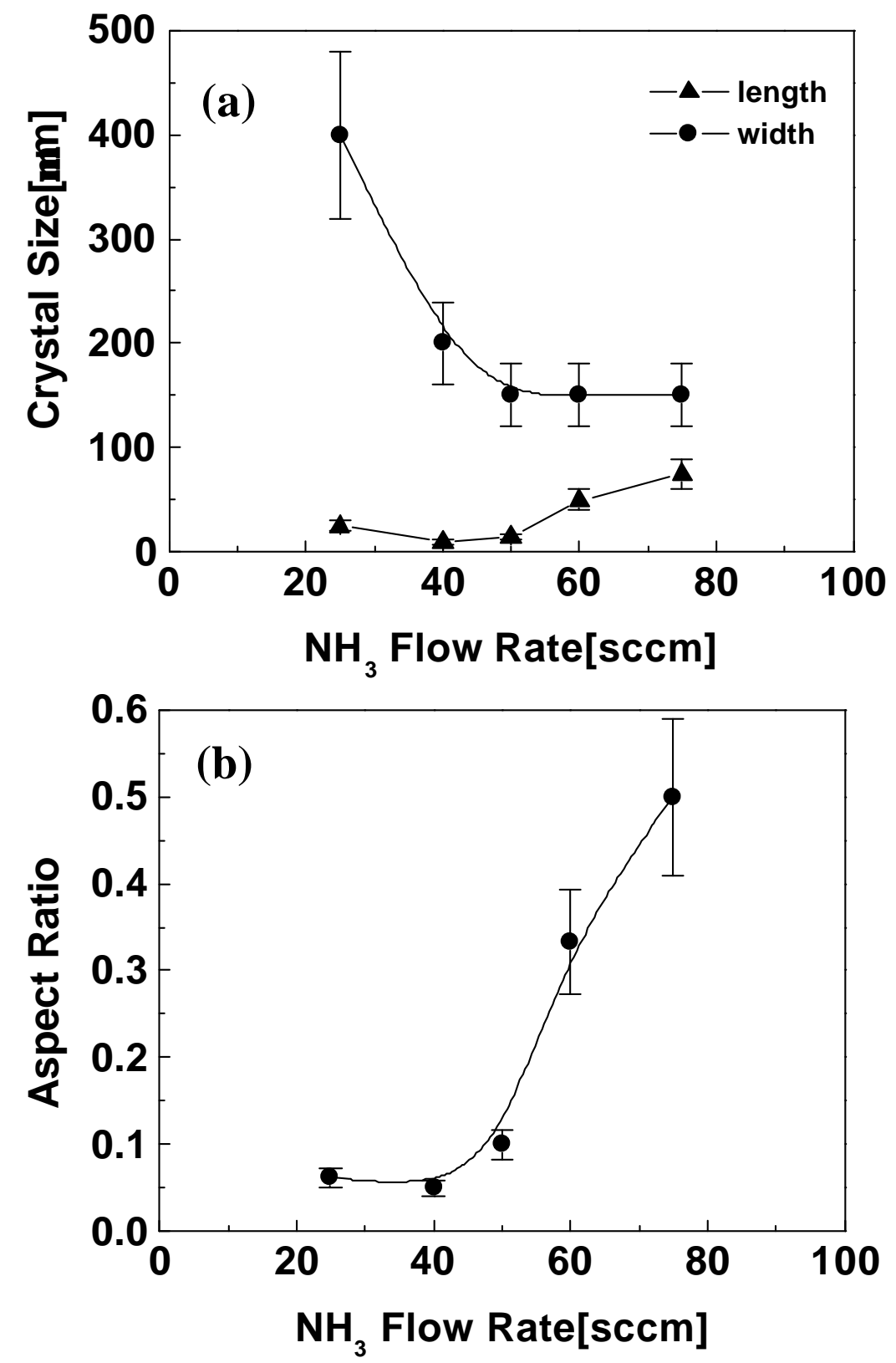

Figure 4.6 (a) Variation in crystal size and (b) aspect ratio of the GaN crystals as a function of $\mathrm{NH}_{3}$ flow rate at $1130^{\circ} \mathrm{C}$ and 430Torr for $2 \mathrm{hrs}$. 

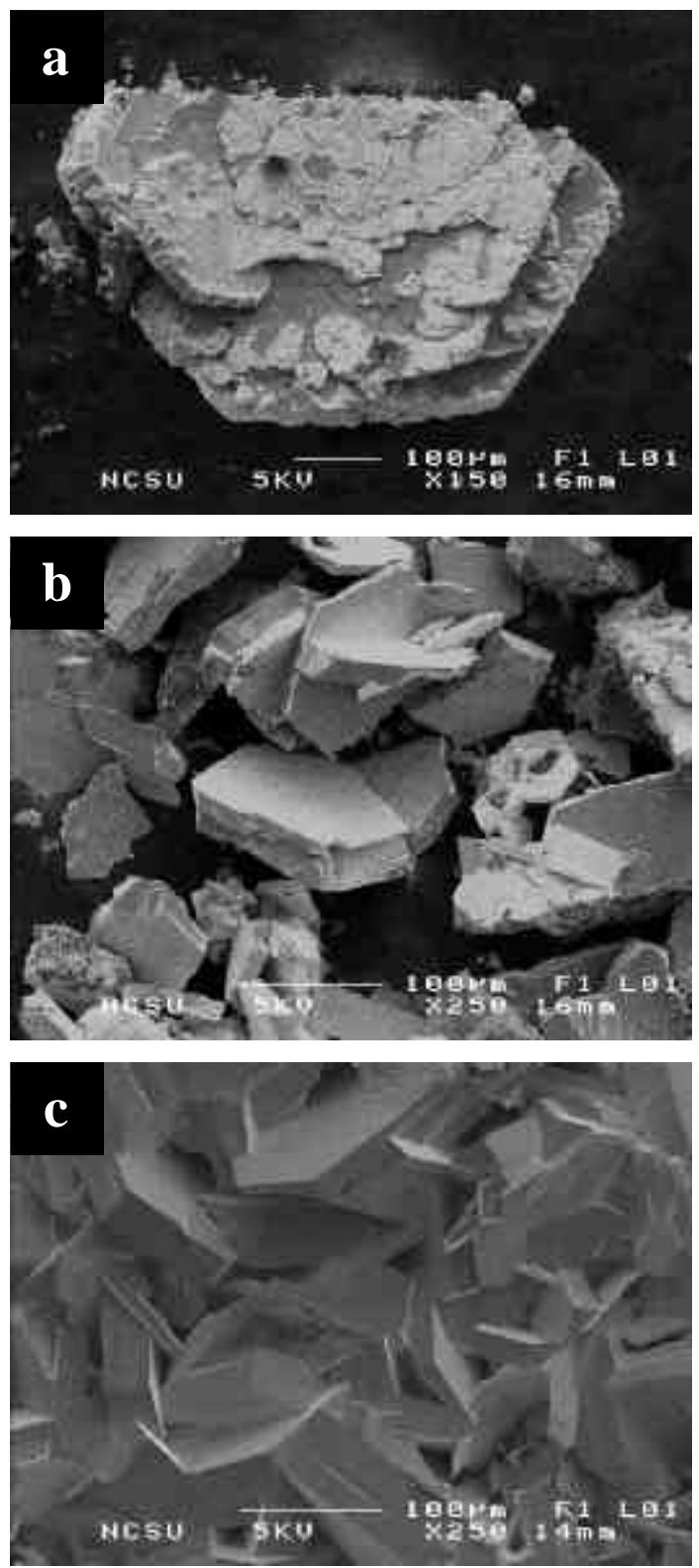

Figure 4.7 SEM micrographs of GaN crystals grown at $1130^{\circ} \mathrm{C}$ and $430 \mathrm{Torr}$ for $2 \mathrm{hrs}$ with different $\mathrm{NH}_{3}$ flow rates:(a) $25 \mathrm{sccm}$, (b) $50 \mathrm{sccm}$, and (c) $60 \mathrm{sccm}$. 

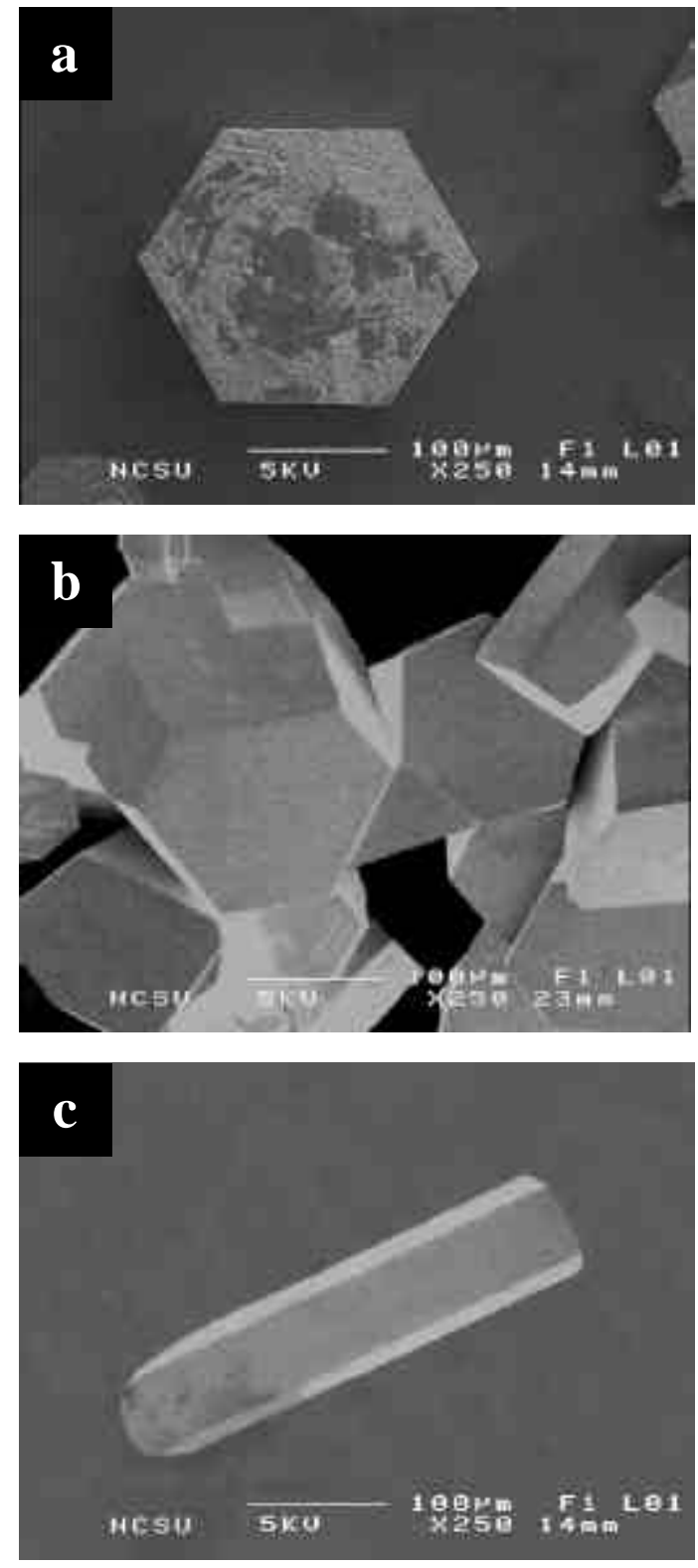

Figure 4.8 SEM micrographs of GaN crystals grown at $1130^{\circ} \mathrm{C}, 60 \mathrm{sccm}$ of $\mathrm{NH}_{3}$ and total pressures of (a) 430Torr, (b) 595Torr, and (c) 760Torr for 2hrs. 


\section{high aspect ratio crystal}

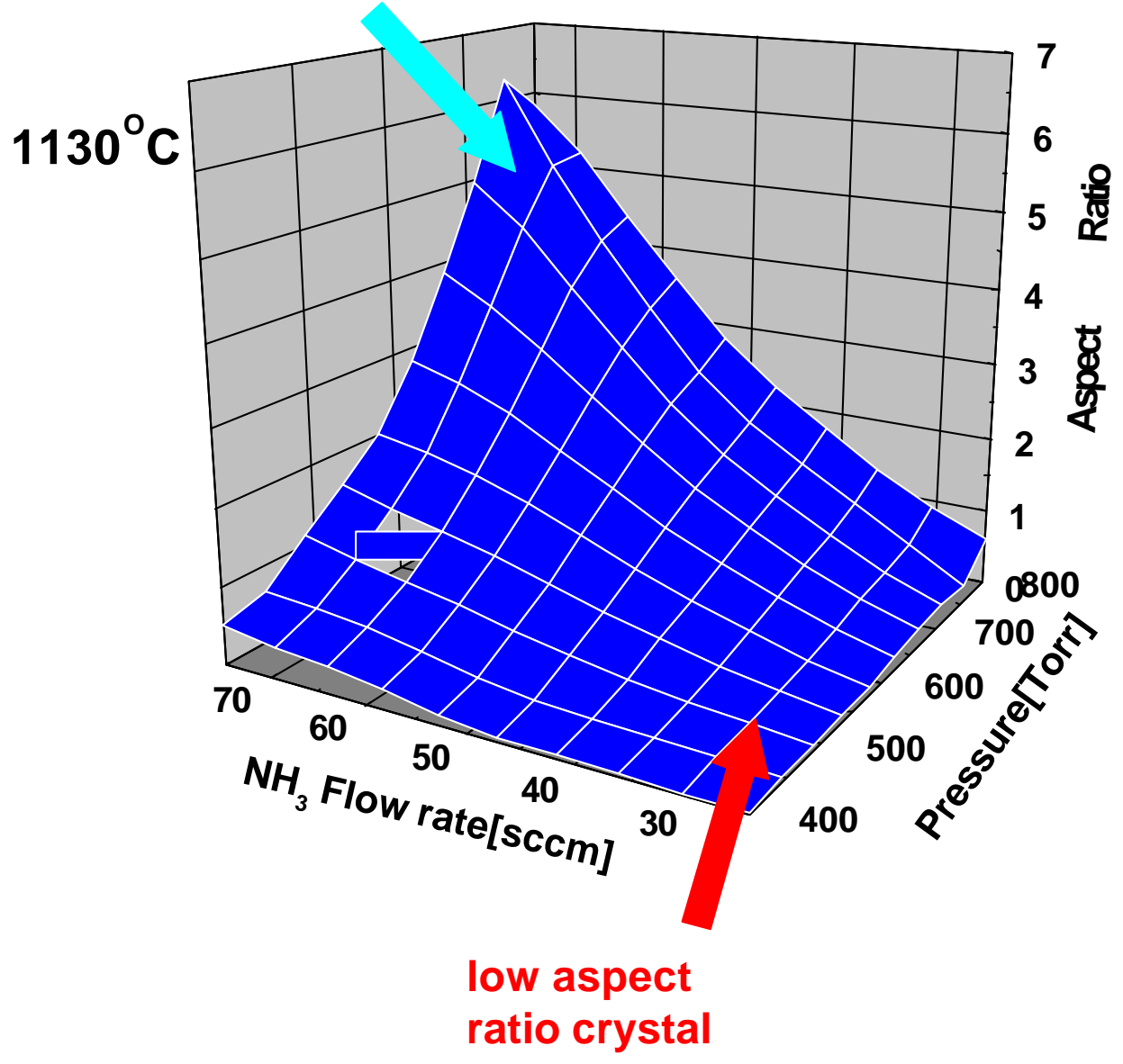

Figure 4.9 Three dimensional-surface plot of aspect ratio versus total pressure and $\mathrm{NH}_{3}$ flow rate field for crystals grown at $1130^{\circ} \mathrm{C}$. 

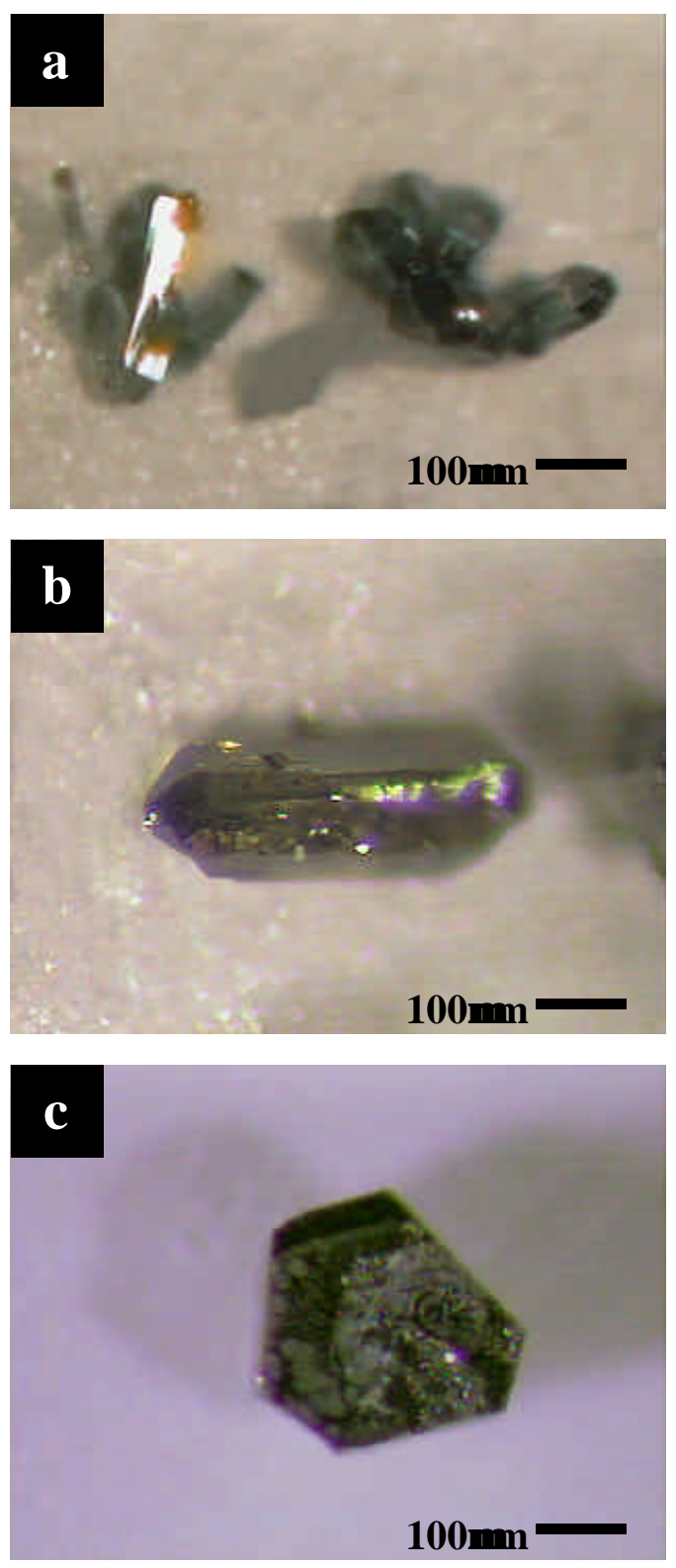

Figure 4.10 Effect of Ga source temperature on the morphology of crystals grown at the growth temperature of $1130^{\circ} \mathrm{C}, 430 \mathrm{Torr}$ and $60 \mathrm{sccm}$ of $\mathrm{NH}_{3}$ for $2 \mathrm{hrs}$ for the Ga source temperature of (a) $1240^{\circ} \mathrm{C}$, (b) $1250^{\circ} \mathrm{C}$, and (c) $1260^{\circ} \mathrm{C}$. 

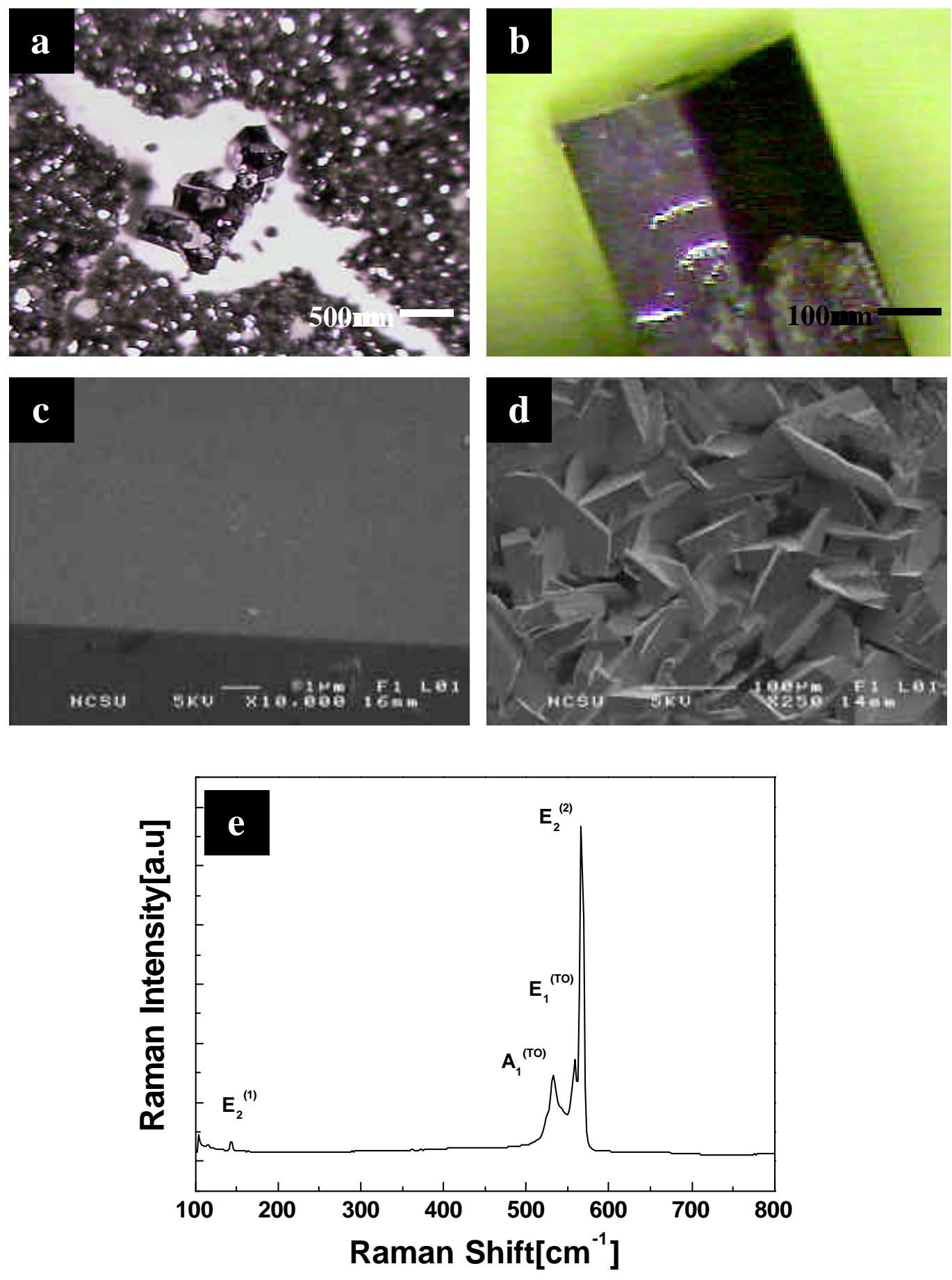

Figure 4.11 Optical and SEM micrographs of GaN crystals from cluster of GaN needles grown at $1130^{\circ} \mathrm{C}, 430$ Torr, and $60 \mathrm{sccm}$ of $\mathrm{NH}_{3}$ for 6hrs: (a) final crystals after seeded growth, (b) a magnified view of a crystal in (a), (c) a SEM micrograph of the surface of the crystal in (b), (d) GaN crystals grown on $\mathrm{BN}$, (e) Raman spectrum of the crystal in (b). 

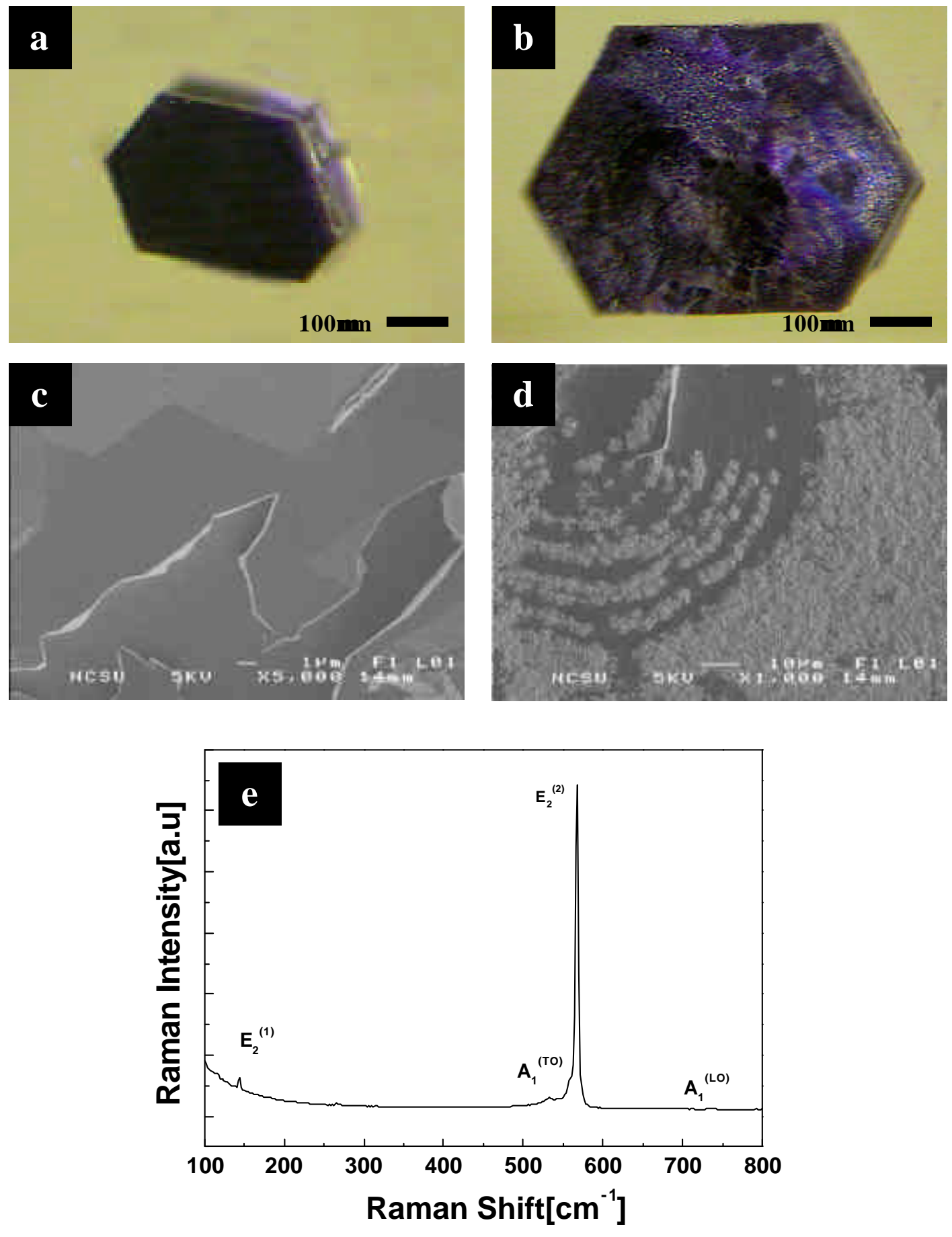

Figure 4.12 A GaN platelet grown from a GaN seed at $1130^{\circ} \mathrm{C}, 430 \mathrm{Torr}$ and $60 \mathrm{sccm}$ of $\mathrm{NH}_{3}$ for 6hrs: (a) original seed (b) after growth for 6hrs (c) a SEM micrograph of a smooth area of the (0001) surface of (b), (d) a rough area of the (0001) surface of (b), (e) Raman spectrum of the platelet shown in (b). 


\section{A New Processing Route for Growth of Bulk GaN Crystals}

to be submitted to the Journal of Crystal Growth

by

H. Shin, E. F. Arkun, D. B. Thomson, P. Miraglia, E. Preble, S. Wolter, R. Schlesser, Z. Sitar, and R. F. Davis

Department of Materials Science and Engineering,

North Carolina State University, Raleigh, NC, 27695-7907 


\subsection{Abstract}

GaN single crystals grown at a high ammonia pressure( 760Torr) for longer times( $>10 \mathrm{hrs})$ generally possessed poor surface morphologies due to enhanced decomposition. Gas composition analysis using quadruple mass spectroscopy revealed that hydrogen concentration in the gas phase increased with increasing ammonia pressure at $\sim 475$ Torr without the presence of $\mathrm{Ga}$ and at $\sim 300$ Torr in the presence of $\mathrm{Ga}$. The enhanced decomposition of $\mathrm{GaN}$ at high ammonia pressures can be attributed to etching of $\mathrm{GaN}$ via reaction of hydrogen with the surface. Decomposition of $\mathrm{GaN}$ at low pressures in the current study can be attributed to thermodynamic instability and evaporation. Dilution of ammonia with nitrogen reduced the amount of hydrogen generated as a result of dissociation of ammonia. AFM images revealed that the GaN surface annealed at $1130^{\circ} \mathrm{C}, 430$ Torr in ammonia diluted with $33 \% \mathrm{~N}_{2}$ maintained the smoothest surface morphology. Nitrogen molecules may increase the kinetic barrier to desorption of reactants from the GaN surface and thereby increase the stability of GaN crystals. A $2 \mathrm{~mm} \times 1.5 \mathrm{~mm} \mathrm{GaN}$ crystal was successfully grown without any visible decomposition via seeded growth in a $67 \% \mathrm{NH}_{3}+33 \% \mathrm{~N}_{2}$ gas mixture. 


\subsection{Introduction}

Growth of bulk GaN crystals is still in its early stage of development. Atomistic mechanisms regarding numerous nucleation, aspect ratio control, and decomposition have been remained unsolved. Due to the strong bonding $(9.8 \mathrm{eV})$ of $\mathrm{N}_{2}$ molecule, it is impossible to obtain active nitrogen at growth temperatures used in MOVPE and $\mathrm{HVPE}\left(\sim 1000^{\circ} \mathrm{C}\right)$. For this reason, $\mathrm{NH}_{3}$ has been mainly used in MOVPE and HVPE as a nitrogen source due to its lower activation barrier for dissociation into more reactive species, $\mathrm{NH}_{\mathrm{x}}(\mathrm{x}=1,2)$. Hydrogen as a byproduct of the dissociation of $\mathrm{NH}_{3}$ may play a significant role in $\mathrm{GaN}$ growth kinetics. On surface cracking of $\mathrm{NH}_{3}$ has been proposed to explain the growth kinetics in MBE grown GaN[1,2]. However, the role of hydrogen in the growth kinetics has not been uncovered to date. Deposition of $\mathrm{GaN}$ thin films for a relatively short period may not experience the influence of hydrogen. For prolonged growth of bulk GaN crystals, however, hydrogen may play a significant role in surface reaction kinetics(i.e., decomposition).

Decomposition of $\mathrm{GaN}$ in $\mathrm{MBE}$ environment has been studied by many researchers(Table 5.1). Munir et al.[3] reported that GaN decomposed congruently from a torsion-effusion cell when the ratio of orifice area to sample area was about 0.033 and incongruently when the ratio was 0.01 and less. Groh et al.[4] found the activation energy of the decomposition of $\mathrm{GaN}$ in vacuum to be $3.24 \mathrm{eV}$ in the temperature range from $940^{\circ} \mathrm{C}$ to $1025^{\circ} \mathrm{C}$. Grandjean et al.[5] reported the value of the activation energy to be $3.6 \mathrm{eV}$ in the temperature range $750 \sim 875^{\circ} \mathrm{C}$. They used laser reflectivity to measure the decomposition rate in vacuum. The observation of a streaky RHEED pattern during the 
evaporation process was in favor of a layer-by-layer evaporation of the species rather than a crystal decomposition accompanied by degradation of surface morphology. Actually, they did not observe RHEED intensity oscillations during GaN evaporation. They suggested a step-edge evaporation mechanism; if two dimensional evaporation occurs by vacancy formation on terraces we should observe RHEED intensity oscillations by analogy to what is observed when growth proceeds by $2 \mathrm{D}$ nucleation. It should be remarked that the RHEED pattern indicates a faceting of the surface when a large amount of material has been evaporated (several thousand angstroms). This could be partly ascribed to an enhanced evaporation rate near defects or/and grain boundaries[6]. Ambacher et al.[7] measured the flux of $\mathrm{N}_{2}$ and activation energy $(\sim 3.93 \mathrm{eV})$ for $\mathrm{GaN}$ decomposition in vacuum using quadrupole mass spectrometry (QMS). The discrepancy in the activation energy may come from the $\mathrm{GaN}$ material used in the different experiment. Polarity, the surface morphology, crystallinity, crystallographic orientation, and impurities may influence the evaporation rate and thus the activation energy. The high growth temperature and the high vapor pressure of nitrogen lead to the problem of nitrogen loss from the GaN film. The loss of nitrogen can be partially alleviated by the use of high V/III gas phase ratios(>2000:1) during the deposition. This is not a problem for the growth of $\mathrm{GaN}$ in MBE using atomic nitrogen. Averyanova et al.[8] found that there was a critical orifice area at which switching between congruent and incongruent evaporation occurs. Depending on the ratio of orifice area to the evaporating area of the sample, the gallium vapor pressure in the Knudsen cell could be either higher or lower than the saturated vapor pressure over the liquid gallium. Therefore, incongruent evaporation of $\mathrm{GaN}$ was predicted for low orifice area and high temperatures. In contrast, 
the congruent evaporation should take place at low temperatures and higher orifice area. Munir et al[3] observed the formation of liquid Ga droplets at the ratio of $\sim 0.01$ and no Ga droplets at $\sim 0.033$. Averyanova et al.[8] calculated the critical ratio to be $3 \times 10^{-6}$ to $3 \times 10^{-5}$ in the temperature range $890^{\circ} \mathrm{C} \sim 1080^{\circ} \mathrm{C}$. The disagreement between the theory and experiment can be due to the uncertainty in evaluation of the sample area in the evaporation experiment. This implies that the decomposition kinetics of $\mathrm{GaN}$ can be influenced to a great extent by the ambient gas that affects the concentration of Ga and nitrogen species in the vapor during decomposition.

Hydrogen is a reaction product in $\mathrm{GaN} C \mathrm{CVD}$ and $\mathrm{MBE}$ using $\mathrm{NH}_{3}$ as a nitrogen source. In molecular beam epitaxy of $\mathrm{GaN}$, hydrogen molecules formed as a result of formation of $\mathrm{GaN}$ from $\mathrm{Ga}$ and ammonia probably have relatively shorter residence time on the growing surface as compared with that in MOCVD system before they are pumped away, for desorption process is faster in such a low pressure regime. On the other hand, hydrogen molecules formed in a CVD system as a byproduct have higher probability of reacting with the growing surface due to their longer residence time. Consequently, hydrogen is expected to play an important role in the growth of GaN via CVD. For growth of bulk crystals, growth time of which is even longer, the role of hydrogen becomes increasingly important. Therefore, It is desirable to understand the role of ambient gases during decomposition of $\mathrm{GaN}$, because it would provide a deeper understanding of the decomposition mechanism, which may lead to a processing route for the GaN growth.

The influence of ambient gases on the decomposition of GaN has been reported by many researchers[9-17]. They showed that the hydrogen carrier gas had a profound 
effect on the decomposition. Johnson et al.[9] first reported the decomposition rate of $\mathrm{GaN}$ in the stream of $\mathrm{H}_{2}$ at $800^{\circ} \mathrm{C}$ to be $0.0016 \mathrm{~g} / \mathrm{hr}$. Thurmond and $\operatorname{Logan}[10,11]$ also found that products of the reaction of $\mathrm{H}_{2}$ with $\mathrm{GaN}$ were liquid gallium and ammonia gas in the temperature range from $900^{\circ} \mathrm{C}$ to $1150^{\circ} \mathrm{C}$. Morimoto[12] reported that the decomposition of $\mathrm{GaN}$ in $\mathrm{H}_{2}$ was noticeable at $800^{\circ} \mathrm{C}$ and liquid $\mathrm{Ga}$ began to appear at $900^{\circ} \mathrm{C}$ while no change in weight and surface morphology was observed in $\mathrm{N}_{2}$ up to $1000^{\circ} \mathrm{C}$. Jacob et al.[13] also studied the decomposition of GaN in different ambient gases and found a value of initial decomposition temperature of $970^{\circ} \mathrm{C}$ in $\mathrm{Ar}$ or $\mathrm{N}_{2}$ and $600^{\circ} \mathrm{C}$ in $\mathrm{H}_{2}$. In addition, $\mathrm{GaN}$ was not attacked when $\mathrm{HCl}$ was mixed with $\mathrm{N}_{2}$ or $\mathrm{Ar}$, but decomposed when $\mathrm{H}_{2}$ was added to $\mathrm{HCl}$. Rebey et al.[14] reported that decomposition rate at $1050^{\circ} \mathrm{C}$ increased rapidly with increasing the $\mathrm{H}_{2}$ flow rate and reached $30 \mu \mathrm{m} / \mathrm{hr}$ for 3SLM of $\mathrm{H}_{2}$. They also showed that the increase of $\mathrm{N}_{2}$ proportion reduced the decomposition rate monotonically, a maximum of $75 \%$ reduction being reached for a mixture of $2.5 \mathrm{~s} l \mathrm{~m} \mathrm{~N}_{2}$ and $0.5 \mathrm{slm} \mathrm{H}_{2}$. The addition of small amount of $\mathrm{NH}_{3}$ to $\mathrm{H}_{2}$ also inhibited the decomposition of GaN. They found the critical temperature of $830^{\circ} \mathrm{C}$, at which the rate-limiting decomposition process changed from surface kinetics $\left(E_{a}\right.$ $\sim 1.87 \mathrm{eV})$ to diffusion in the boundary layer $\left(\mathrm{E}_{\mathrm{a}} \sim 0.38 \mathrm{eV}\right)$. Their postulation was as follows; the decomposition of $\mathrm{GaN}$ starts with desorption of surface nitrogen atoms leading to formation of a metallic surface (rich in Ga atoms) and then, the second step of the GaN decomposition involves the diffusion of bulk nitrogen atoms toward the surface, where the nitrogen atoms are combined to form nitrogen molecules and desorbed and simultaneous desorption of $\mathrm{Ga}$ species and formation of Ga droplets occurs. Mayumi et al.[15] used an in-situ gravimetric monitoring (GM) method to investigate the 
decomposition of $\mathrm{GaN}$ under atmospheric pressure. In the $\mathrm{H}_{2}$ carrier gas ambient, the decomposition rate increased exponentially with increasing substrate temperature in the temperature range from $800^{\circ} \mathrm{C}$ to $950^{\circ} \mathrm{C}$. On the other hand, no decomposition of the $\mathrm{GaN}$ was observed up to $900^{\circ} \mathrm{C}$ in $\mathrm{He}$ ambient gas. They also found the decomposition rate of GaN in $\mathrm{H}_{2}$ and $\mathrm{He}$ mixture to proportional to $\mathrm{P}_{\mathrm{H}_{2}}^{3 / 2}$, which indicates that the rate-limiting reaction for the $\mathrm{GaN}$ decomposition is

$$
\mathrm{GaN}(\text { surface })+3 / 2 \mathrm{H}_{2}(\mathrm{~g})=\mathrm{Ga}(\text { surface })+\mathrm{NH}_{3}(\mathrm{~g})
$$

In addition, no $\mathrm{Ga}$ droplet was observed on the surface of $\mathrm{GaN}$ after the experiment. Thus, the Ga droplets formed by the decomposition of the GaN evaporate immediately with the formation of gaseous $\mathrm{GaH}_{\mathrm{x}}$, which does not play a rate-limiting role in their study. Koleske et al.[16,17] investigated the influence of the $\mathrm{H}_{2}$ total pressure (10 700Torr) on the decomposition of $\mathrm{GaN}$ on sapphire in the temperature range from $850^{\circ} \mathrm{C}$ to $1050^{\circ} \mathrm{C}$. The $\mathrm{GaN}$ decomposition rate was accelerated when the $\mathrm{H}_{2}$ pressure was increased above 100Torr. The mechanism for the enhanced GaN decomposition with increasing pressure is not understood well.

Ga metal is known to dissociate $\mathrm{H}_{2}$ at high temperatures to form Ga hydrides, which may be more mobile on the surface[18]. This has been observed by Morishita et al.[19] who have shown that the Ga diffusion length was increased when $\mathrm{H}_{2}$ or atomic $\mathrm{H}$ were used in the molecular beam epitaxy growth of GaAs. They also speculated that $\mathrm{GaH}_{\mathrm{x}}$ species were more weakly bound to the surface, and therefore, could diffuse farther before incorporation. The increase in the Ga diffusion length would more rapidly uncover new areas of the GaN surface for $\mathrm{N}_{2}$ desorption, which is $10-1000$ times faster than the 
Ga desorption. The active dissociation of surface $\mathrm{H}_{2}$ may also occur on the highly polar GaN surface, and this may be enhanced at high pressures.

Although $\mathrm{Ga}$ droplet formation coincides with an increase in the $\mathrm{GaN}$ decomposition rate, it is not known if the liquid $\mathrm{Ga}$ accumulation is the cause or a result of the increased $\mathrm{GaN}$ decomposition rate. The $\mathrm{GaN}$ decomposition rate was enhanced at higher pressure (>100Torr) in $\mathrm{H}_{2}$ [16]. This suggests that $\mathrm{H}_{2}$ is acting chemically to reduce the barrier for GaN decomposition. This may occur through a surface mediated dissociation of $\mathrm{H}_{2}$ followed by the formation of more mobile and volatile hydrogenated $\mathrm{N}$ and $\mathrm{Ga}$ species. The GaN surface can be chemically altered in $\mathrm{H}_{2}$ and that $\mathrm{N}$ is preferentially removed from the lattice while the Ga desorption rate remains relatively constant. The surface $\mathrm{H}$ can form more volatile $\mathrm{NH}_{\mathrm{x}}$ species. However, no enhancement was observed in $\mathrm{N}_{2}$ (76 400Torr) and the $\mathrm{GaN}$ decomposition rate was reduced compared to identical annealing conditions in $\mathrm{H}_{2}[17]$.

Pisch and Schmid-Fetzer[20] investigated the influence of liquid gallium on the decomposition of $\mathrm{GaN}$ in $\mathrm{Ar}+5 \% \mathrm{H}_{2}$. No significant change in surface morphology was observed for pure GaN samples without liquid gallium at temperatures to $800^{\circ} \mathrm{C}$. On the other hand, GaN samples with pre-deposited liquid $\mathrm{Ga}$ began to decompose at $720^{\circ} \mathrm{C}$. Schoonmaker et al.[21] determined the pressure over $\mathrm{GaN}$ and $\mathrm{GaN}+\mathrm{Ga}$ mixture by weight loss effusion and torsion effusion techniques. The results supported that the vaporization coefficient for the decomposition is much less than unity. In contrast to that, the binary mixture (a direct contact of $\mathrm{GaN}$ with liquid $\mathrm{Ga}$ ) showed considerable dissociation. They proposed that a non- reactant liquid Ga might participate as catalysts in the vaporization process by dissolving $\mathrm{GaN}$ and disrupting its rigid wurtzite crystal 
structure. However, solubility of nitrogen in $\mathrm{Ga}$ is $\sim 10^{-5} \mathrm{~mol} \%$ at $1100^{\circ} \mathrm{C}$ and 1atmosphere. Therefore, the mechanism of catalytic effect of $\mathrm{Ga}$ on the decomposition of $\mathrm{GaN}$ is still in question.

Tanaka and Nakadaira[22] have investigated the decomposition of cubic-GaN at various temperatures $\left(800 \sim 950^{\circ} \mathrm{C}\right)$ in $\mathrm{H}_{2}$ and estimated the activation energy of $1.6 \mathrm{eV}$ for GaN decomposition. Cubic GaN was annealed in different ambient gases at various temperatures from 800 to $950^{\circ} \mathrm{C}$. Cubic $\mathrm{GaN}$ remained stable in inert gases, but it sublimated in hydrogen ambient. This sublimation was suppressed in $\mathrm{H}_{2}+\mathrm{NH}_{3}$ and $\mathrm{H}_{2}+$ TEG mixtures. They claimed that the $\mathrm{GaN}+\mathrm{H}_{2}$ changed into $\mathrm{Ga}+\mathrm{NH}_{3}$ and $\mathrm{Ga}$ evaporated. This enhanced sublimation of cubic $\mathrm{GaN}$ in $\mathrm{H}_{2}$ is similar to that of hexagonal $\mathrm{GaN}$ reported by Morimoto[12].

In this paper we have investigated decomposition behavior of $\mathrm{GaN}$ in ammonia and ammonia-nitrogen mixture in our bulk GaN growth reactor. The composition of the gas phase was analyzed using quadruple mass spectrometry. Based upon the result of mass spectrometry, nitrogen dilution of ammonia was then applied to growth of $\mathrm{GaN}$ bulk crystals to grow larger crystals with minimal decomposition.

\subsection{Experimental Procedures}

Gallium nitride thin films used in the decomposition study were grown at $1000^{\circ} \mathrm{C}$ on $\mathrm{SiC}$ substrate with AlN buffer layer using $26.1 \mu \mathrm{mol} / \mathrm{min}$ of triethylgallium(TEG), 1.5 SLM of $\mathrm{NH}_{3}$ and 3 SLM of $\mathrm{H}_{2}$ as a carrier gas at the total pressure of 45Torr in a 
MOVPE reactor. A 1/4’x 1/4' GaN thin film along with several needle-shaped GaN crystals of $500 \mu \mathrm{m}$ in length were placed at the center of the BN substrate in the GaN bulk growth reactor for decomposition study. The GaN growth system has been described in detail in a forthcoming publication[23]. Processing conditions for decomposition study were the same as those for the growth of bulk GaN crystals except the absence of Ga source. The decomposition rates were determined from thickness measurement using scanning electron microscopy(SEM). A thickness of $1 \mu \mathrm{m} / \mathrm{hr}$ is equivalent to the decomposition rate of $1.145 \times 10^{15} \mathrm{~cm}^{-2} \mathrm{~s}^{-1}$. Surface morphologies of the samples after heat treatment were examined by atomic force microscopy(AFM). Quadruple mass spectrometry(QMS) was employed to analyze the composition of the gas during heat treatment. An alumina tube of $1 / 16$ " inner diameter was used as a sampling probe, the inlet of which was placed $3 \mathrm{~mm}$ above the $\mathrm{BN}$ center, as shown in Fig. 5.1. Differential pumping system was employed between the reactor and the mass spectrometer to maintain the working pressure of $\sim 1 \times 10^{-6}$ Torrr in the spectrometer chamber. For stable reading, measurement was made 20 30minutes after any experimental variable was changed. The high temperature nucleation technique developed in our laboratory[23] was employed to conduct the seeded growth. Ammonia was introduced when the $\mathrm{BN}$ substrate temperature reached $1050^{\circ} \mathrm{C}$ to avoid decomposition of the seed crystals. The $\mathrm{GaN}$ crystals after seeded growth were subsequently characterized using optical microscopy, scanning electron microscopy(SEM), and X-Ray diffraction(XRD). Micro-Raman spectra of the GaN crystals were obtained at room temperature using a back scattering geometry from the $(10 \overline{1} 0)$ face and the $514.5 \mathrm{~nm}$ line of an Ar-ion laser. The spot size and the spectral resolution were $4 \mu \mathrm{m}$ and $1 \mathrm{~cm}^{-1}$, respectively. Photoluminescence (PL) measurements of 
the samples were made at room temperature using a He-Cd laser $(\lambda=325 \mathrm{~nm})$ as the excitation energy source. The luminescence detection system consists of a 0.5 meter McPherson model 219 scanning vacuum monochromater with a Hamamatsu model R1527-P photomultiplier tube. The sample orientation in the PL system was such that the normal to the sample surface was aimed directly at the detection system entrance port and the laser incidence angle is $30^{\circ}$ from the sample surface normal.

\subsection{Results and Discussion}

Figure 5.2 shows GaN crystals grown at $1130^{\circ} \mathrm{C}$ and 760 Torr for 2,8 , and $15 \mathrm{hrs}$. The apparent crystal size increased with increasing growth time. However, the surface morphologies of the crystals began to deteriorate after 8hours of growth and crystals turned white after $15 \mathrm{hrs}$ due to significant decomposition. The white crystals were analyzed using X-ray powder diffraction and only diffraction patterns for hexagonal GaN were found. To investigate the influence of ammonia total pressure on decomposition of $\mathrm{GaN}$, decomposition rate of $\mathrm{GaN}$ thin films was measured at $1130^{\circ} \mathrm{C}$ as a function of ammonia total pressure and shown in Fig. 5.3. The decomposition rate of GaN decreased initially as the ammonia total pressure increased from 100Torr to 510Torr, corresponding to ammonia density from $6.9 \times 10^{17}$ to $3.5 \times 10^{18} \mathrm{~cm}^{-3}$ at $1130^{\circ} \mathrm{C}$. Then, decomposition rate increased again with increasing the ammonia total pressure to 760Torr. A minimum in the decomposition rate of $\mathrm{GaN}$ occurred between 430 and 510Torr at $1130^{\circ} \mathrm{C}$; however, the error in each measurement disallowed the determination 
of the exact pressure. The initial decrease in $\mathrm{k}_{\mathrm{GaN}}$ with increasing the $\mathrm{NH}_{3}$ density is due to $\mathrm{NH}_{3}$ adsorption, supplying active nitrogen to compensate the loss of nitrogen from the surface of GaN, which blocks sites needed for GaN decomposition. Koleske et al.[24] reported that the minimum decomposition occurred at an ammonia density of $1 \times 10^{19} \mathrm{~cm}^{-3}$ at $992^{\circ} \mathrm{C}$ and 150 Torr of $\mathrm{NH}_{3}-\mathrm{H}_{2}$ mixture. The higher value of the ammonia density for the minimum decomposition may be due to larger concentration of hydrogen in their experiment. One would expect lower decomposition rate of $\mathrm{GaN}$ at higher ammonia pressures. At pressures higher than 510Torr, however, decomposition rate increased again with increasing ammonia pressure. This may be due to a decrease in the suppression of $\mathrm{N}_{2}$ desorption by $\mathrm{NH}_{3}$ site blocking due to a gradual increase in the $\mathrm{H}$ surface coverage. The increased $\mathrm{H}$ coverage may block sites necessary for $\mathrm{NH}_{3}$ adsorption. Sung et al.[25] reported using time of flight scattering and recoiling spectroscopy (TOF-SARS) that $\mathrm{GaN}(000 \overline{1})$ was terminated by three-fourths of a monolayer of hydrogen bonded to surface nitrogen even without intentional hydrogen exposure and that thermal decomposition with the evolution of $\mathrm{H}_{2}$ begins at $850^{\circ} \mathrm{C}$. In addition, surface hydrogen can aid $\mathrm{N}$ desorption by combining with adsorbed $\mathrm{NH}_{\mathrm{x}}$ species to form $\mathrm{NH}_{3}$ molecules. Unlike $\mathrm{NH}_{3}$, site blocking with surface $\mathrm{H}$ should lead to an increase in the decomposition rate. Reduction in growth rate has been observed in growth at increased total pressures[26] and growth with higher $\mathrm{NH}_{3}$ fluxes[27]. The GaN growth rate decreased as the growth pressure increased because of the increased GaN decomposition at higher pressures. Ambacher et al.[7] and Hashimoto et al.[28] reported that the growth rate was decreased in $\mathrm{H}_{2}$ as compared with that in $\mathrm{N}_{2}$ carrier gas. 
Ammonia decomposes on a $\mathrm{GaN}$ surface through the reaction of hydrogen with surface $\mathrm{Ga}$ or $\mathrm{N}$ depending on the surface termination. Hydrogen can be adsorbed on either Ga sites or $\mathrm{N}$ sites depending upon growth conditions through a surface mediated dissociation of $\mathrm{H}_{2}$. Let us consider a case that $\mathrm{H}$ is adsorbed on $\mathrm{Ga}$ sites and form volatile hydrogenated species.

The different diffusivity of $\mathrm{Ga}$ and $\mathrm{N}$ adatoms on $\mathrm{GaN}$ surface may provide an explanation for the stability and residence time of $\mathrm{N}$ adatoms on the GaN surface. Although $\mathrm{N}$ atoms are thermodynamically unstable against desorption as $\mathrm{N}_{2}$ molecules the low mobility of this specie implies that desorption of $\mathrm{N}$ adatoms is kinetically hindered. In order to desorb, the $\mathrm{N}$ adatoms have to form molecules. Since the diffusion barrier for $\mathrm{N}$ is $\operatorname{high}(\sim 1.4 \mathrm{eV}$ for $(0001)$ and $0.9 \mathrm{eV}$ for $(000 \overline{1}))[29,30]$, the migration is slow and consequently the residence time of $\mathrm{N}$ should be reasonably large. On the other hand, since $\mathrm{Ga}$ adatoms are very mobile $(\sim 0.4 \mathrm{eV}$ for $(0001)$ and $0.2 \mathrm{eV}$ for $(000 \overline{1}))[29,30]$, the probability that Ga atoms capture $\mathrm{N}$ atoms is much higher than the other process where $\mathrm{N}$ atoms form molecules and desorb from the surface. Thus, if there are enough $\mathrm{Ga}$ atoms present (which is the case under more Ga-rich conditions) the incorporation probability of $\mathrm{N}$ atoms is enhanced. If volatile hydrogenated Ga species are formed, incorporation probability of $\mathrm{N}$ atoms into crystal is reduced. Instead, nitrogen atoms relatively have more chance to combine each other and desorb as a nitrogen molecule. Independent of the chemical environment (Ga- or N-rich) polar GaN surfaces turn out to be always Ga stabilized with no $\mathrm{N}$ atoms in or on top of the surface layer. The only known exception so far is a N $(2 \times 2)$ adatom structure on the $(0001)$ surface found to be stable under very N-rich conditions[31]. 
Under N-rich growth conditions, the excess $\mathrm{N}$ strongly increases the diffusion barrier of the Ga adatoms because of the strong bonding of Ga-N. Zywietz et al.[30] found employing density-functional theory calculations that the diffusion barrier of $\mathrm{Ga}$ adatoms increased from $0.4 \mathrm{eV}$ to $1.8 \mathrm{eV}$ on (0001) surface and from $0.2 \mathrm{eV}$ to $1.0 \mathrm{eV}$ on (0001) surface. On the surface, the $\mathrm{N}$ adatoms are under-coordinated and can form only two or three bonds making $\mathrm{N}$ in these configurations less stable than in a $\mathrm{N}_{2}$ molecule. Therefore, nitrogen adatoms have more probability to combine with each other and desorb from the surface. When hydrogen is adsorbed on GaN surface under N-rich growth conditions, reconstructions maximizing the number of $\mathrm{N}-\mathrm{H}$ bonds are favored, due to the large $\mathrm{N}-\mathrm{H}$ bond strength. These include structures in which a nitrogen atom is bonded to a surface $\mathrm{Ga}$ atom in an on-top position, as well as to two or three $\mathrm{H}$ atoms - a configuration directly related to adsorption of $\mathrm{NH}_{2}$ or $\mathrm{NH}_{3}$. It has been found that hydrogen atoms are bound to the outmost $\mathrm{N}$ atoms with a coverage of $\sim 3 / 4$ monolayer and protrude outward from the surface[32]. Thermal decomposition commenced at $\sim 850^{\circ} \mathrm{C}$ with the evolution of $\mathrm{N}_{2}, \mathrm{NH}_{2}$, and $\mathrm{H}_{2}[32]$ provides evidence for $\mathrm{N}-\mathrm{H}$ bonds on the surface. Surface coverage of $\mathrm{H}$ hinders further dissociation of ammonia on the surface and decreases the stability of $\mathrm{GaN}$ surface.

It is well known that nitrogen and hydrogen molecules are generated as a byproduct in the reaction of $\mathrm{NH}_{3}$ with Ga. Nitrogen molecules are not to react with $\mathrm{Ga}$ or GaN surface because of their strong bonding. Hydrogen, however, is a well-known etchant for GaN. To investigate the cause of the enhanced decomposition at higher pressures than 510Torr, the composition of the gas was analyzed using a quadruple mass spectrometer. When only $\mathrm{NH}_{3}$ gas was flowing at a rate of $60 \mathrm{sccm}$ without $\mathrm{Ga}$ 
source in the growth reactor, the hydrogen concentration began to increase at 475Torr and increased monotonously to 760Torr. On the other hand, concentrations of $\mathrm{NH}_{3}$ and $\mathrm{NH}_{2}$ began to decrease at 430Torr. The concentration of $\mathrm{NH}_{2}$ shown in Fig. 4 is not the concentration of the $\mathrm{NH}_{2}$ specie that had been created in the reactor as a result of thermal dissociation of $\mathrm{NH}_{3}$ since $\mathrm{NH}_{2}$ has a short lifetime as compared with $\mathrm{NH}_{3}$ and $\mathrm{NH}_{2}$ specie amounts to $80 \%$ of $\mathrm{NH}_{3}$ intensity in mass spectrometry due to ionization[33]. The amount of $\mathrm{NH}_{2}$ in Fig. 5.4 is about $80 \%$ of $\mathrm{NH}_{3}$ concentration. Therefore, it is obvious that $\mathrm{NH}_{2}$ specie detected in the study is originated from the ionization in the mass spectrometer. Relative amount of $\mathrm{NH}_{3}$ and $\mathrm{NH}_{2}$ did not change even at room temperature. The increase in $\mathrm{H}_{2}$ concentration is attributed to decomposition of $\mathrm{NH}_{3}$ at $1130^{\circ} \mathrm{C}$. Only a trace of hydrogen was detected $(<3 \%)$ at room temperature. The similar shape of the curve of $\mathrm{N}_{2}$ concentration indicated that the hydrogen signal was originated from decomposition of ammonia. The reason for the increase in $\mathrm{H}_{2}$ concentration at $\sim 475$ Torr is not clear at present. This may be due to the increased number of collisions in the gas phase that increases the temperature and the consequent dissociation of ammonia molecules. Figure 5.4(b) shows the gas composition in the reactor at $1130^{\circ} \mathrm{C}$ in the presence of Ga. The hydrogen concentration initially began to decrease at 100Torr and increased abruptly at 300Torr. The increase in hydrogen concentration occurred at lower ammonia pressure( $\sim 300$ Torr) as compared with the case of $\mathrm{NH}_{3}$ dissociation in the absence of Ga. This indicates that more dissociation of $\mathrm{NH}_{3}$ occurred as a result of the reaction between $\mathrm{Ga}$ and $\mathrm{NH}_{3}$. It is noted that hydrogen concentration in the presence of $\mathrm{Ga}$ is higher than the case of $\mathrm{NH}_{3}$ only. In addition, higher concentration of hydrogen at lower pressures (<300Torr) can be attributed to increased diffusion length of Ga. As more Ga is 
transported to the substrate region, more reaction of $\mathrm{Ga}$ with $\mathrm{NH}_{3}$ occurs near the inlet of the sampling probe and more ammonia is dissociated. Ga vapor was not detected in this study probably because condensation of Ga may have occurred on the probe wall on its way to QMS ionizer. Based upon the result of the mass spectrometry, the enhanced decomposition of $\mathrm{GaN}$ at higher ammonia pressures is due to the increased hydrogen concentration. During crystal growth with Ga vapor, more decomposition would be anticipated to counteract the deposition of GaN.

Figure 5.5 shows $\mathrm{AFM}$ images of the $\mathrm{GaN}$ surface annealed at $1130^{\circ} \mathrm{C}$ and various ammonia pressures. The sample annealed at 760Torr showed a roughest surface $(\sim 32.6 \mathrm{~nm})$ as a result of enhanced decomposition and reaction of the GaN surface with ambient gas. The sample annealed at 100Torr showed a smooth surface roughness $(\sim 6.8 \mathrm{~nm})$ despite the higher decomposition rate as shown in Fig. 5.3. This is probably due to enhanced desorption process at lower pressures. At a high ammonia pressure, some of byproduct as a consequence of decomposition of $\mathrm{GaN}$, $\mathrm{Ga}$ and $\mathrm{GaH}_{\mathrm{x}}$, can be accumulated on the surface because desorption process is more sluggish at high pressures than low pressures. Nitrogen desorption rate has been reported to be four orders of magnitude higher than that of $\mathrm{Ga}$ at $\sim 1150^{\circ} \mathrm{C}[34]$. These byproducts may react again with incoming ammonia. High decomposition rates obtained at lower ammonia pressures(<300Torr) are more likely due to more contribution from the thermal instability of $\mathrm{GaN}$ than the consequence of chemical reaction with hydrogen. It is worth mentioning that the high concentration of hydrogen may be largely due to the reactor configuration used in the current research. Since the growth reactor is similar to hot wall epitaxy system, dissociation of ammonia tends to occur on the wall of growth crucible, 
temperature of which is $1260^{\circ} \mathrm{C} \sim 1300^{\circ} \mathrm{C}$. For GaN growth in MOVPE system the epitaxy temperature is usually $\sim 1000^{\circ} \mathrm{C}$ and rates of kinetic processes are exponential function of temperature. In addition to this, growth time for $\mathrm{GaN}$ thin films of $\sim 1 \mu \mathrm{m}$ thick is relatively shorter(<several hours) and appropriate amount of hydrogen is also required to obtain smoother surface morphology. Therefore, the detrimental effect of hydrogen observed in this study is unlikely to be seen in usual MOVPE growth system unless the hydrogen concentration exceeds a critical value over which etching rate is much greater than growth rate.

One way to reduce the hydrogen concentration in the gas phase during the growth is dilution of ammonia with nitrogen. Nitrogen molecules are not to dissociate at this growth temperature because of their strong bonding( $\sim 9.8 \mathrm{eV})$. Figure 5.6 shows $\mathrm{GaN}$ crystals before and after annealing at $1130^{\circ} \mathrm{C}, 430$ Torr and different nitrogen flow rates. Amber crystals turned to white after the annealing in $100 \% \mathrm{NH}_{3}($ Fig. 5.6(a)). The surface morphologies of the crystals annealed in $40 \mathrm{sccmNH}_{3}+20 \mathrm{scmN}_{2}$ gas mixture remained smooth even after the annealing as compared with that in pure ammonia, as shown in Fig. 5.6(b). When $40 \mathrm{sccm}$ of $\mathrm{N}_{2}$ gas was added to $\mathrm{NH}_{3}$, the surface became rougher, as revealed in the SEM micrograph shown in Fig. 5.6(c). Figure 5.7 shows the AFM images of the surface of $\mathrm{GaN}$ films after annealing at $1130^{\circ} \mathrm{C}$ and 430 Torr of total pressure in different gas mixtures. Surface roughness initially decreased from $21.4 \mathrm{~nm}$ (pure ammonia) to $10.4 \mathrm{~nm}$ when $20 \mathrm{sccm}$ of $\mathrm{N}_{2}$ was added and increased to $39.5 \mathrm{~nm}$ for the addition of $30 \mathrm{sccm}$ of $\mathrm{N}_{2}$ to $\mathrm{NH}_{3}$. For $60 \mathrm{sccm}$ of pure $\mathrm{N}_{2}$, the GaN film was completely decomposed at this temperature due to the lack of active nitrogen to block the sites for decomposition on the surface of GaN. The initial decrease in the surface roughness can 
be attributed to the decrease in hydrogen concentration in the gas phase. The surface roughness increased again at $30 \mathrm{sccmNH}_{3}+30 \mathrm{sccmN}_{2}$ probably because the amount of active nitrogen provided from ammonia decreased and could not block the sites for decomposition on the surface. For the gas mixture of $20 \mathrm{sccmNH}_{3}+40 \mathrm{sccmN}_{2}$, surface roughness increased abruptly upon losing its thermal stability.

Decomposition rate was measured in the same manner described previously for different compositions of gas mixture. Though the decomposition rate did not change appreciably to 20sccm of nitrogen dilution, as shown in Fig. 5.8, the magnitude would be larger in the presence of Ga because more hydrogen would be generated. Decomposition rate began to increase again at $30 \mathrm{sccm}$ of nitrogen dilution. The reason for the minimum decomposition rate at $40 \mathrm{sccm} \mathrm{NH}_{3}+20 \mathrm{sccm} \mathrm{N}_{2}$ is not clear at present. The increase in the decomposition rate at total pressures less than 475Torr was ascribed to evaporation due to thermodynamic instability, as shown in Fig. 5.3. Since the total pressure was kept constant, the decrease in the decomposition rate may be attributed to reduced surface chemical reactions with hydrogen due to less amount of hydrogen produced as a byproduct. The hydrogen partial pressure, however, may not be the only decisive factor influencing the decomposition kinetics of $\mathrm{GaN}$ in this research. The decomposition rate in $20 \mathrm{sccm}$ of $\mathrm{NH}_{3}+20 \mathrm{sccm}$ of $\mathrm{N}_{2}$ was $\sim 7.8 \times 10^{14} \mathrm{~cm}^{-1} \mathrm{~s}^{-1}$ (Fig. 5.8). The dilution of ammonia with $20 \mathrm{sccm} \mathrm{N}_{2}$ corresponds to $\sim 287$ Torr of ammonia partial pressure. The decomposition rate at 287Torr of pure ammonia was interpolated to be $\sim 8.7 \times 10^{14} \mathrm{~cm}^{-1} \mathrm{~s}^{-1}$ from Fig. 5.3. The concentrations of hydrogen in 287Torr of pure $\mathrm{NH}_{3}$ and in the corresponding $\sim 287$ Torr of $\mathrm{NH}_{3}+\sim 143$ Torr of $\mathrm{N}_{2}$ mixture were $\sim 28 \%$ and $\sim 24 \%$, respectively. However, $\mathrm{NH}_{3} / \mathrm{H}_{2}$ ratios for both cases were the same( 2). Assuming that 
the surface reaction kinetics is governed by competitive reaction of $\mathrm{NH}_{3}$ and $\mathrm{H}_{2}$ with the surface, statistically speaking, the decomposition rate in $\mathrm{NH}_{3}+\mathrm{N}_{2}$ gas mixture would be higher because diffusion length of ammonia in the gas phase decreases with the total pressure. Therefore, the difference in the decomposition rate may well be attributed to the kinetic effect of nitrogen molecules, which increases the residence time of reactants on the surface and in turn decreases their evaporation rates via continuous impingement on the surface. The heat transfer between the $\mathrm{N}_{2}$ and the hot surface is more efficient than between $\mathrm{H}_{2}$ and the surface, because of its larger mass (more impulsive collision) and slower speed (mean speed of $\mathrm{N}_{2}$ is 3.7 times slower than $\mathrm{H}_{2}$ ) its collision time with the surface is longer. As of result of the increased collision time, heat transfer from the hotter surface $\mathrm{Ga}$ atoms to the cooler $\mathrm{N}_{2}$ molecules is more efficient, resulting in a reduced population density of the Ga surface vibrations which lead to Ga desorption. The net effect of this is a reduction in attempt frequency (pre-exponential factor) for $\mathrm{Ga}$ desorption in $\mathrm{N}_{2}$ compared to $\mathrm{H}_{2}$.

Kobayashi et al.[35] reported that $\mathrm{N}$ desorption from the $\mathrm{GaN}$ surface in $\mathrm{N}_{2}$ carrier gas was remarkably suppressed compared with that in $\mathrm{H}_{2}$ carrier gas. The activation energy $(\sim 1.88 \mathrm{eV})$ of $\mathrm{N}$ desorption in $\mathrm{N}_{2}$ was larger than that $(\sim 0.98 \mathrm{eV})$ in $\mathrm{H}_{2}$. They suggested that $\mathrm{H}_{2}$ carrier gas may react with $\mathrm{N}$ atoms on the surface and enhance the $\mathrm{N}$ desorption by etching from the GaN surface, whereas the reaction may not occur in $\mathrm{N}_{2}$ carrier gas. Figure 5.9 shows gas compositions during the annealing in different nitrogen and ammonia mixtures. Any peculiar change in concentration of gas species was not observed. The amount of $\mathrm{NH}_{3}$ and $\mathrm{H}_{2}$ decreased monotonously with increasing nitrogen dilution, while the nitrogen concentration increased proportionally for both with 
and without Ga source. The hydrogen concentration was higher in the presence of $\mathrm{Ga}$ source than in the absence of Ga source as expected.

Based upon the above results, nitrogen dilution of ammonia was applied to the seeded growth of bulk GaN crystals. A $2 \mathrm{~mm} \times 1.5 \mathrm{~mm} \mathrm{GaN}$ crystal was grown at $1130^{\circ} \mathrm{C}$ and 430 Torr for $36 \mathrm{hrs}$ in a $40 \mathrm{sccmNH}_{3}+20 \mathrm{sccmN}_{2}$ mixture with minimal decomposition, as shown in Fig. 5.10(a). The well-developed c-face and a-face of the crystal (Fig. 5.10(b) and 5.10(c)), confirmed by XRD patterns, showed smooth surface morphologies, which are indicative of suppressed decomposition under the aforementioned growth conditions. Without nitrogen dilution, crystals grown under the same growth conditions tended to decompose after $\sim 10 \mathrm{hrs}$ of growth and turned white crystals with very poor surface morphologies. Raman spectrum of the crystal grown with nitrogen dilution showed the only allowed mode of the wurtzite structure, shown in Fig. 5.11. The excellent crystallinity was confirmed by the FWHM of $\sim 3 \mathrm{~cm}^{-1}$ of the Raman $\mathrm{E}_{2}^{(2)}$ mode. It has been suggested that disorders in the crystal and strain associated with these defects could increase in the $\mathrm{E}_{2}^{(2)}$ phonon linewidth[36]. A room temperature PL spectrum of the crystal grown in ammonia-nitrogen mixture is shown in Fig. 5.12. Strong bound exciton emission with a FWHM of $85 \mathrm{meV}$ was observed at $365 \mathrm{~nm}(3.4 \mathrm{eV})$. No yellow luminescence was observed in the visible portion of the spectrum.

Decomposition of ammonia yields surface hydrogen and surface nitrogen can be removed from the surface as ammonia via reaction with surface hydrogen yielded as a result of surface decomposition of ammonia. When the surface is rich in nitrogen adatoms without significant amount of surface hydrogen, the irreversible removal of nitrogen as nitrogen molecules from the surface offers a different surface reaction path. 
These interwoven surface reactions find their order of sequence or occur simultaneously depending on the growth environment. Thus to achieve continued growth of larger GaN crystals, one must determine the process conditions that produce the desired compromise between thermodynamic instability and evaporation at low total pressures and decomposition due to hydrogen etching as a result of the decomposition of ammonia at high total pressures.

\subsection{Conclusions}

Prolonged growth of GaN single crystals at high ammonia pressures resulted in poor surface morphologies due to decomposition. The concentration of hydrogen in the gas phase began to increase with increasing ammonia total pressure at $~ 475$ Torr without the presence of $\mathrm{Ga}$ and at $\sim 300 \mathrm{Torr}$ in the presence of $\mathrm{Ga}$, as revealed by quadruple mass spectroscopy. Decomposition of GaN crystals in the current study may be attributed to thermodynamic instability and evaporation at low total pressures $(<475$ Torr) and the enhanced decomposition due to hydrogen etching as a result of the decomposition of ammonia at high total pressures (>475Torr). Nitrogen dilution of ammonia reduced the amount of hydrogen in the gas phase generated as a result of ammonia decomposition and increased the kinetic barrier to desorption of reactants from the GaN surface and thereby alleviated the enhanced decomposition of GaN crystals at high ammonia total pressures. The surface morphology of the GaN crystal annealed in $33 \% \mathrm{~N}_{2}(20 \mathrm{sccm})$ diluted ammonia was maintained to be smooth, as confirmed by atomic force microscopy. A 
prismatic GaN crystal of $2 \mathrm{~mm} \times 1.5 \mathrm{~mm}$ was grown with minimal decomposition via seeded growth in a $40 \mathrm{sccmNH}_{3}+20 \mathrm{sccmN}_{2}$ gas mixture.

\subsection{Acknowledgements}

The authors acknowledge support of the Office of Naval Research under contract N00014-00-1-0192 (Colin Wood, monitor). 


\subsection{References}

1. Markus Kamp, M. Mayer, A. Pelzmann, K. J. Ebeling, MRS Internet J. Nitride Semicond. Res. 2, 26(1997).

2. Esther Kim, I. Berishev, A. Bensaoula, I. Rusakova, K. Waters and J. A. Schultz, J. Appl. Phys., 85(2), 1178(1999)

3. Z. A. Munir, and A. W. Searcy, J. Chem. Phys, 42. 4223(1965)

4. R. Groh, G. Gerey, L. Bartha, and J. I. Pankove, Phys. Status. Solidi A 26, 353(1974)

5. N. Grandjean, J. Massies, F. Semond, S. Yu. Karpov and R. A. Talalaev, Appl. Phys. Lett., 74(13), 1854(1999)

6. S. Guha, N. A. Bojarczuk, and D. W. Kisker, Appl. Phys. Lett., 69, 2879(1996)

7. O. Ambacher, M. S. Brandt, R. Dimitrov, T. Metzger, M. Stutzmann, R. A. Fischer, A. Bergmaier and G. Dollinger, J. Vac. Sci. Technol. B 14(6), 3532(1996)

8. M. V. Averyanova, I. N. Przhevalskii, S. Y. Karpov, Y. N. Makarov, M. S. Ramm, R. and A. Talalaev, Mat. Sci. \& Eng., B43, 167(1997)

9. W. Johnson, J. Parsons, M. Crew, J. Phys. Chem. 36, 2651(1932)

10. C.D. Thurmond, R.A. Logan, J. Electrochem. Soc. 119, 622(1972)

11. R.A. Logan, C.D. Thurmond, J. Electrochem. Soc. 119, 1727(1972)

12. Y. Morimoto, J. Electrochem. Soc., 1383(1974)

13. G. Jacob, R. Madar, J. Hallais, Mater. Res. Bull. 11, 445(1976)

14. Rebey, T. Boufaden, B. El Jani, J. Crystal Growth, 203, 12(1999)

15. M. Mayumi, F. Satoh, Y. Kumagai, K. Takemoto, and A. Koukitu, Jpn. J. Appl. Phys., 39, L707(2000) 
16. D. D. Koleske, A. E. Wickenden, R. L. Henry, M. E. Twigg, J. C. Culbertson, and R. J. Gorman, Appl. Phys. Lett., 73(14) 2018(1998)

17. D. D. Koleske, A. E. Wickenden, R. L. Henry, M. E. Twigg, J. C. Culbertson, and R. J. Gorman, MRS Internet J. Nitride Semicond. Res. 4S1, G3.70(1999)

18. H. Remy, Treatise on Inorganic Chemistry, Elsevier, New York, 18(1960)

19. Y. Morishita, Y. Nomura, S. Goto, and Y. Katayama, Appl. Phys. Lett., 67, 2500(1995)

20. A. Pisch, R. Schmid-Fetzer, J. Crystal Growth 187, 329(1998)

21. R. C. Schoonmaker, A. Buhl and J. Lemley, J. Phys. Chem., 69, 3455(1965)

22. H. Tanaka, A. Nakadaira, J. Crystal Growth, 189/190, 730(1998)

23. H. Shin, D. Thomson, R. Schlesser, Z. Sitar, and R. F. Davis, J. Cryst. Growth, to be published.

24. D.D. Koleske, A.E. Wickenden, and R.L. Henry, MRS Internet J. Nitride Semicond. Res. 5S1, W3.64 (2000).

25. M.M. Sung, J. Ahn, V. Bykov, J.W. Rabalais, D.D. Koleske, and A.E. Wickenden, Phys. Rev. B 54, 14652(1996)

26. M.A. Khan, R.A. Skogman, R.G. Schulze, and M. Gershenzon, Appl. Phys. Lett. 43, 493 (1983).

27. O. Briot, S. Clur, and R.L. Aulombard, Appl. Phys. Lett. 71, 1990 (1997).

28. M. Hashimoto, H. Amano, N. Sawaki, and I. Akasaki, J. Cryst. Growth 68, 163 (1984).

29. T. K. Zywietz, J. Neugebauer, M. Scheffler, J. Northrup and Chris G. Van de Walle, MRS internet J. Nitride Semicon., 3.26(1998) 
30. T. K. Zywietz, J. Neugebauer, M. Scheffler, Appl. Phys. Lett., 73, 487(1998)

31. A. R. Smith et al., Phys. Rev. Lett. 79, 3934 (1997).

32. M.M. Sung, J. Ahn, V. Bykov, J.W. Rabalais, D.D. Koleske, A.E. Wickenden, Phys. Rev. B 54, 14652(1996)

33. Cornu and R. Massot, Compilation of Mass Spectral Data, $2^{\text {nd }}$ Ed,

34. D. D. Koleske, A. E. Wickenden, R. L. Henry, W. J. Desisto, and R. J. Gorman, J. Appl. Physics, 84(4), 1998(1998)

35. Y. Kobayashi, N. Kobayashi, J. Cryst. Growth, 189/190, 301(1998)

36. M. Pophristic, F. H. Long, M. Schurman, J. Ramer, and I. T. Ferguson, Appl. Phys. Lett., 74(23), 3519(1999) 
Table 5.1 Decomposition studies of GaN

\begin{tabular}{|c|c|c|c|c|c|c|c|}
\hline $\begin{array}{c}\text { Pressure } \\
\text { (Torr) }\end{array}$ & $\begin{array}{l}\text { Temp. } \\
\left({ }^{\circ} \mathrm{C}\right)\end{array}$ & Gas & Material & $\begin{array}{l}\text { Pre-exponent } \\
\quad\left(\mathrm{cm}^{-2} \mathrm{~s}^{-1}\right)\end{array}$ & $\begin{array}{c}E_{A} \\
(e V)\end{array}$ & Method & Ref \\
\hline vacuum & $900-1150$ & & $\begin{array}{c}\text { Pressed } \\
\text { poly-GaN }\end{array}$ & $4 \times 10^{29}$ & 3.2 & Thermogravimetry & 3 \\
\hline vacuum & $940-1025$ & & GaN/sapphire & $5 \times 10^{28}$ & 3.24 & Mass spectrometry & 4 \\
\hline vacuum & $750-875$ & & GaN/sapphire & & 3.6 & Laser reflectometry & 5 \\
\hline vacuum & $850-1000$ & & GaN/sapphire & $1.2 \times 10^{31}$ & 3.93 & Mass spectrometry & 7 \\
\hline 760 & $\begin{array}{c}830-1050 \\
650-830\end{array}$ & $\mathrm{H}_{2}$ & GaN/sapphire & & $\begin{array}{l}0.38 \\
1.87\end{array}$ & Laser reflectometry & 14 \\
\hline 760 & $\begin{array}{l}750-950 \\
600-730\end{array}$ & $\mathrm{H}_{2}$ & GaN/sapphire & & $\begin{array}{l}3.18 \\
0.43\end{array}$ & Thermogravimetry & 15 \\
\hline $40-250$ & $815-1043$ & & GaN/sapphire & $6.6 \times 10^{29}$ & 2.74 & & 16 \\
\hline 76 & $902-1042$ & $\mathrm{H}_{2}$ & GaN/sapphire & $6.3 \times 10^{27}$ & 2.96 & Weight loss & 17 \\
\hline 76,150 & $992-1176$ & $\mathrm{~N}_{2}$ & & $1.2 \times 10^{29}$ & 3.62 & & \\
\hline
\end{tabular}




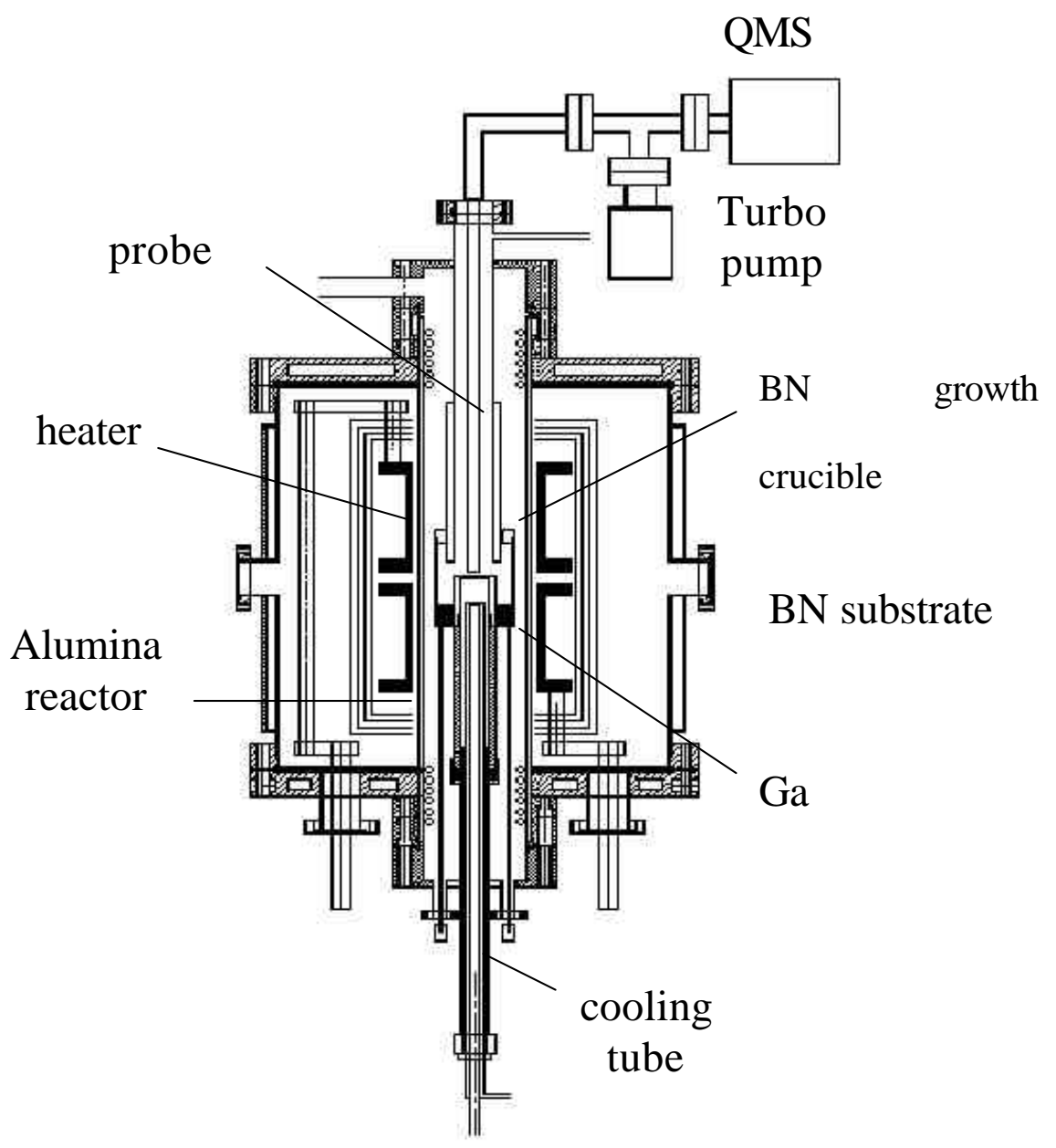

Figure 5.1 A schematic diagram of the growth chamber with the quadruple mass spectrometer for gas composition analysis. 

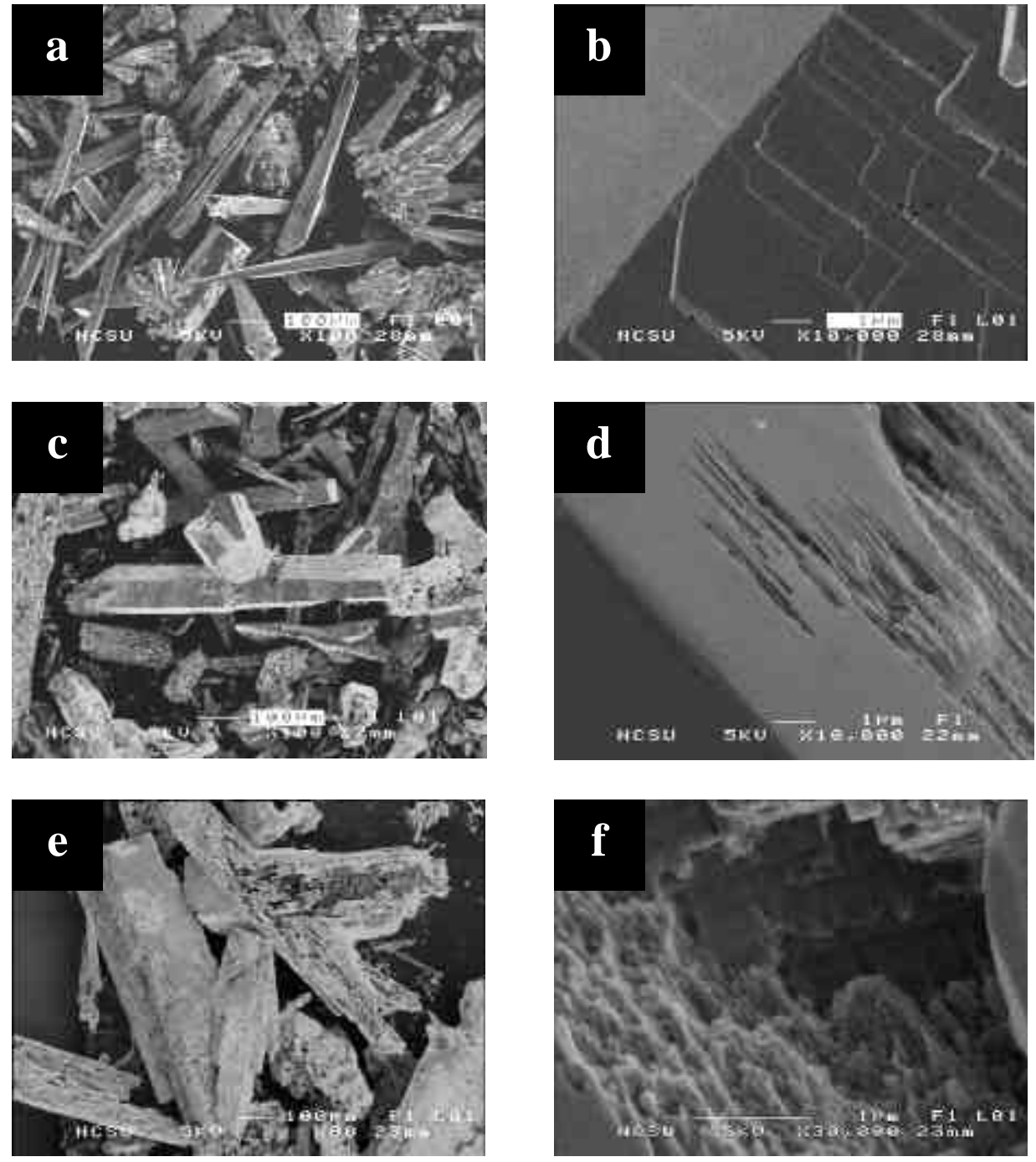

Figure 5.2 Time-dependent evolution of the surface morphologies at $1130^{\circ} \mathrm{C}, 760$ Torr of $\mathrm{NH}_{3}$ for (a) $2 \mathrm{hrs}$, (b) $8 \mathrm{hrs}$, and (c) $15 \mathrm{hrs}$. 


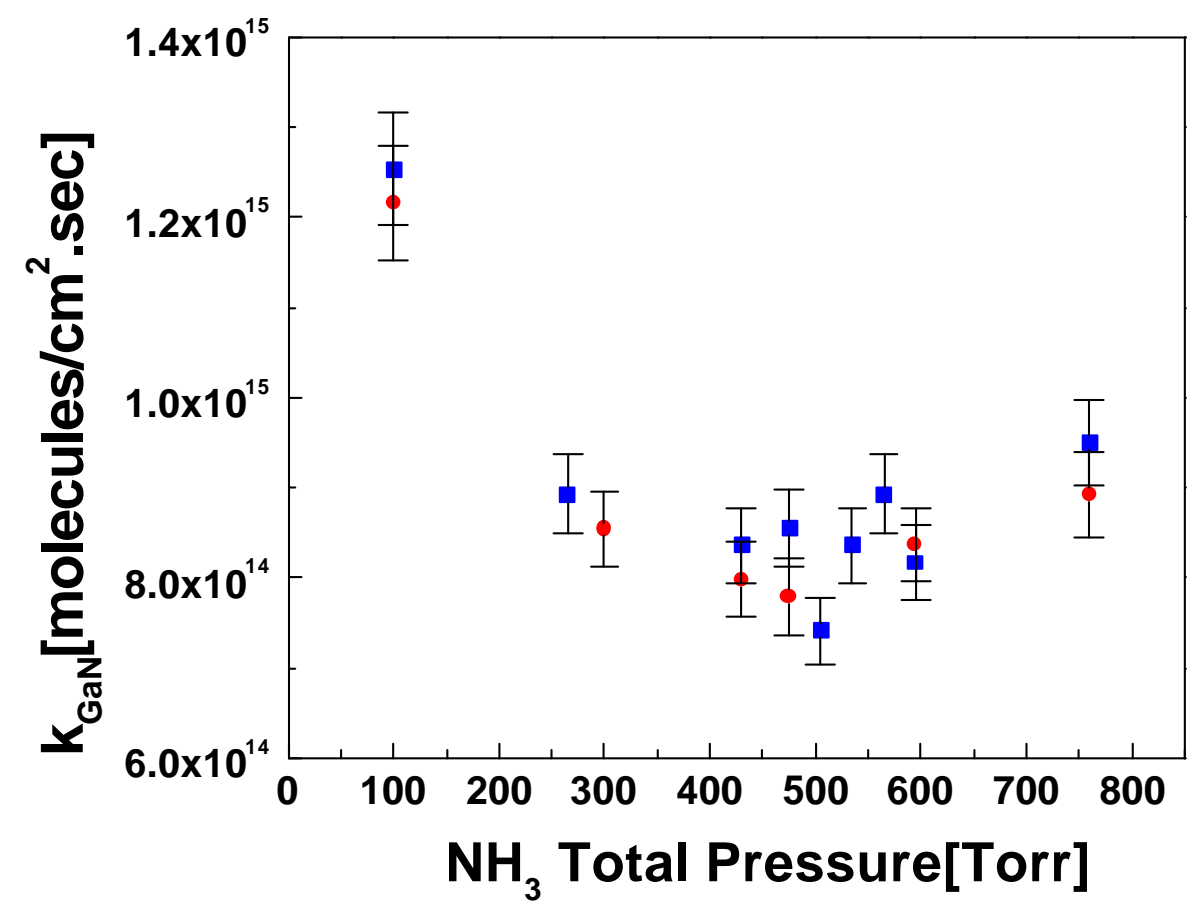

Figure 5.3 Decomposition rate of $\mathrm{GaN}$ at $1130^{\circ} \mathrm{C}, 60 \mathrm{sccm}$ of $\mathrm{NH}_{3}$ in the total pressure range from 100Torr to 760Torr. 

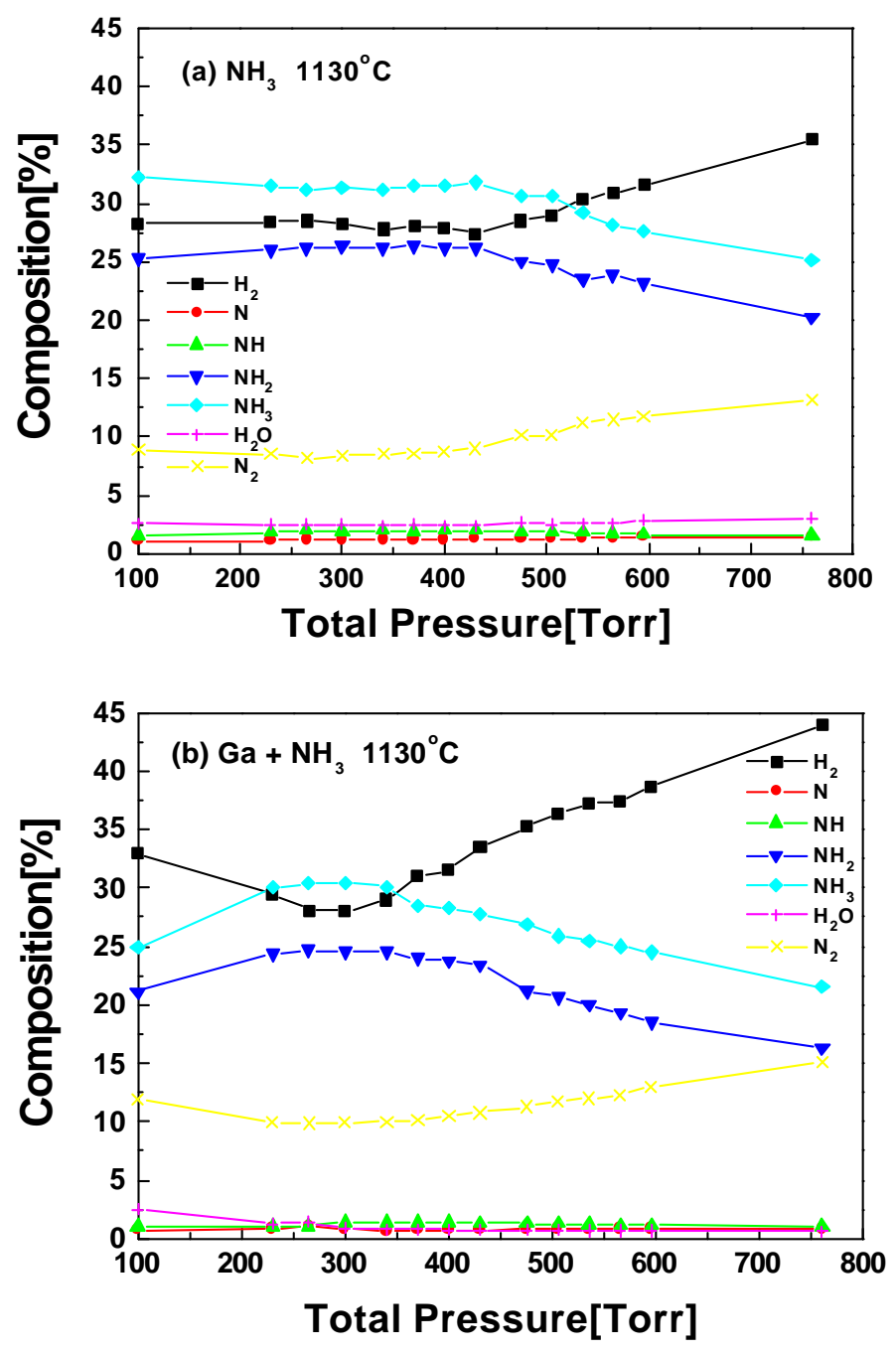

Figure 5.4 Composition of the gas at $1130^{\circ} \mathrm{C}$ in the growth reactor (a) without the presence of $\mathrm{Ga}$ and (b) in the presence of $\mathrm{NH}_{3}$ and $\mathrm{Ga}$. 

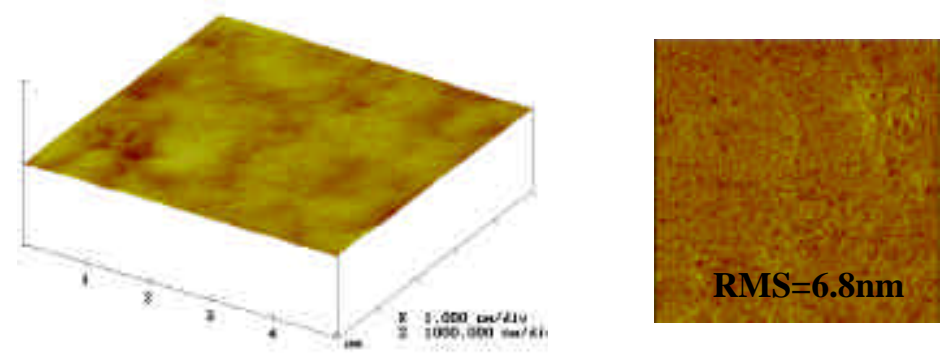

(a)100Torr $\mathrm{NH}_{3}$
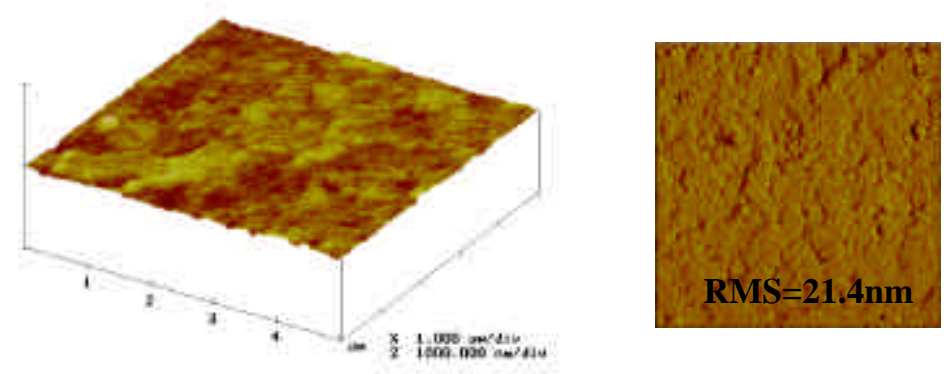

(b)430TorrNH
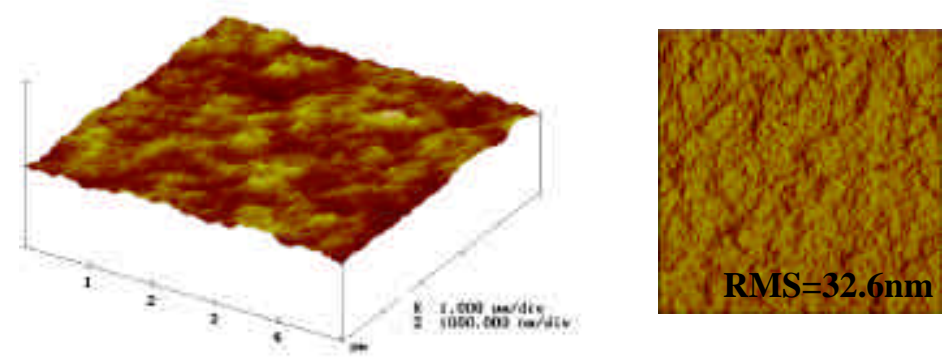

\section{(c)760TorrNH 3}

Figure 5.5 AFM images of the surfaces of GaN samples after annealing at $1130^{\circ} \mathrm{C}$, $60 \mathrm{sccm}$ of $\mathrm{NH}_{3}$, and various $\mathrm{NH}_{3}$ total pressures. 


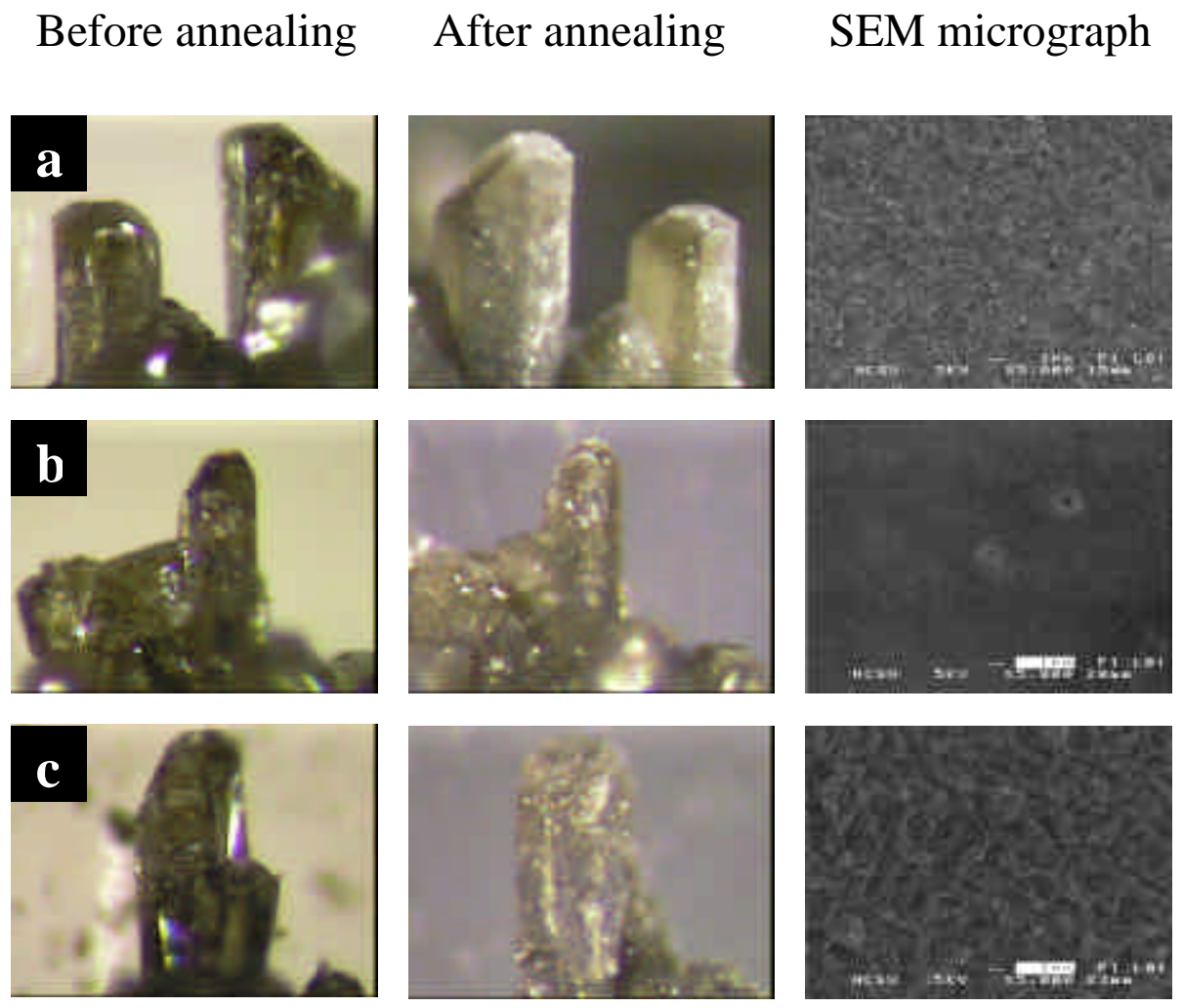

Figure 5.6 Optical and SEM micrographs of GaN crystals annealed at $1130^{\circ} \mathrm{C}$ and 430Torr for $2 \mathrm{hrs}$ in different ambient gas mixtures: (a) $60 \mathrm{sccm} \mathrm{NH}_{3}$ (b) $40 \mathrm{sccm} \mathrm{NH} 3+20 \mathrm{sccm} \mathrm{N} \mathrm{N}_{2}$ (c) $20 \mathrm{sccm} \mathrm{NH} \mathrm{NH}_{3}+40 \mathrm{sccm} \mathrm{N}$. 

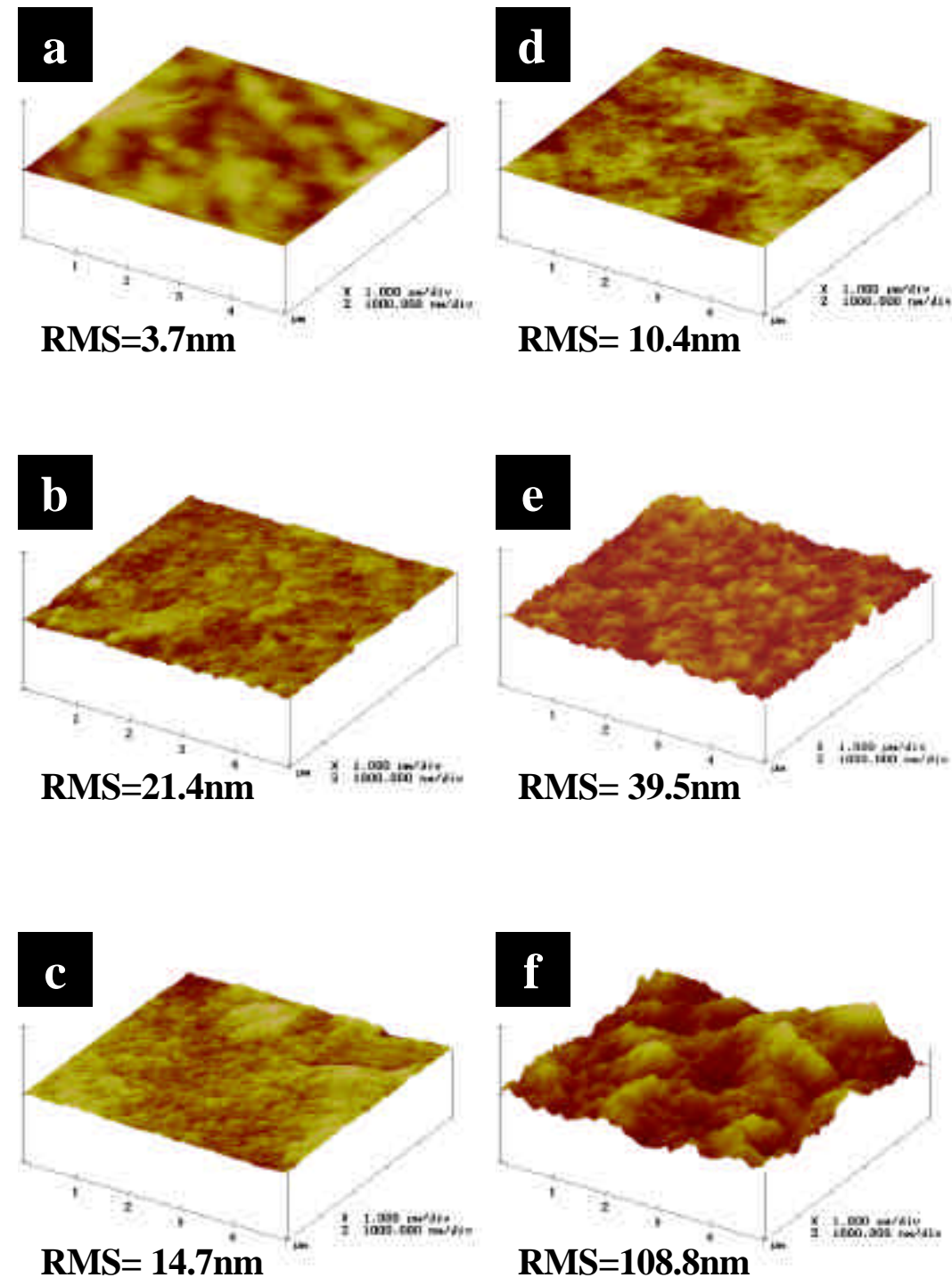

Figure 5.7 AFM images of the $\mathrm{GaN}$ surfaces annealed at $1130^{\circ} \mathrm{C}, 430$ Torr of different gas mixtures: (a)before annealing, (b)60sccm of $\mathrm{NH}_{3}$, (c) $50 \mathrm{sccm} \mathrm{NH}_{3}+10 \mathrm{sccm} \mathrm{N}$, (d) $40 \mathrm{sccm} \mathrm{NH} \mathrm{N}_{3}+20 \mathrm{sccm} \mathrm{N} 2$, (e) $30 \mathrm{sccm} \mathrm{NH} \mathrm{N}_{3}+30 \mathrm{sccm} \mathrm{N}$, and (f) $20 \mathrm{sccm} \mathrm{NH}$ $+40 \operatorname{sccm~N} \mathrm{N}_{2}$. 


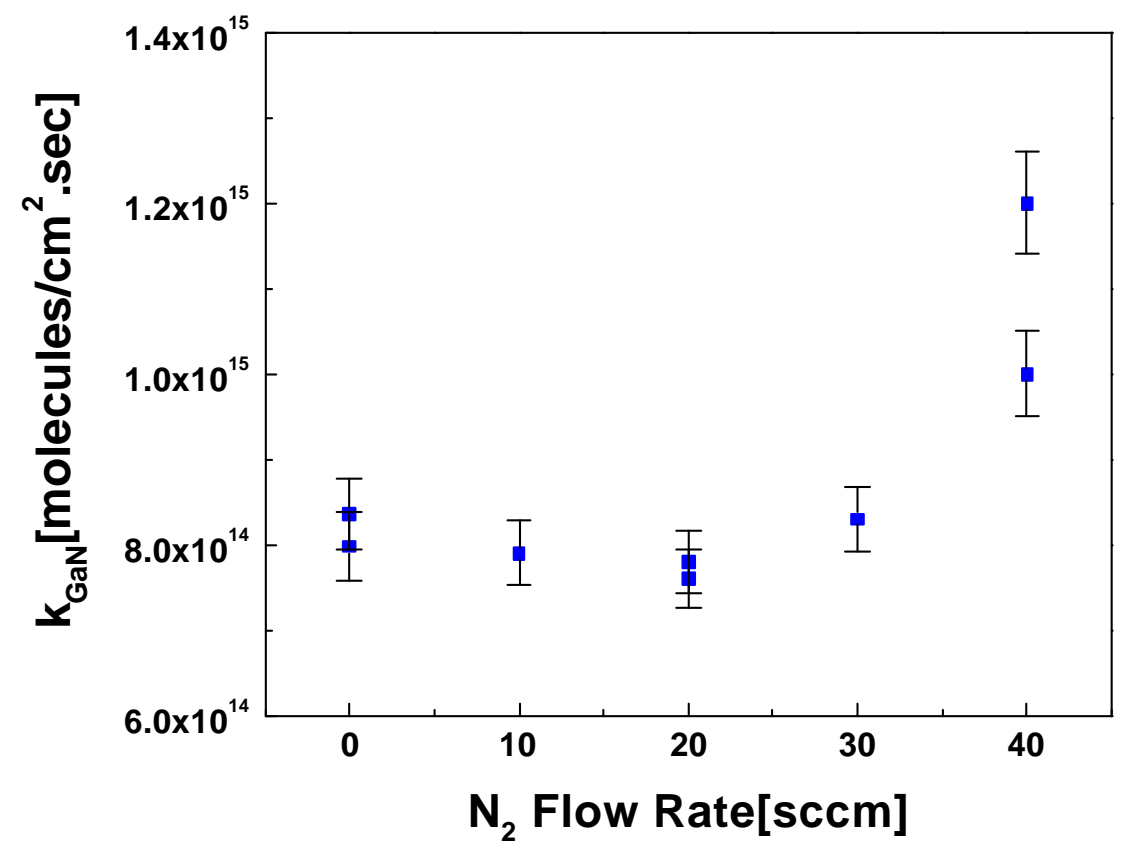

Figure 5.8 Decomposition rates of $\mathrm{GaN}$ at $1130^{\circ} \mathrm{C}$, 430Torr in (60-x) sccm $\mathrm{NH}_{3}+\mathrm{x} \mathrm{sccm}$ $\mathrm{N}_{2}$ gas mixture. 

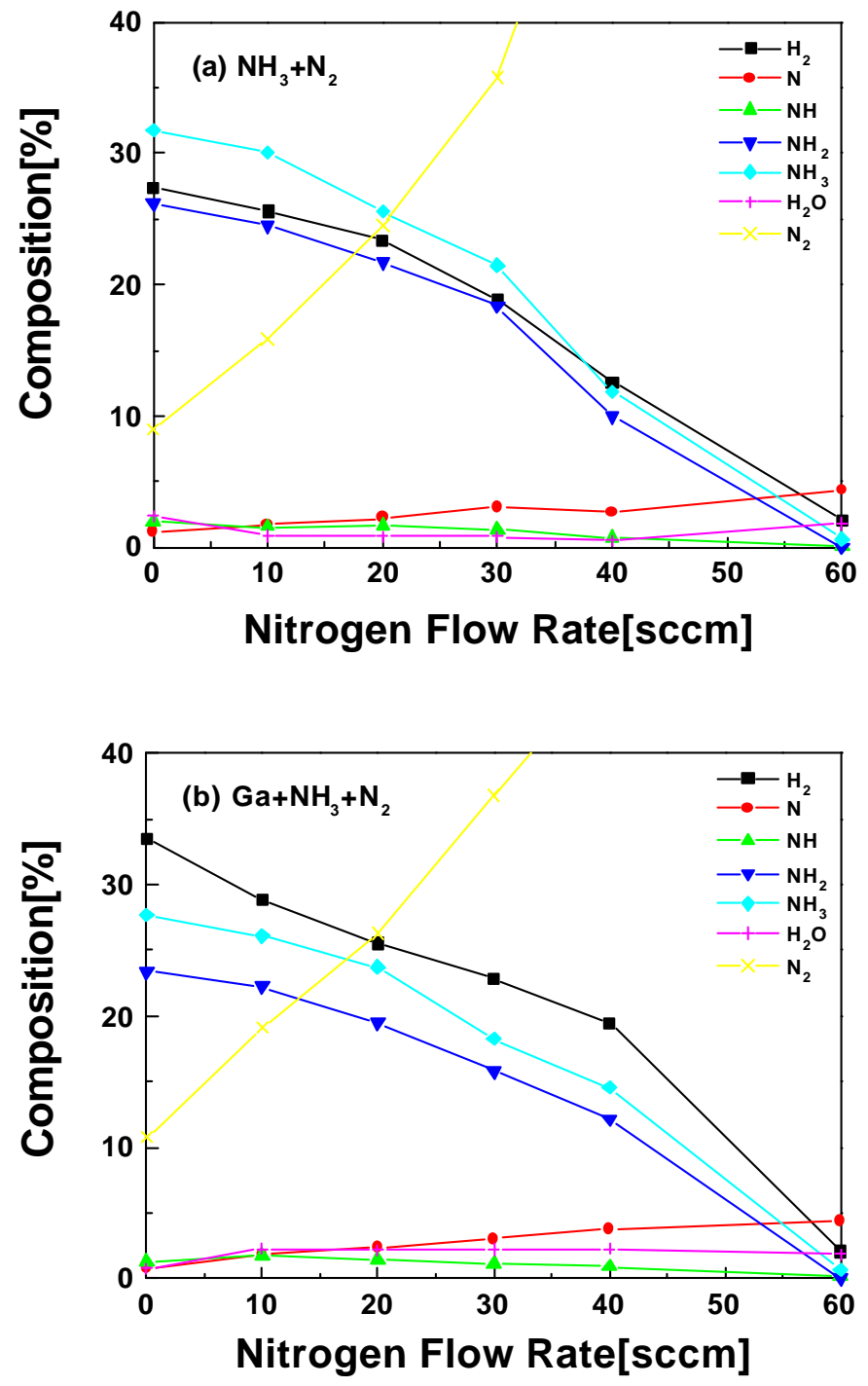

Figure 5.9 Composition of the gas in the growth reactor at $1130^{\circ} \mathrm{C}$ (a) without the $\mathrm{Ga}$ source and (b) with the Ga source in (60-x) $\mathrm{sccm} \mathrm{NH} \mathrm{N}_{3}+\mathrm{x} \operatorname{sccm~} \mathrm{N}_{2}$ gas mixture. 

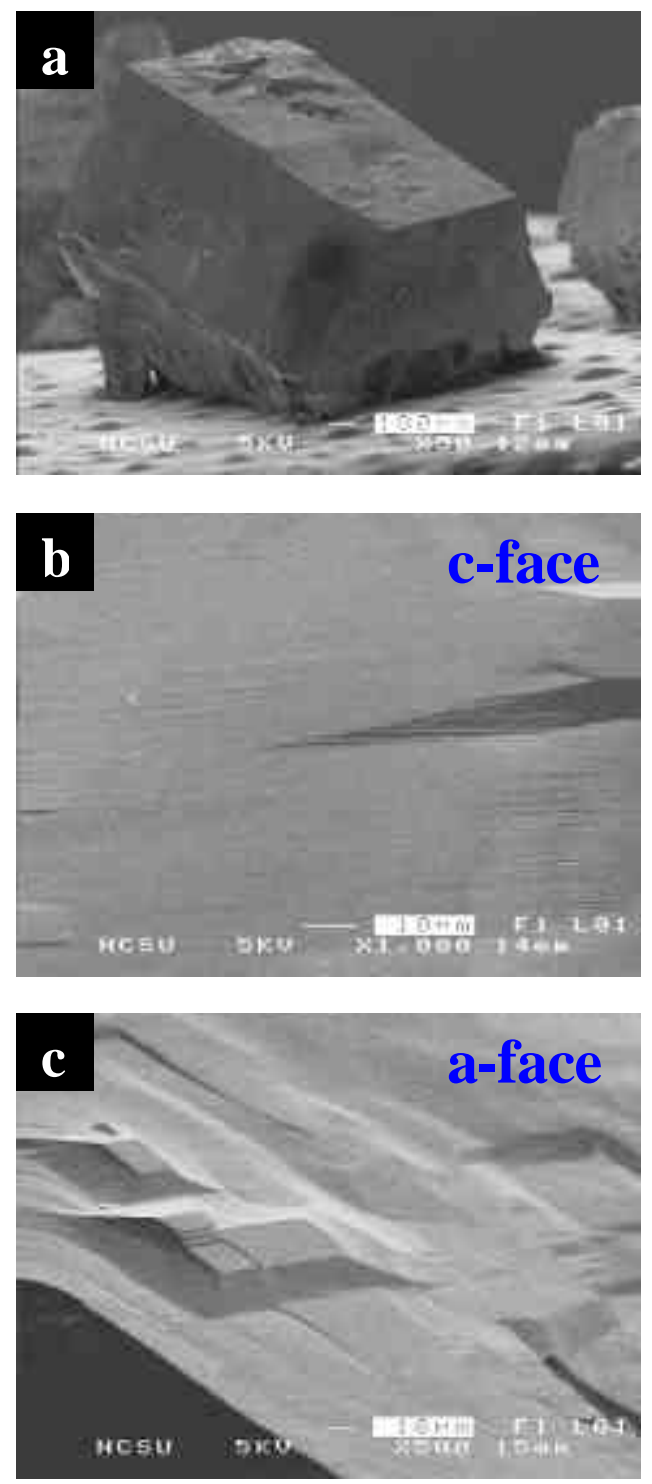

Figure 5.10 Prismatic GaN crystal seeded-grown at $1130^{\circ} \mathrm{C}$, 430Torr and 40sccm $\mathrm{NH}_{3}+20 \mathrm{sccm} \mathrm{N} \mathrm{N}_{2}$; (a) SEM micrograph of the crystal, (b) SEM surface morphology of the c-face (c) SEM surface morphology of the a-face. 


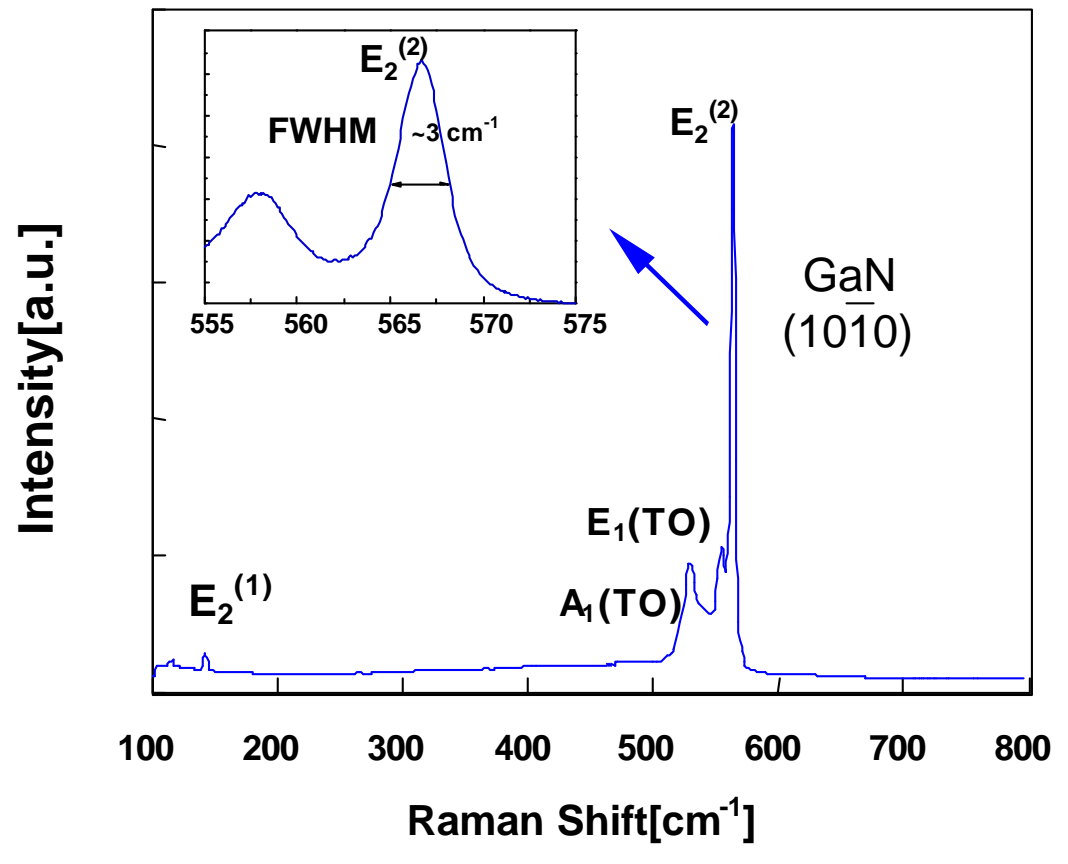

Figure 5.11 Raman spectrum of the GaN crystal seeded-grown in Fig. 5.10. Inset is a magnified view of the $\mathrm{E}_{2}{ }^{(2)}$ peak. 


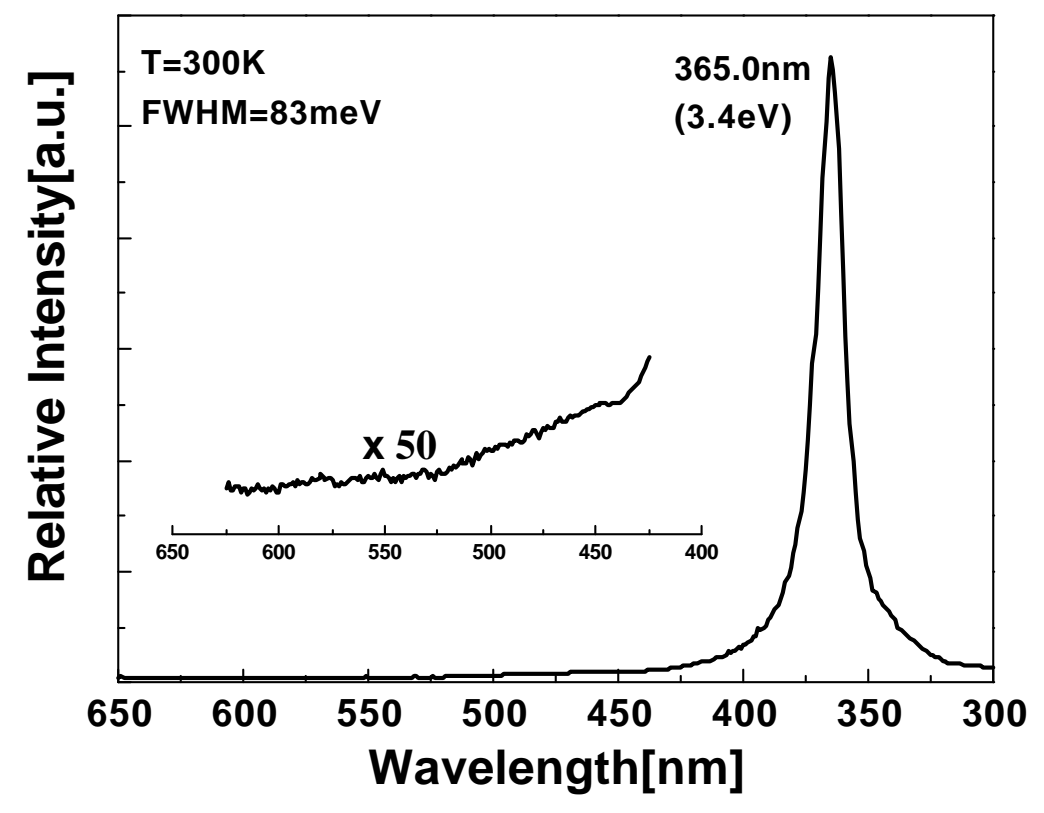

Figure 5.12 Photoluminescence spectrum of the bulk GaN crystal shown in Fig. 5.10(a). 


\section{Effect of Nitrogen Dilution on the Growth of Bulk GaN Crystals}

to be submitted to the Journal of Crystal Growth

by

H. Shin, D. B. Thomson, E. Preble, S. Wolter, R. Schlesser, Z. Sitar, and R. F. Davis

Department of Materials Science and Engineering,

North Carolina State University, Raleigh, NC, 27695-7907 


\subsection{Abstract}

The effect of nitrogen dilution of ammonia on $\mathrm{GaN}$ bulk growth has been investigated. Seeded growth in ammonia diluted with 33\%nitrogen resulted in a prismatic GaN crystal of $2 \mathrm{~mm} \times 1.5 \mathrm{~mm}$ and a platelet of $2.3 \mathrm{~mm} \times 1.8 \mathrm{~mm} \times 0.3 \mathrm{~mm}$ with minimal decomposition at $1130^{\circ} \mathrm{C}$, 430Torr. Platelet growth was favored as the nitrogen concentration was increased. The secondary nucleation on the growing surface observed in the growth with pure ammonia at high total pressures due to thermodynamic propensity of GaN formation and convection was reduced by growing crystals at a lower total pressure( 430 Torr) of a $67 \% \mathrm{NH}_{3}+33 \% \mathrm{~N}_{2}$ gas mixture. The AFM images of the cface of the platelet revealed the self-sustaining growth originated from screw dislocations with the step height of $5 \AA$. Excellent crystalline quality was confirmed by Raman spectroscopy (FWHM of $\mathrm{E}_{2}{ }^{(2)} \sim 3 \mathrm{~cm}^{-1}$ ) and Photoluminescence measurement. 


\subsection{Introduction}

Development of bulk GaN wafers is critical to the realization of laser diode based on III nitride. Unfortunately, many problems encountered in growth of bulk GaN have delayed the advent of GaN substrate: multiple nucleation, aspect ratio control, enhanced decomposition in hydrogen. High temperature nucleation technique[1] developed previously in our laboratory enabled us to grow larger seed crystals by reducing the number of nuclei during ramp-up. Seeded growth was conducted to grow larger crystals without secondary nucleation. The aspect ratio was successfully controlled by adjusting V/III ratio via ammonia flow rates and/or ammonia total pressures[1]. We also reported that enhanced decomposition of GaN crystals occurred at higher ammonia total pressures and nitrogen dilution suppressed the enhanced decomposition at high pressures[2]. The enhanced decomposition of $\mathrm{GaN}$ at higher pressures was attributed to the increased concentration of $\mathrm{H}_{2}$ at total pressures higher than $~ 475$ Torr and its subsequent etching of GaN. Decomposition of $\mathrm{GaN}$ at lower pressures may be attributed to thermodynamic instability and evaporation. Nitrogen dilution of ammonia may kinetically hinder the desorption of $\mathrm{Ga}$ or $\mathrm{N}$ on the surface and reduced the amount of hydrogen in the gas phase generated as a result of ammonia dissociation and then alleviated the enhanced decomposition of $\mathrm{GaN}$ crystals. It has been reported that the lateral growth rate in nitrogen ambient was enhanced remarkably in contrast with that in hydrogen ambient $[3,4]$. Therefore, one may expect a variation in crystal morphology upon nitrogen dilution. 
In this paper, we have applied the nitrogen dilution of ammonia to the growth of GaN bulk crystals. We report the effect of nitrogen dilution on the morphologies of the GaN crystal and surface. As a consequence of the suppressed decomposition upon nitrogen dilution, large crystals were grown by seeded growth in nitrogen-ammonia mixture. The crystal and surface morphologies were examined by scanning electron microscopy and atomic force microscopy(AFM), Raman spectroscopy and photoluminescence measurement were used to examine the crystal quality.

\subsection{Experimental Procedures}

Growth experiment was conducted in the dedicated system especially designed for bulk GaN crystal growth. The high temperature nucleation technique was used to form the seed crystals. The vertical growth rate was calculated by dividing the length of each crystal along the c-direction by the growth time; the lateral growth rate was calculated by dividing half of the width of each crystal along the a-direction by the growth time. Needles and platelets with smooth surface morphologies were selected for seeded growth that was conducted under the conditions of $1130^{\circ} \mathrm{C}, 430 \mathrm{Torr}$ and $60 \mathrm{sccm}$ of ammonia or an ammonia/nitrogen mixture. Nitrogen and ammonia gas was pre-mixed prior to entering the growth zone in the reactor. The total flow rate of ammonia was fixed at $60 \mathrm{sccm}$. The grown crystals were characterized using optical microscopy, scanning electron microscopy(SEM), and X-Ray diffraction(XRD). To measure the surface roughness, grown crystals were fixed on a carbon tape for AFM. Micro-Raman spectra of 
the GaN crystals were obtained at room temperature using a backscattering geometry from the $\{10 \overline{1} 0\}$ face and the $514.5 \mathrm{~nm}$ line of an Ar-ion laser. The spot size and the spectral resolution were $4 \mu \mathrm{m}$ and $1 \mathrm{~cm}^{-1}$, respectively. Photoluminescence (PL) measurements of the samples were made at room temperature using a $\mathrm{He}-\mathrm{Cd}$ laser $(\lambda=325 \mathrm{~nm})$ as the excitation energy source. The sample orientation in the PL system was such that the normal to the sample surface was aimed directly at the detection system entrance port and the laser incidence angle is $30^{\circ}$ from the sample surface normal.

\subsection{Results and Discussion}

Figure 6.1 shows $\mathrm{GaN}$ crystals nucleated and grown on $\mathrm{BN}$ substrate at $1130^{\circ} \mathrm{C}$ and 760Torr of different $\mathrm{NH}_{3}-\mathrm{N}_{2}$ mixtures. In pure $\mathrm{NH}_{3}$, long needles with welldeveloped (1010) faces were formed. As the nitrogen concentration increased by increasing the flow rate of nitrogen, lateral growth was promoted. This is a typical trend observed at 760Torr. At the total pressure of 430Torr, needle-shaped crystals were not observed for any nitrogen dilution used in this research. However, tendency of lateral growth was still observed as the nitrogen concentration increased. Aspect ratio was successfully controlled in our reactor and was found to be dependent on V/III ratio in the previous experiment. Previous results showed that low V/III ratio promoted lateral growth at this growth temperature. Since nitrogen molecules do not participate in the reaction with Ga vapor, dilution of ammonia with nitrogen decreases V/III ratio. In addition, formation of thin $\mathrm{GaN}$ crust over molten Ga source may be suppressed to a 
certain extent as the ammonia flow rate decreased[1]. As a consequence, nitrogen dilution tend to increase Ga flux and in turn decrease V/III ratio. Therefore, this is consistent with our previous work. It has been reported[3,4] that the lateral growth rate in nitrogen ambient was enhanced remarkably in contrast with that in hydrogen ambient. The mechanism has not yet been explained for this phenomenon.

The surface morphology became rougher as the nitrogen dilution increased. A similar observation was also made by other researchers [3,4] that a smooth surface was not obtained in nitrogen ambient, while a smooth and coalesced surface was obtained in hydrogen ambient. Tadatomo et al.[4] improved the surface morphology using hydrogennitrogen mixture(1:1) without sacrificing lateral growth rate significantly. Surface morphology is closely related $\mathbf{b}$ the local supersaturation of reactants over a surface. If there are excess amount of reactants and surface kinetics is not sufficiently fast to incorporate all of them into lowest energy sites on the surface, they tend to find another nucleation sites and form 3D growth features. Kobayashi et al.[5] found that $\mathrm{N}$ desorption from the $\mathrm{GaN}$ surface in $\mathrm{N}_{2}$ carrier gas was remarkably suppressed compared with that in $\mathrm{H}_{2}$. A stable $\mathrm{N}$-rich surface was formed at temperatures to $1030^{\circ} \mathrm{C}$ and the surface became Ga-rich above this temperature. The activation energy $(\sim 1.88 \mathrm{eV})$ of $\mathrm{N}$ desorption in $\mathrm{N}_{2}$ was found to be larger than that $(\sim 0.98 \mathrm{eV})$ in $\mathrm{H}_{2}$. This is possibly because $\mathrm{H}_{2}$ carrier gas may react with $\mathrm{N}$ atoms on the surface and enhance the $\mathrm{N}$ desorption by etching from the $\mathrm{GaN}$ surface, whereas the reaction may not occur in $\mathrm{N}_{2}$ carrier gas. Koleske et al.[6] reported that the desorption rate of Ga was larger than that of nitrogen at temperatures below $780^{\circ} \mathrm{C}$ but the situation became reversed at temperatures above $780^{\circ} \mathrm{C}$. Therefore, at the growth temperature of $1130^{\circ} \mathrm{C}$ in the current study the surface 
may become Ga-rich even in $\mathrm{NH}_{3}$ ambient due to preferential desorption of $\mathrm{N}$ and tend to be even more Ga-rich in nitrogen ambient due to lower incoming V/III flux ratio. In case of MBE based on activated $\mathrm{N}_{2}$, it has been clearly shown that Ga-rich conditions as close as possible to the stoichiometric point are necessary to obtain better structural quality GaN layers, since use of N-rich conditions usually results in faceting of the growth surface due to 3-D growth[7,8]. In contrast, if ammonia is employed as the source of reactive nitrogen, growth conditions that should be used, i.e. N-rich or Ga-rich conditions, to obtain better structural and optical quality material are less clear. Held et al[9] found that 3-D growth occurred under the N-rich conditions, while layer-by-layer growth took place under the Ga-rich conditions between the GaN decomposition and $\mathrm{Ga}$ accumulation limits. Grandjean et al.[10] found a contradicting result that a higher V/III ratio in the range from 1 to 4 resulted in smoother surface morphology. The reason for the difference between the two cases is not clear at present, but it might be related to the kinetics of the $\mathrm{NH}_{3}$ decomposition on the surface and the existence of $\mathrm{H}_{2}($ or $\mathrm{H})$ on the surface. In the current experiment, excess Ga caused rough surface morphology probably due to the lack of active nitrogen available for the reaction with $\mathrm{Ga}$ and in turn the reduced surface diffusion of $\mathrm{Ga}$ atoms. Figure 6.2 shows a $\mathrm{GaN}$ crystal grown in $20 \mathrm{sccmNH} 3+40 \mathrm{sccmN}_{2}$ gas mixture $\left(33 \% \mathrm{~N}_{2}\right.$ dilution). A magnified view of the crystal surface(Fig. 6.2(b)) indicated that lateral growth was favored under these growth conditions.

At the total pressure of 430Torr, regardless of nitrogen concentration $(<40 \mathrm{sccm})$, platelet-shaped crystals were formed. A prolonged growth without intentional seeding in pure $\mathrm{NH}_{3}$ resulted in poor crystal morphology due to secondary nucleation as shown in 
Fig. 6.3(a). Secondary nucleation occurred randomly at any part of the crystal for crystals grown in pure $\mathrm{NH}_{3}$ gas. However, for crystals seeded grown in $40 \mathrm{sccmNH} 3+20 \mathrm{sccmN} N_{2}$ gas mixture at 760Torr, secondary nucleation was observed only on the c-face of the crystal, forming a swirling pattern. This implies that supersaturation on the c-face was sufficiently high to cause additional nucleation, whereas the a-face remained free of secondary nucleation. This may be due to the accumulation of Ga adatoms on the c-face. The secondary nucleation problem encountered in the growth in pure ammonia due to thermodynamic propensity of $\mathrm{GaN}$ formation and in the growth at high pressures due to convection can be alleviated by growing crystals at lower total pressure of ammonianitrogen mixture. Therefore, seeded growth was conducted at 430Torr in an ammonianitrogen gas mixture.

To grow a larger crystal, seeded growth was conducted on both needles and platelets that were previously grown at $1130^{\circ} \mathrm{C}$ and carefully selected. Figure 6.4 (a) shows a $2 \mathrm{~mm} \times 1.5 \mathrm{~mm}$ prismatic $\mathrm{GaN}$ crystal, bound by well-developed (0001) and (1010) faces(confirmed by $\mathrm{X}$-ray diffraction), seeded grown at $1130^{\circ} \mathrm{C}, 430 \mathrm{Torr}$ in $40 \mathrm{sccm} \mathrm{NH}_{3}+20 \mathrm{sccm} \mathrm{N}_{2}$ gas mixture for 36hrs. Crystals grown under the same growth conditions in pure $\mathrm{NH}_{3}$ showed significantly decomposed surfaces after 10hrs of growth. However, crystals grown in $40 \mathrm{sccmNH}_{3}+20 \mathrm{sccmN}_{2}$ gas mixture exhibited smoother surface morphologies on both the a- and c-face as shown in Figs. 6.4(b) and 6.4(c). AFM images of the afface and the c-face of the crystal revealed that the a-face (RMS:0.9nm) was smoother than the c-face(RMS:2.6nm), as shown in Fig. 6.5(a) and 6.5(b). Raman spectroscopy showed only allowed modes for hexagonal $\mathrm{GaN}$ and the quality of the crystal was confirmed by the value of $\operatorname{FWHM}\left(\sim 3 \mathrm{~cm}^{-1}\right)$ of $\mathrm{E}_{2}(2)$ peak, as shown in Fig. 
6.6. A GaN platelet of $2.3 \mathrm{~mm} \times 1.8 \mathrm{~mm} \times 0.3 \mathrm{~mm}$ was also grown via seeded growth at $1130^{\circ} \mathrm{C}$, 430Torr in $40 \mathrm{sccmNH}_{3}+20 \mathrm{sccmN}_{2}$ gas mixture for $48 \mathrm{hrs}$ and is shown in Fig. 6.7(a). The surface of the GaN platelet after seeded growth was partly covered by small powder-like GaN particles in a swirling pattern, as can be seen in Fig. 6.7(b). This appears to be a post-growth feature that may have formed during cool-down, as the excess free $\mathrm{Ga}$ on the c-face reacts with ammonia at a lower temperature to form powerlike GaN that is weakly bonded to the surface. The smooth area of the c-face was examined by atomic force microscopy. The AFM images of the c-face revealed the selfsustaining growth aided by screw dislocations, as shown in Fig. 6.8. Each step possessed a height of $\sim 5 \AA$, which corresponds to one unit cell height of the GaN and average terrace width of $\sim 130 \mathrm{~nm}$. The RMS surface roughness was as small as $\sim 1.1 \mathrm{~nm}$. A Raman spectrum(Fig. 6.9) obtained from the c-face clearly shows hexagonal structure of GaN and the value of FWHM of $\mathrm{E}_{2}^{(2)}$ peak was found to be $3.2 \mathrm{~cm}^{-1}$. A room temperature PL spectrum of the crystal grown in ammonia-nitrogen mixture is shown in Fig. 6.10. Strong bound exciton emission with a FWHM of $83 \mathrm{meV}$ was observed at $365 \mathrm{~nm}(3.4 \mathrm{eV})$. No yellow luminescence was observed in the visible portion of the spectrum.

Both the needle and the platelet were grown at a growth rate of $\sim 15 \mu \mathrm{m} / \mathrm{hr}$ in the adirection and $\sim 5 \mu \mathrm{m} / \mathrm{hr}$ in the c-direction. The growth rates in nitrogen-ammonia mixture were slightly reduced as compared with that in pure ammonia, $25 \mu \mathrm{m} / \mathrm{hr}$ in a-direction and $\sim 10 \mu \mathrm{m} / \mathrm{hr}$ in c-direction, respectively. To reduce the amount of hydrogen, byproduct resulted from ammonia dissociation, the amount of ammonia was decreased upon nitrogen dilution. Therefore, the growth rate and the enhanced decomposition rate due to hydrogen must be compromised. Several growth runs under different total flow rates 
were attempted to increase the growth rate. At total flow rates higher than $75 \mathrm{sccm}$ secondary nucleation was observed during in situ monitoring through a long distance microscope. This can be attributed to a forced convection caused by the current growth crucible configuration. At lower ammonia flow rates $(<30 \mathrm{sccm})$ Ga droplets appeared intermittently during growth and hindered continuous growth of crystal. It is because there was not enough active nitrogen available on the growing surface. The appearance of Ga droplets must be avoided because they would exist throughout the growth run and alter the growth kinetics.

Nitrogen dilution of ammonia alleviated the enhanced decomposition problem due to hydrogen. Dilution of ammonia with other inert gases would exhibit a similar behavior observed in this study because $\mathrm{N}_{2}$ does not react with $\mathrm{Ga}$ or $\mathrm{GaN}$ surface under a typical vapor phase growth condition for GaN. To maximize the growth and minimize decomposition, growth parameters, i.e. growth temperature, total pressure, gas flow rate and gas composition, must be precisely controlled.

\subsection{Conclusions}

Effect of nitrogen of ammonia on the growth of bulk GaN has been investigated. Crystal morphology changed from needle to platelet as the nitrogen concentration was increased. The secondary nucleation problem encountered in the growth of GaN with pure ammonia at a high pressure( 760 Torr) due to the thermodynamic propensity of GaN formation and convection was alleviated by growing crystals at a lower total 
pressure( 430Torr) of ammonia-nitrogen mixture. A prismatic GaN crystal of $2 \mathrm{~mm} x$ $1.5 \mathrm{~mm}$ and a platelet of $2.3 \mathrm{~mm} \times 1.8 \mathrm{~mm} \times 0.3 \mathrm{~mm}$ were grown in $67 \% \mathrm{NH}_{3}+33 \% \mathrm{~N}_{2}$ gas mixture using seeded growth with minimal decomposition. The screw dislocation-aided growth mode was observed on the c-face of the $\mathrm{GaN}$ platelet using atomic force microscopy. The Excellent crystalline quality was confirmed by Raman spectroscopy (FWHM of $\mathrm{E}_{2}^{(2)} \sim 3 \mathrm{~cm}^{-1}$ ) and Photoluminescence measurement.

\subsection{Acknowledgements}

The authors acknowledge support of the Office of Naval Research under contract N00014-00-1-0192 (Colin Wood, monitor). 


\subsection{References}

1. H. Shin, D. Thomson, S. Wolter, R. Schlesser, Z. Sitar, and R. F. Davis, to be published in J. Cryst. Growth, (2001)

2. H. Shin, E. F. Arkun, D. Thomson, P. Miraglia, E. Preble, S. Wolter, R. Schlesser, Z. Sitar, and R. F. Davis, to be published in J. Cryst. Growth, (2001)

3. Y. Kawaguchi, S. Nambu, M. Yamaguchi, N. Sawaki, H. Miyake, K. Hiramatsu, K. Tsukamoto, N. Kuwano, and K. Oki, Phys. Stat. Sol. (a) 176, 561(1999)

4. K. Tadatomo, Y. Ohuchi, H. Okagawa, H. Itoh, H. Miyake, and K. Kiramatsu, MRS Internet J. Nitride Semicond. Res. 4S1, G3.1 (1999)

5. Y. Kobayashi and N. Kobayashi, J. Cryst. Growth, 189/190, 301(1998)

6. D. D. Koleske, A. E. Wickenden, R. L. Henry, W. J. Desisto, and R. J. Gorman, J. Appl. Phys., 84(4), 1998(1998)

7. L. T. Romano and T. H. Myers, Appl. Phys. Lett. 71, 3486 (1997)

8. R. J. Molnarand T. D. Moustakas, J. Appl. Phys., 76, 4587(1994)

9. R. Held,_ D. E. Crawford, A. M. Johnston, A. M. Dabiran and P. I. Cohen, Sur. Rev. and Lett., 5, 913(1998)

10. N. Grandjean, M. Leroux, J. Massies, M. Mesrine, and M. Laugt, J. J. Appl. Phys., 38, 618(1999) 

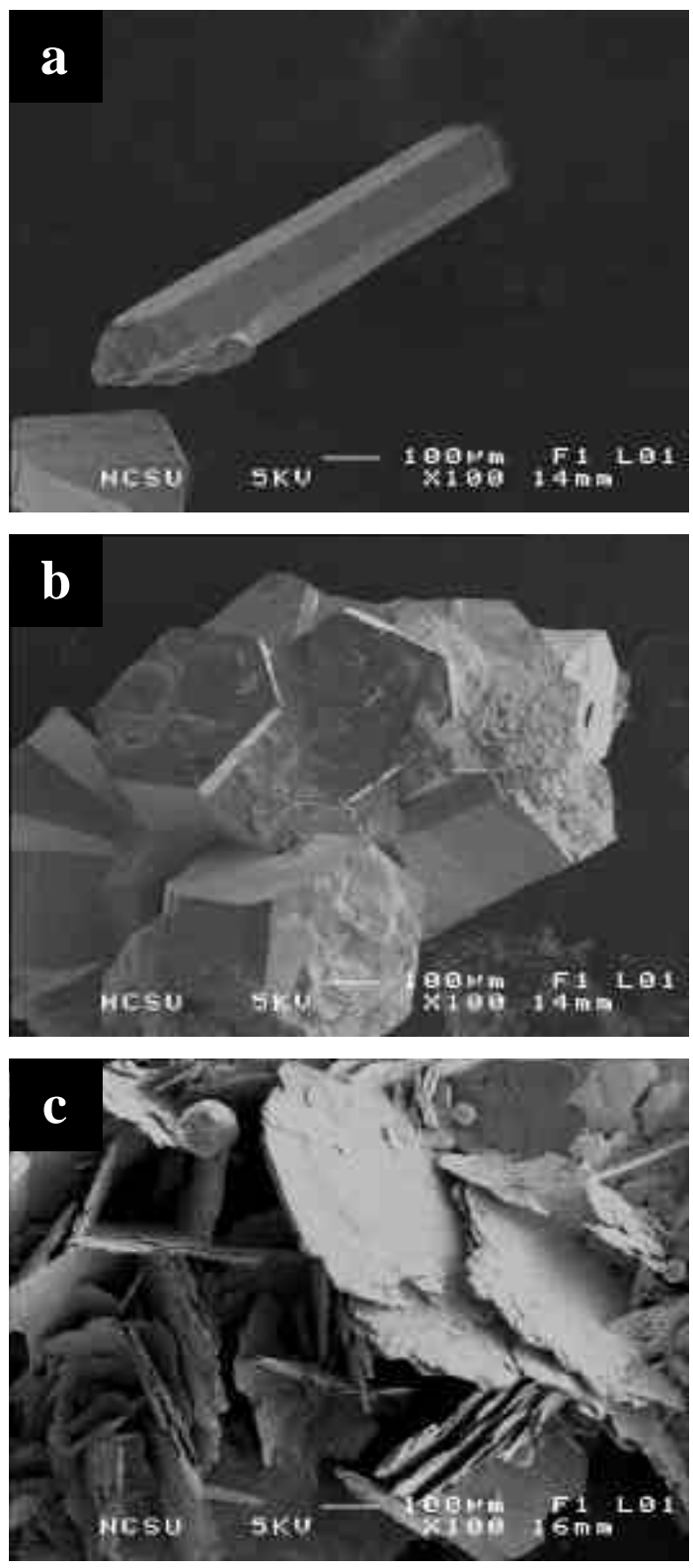

Figure 6.1 Effect of nitrogen dilution on the morphology of crystals grown for $4 \mathrm{hrs}$ at $1130^{\circ} \mathrm{C}$, 760Torr, (a) $60 \mathrm{sccm}$ of $\mathrm{NH}_{3}$, (b) $40 \mathrm{sccm}$ of $\mathrm{NH}_{3}+20 \mathrm{sccm}$ of $\mathrm{N}_{2}$ and (c) $20 \mathrm{sccm}$ of $\mathrm{NH}_{3}+40 \mathrm{sccm}$ of $\mathrm{N}_{2}$. 

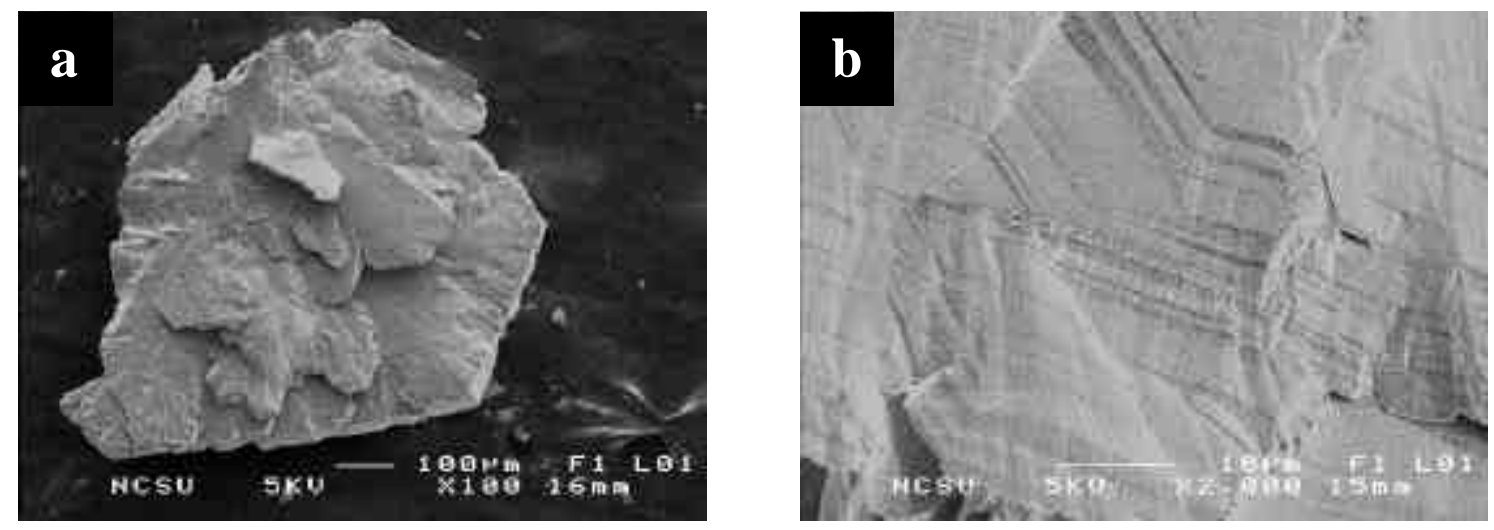

Figure 6.2 SEM micrographs of (a) a GaN platelet grown at $1130^{\circ} \mathrm{C}$ and $760 \mathrm{Torr}$ of $20 \mathrm{sccm} \mathrm{NH}+40 \mathrm{sccm} \mathrm{N} \mathrm{N}_{2}$ (b) a magnified view of the crystal surface.
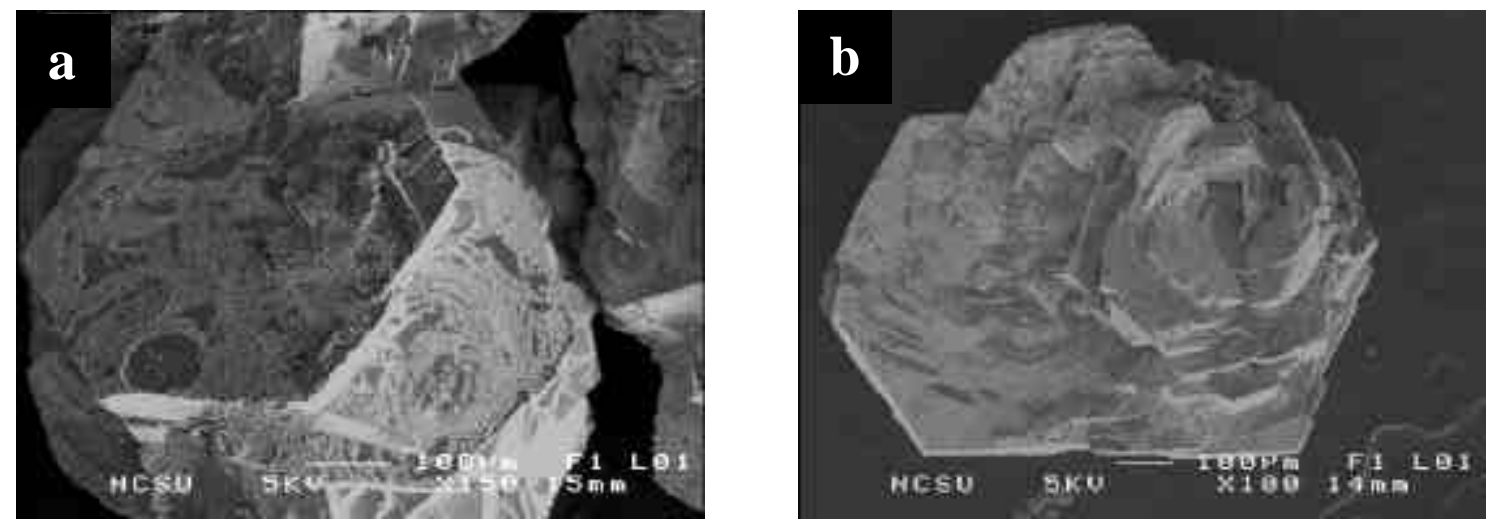

Figure 6.3 SEM micrographs of (a) GaN crystals grown at $1130^{\circ} \mathrm{C}$ and $430 \mathrm{Torr}$ of $60 \mathrm{sccm}$ of $\mathrm{NH}_{3}$ and (b) seeded growth on a seed platelet at $1130^{\circ} \mathrm{C}$ and 760Torr of $40 \mathrm{sccm} \mathrm{NH}_{3}+20 \mathrm{sccmN}_{2}$ for $8 \mathrm{hrs}$. 

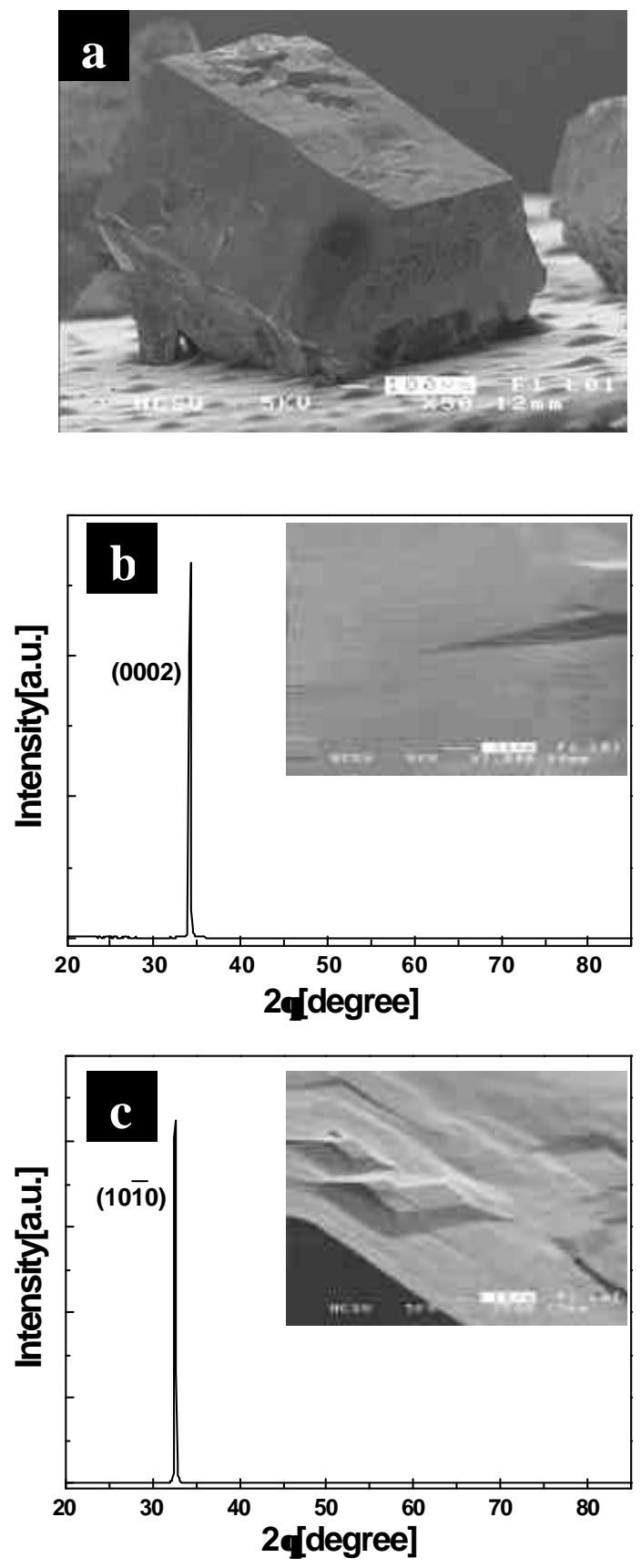

Figure 6.4 A GaN crystal seeded-grown at $1130^{\circ} \mathrm{C}$, 430Torr and 40sccm $\mathrm{NH}_{3}+20 \mathrm{sccm} \mathrm{N} \mathrm{N}_{2}$ ; (a) SEM micrograph, (b) XRD pattern and SEM surface morphology of the c-face, and (c) XRD pattern and SEM surface morphology of the a-face. 


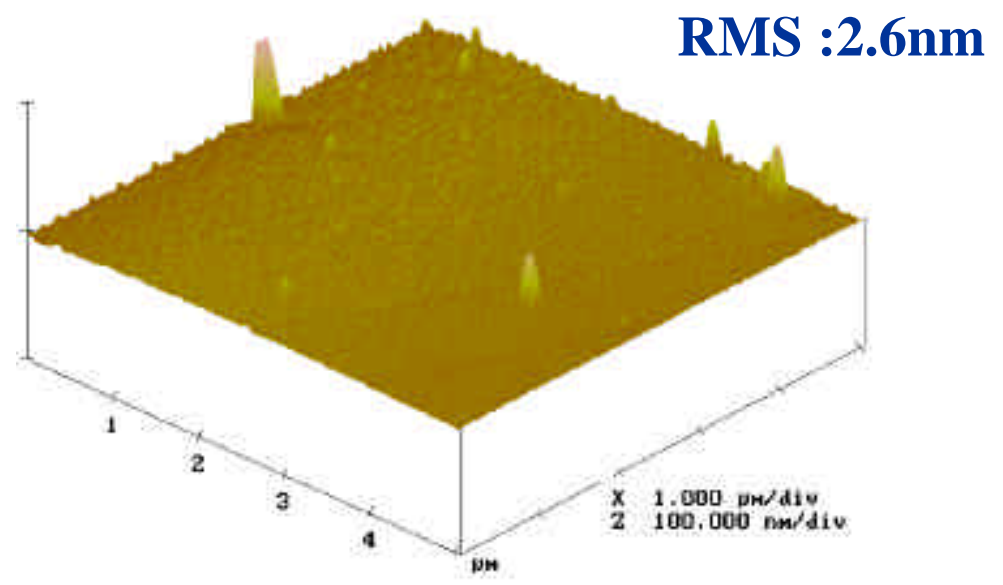

(a) c-face

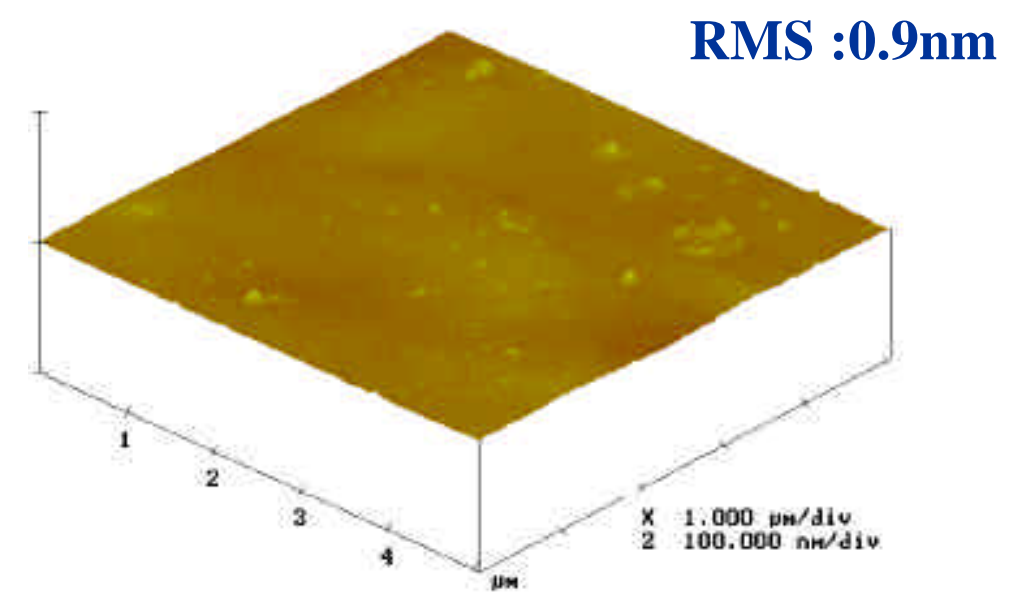

(b) a-face

Figure 6.5 AFM images of the smooth area of (a) the a-face and (b) the c-face of the prismatic $\mathrm{GaN}$ crystal seeded-grown at $1130^{\circ} \mathrm{C}, 430$ Torr and $40 \mathrm{sccm}$ $\mathrm{NH}_{3}+20 \mathrm{sccm} \mathrm{N}_{2}$ for $36 \mathrm{hrs}$. 


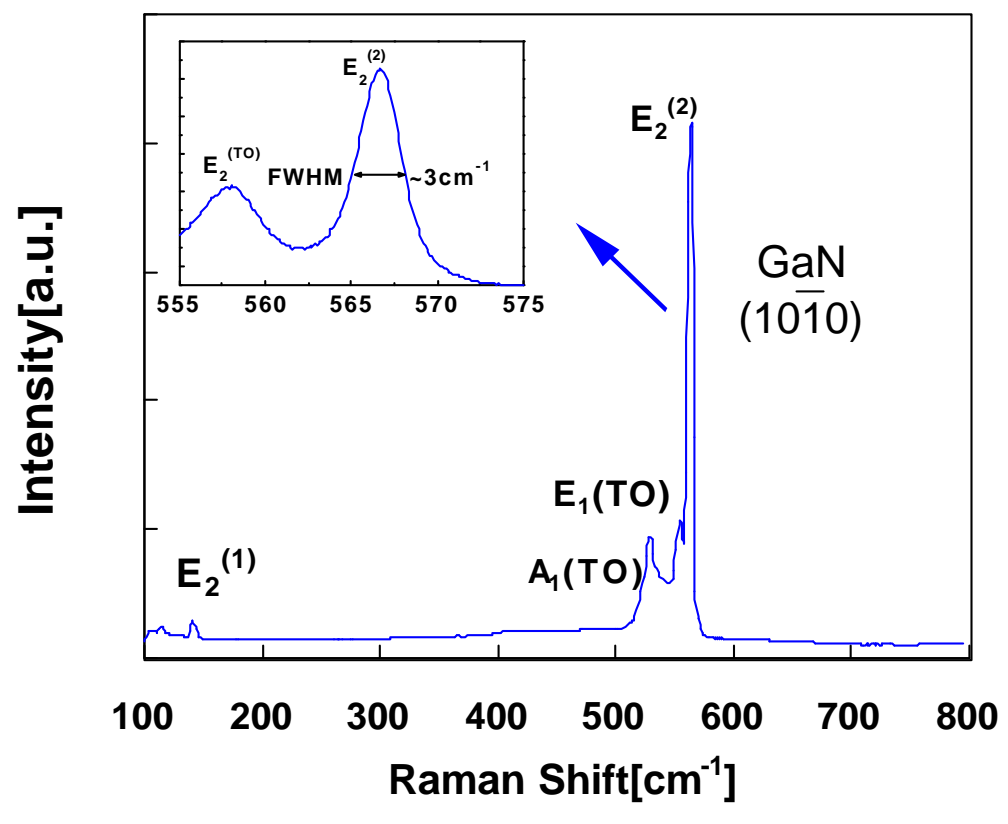

Figure 6.6 A Raman spectrum of the GaN crystal seeded-grown in Fig. 6.4. Inset is a magnified view of the $\mathrm{E}_{2}^{(2)}$ peak. 

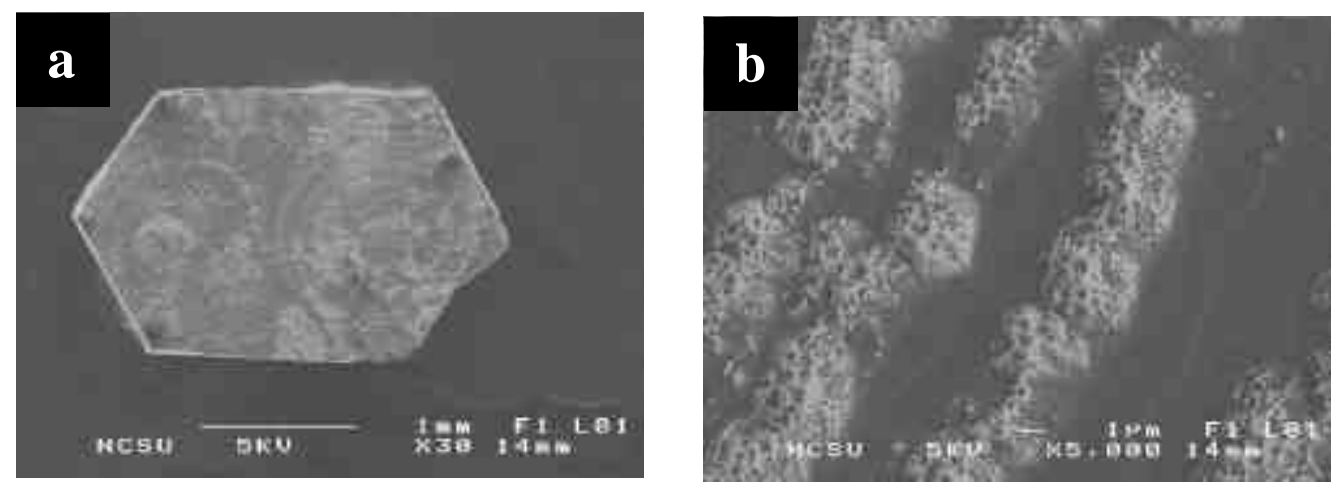

Figure 6.7 SEM micrographs of (a) a GaN platelet seeded-grown at $1130^{\circ} \mathrm{C}, 430 \mathrm{Torr}$ and $40 \mathrm{sccmNH}_{3}+20 \mathrm{sccmN}_{2}$ for $48 \mathrm{hrs}$ and (b) the surface morphology of the c-face.
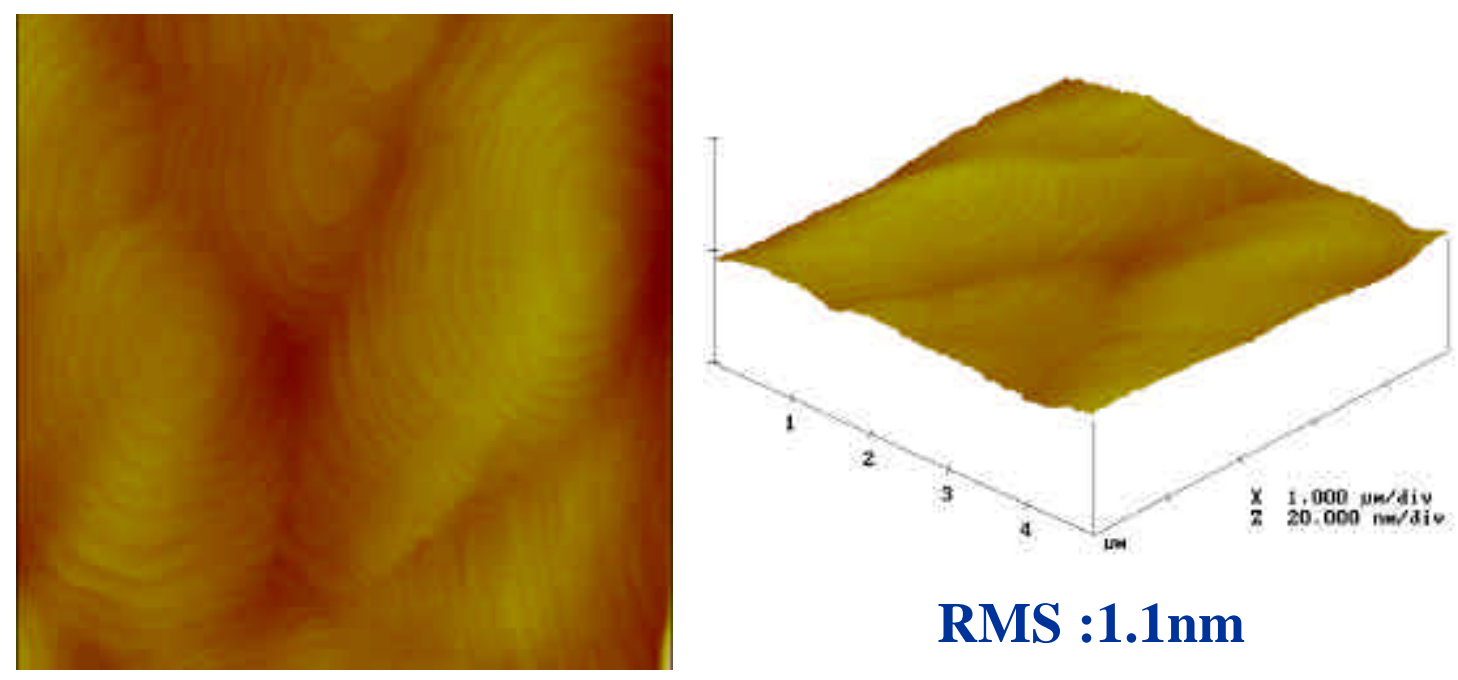

\section{RMS :1.1nm}

Figure 6.8 AFM images of the smooth area of the surface of the GaN platelet grown at $1130^{\circ} \mathrm{C}$, 430Torr and $40 \mathrm{sccm} \mathrm{NH}_{3}+20 \mathrm{sccm} \mathrm{N} \mathrm{N}_{2}$ for $48 \mathrm{hrs}$. 


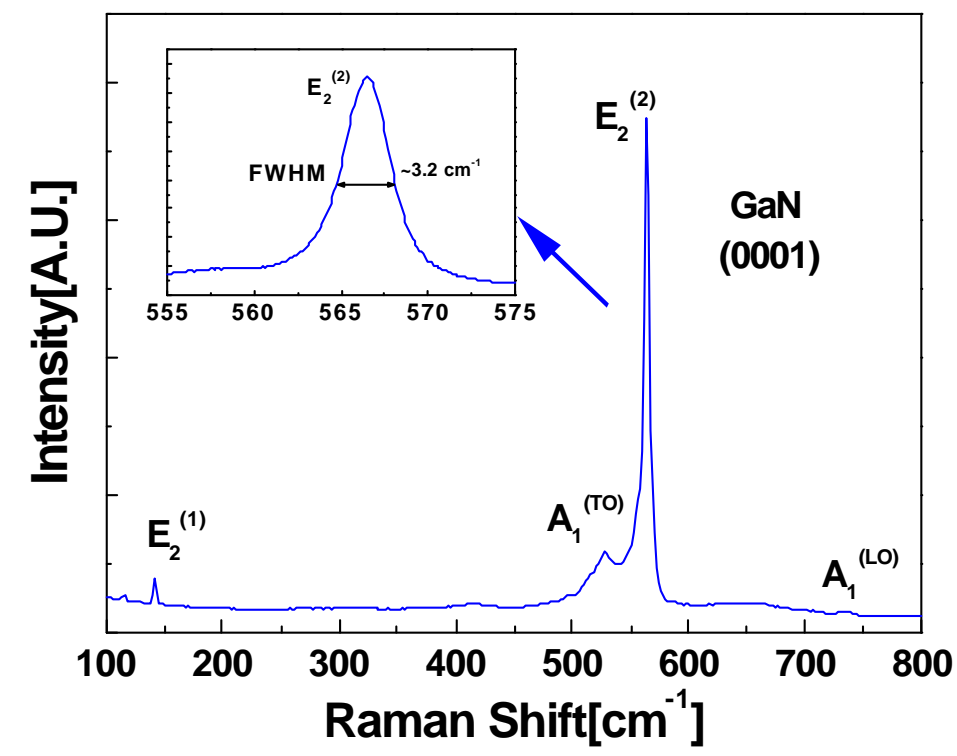

Figure 6.9 A Raman spectrum of the GaN crystal seeded-grown in Fig. 6.7. Inset is a magnified view of the $\mathrm{E}_{2}{ }^{(2)}$ peak.

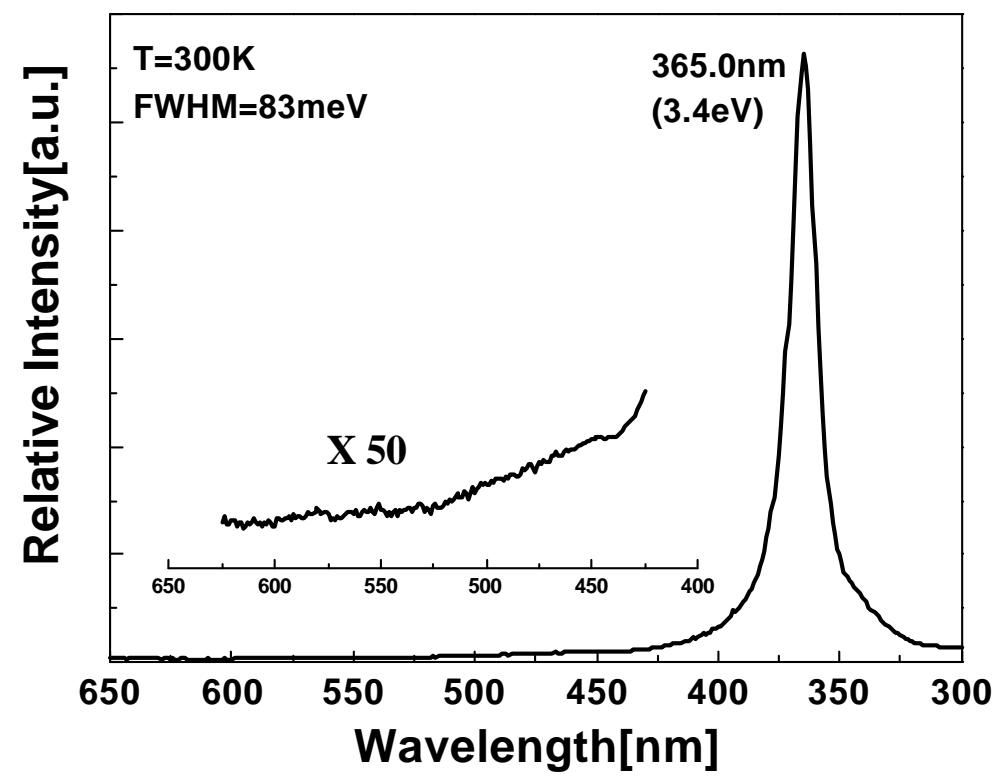

Figure 6.10 Photoluminescence spectrum of a bulk GaN crystal seeded grown at $1130^{\circ} \mathrm{C}$ in ammonia diluted with $33 \% \mathrm{~N}_{2}$. 
7. Effects of the Presence of Silicon on the Growth of GaN bulk

\author{
Crystals
}




\subsection{Introduction}

The surface morphologies of GaN films grown via MOVPE on AlN/sapphire (0001) substrates and undoped and donor doped with silicon within the carrier concentration range of $1.0 \times 10^{17}$ to $4.7 \times 10^{18} \mathrm{~cm}^{-3}$, as measured using Van der Pauw-Hall measurements, were investigated by Murakami et al.[1] The surfaces of GaN films with the carrier concentration to $1 \times 10^{18} \mathrm{~cm}^{-3}$ were typically smooth and mirror-like with no cracks or pits. However, increasing the carrier concentration via increasing the flow rate of $\mathrm{SiH}_{4}$ to $4.7 \times 10^{18} \mathrm{~cm}^{-3}$ resulted in the formation of $\mathrm{V}$-shaped grooves and cracks. These authors also reported[1] that the full width at half maxima (FWHM) of the X-ray diffraction rocking curves for the (0002) peaks of their Si-doped GaN films having a carrier concentration of $4.7 \times 10^{18} \mathrm{~cm}^{-3}$ were more than twice that of Si-doped GaN films with carrier concentrations less than $1 \times 10^{18} \mathrm{~cm}^{-3}$. By contrast, Nakamura et al.[2] reported that the surfaces of their Si-doped $\mathrm{GaN}$ films grown on sapphire(0001) substrates having a GaN buffer layer, and having a carrier concentration as high as $2 \mathrm{x}$ $10^{19} \mathrm{~cm}^{-3}$, were smooth and mirror-like and showed no cracks over the two-inch substrates. It is believed that the cause of this difference lies either in the growth method or the buffer layer employed by the different groups or that the values of the highest carrier concentration in the films grew by Nakamura and co-workers were incorrect, as their results have not been repoduced by any other investigators. The latter investigators also observed[2] a similar increase in the FWHM of the (0002) (4.2arcmin to 6.2arcmin) when the carrier concentration was increased from $3 \times 10^{17} \mathrm{~cm}^{-3}$ to $2 \times 10^{19} \mathrm{~cm}^{-3}$. An increase in the FWHM of the (0002) peaks of Si-doped $\mathrm{GaN}$ films on 
GaN/sapphire(0001) within the carrier concentration range of $4 \times 10^{17}$ to $1.6 \times 10^{19}$ was also reported by Lee et al.[3].These results indicate that $\mathrm{Si}$ doping in $\mathrm{GaN}$ epilayers induces additional stresses relative to those found in the undoped films. Doping with Si also apparently introduces additional defects, though these results have not been reported by all investigators, as described below.

Molina et al.[4] reported that the densities of dislocations and inverted domains at the free surface of their GaN layer decreased with Si doping, while the density of planar defects on the (0001) planes within the GaN layer followed the opposite trend. It was observed using TEM that the interaction of these planar defects with the vertically oriented edge $(b=1 / 3<11 \overline{2} 0>)$ or mixed $(b=1 / 3<11 \overline{2} 3>)$ dislocations contributed to the decrease in the number of the latter that reach the free surface of the GaN. Calleja et al.[5] also found a strong reduction in the density of threading dislocations for $\mathrm{Si}$ doping levels above $1 \times 10^{18} \mathrm{~cm}^{-3}$, by almost an order of magnitude as compared to undoped layers (from $6 \times 10^{9}$ to $8 \times 10^{8} \mathrm{~cm}^{-2}$ ). This dislocation density reduction is due to a particular orientation and size of the crystal subgrains, namely, by an increase of the out plane(tilt) subgrain misorientation, together with an increase in the density of planar defects. They also observed that the c-axis lattice parameter decreased as the Si-doping increased, indicating an enhancement of the biaxial tensile strain in the film. The strain increase was a consequence of a strong reduction in the density of dislocations reaching the free surface.

The large difference in the aplane lattice constants between GaN (3.19 ̊) and sapphire (4.76̊̊) induces a substantial tensile stress for GaN epitaxial films. Though the largest part of the this stress is relieved by generation of misfit dislocations, another and 
larger stress contribution comes from the difference in the thermal expansion coefficients between $\mathrm{GaN}\left(5.6 \times 10^{-6} / \mathrm{K}\right)$ and sapphire $\left(7.5 \times 10^{-6} / \mathrm{K}\right)$. As a consequence of the latter, a compressive biaxial stress remains in the GaN epilayers grown on sapphire. By contrast, Ruvimov et al.[6] demonstrated stress relaxation in the Si-doped GaN films grown on Aface $(11 \overline{2} 0)$ sapphire using a AlN buffer layer, suggesting that the relaxation mechanism of residual stress in the epitaxial layer correlates with the concentration of the impurities incorporated. A Si-doped GaN film with a carrier concentration of $3 \times 10^{18} \mathrm{~cm}^{-3}$ showed a reduction in the dislocation density near the GaN surface, from $5 \times 10^{9} \mathrm{~cm}^{-2}$ to $7 \times 10^{8} \mathrm{~cm}^{-}$ 2. While dislocations in undoped $\mathrm{GaN}$ formed small-angle boundaries, they were randomly distributed in the Si-doped layers. However, the density of micropipes at the top surface of GaN was higher in a Si-doped layer. Micropipes are usually associated with screw or mixed threading dislocations. In addition, the value of the FWHM of the xray rocking curves was smaller in a $\mathrm{Si}$-doped $\mathrm{GaN}$ layer (4.2arcmin) as compared with that of an undoped GaN layer (8.0arcmin). The Si-doped GaN layer had a smoother surface morphology than the undoped GaN layer. They also postulated that the Si mostly affects the dislocation structure during the initial $\mathrm{GaN}$ growth perhaps by changing the atom mobility and number of growth islands at the initial stage of the growth. Both undoped and Si-doped GaN layers were under compression but with higher stress in the undoped sample. Similar results were derived from the Raman spectra. The stress in the GaN was measured by use of the $\mathrm{E}_{2}$ phonon frequency mode. They found that the thermal stress was partly relaxed by the migration of threading dislocations leaving additional misfit dislocations in the basal plane. No cracking of the layer was observed. 
Romano et al.[7] observed a transition of the residual stress state from compressive to tensile in $\mathrm{GaN}$ films grown via MOVPE on $\mathrm{GaN} / \mathrm{sapphire(0001)}$ as the $\mathrm{Si}$ concentration increased. The transition of the stress state, as measured by XRD, Raman, and curvature, occurred at the Si atomic concentration, measured by SIMS, of $\sim 10^{19} \mathrm{~cm}^{-3}$ for $1 \mu \mathrm{m}$ films and $\sim 10^{18} \mathrm{~cm}^{-3}$ for $2 \mu \mathrm{m}$ films. This is because a thicker layer can relax the compressive stress via plastic deformation and a lower Si concentration was required to offset the residual compressive stress. Shmit et al[8] observed only a decrease in compressive stress in the $\mathrm{Si}$ atomic concentration range to $\sim 6 \times 10^{18} \mathrm{~cm}^{-3}$ in $2 \sim 4 \mu \mathrm{m} \mathrm{GaN}$ films grown on GaN/sapphire(0001) via MOCVD. This implies that the Si concentration that changes the stress state depends on various growth parameters. Due to the presence of this transition of stress, there are many conflicting data regarding the stress state induced by the presence of $\mathrm{Si}$. In a Si concentration range exhibiting a compressive stress state, the value of FWHM decreases and the residual stress decreases with $\mathrm{Si}$ concentration and vice-versa in a tensile stress region.

The stress in the GaN film was also analyzed using Raman spectroscopy as a local stress probe[9] and the $E_{2}$ phonon frequency which is not sensitive to the doping level of the GaN due to its transverse optical character. This frequency shifts to higher wave numbers in thin films with increasing biaxial compressive stress. The overall compressive stress in GaN films on sapphire increased as the $\mathrm{Si}$ concentration was raised from $8.6 \times 10^{16}$ to $1 \times 10^{19} \mathrm{~cm}^{-3}$ from $\sim 120 \mathrm{MPa}$ to $320 \mathrm{MPa}$. However, the residual stress in $\mathrm{GaN}$ grown on $\mathrm{SiC}$ was observed to be 660Mpa in tension.

On the other hand, decreasing $\mathrm{E}_{2}$ mode frequencies with increasing $\mathrm{Si}$-doping concentration in the range from $1.6 \times 10^{18} \mathrm{~cm}^{-3}$ to $1.6 \times 10^{19} \mathrm{~cm}^{-3}$ were also reported[10]. The 
$\mathrm{E}_{2}$ frequency finally reached the value of strain-free bulk $\left(\sim 567 \mathrm{~cm}^{-1}\right)$. The frequency shift verified the presence of biaxial compressive stress in the undoped films and its gradual relaxation with Si-doping level. The residual stress in the film was believed to be fully relaxed when electron concentration exceeded $\sim 2 \times 10^{19} \mathrm{~cm}^{-3}$. As the doping concentration increased, the Raman spectrum became broadened possibly due to increased lattice imperfections by $\mathrm{Si}$ incorporation and widely distributed strain along the growth direction. One possible interpretation was that the relaxation arises via Si-induced generation of misfit dislocations. These contradicting results imply that the initial stress state in the GaN film influences the resultant stress state upon Si doping.

Wang et al[11] employed a new processing step, where $\mathrm{SiH}_{4}$ and $\mathrm{NH}_{3}$ gases were introduced at a low temperature for $125 \mathrm{sec}$ before the growth of a low-temperature GaN buffer layer on sapphire to reduce the dislocation density. The value of FWHM of the rocking curve for the GaN layer subsequently grown at high temperature by this method was reduced from $285 \mathrm{arcsec}$ to $240 \mathrm{arcsec}$. They proposed that the appearance of nanometer-sized holes due to $\mathrm{Si}_{\mathrm{x}} \mathrm{N}_{\mathrm{y}}$ deposition both enhanced the lateral growth of the latter $\mathrm{GaN}$, and decreased the threading dislocation density.

In preliminary experiments in the present research, the growth of GaN crystals ceased after a certain growth time $(\sim 6 \mathrm{hrs})$ at $1130^{\circ} \mathrm{C}$, and poor surface morphologies resulted. This was attributed to enhanced decomposition via hydrogen etching. In an attempt to improve the surface morphology of $\mathrm{GaN}$ crystals grown for a longer growth times and to facilitate continuous growth, $\mathrm{Si}$ was chosen as a candidate catalyst in this regard due to its highly efficient incorporation in GaN[12] and its reported[6] effect concerning the reduction in the density of threading dislocations in this material. 
In the current research, the effect of the presence of $\mathrm{Si}$ in the growth environment on the growth character of bulk $\mathrm{GaN}$ has been investigated. Surface microstructures and crystal morphologies were examined using optical microscopy, SEM, and Raman spectroscopy.

\subsection{Experimental Procedures}

Growth of the GaN crystals was conducted via vapor phase transport in the dedicated growth reactor described in the previous Sections. A 3/8" x 3/8" piece of a $\mathrm{Si}(100)$ wafer was placed at the center of the $\mathrm{BN}$ sample platform/substrate for each run. The resulting crystals were characterized using optical microscopy, scanning electron microscopy(SEM) and Raman spectroscopy at room temperature. For the measurements of the micro-Raman scattering spectra, polarized light from the 514.5nm line of an Ar-ion laser was focused on the samples within a $4 \mu \mathrm{m}$ diameter. The polarization of the scattered light was not defined. A backscattering geometry was employed. The spectral resolution was set to $0.2 \mathrm{~cm}^{-1}$. X-ray photoelectron spectroscopy (XPS) measurements were also conducted on the crystals to assess the effect of introducing Si during the growth. Although XPS is a surface sensitive technique, it can offer insight regarding the chemical composition of the bulk material. The XPS spectra of the GaN crystals grown before the introduction of the $\mathrm{Si}$ wafer were compared to the analogous spectra of the crystals grown on the BN surface in the presence of the Si. No further processing was performed on the samples to avoid any accidental contamination. The XPS experiments 
were performed in a surface analysis chamber equipped with a VG Clam II semihemispherical electron spectrometer with a base pressure of $1 \times 10^{-10}$ Torr. The sample was placed on a Au- coated Mo sample holder. The Al anode was used to produce X-rays with energies of $1486.6 \mathrm{eV}$.

\section{3. $\quad$ Results \& Discussion}

Equilibrium vapor pressures of $\mathrm{Al}, \mathrm{Ga}$, and $\mathrm{Si}$ as a function of temperature are shown in Fig. 7.1[13]. The vapor pressure of $\mathrm{Si}$ at $1130^{\circ} \mathrm{C}$ is $\sim 3.45 \times 10^{-6}$ Torr, corresponding to an impingement rate $(\Phi)$ of $\sim 6.1 \times 10^{14} \mathrm{~cm}^{-2} \mathrm{~s}^{-1}$. The calculated $\mathrm{Si} / \mathrm{Ga}$ flux ratio at the substrate temperature of $1130^{\circ} \mathrm{C}$ is $\sim 1.6 \times 10^{-4}$, which would result in a $\mathrm{Si}$ atomic concentration of $\sim 7.7 \times 10^{18} \mathrm{~cm}^{-3}$ if the incorporation efficiencies were assumed to be unity for both $\mathrm{Ga}$ and Si. Grandjean et al.[14] achieved n-type doping of GaN films within the carrier concentration range from $2 \times 10^{17}$ to $4 \times 10^{18} \mathrm{~cm}^{-3}$ at $830^{\circ} \mathrm{C}$ via gas source MBE using a $\mathrm{Si}$ solid source and $\mathrm{NH}_{3}$ as a nitrogen source. Kim et al. [15] obtained a carrier concentration of $\sim 1 \times 10^{19} \mathrm{~cm}^{-3}$ using Si source temperatures between $997^{\circ} \mathrm{C}\left(p^{\mathrm{o}}{ }_{\mathrm{Si}} \sim 9.6 \times 10^{-8} \mathrm{Torr}\right)$ and $1097^{\circ} \mathrm{C}\left(p^{\circ}{ }_{\mathrm{Si}} \sim 1.6 \times 10^{-6} \mathrm{Torr}\right)$ for $\mathrm{GaN}$ films grown at $725^{\circ} \mathrm{C}$ via plasma-assisted MBE.

The gallium nitride crystals grown in the presence of Si were 10 20\% larger in volume as compared to those grown without $\mathrm{Si}$. No change in the crystal morphology was observed during growth of the former crystals in comparison to the morphology of the latter crystals grown in a Si-free environment. The color of the former crystals was 
darker amber than the latter. The change in color was not due to decomposition, since lighter shades of the same color were observed in crystals grown at lower temperatures $\left(\sim 1010^{\circ} \mathrm{C}\right)$ where decomposition was minimal. One distinct difference between the growths in the different environments was the nucleation density of the GaN crystals on the BN substrate. The total number of crystals was reduced in the Si-containing environment. No nucleation was observed within $\sim 1 \mathrm{~cm}$ of the Si wafer. The number of crystals increased as a function of the distance from the perimeter of the crystal-free zone.

In situ monitoring with a long distance microscope revealed that the growth rate was initially faster in the presence of $\mathrm{Si}$; however, the rate decreased gradually and remained mearly constant $\sim 30 \mathrm{~min}$ after this initial period. This may be due to a feature of the high temperature nucleation process, where the substrate temperature was initially raised to $1260^{\circ} \mathrm{C}$ in a nitrogen ambient. This would give rise to a higher Si concentration in the vapor $\left(p_{\mathrm{Si}}^{\mathrm{o}} \sim 6.7 \times 10^{-5}\right.$ Torr, $\Phi \sim 1.1 \times 10^{16} \mathrm{~cm}^{-2} \mathrm{~s}^{-1}$ at $\left.1260^{\circ} \mathrm{C}\right)$ during this early growth period. Therefore, the higher initial growth rate and the darker color can be attributed to the higher $\mathrm{Si}$ vapor concentration; the growth rate was reduced as (1) the $\mathrm{Si}$ vapor pressure decreased with decreasing the substrate temperature to $1130^{\circ} \mathrm{C}$ and (2) a thin $\mathrm{Si}_{\mathrm{x}} \mathrm{N}_{\mathrm{y}}$ layer formed on the $\mathrm{Si}$ surface upon the introduction of ammonia. Mula et al.[12] also observed upon Si doping an increase in the growth rate of GaN films grown on GaN/sapphire(0001) buffer layer/substrates via plasma-assisted MBE in the nitrogensaturated region. The increase in the growth rate was attributed to an increased residence time of the $\mathrm{N}$ atoms on the surface that facilitated their incorporation via the formation of GaN. 
Plate-like crystals were observed intermittently in the research of this thesis under growth conditions that otherwise would form needle-like crystals without the presence of Si. The reason for this is unclear at this time. It may be, as noted above, that $\mathrm{Si}$ forms an alloy with $\mathrm{Ga}$ that increases the residence time of $\mathrm{Ga}$ on the growing crystal or that $\mathrm{Si}$ promotes lateral growth in a manner similar to that of $\operatorname{Mg}[16,17]$. It is worth noting that a higher Ga flux promoted lateral growth of $\mathrm{GaN}$ in this research, as described in Chapter 4 of this thesis.

The surface morphologies on both the a- and the c- faces of the GaN crystals grown at $1130^{\circ} \mathrm{C}$ for $10 \mathrm{hrs}$ without the presence of $\mathrm{Si}$ revealed significant decomposition, and white crystals resulted due to hydrogen etching, as described in Chapter 5 of this thesis. The GaN crystals grown in the presence of $\mathrm{Si}$ at $1130^{\circ} \mathrm{C}$ for $10 \mathrm{hrs}$ showed a rough surface morphology on the a-face, as shown in Figs. 7.2(a) and 7.2(b) but a rather smoother surface morphology on the c-face(Fig. 7.2(c)). The decomposition of both faces was reduced as compared with that of GaN crystals grown without the presence of Si.

As the growth temperature was increased to $1170^{\circ} \mathrm{C}$, the a-and the c-faces of the crystals became smoother and rougher, respectively, as shown in Figs. 7.2(d), (e) and (f). However, the rough surface morphology of the c-face was not a consequence of decomposition but rather a three-dimensional growth feature. At this higher temperature, it was expected that more Si would be incorporated into the GaN crystals because of a higher vapor pressure of this element at $1170^{\circ} \mathrm{C}\left(p^{\circ}{ }_{\mathrm{Si}} \sim 9.1 \times 10^{-6} \mathrm{Torr}, \Phi \sim 1.6 \times 10^{15} \mathrm{~cm}^{-2} \mathrm{~s}^{-1}\right)$ than $1130^{\circ} \mathrm{C}\left(p_{\mathrm{Si}}^{\mathrm{o}} \sim 3.45 \times 10^{-6} \mathrm{Torr}, \Phi \sim 6.1 \times 10^{14} \mathrm{~cm}^{-2} \mathrm{~s}^{-1}\right)$. The crystals grown without the presence of $\mathrm{Si}$ at $1170^{\circ} \mathrm{C}$ possessed a poor surface morphology as a result of significant decomposition, because this growth temperature was significantly close to the 
thermodynamic limit after which crystals completely decomposed. In addition, the etching rate of $\mathrm{GaN}$ in hydrogen was very likely accelerated at the higher temperature. The presence of $\mathrm{Si}$ on the GaN surface may increase the residence time of nitrogen and consequently decelerate the decomposition rate. Guha et al.[18] reported that GaN epilayers grown on $\mathrm{GaN} /$ sapphire at higher temperatures $\left(\sim 860^{\circ} \mathrm{C}\right)$ via plasma-assisted MBE possessed a porous columnar structure due to preferential thermal etching at defect sites on the surface and the porous columnar structure was eliminated upon $\mathrm{Si}$ or $\mathrm{Mg}$ doping. They speculated that the addition of $\mathrm{Mg}$ or $\mathrm{Si}$ passivated the surface and suppresses surface evaporation: possibly by contributing to surface bond strengthening or by increasing the barrier to evaporation. Therefore, the improvement in the surface morphologies of the crystals in the present research may be attributed to incorporation of Si.

Figure 7.3 shows typical Raman spectra on the different faces of a typical crystal grown in the presence of Si. Different relative intensities among $\mathrm{A}_{1}(\mathrm{TO}), \mathrm{E}_{1}(\mathrm{TO})$ and $E_{2}(2)$ were observed for the different faces. Similar observations have been reported[10, $11,14]$ for the different planes of the GaN thin films. These optical signatures are a very useful tool for the identification of different planes of a GaN crystal and, in turn, provide useful information regarding the growth mechanism. The GaN crystals grown in the presence of Si consisted of wide and narrow (10 $\overline{1} 0$ ) faces, as shown in Fig. 7.3. The GaN crystals bound by the $(10 \overline{1} 0)$ planes were elongated in the $\langle 11 \overline{2} 0\rangle$ direction. Though the $(11 \overline{2} 0)$ planes were not observed, these results indicated that growth in these $\langle 11 \overline{2} 0\rangle$ directions was slightly faster than in the $\langle 10 \overline{1} 0\rangle$ directions. 
The lateral growth rate of LEO-GaN has been reported by Nam et al.[19-21] to be affected by the stripe direction, growth temperature and the flow rate of the Group III reactant. These investigators observed $(1 \overline{1} 01)$ and $(11 \overline{2} 0)$ facets on the $\langle 11 \overline{2} 0\rangle$ oriented stripe pattern as well as $(1 \overline{101})$ facets on the $\langle 1 \overline{1} 00>$-oriented strip pattern. Higher lateral growth rates was observed on the $\langle 1 \overline{1} 00\rangle$ strip pattern, and the $(1 \overline{101})$ facets disappeared at higher temperatures. An increase in the supply of TEG enhanced the lateral growth as compared with the vertical growth.

Beaumont et al.[16,17] reported that the addition of $\mathrm{Mg}$ during metallorganic chemical vapor deposition(MOCVD) growth enhanced the lateral growth rate and improved the structural quality by reducing the defect density. Whether the addition of Si promotes the growth in $\langle 11 \overline{2} 0>$ is unclear.

Raman spectra indicated that there was no significant shift in the peak positions, as shown in Fig. 7.4. This is probably because free-standing GaN crystals grown by spontaneous nucleation on $\mathrm{BN}$ in this research are almost strain-free. The values of the FWHM of the $\mathrm{E}_{2}(2)$ peaks were not significantly different from that of pure GaN. X-ray photoelectron spectroscopy was conducted on the BN surface and the GaN crystals grown in the presence of Si to determine whether or not the reduction of the nucleation density on the $\mathrm{BN}$ substrate, as described above, was due to the formation of $\mathrm{Si}_{\mathrm{x}} \mathrm{N}_{\mathrm{y}}$. Figure 7.5(a) shows an XPS survey scan from $1200 \mathrm{eV}$ to $0 \mathrm{eV}$ in binding energy obtained from the GaN crystals grown without the presence of Si. The peaks corresponding to $\mathrm{Ga}$ and $\mathrm{N}$, along with the peaks corresponding to $\mathrm{Au}$ and the usual ambient components are shown. A closer examination of the $\mathrm{N}$ peak in Fig. 7.5(b) reveals the presence of three peaks. One of these peaks corresponds to ambient nitrogen, the second one is shifted 
towards lower binding energies. This shift corresponds to the expected shift for nitrogen bonded in a nitride, as in GaN. A third, smaller peak corresponds to the Ga LMM Auger transition. A third scan shown in Fig. 7.5(c) was performed in the energy range expected for $\mathrm{Si}$. It shows that no $\mathrm{Si}$ was present on the sample.

A sample grown using the same process conditions as the previous sample but with the introduction of a piece of silicon was examined. A number of small GaN crystals were attached to the sample holder using a silver paste and found to show the same spectra as described above, as show in Fig. 7.6. Therefore, Si was not detected on the surface of $\mathrm{GaN}$ crystals grown in the presence of $\mathrm{Si}$ within the sensitivity ( 1at\%) of XPS. A section of the BN surface where nucleation did not occur was also examined. Figure 7.7(a) shows an XPS survey scan from $1200 \mathrm{eV}$ to $0 \mathrm{eV}$ in binding energy performed on this sample. The peaks corresponding to Ga, N, B, Si and Au along with the ambient components are present. A closer examination of the $\mathrm{N}$ peak (Fig. 7.7(b)) shows a shift of around $6 \mathrm{eV}$ towards higher binding energies. This shift is also present in the B peak, indicating electrostatic charging of the sample. This sample was expected to acquire an electrostatic charge during photoemission, since the BN "substrate" is insulating. Thus, all the peaks present in the spectra are shifted by the same amount. Taking this into account, a closer examination of the Si peak(Fig. 7.7(c)) shows an additional shift to higher energies of $\sim 1.5 \mathrm{eV}$. This is characteristic of the energy corresponding to the $\mathrm{Si} 2 \mathrm{p}$ peak in $\mathrm{Si}_{\mathrm{x}} \mathrm{N}_{\mathrm{y}}$. The presence of $\mathrm{Si}_{\mathrm{x}} \mathrm{N}_{\mathrm{y}}$ on the surface would indicate that the $\mathrm{Si}$ introduced in the growth process reacted with the $\mathrm{N}$ to form at least a crust of the chemically stable $\mathrm{Si}_{\mathrm{x}} \mathrm{N}_{\mathrm{y}}$. Therefore, the reduction in nucleation density in the early stage of the growth of the GaN crystals in the presence of Si is likely due to the 
formation of a $\mathrm{Si}_{\mathrm{x}} \mathrm{N}_{\mathrm{y}}$ layer on the $\mathrm{BN}$ substrate. Silicon nitride is used as a mask material in lateral epitaxial overgrowth. Therefore, a $\mathrm{Si}_{\mathrm{x}} \mathrm{N}_{\mathrm{y}}$ coating of the inner wall of a mold, where a GaN crystal nucleates, would render the formation of shaped crystals.

\subsection{Conclusions}

Nucleation of GaN was prevented in the proximity of the Si pieces, possibly due to the formation of $\mathrm{Si}_{\mathrm{x}} \mathrm{N}_{\mathrm{y}}$ on the $\mathrm{BN}$ surface. The presence of $\mathrm{Si}$ resulted in growth of larger crystals as compared with those grown without the presence of Si. The surface morphology of the a-face of the $\mathrm{GaN}$ crystals grown in the presence of $\mathrm{Si}$ was significantly improved relative to that of $\mathrm{GaN}$ grown without the presence of $\mathrm{Si}$ at the growth temperature of $1170^{\circ} \mathrm{C}$, while three-dimensional growth was observed on the cface. Decomposition of $\mathrm{GaN}$ at higher growth temperatures $\left(>1130^{\circ} \mathrm{C}\right)$ was suppressed in the presence of Si possibly due to the increased residence time of nitrogen on the growing surface. The needle-shaped GaN crystals bound by the $\{10 \overline{1} 0\}$ and $\{0001\}$ faces and elongated in the $\langle 11 \overline{2} 0>$ direction were observed with the addition of $\mathrm{Si}$, indicating the presence of Si promoted the growth in this direction. Raman spectroscopy revealed that all the GaN crystals grown in the presence of Si were nearly strain free. 


\subsection{References}

1. H. Murakami, T. Asahi, H. Amano, K. Hiramatsu, N. Sawaki, and I. Akasaki, J. Cryst. Growth. 115, 648(1991)

2. S. Nakamura, G. Fasol, “The Blue Laser Diode”, Springer, New York, p95 (1997)

3. I. H. Lee, I. H. Choi, C. R. Lee and S. K. Noh, Appl. Phys. Lett., 71(10), 1359(1997)

4. S. I. Molina, A. M. Sanchez, F. J. Pacheco, and R. Garcia, Appl. Phys. Lett., 74(22), 3362(1999)

5. E. Calleja, M.A. SaHnchez-GarcmHa, F.J. SaHnchez, F. Calle, F.B. Naranjo, J. of Cryst. Growth, 201/202, 296(1999)

6. S. Ruvimov, Z. Liliental-Weber, T. Suski, J. Ager III, and J. Washburn, Appl. Phys. Lett., 69(7), 990(1996)

7. L.T. Romano, C. G. Van de Walle, B. S. Krusor, R. Lau, J. Ho, T. Schmidt, J. W. Ager, W. Gotx, R. S. Kern, Physica B, 273/274, 50(1999)

8. N. M. Shmidt, A. V. Lebedev, W. V. Lundin, B. V. Pushnyi, V. V. Ratnikov, T. V. Shubina, B. Monemar, Materials Science and Engineering, B59, 195(1999)

9. J. W. Ager, T. Suski, S. Ruvimov, J. Krueger, G. Conti, E. R. Weber, M. D. Bremser, R. F. Davis, and C. P. Kuo, Mat. Res. Soc. Symp. Proc. Vol. 449, 775 (1997)

10. I. Lee, I. Choi, C. Lee, E. Shin, D. Kim, and S. Noh, J. Appl. Phys., 83(11), $5787(1998)$

11. T. Wang, Y. Morishima, N. Naoi, S. Sakai, J. Cryst. Growth, 213, 188(2000) 
12. G. Mula, B. Daudin, C. Adelmann, and P. Peyla, MRS Internet J. Nitride Semicon, Res., 3.35(1999)

13. A. Roth, "Vacuum Technology, North-Holland, Amsterdam (1976)

14. N. Grandjean, J. Massies, and M. Leoux, Mat. Res. Soc. Symp. Proc. Vol. 482, $211(1998)$

15. Y. Kim, R. Klockenbrink, C. Kisielowski, J. Krueger, D. Corlatan, G. S. Sudhir, Y. Peyrot, Y. cho, M. Rubin, and E. R. Weber, Mat. Res. Soc. Symp. Proc. Vol. 482, 217 (1998)

16. B. Beaumont, M. Valle, G. Nataf, A. Bouille, J. C. Guillaume, P. Vennehues, S. Haffouz, and P. Gibart, MRS Internet J. Nitride Semicon, Res., 3.20(1998)

17. B. Beaumont, S. Haffouz, and P. Gibart, Appl. Phys. Lett., 72, 921(1998)

18. S. Guha, N. A. Bojarczuk, and D. W. Kisker, Appl. Phys. Lett., 69(19) 2879(1996)

19. J. A. Freitas, O. H. Nam, T. S. Zheleva, and R. F. Davis, J. Cryst. Growth, 189/190, 92(1998)

20. O. H. Nam, T. S. Zheleva, M.D. Bremser, D. B. Thomson, and R. F. Davis, Mat. Res. Soc. Symp. Proc., Vol 482, 301(1998)

21. O. H. Nam, T. S. Zheleva, M.D. Bremser, D. B. Thomson, and R. F. Davis, J. Electron. Mater., 27, 233(1998) 


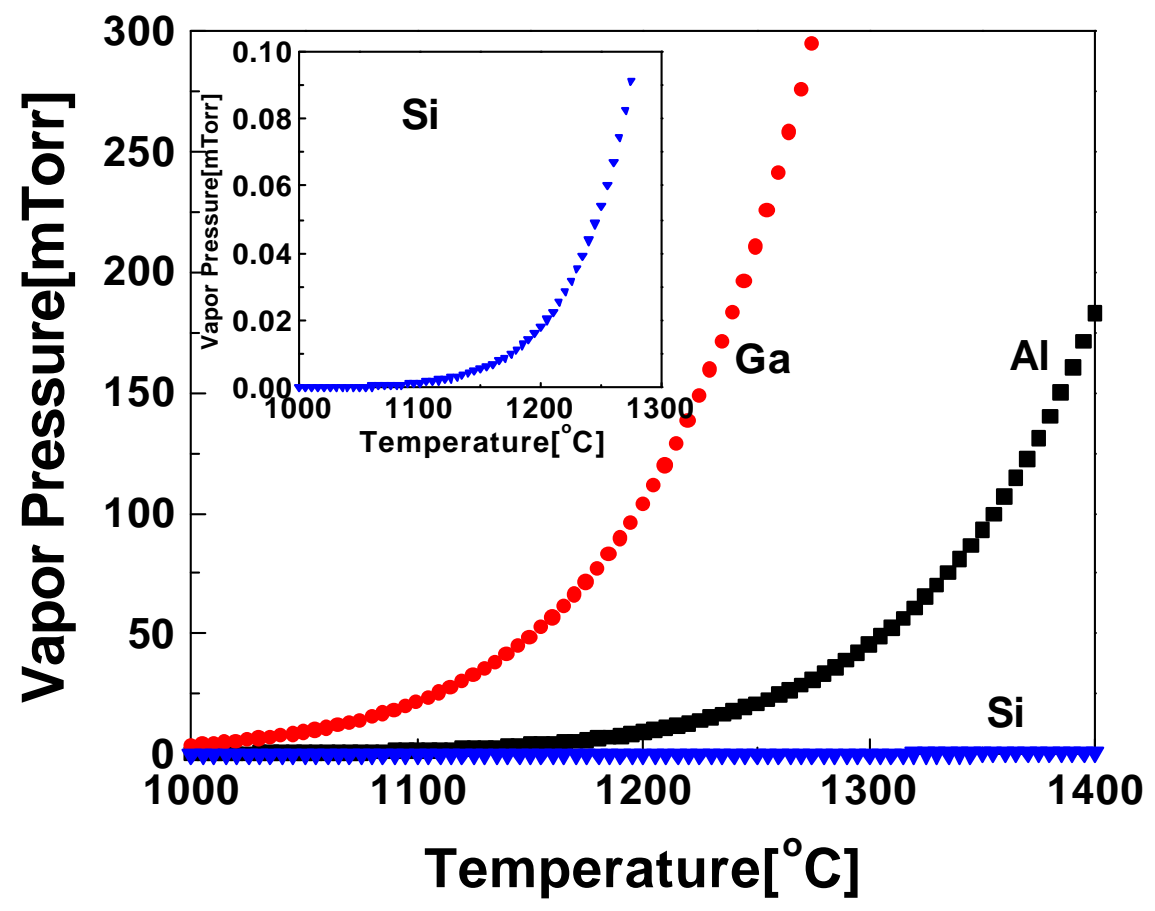

Figure 7.1 Equilibrium vapor pressures of $\mathrm{Al}, \mathrm{Ga}$, and $\mathrm{Si}$ as a function of temperature [13]. 

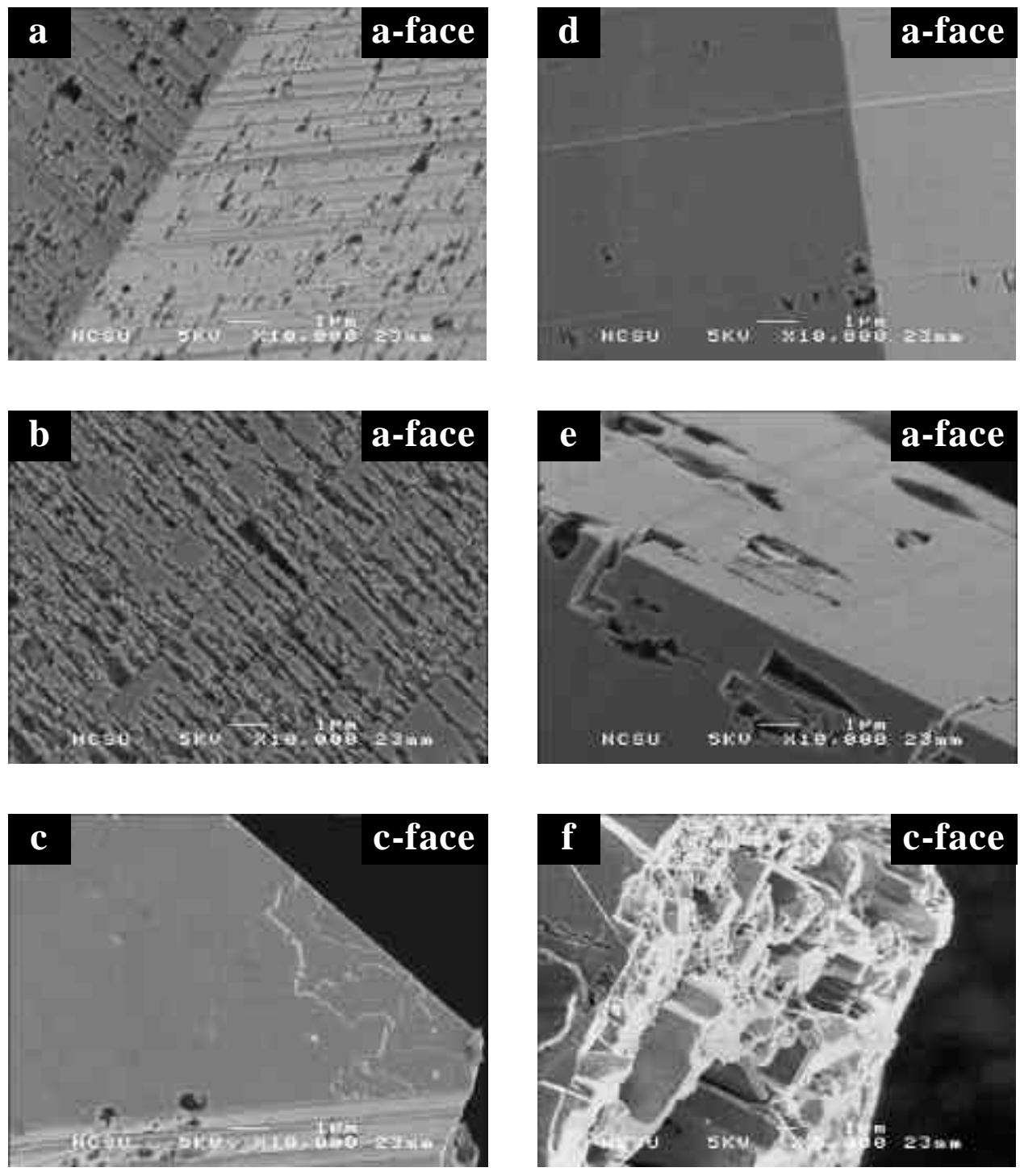

Figure 7.2 SEM micrographs of GaN crystals grown in the presence of $\mathrm{Si}$ in 760Torr of $\mathrm{NH}_{3}$ ambient for $10 \mathrm{hrs}$ at $1130^{\circ} \mathrm{C}$ showing the a-face(a), the a-face(b), and the c-face(c), respectively and at $1170^{\circ} \mathrm{C}$ showing the a-face(d), the a-face(e), and the c-face(f) respectively. 

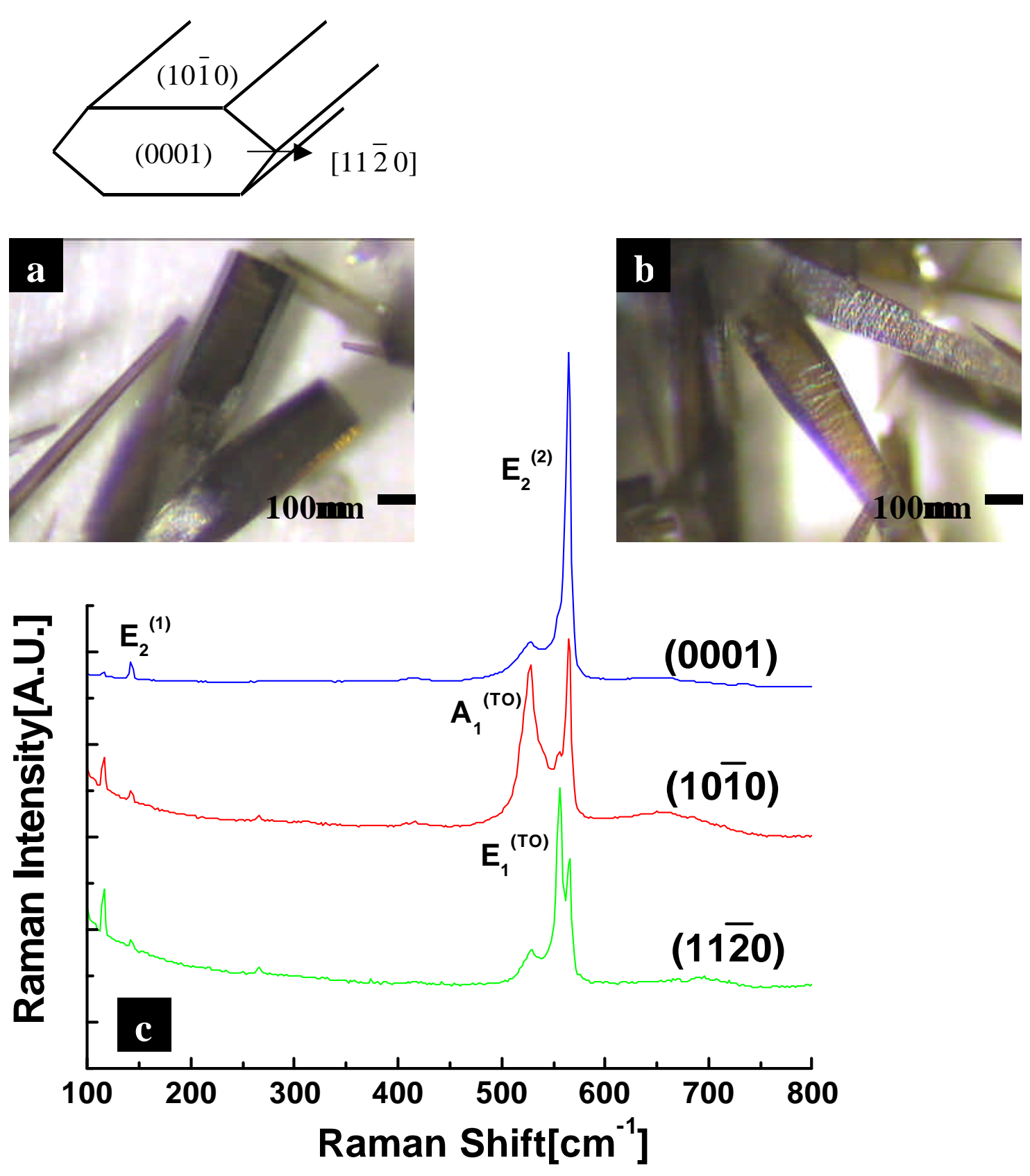

Figure 7.3 Micrographs of the GaN crystals showing the wider a-face(a)(b) as well as the Raman spectra(c) of GaN crystals grown in the presence of $\mathrm{Si}$ in the growth chamber at $1130^{\circ} \mathrm{C}$ in $\mathrm{NH}_{3}$ ambient of 760Torr for $10 \mathrm{hrs}$. 


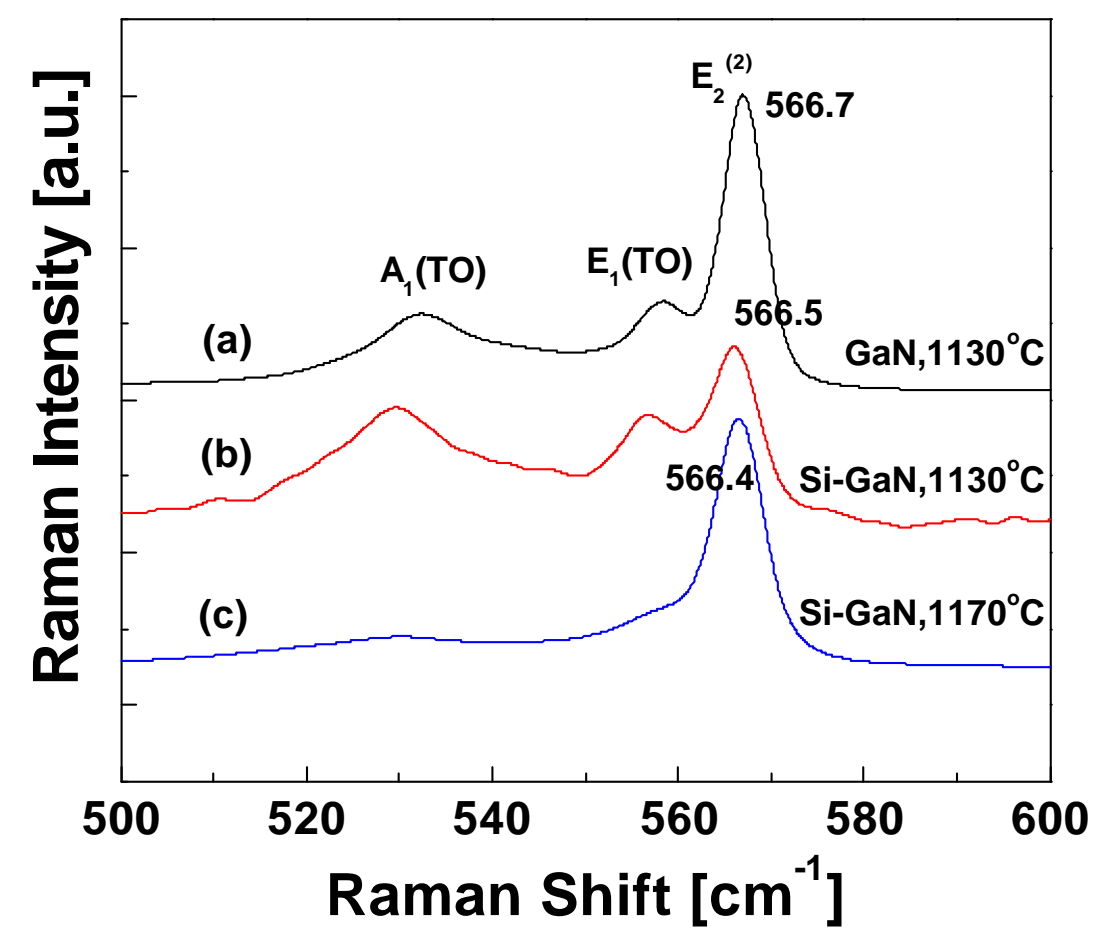

Figure 7.4 Raman spectra from the a-face of $\mathrm{GaN}$ crystals grown at $1130^{\circ} \mathrm{C}$ without the presence of $\mathrm{Si}$ in the growth chamber(a), at $1130^{\circ} \mathrm{C}$ in the presence of $\mathrm{Si}(\mathrm{b})$, at $1170^{\circ} \mathrm{C}$ in the presence of $\mathrm{Si}$. 

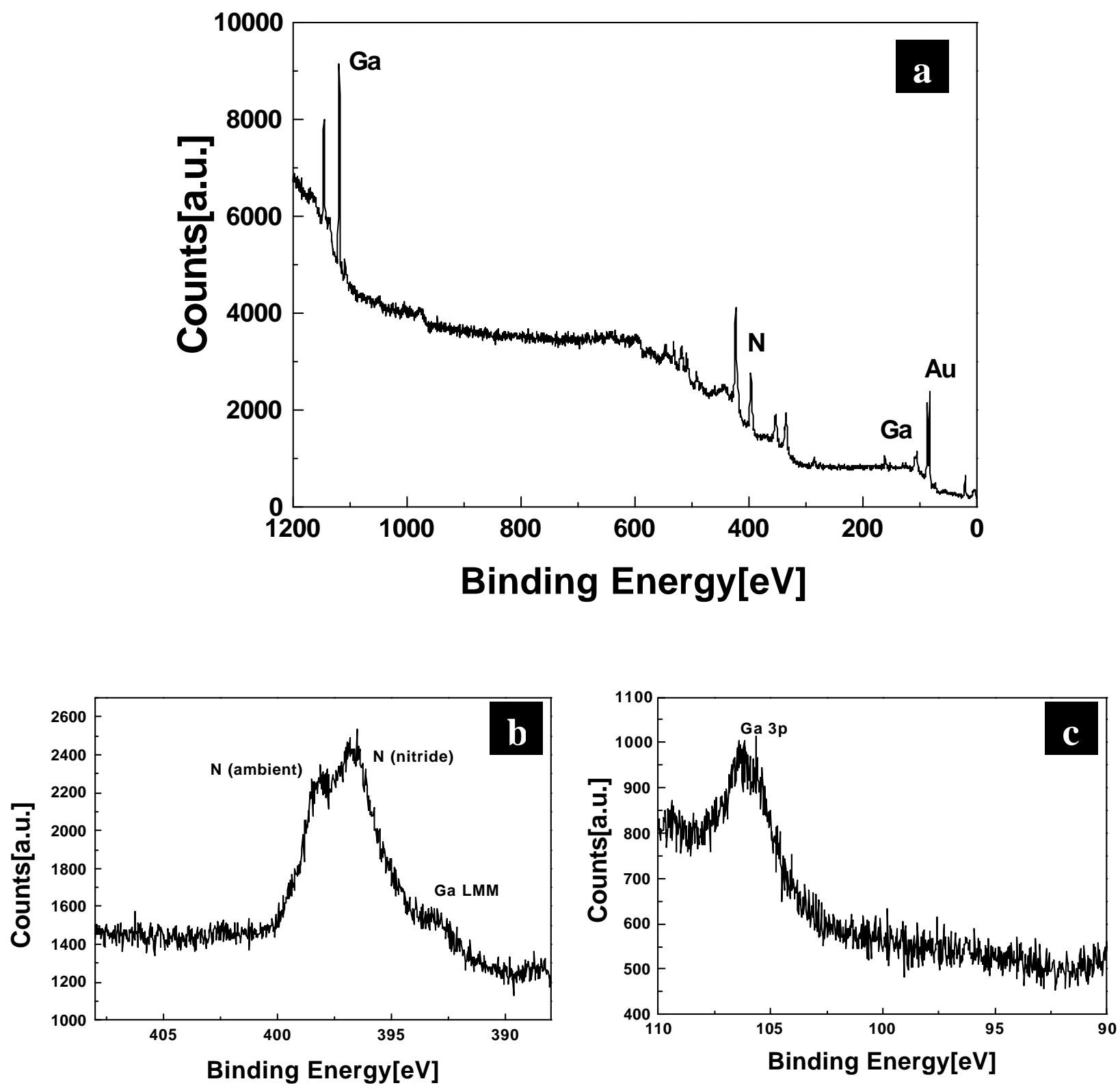

Figure 7.5 XPS spectra of $\mathrm{GaN}$ crystals grown at $1130^{\circ} \mathrm{C}$ without the presence of $\mathrm{Si}$ in the growth chamber. 

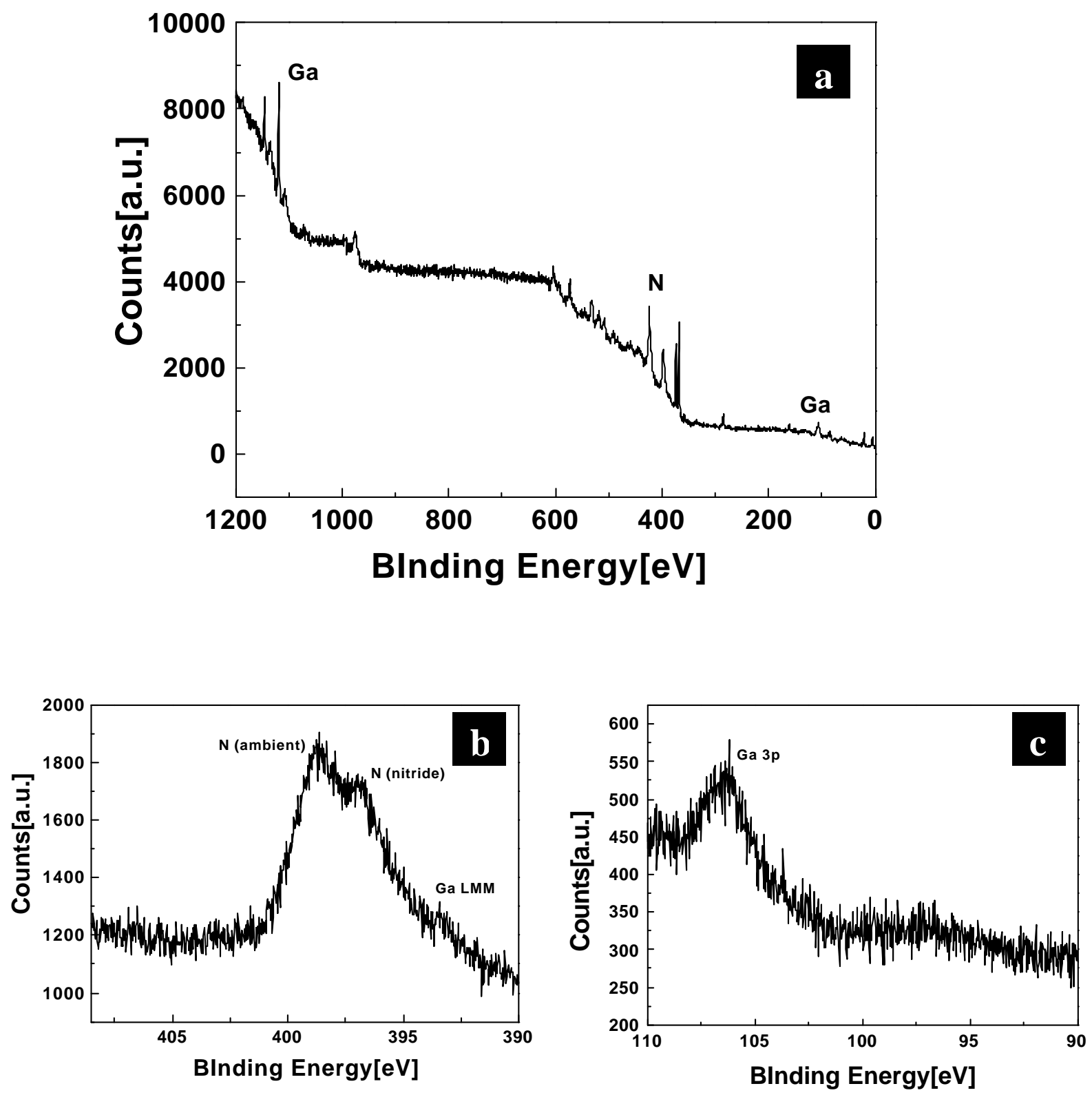

Figure 7.6 XPS spectra of GaN crystals grown at $1130^{\circ} \mathrm{C}$ in the presence of $\mathrm{Si}$ in the growth chamber. 

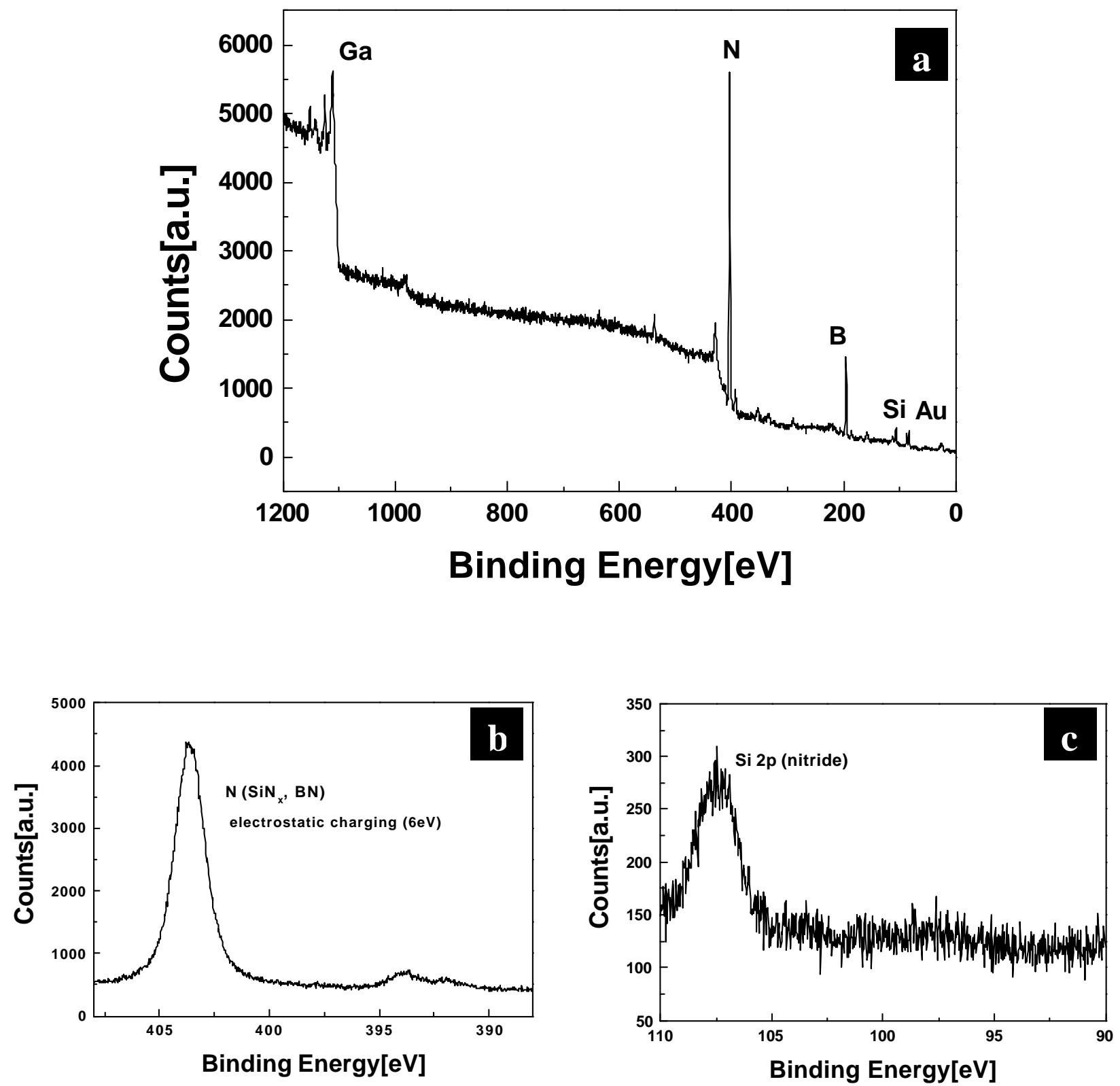

Figure 7.7 XPS spectra of the BN surface after GaN growth in the presence of $\mathrm{Si}$ at $1130^{\circ} \mathrm{C}$. 
8. Effects of the Presence of Aluminum on the Growth of GaN bulk Crystals 


\subsection{Introduction}

Aluminum nitride possesses better thermal stability than gallium nitride; it remains stable to $\sim 2230^{\circ} \mathrm{C}$ in $1 \mathrm{~atm}$ of nitrogen, due to its higher binding energy(Al-N: $2.88 \mathrm{eV} /$ bond) than $\mathrm{GaN}(\mathrm{Ga}-\mathrm{N}: 2.2 \mathrm{eV} /$ bond $)[1]$. Therefore, incorporation of $\mathrm{Al}$ into $\mathrm{GaN}$ may improve the thermal stability of the latter. Jenny et al.[2] suggested that Al has a ammonia cracking efficiency 2.5 times greater than that of $\mathrm{Ga}$, and that $\mathrm{Al}$ participates in an Al-for-Ga exchange. The higher reactivity of $\mathrm{Al}$ with ammonia was also reported by Thon and Kuech[3], who studied the gas-phase formation of the adduct TMGa: $\mathrm{NH}_{3}$ via reaction of TMGa with $\mathrm{NH}_{3}$. These investigators also observed the parasitic reaction between TMAl and $\mathrm{NH}_{3}$ to be kinetically more favorable than that between TMGa and $\mathrm{NH}_{3}$. The TMAl has been observed by Interrante et al. [4] to react with $\mathrm{NH}_{3}$ to form a white crystalline solid at and below room temperature.

The incorporation of $\mathrm{Al}$ into $\mathrm{GaN}$ in substantial amounts in the presence of $\mathrm{Al}_{2} \mathrm{O}_{3}$ at elevated temperatures has been reported by Monemar and Lagerstedt[4]. Visual inspection showed that after several deposition runs the surface of the alumina inside the furnace had roughened due to the reduction of $\mathrm{Al}_{2} \mathrm{O}_{3}$ by $\mathrm{Ga}$ at $1000-1050^{\circ} \mathrm{C}$ and the resulting formation of volatile aluminum suboxides[5]. A hot alumina reactor tube surrounded the $\mathrm{BN}$ crucible containing the $\mathrm{Al}$ and the $\mathrm{Al} / \mathrm{Ga}$ solution in the growth system of the present research. However, no decomposition of this tube was observed, because the crystal growth on the surface of these metals was sufficiently rapid and prevented much of the evaporation. 
In preliminary experiments, polycrystalline $\mathrm{Al}_{2} \mathrm{O}_{3}$ and sapphire were used substrates for GaN crystal growth. The former suffered similar surface corrosion, as described above, after long growth times; the latter showed no evidence of corrosion. The reduction process occurred in the more defective and higher energy grain boundaries. The GaN crystals grown near and/or on the polycrystalline $\mathrm{Al}_{2} \mathrm{O}_{3}$ substrate in the range $1130 \sim 1170^{\circ} \mathrm{C}$ showed smoother surface morphologies than those crystals grown on the $\mathrm{BN}$ surface at $1170^{\circ} \mathrm{C}$, indicating better resistance in the former to thermal decomposition as a result of $\mathrm{Al}$ incorporation.

Davis et al.[6-8] reported that $\mathrm{Al}_{\mathrm{x}} \mathrm{Ga}_{1-\mathrm{x}} \mathrm{N}$ thin films grown directly on both vicinal and on-axis $6 \mathrm{H}-\mathrm{SiC}(0001)$ substrates at $1100^{\circ} \mathrm{C}$ showed smooth and featureless surfaces for composition $\mathrm{x}<0.5$. For films having $\mathrm{x}>0.5$, the optimum temperature was determined to be increased to $1120 \sim 1130^{\circ} \mathrm{C}$ to eliminate pits on the surface which increased with increasing $\mathrm{Al}$ content. However, the growth rate decreased by more than a factor of three. Zsebök et al.[9] reported that $\mathrm{GaN}$ thin films grown on $\mathrm{GaN} /$ sapphire(0001) via plasma assisted $\mathrm{MBE}$ at $750^{\circ} \mathrm{C}$ possessed the smoothest surface morphology with the addition of 0.1at\% Al, determined by Secondary Ion Mass Spectroscopy. Ruffenach-Clur et al.[10] observed an increase in the FWHM of (0002) peak with increasing Al content $(0 \sim 80 a t \%)$ in $\mathrm{GaN}$ layer deposited at $980^{\circ} \mathrm{C}$ on sapphire(0001) using MOVPE. It was attributed to the low surface mobility of Al. The crystalline quality (FWHM) was increased with increasing growth temperature to $1080^{\circ} \mathrm{C}$. In the present study, a molten $\mathrm{Ga}-5 \mathrm{at} \% \mathrm{Al}$ source has been used to investigate the effect of $\mathrm{Al}$ additions on the growth of $\mathrm{GaN}$ crystals. To understand the effect of the Al additions in this regard, an elemental Al source was used initially to exclude the effects of oxygen released as a result of any 
reduction of the $\mathrm{Al}_{2} \mathrm{O}_{3}$ tube. The morphological changes in the resulting crystals are described, shown in accompanying figures and compared with crystals grown using a pure Ga source.

\subsection{Experimental Procedures}

In preliminary experiments, $\mathrm{Al}$ metal was evaporated from a $50 \mathrm{~g}$ source of solid $\mathrm{Al}$ and reacted with $\mathrm{NH}_{3}$ to investigate the growth conditions for and morphologies of the resulting AlN crystals. The temperatures of the crystal growth locations were measured with a type-C thermocouple.

Five at\% $\mathrm{Al}(99.9 \%)$ was added to a pure $\mathrm{Ga}(99.999 \%)$ source to determine the effect of the former on the growth rates, morphologies and optical properties of the resulting GaN crystals. Growths of the GaN crystals from this source were conducted using the high-temperature nucleation technique in the same manner as the growths from the pure Ga source. Due to the nitridation of the source materials during the growths of both the AlN and the GaN crystals, the nitride crystals were removed, and new source materials were replenished after each run. Both nitrides were characterized using optical microscopy, scanning electron microscopy (SEM), X-ray diffraction and Raman spectroscopy. X-ray photoelectron spectroscopy (XPS) measurements were also conducted on the crystals to assess the effect of the addition of Al during the growth. The XPS spectra of the GaN crystals grown with Ga-5at\%Al source were compared to the analogous spectra of the crystals grown with pure Ga source. No further processing was 
performed on the samples to avoid any accidental contamination. The sample was attached to a Au-coated Mo sample holder using silver paste. The XPS experiments were performed in a surface analysis chamber equipped with a VG Clam II semi-hemispherical electron spectrometer with a base pressure of $1 \times 10^{-10}$ Torr. The Al anode was used to produce X-rays with energies of $1486.6 \mathrm{eV}$.

\subsection{Results and Discussion}

No AlN crystals were observed within the chamber when the $\mathrm{Al}$ source temperature was $\sim 1260^{\circ} \mathrm{C}$. Raising this temperature to $\sim 1350^{\circ} \mathrm{C}$ increased the $\mathrm{Al}$ vapor pressure sufficiently to achieve $\sim 400 \mu \mathrm{m}$ long AlN needles, as shown in Fig. 8.1(a), on the inner walls of the BN crucible. The temperature of these walls within the areas of growth of the needles was $\sim 1370^{\circ} \mathrm{C}$. Platelets as large as $600 \mu \mathrm{m} \times 400 \mu \mathrm{m}$ were formed in the inner wall regions where the temperature was $\sim 1400^{\circ} \mathrm{C}$ (Fig. $8.1(\mathrm{~b})$ and $8.1(\mathrm{c})$ ). All the crystals were strongly adhered to the $\mathrm{BN}$ wall and had to be broken for characterization. By contrast, an aluminum-rich grayish powder formed on the $\mathrm{BN}$ substrate, the temperature of which was $\sim 1270^{\circ} \mathrm{C}$. The powder was a result of either insufficient cracking of ammonia at this temperature or the presence of much higher concentrations of metal than at the crucible wall. Figures 8.2(a) and (c) show SEM micrographs of a representative platelet and a representative needle of AlN. The rough surface features of the platelets shown in Fig. 8.2(b) are believed to be micro-platelets. In contrast, the surfaces of the needle were smooth, as shown in Fig. 8.2(d). Pastrnak et al.[11] reported 
the growth of AlN crystals via evaporation of $\mathrm{Al}$ in $\mathrm{N}_{2}$ in the temperature range from $1750^{\circ} \mathrm{C}$ to $2050^{\circ} \mathrm{C}$. Needle-shaped AlN crystals were grown at lower temperatures $\left(<1900^{\circ} \mathrm{C}\right)$ and platelet crystals were grown at higher temperatures $\left(>1900^{\circ} \mathrm{C}\right)$. AFM images of the surface of the AlN platelet were obtained in $5 \mu \mathrm{m} \times 5 \mu \mathrm{m}$ area and shown in Fig. 8.3. The surface roughness was found to be $6.6 \mathrm{~nm}$.

Gallium nitride crystals grown on the $\mathrm{BN}$ substrate using the $\mathrm{Ga}-5 \mathrm{at} \% \mathrm{Al}$ source are shown in Fig. 8.4. The source was maintained at $1260^{\circ} \mathrm{C}$, the same temperature used for the evaporation of pure Ga. At this temperature, the vapor pressures of $\mathrm{Al}$ and $\mathrm{Ga}$ are 24.6mTorr $\left(\Phi_{\mathrm{Al}} \sim 4.4 \times 10^{18} \mathrm{~cm}^{-2} \mathrm{~s}^{-1}\right)$ and 240mTorr $\left(\Phi_{\mathrm{Al}} \sim 2.6 \times 10^{19} \mathrm{~cm}^{-2} \mathrm{~s}^{-1}\right)$, respectively. However, the vapor pressure of an alloy component is different from that of the pure metal at the same temperature due to the change in chemical potential that the component experiences when it is dissolved in the solvent to form the alloy. Assuming a Raoultian solution, the ratio of the $\mathrm{Al} / \mathrm{Ga}$ flux is given by[12]

$$
\frac{J_{A l}}{J_{G a}}=\frac{X_{A l}}{X_{G a}} \frac{P_{A l}^{o}}{P_{G a}^{o}} \sqrt{\frac{M_{G a}}{M_{A l}}}
$$

where, $\mathrm{X}_{\mathrm{Al}}$ and $\mathrm{X}_{\mathrm{Ga}}$, are the atomic fractions in the binary $\mathrm{Ga}-\mathrm{Al}$ alloy and $\mathrm{P}_{\mathrm{Al}}^{\mathrm{o}}$ and $\mathrm{P}_{\mathrm{Ga}}^{\mathrm{o}}$, and $\mathrm{M}_{\mathrm{Al}}$, and $\mathrm{M}_{\mathrm{Ga}}$ are the vapor pressures and molecular weights of pure $\mathrm{Al}$ and $\mathrm{Ga}$, respectively. For the $\mathrm{Ga}-5 \mathrm{at} \% \mathrm{Al}$ source, the corresponding $\mathrm{Al} / \mathrm{Ga}$ flux ratio in the vapor at $1260^{\circ} \mathrm{C}$ is $\sim 0.01$. However, due to the high ammonia cracking efficiency, the $\mathrm{Al} / \mathrm{Ga}$ flux ratios in the vapor may be different from the calculated values due to the reactions of these metals with the ammonia at the surface of the molten alloy and in the gas phase.

In the use of the Ga-5at\%Al source, $10 \sim 20 \mu \mathrm{m}$ thick needles with poor surface morphologies (Figs. 8.4(a) and 8.4(b)) were obtained at a substrate temperature of 
$1130^{\circ} \mathrm{C}$. These needles were thinner than those grown using the pure Ga source (Fig. 8.4(f)). Hollow crystals resulted when the temperature was increased to $1170^{\circ} \mathrm{C}$, as shown in Figs. 8.4(c) and 8.4(d). Close examination of the surface morphologies of these crystals revealed that they were not a result of decomposition but a growth feature. The surface of the hollow area of the crystal was as smooth as the exterior surface. Elwell et al.[13] observed the appearance of hollow crystals that possessed a depression near the center of the (0001) face when the gallium supply was low. At the growth temperature of $1200^{\circ} \mathrm{C}$, the size of the needles decreased, probably due to their thermal instability of $\mathrm{GaN}$.

Upon cooling following the first growth run, the Ga-5at\% Al source formed into small spheres, as shown in the inset in Fig. 8.5. During several sequential growth runs, tiny AlN and GaN crystals nucleated, grew and partially covered the surface of the Ga-Al source This was confirmed by X-ray diffraction of the source after five runs, as shown in Fig. 8.5(a). GaN crystals grown with and without $\mathrm{Al}$ exhibited the same XRD patterns of hexagonal GaN, as shown in Figs. 8.5(b) and (c). No shift of the peaks was observed- As a result of the formation of $\mathrm{GaN}$ and $\mathrm{AlN}$ in the source, the fluxes of $\mathrm{Ga}$ and $\mathrm{Al}$ were continually reduced after each run. The addition of more than 10 at $\%$ resulted in severe nitridation of the $\mathrm{Ga}-\mathrm{Al}$ source after a single run and the whole $\mathrm{Ga}-\mathrm{Al}$ source had to be replaced. The strong propensity for the formation of AlN crystals via the reaction of $\mathrm{Al}$ with $\mathrm{NH}_{3}$ makes this approach unsuitable for the continuous growth of bulk crystals. A separate $\mathrm{Al}$ source was subsequently employed in an attempt to avoid the progressive reduction of the $\mathrm{Al}$ flux. This source became covered with AlN crystals after a single run. Another method for supplying $\mathrm{Al}$ must be found if $\mathrm{AlGaN}$ bulk crystals are to be grown. 
No evidence of pre-reaction of the $\mathrm{Al}, \mathrm{Ga}$ and ammonia precursors in the gas phase was observed.

Figure 8.6. shows the Raman spectra of GaN and AlN grown using the single elemental metal sources and of GaN grown using the $\mathrm{Al} / \mathrm{Ga}$ solution. The GaN crystals grown using the latter source showed no apparent shift in the positions of the peaks. It has been reported that the $\mathrm{E}_{1}(\mathrm{TO}), \mathrm{E}_{2}$, and the $\mathrm{A}_{1}(\mathrm{TO}, \mathrm{LO})$ modes shift to higher wave numbers, as the $\mathrm{Al}$ fraction is increased[10]. For example, 10 mole\% $\mathrm{Al}$ in $\mathrm{GaN}$ corresponds to a shift of $\sim 30 \mathrm{~cm}^{-1}$. Therefore, the GaN samples grown with $\mathrm{Al}$ in the source may contain less than $\sim 1 \%$ Al. Energy dispersive analysis, with a dectectability of $>1 \%$, indicated no $\mathrm{Al}$ present in the samples grown at substrate temperatures of $1170^{\circ} \mathrm{C}$ and $1200^{\circ} \mathrm{C}$.

XPS survey scan from $1200 \mathrm{eV}$ to $0 \mathrm{eV}$ in binding energy obtained from the $\mathrm{GaN}$ crystals grown at $1170^{\circ} \mathrm{C}$ without the presence of $\mathrm{Al}$ source was compared to that from the $\mathrm{GaN}$ crystals grown with $\mathrm{Ga}-5 \mathrm{at} \% \mathrm{Al}$. No detectable $\mathrm{Al}(\sim 1 \mathrm{at} \%)$ was present on the sample. Though Al was not detected on the sample within the detectability, the morphological changes of the crystals(i.e., hollow crystals) were clearly discerned from the GaN crystals grown with pure Ga source. The appearance of the hollow crystals was reproducible upon the addition of $\mathrm{Al}$ to the Ga source. 


\subsection{Conclusions}

Needles and platelets of AlN were grown on the BN walls of the chamber at $1370^{\circ} \mathrm{C}$ and $1400^{\circ} \mathrm{C}$, respectively, via the reaction of $\mathrm{Al}$ vapor and ammonia. Needles and hollow crystals of $\mathrm{GaN}$ were grown on the $\mathrm{BN}$ substrate at $1130^{\circ} \mathrm{C}$ and $1170^{\circ} \mathrm{C}$, respectively, using a Ga-5at\%Al source. Growth of the latter in the c-direction was promoted with the use of the Ga-5at\% Al source as compared to using the pure Ga source. Thermal stability of the GaN crystals grown with Ga-5at\% Al source was increased as compared with that of GaN crystals grown with pure Ga source, as confirmed by the increase of the optimum growth temperature $\left(1130^{\circ} \mathrm{C}\right.$ to $\left.1170^{\circ} \mathrm{C}\right)$. No detectable incorporation of $\mathrm{Al}$ into $\mathrm{GaN}$ crystal was achieved, as measured using Raman spectroscopy, energy dispersive analysis and X-ray Photoelectron Spectroscopy. 


\subsection{References}

1. J. H. Edgar, "Properties of Group III Nitrides", Inspec, London, UK, 74(1994)

2. J. R. Jenny and J. E. Van Nostrand, Appl. Phys. Lett., 72(1), 85(1998)

3. Thon, T. F. Kuech, Appl. Phys. Lett. 69, 55(1996)

4. L. V. Interrante, L. E. Carpenter II, C. Whitmarsh, W. Lee, M. Garbauskas, G. A. Slack, Mater. Res. Soc. Proc., 73, 359(1986)

5. B. Monemar and O. Lagerstedt, J. Appl. Phys., 50(10), 6480(1979)

6. R. F. Davis, M. D. Bremser, W. G. Perry, and K. S. Ailey, Journal of the European Ceramic Society, 17, 1775(1997)

7. M. D. Bremser, W. G. Perry, T. Zheleva, N. V. Edwards, O. H. Nam, N. Parikh, D. E. Aspnes, R. F. Davis, Diamond and Related Materials, 6, 196(1997).

8. M. D. Bremser, W. G. Perry, T. Zheleva, N. V. Edwards, O. H. Nam, N. Parikh, D. E. Aspnes, R. F. Davis, MRS Internet Journal of Semiconductors, 1.8(1996)

9. Otto Zsebök, Jan V. Thordson, Qingxiang Zhao, Ulf Södervall, Lars Ilver, and Thorvald G. Andersson, MRS Internet Journal of Semiconductors, W3.36 (1999)

10. S. Ruffenach-Clur, Olivier Briot, Bernard Gil, Roger-Louis Aulombard, MRS Internet Journal of Semiconductors, 2.27 (1997)

11. J. Pastrnak and L. Roskovcova, Physica Status Solidi, 7, 331(1964)

12. D. L. Smith, “Thin Film Deposition”, McGraw Hill, Inc., (1996)

13. F. Demangeot, J. Groenen, J. Frandon, and M. A. Renucci, O. Briot, S. Clur, and R. L. Aulombard, Appl. Phys. Lett., 72(21), 2674(1998) 

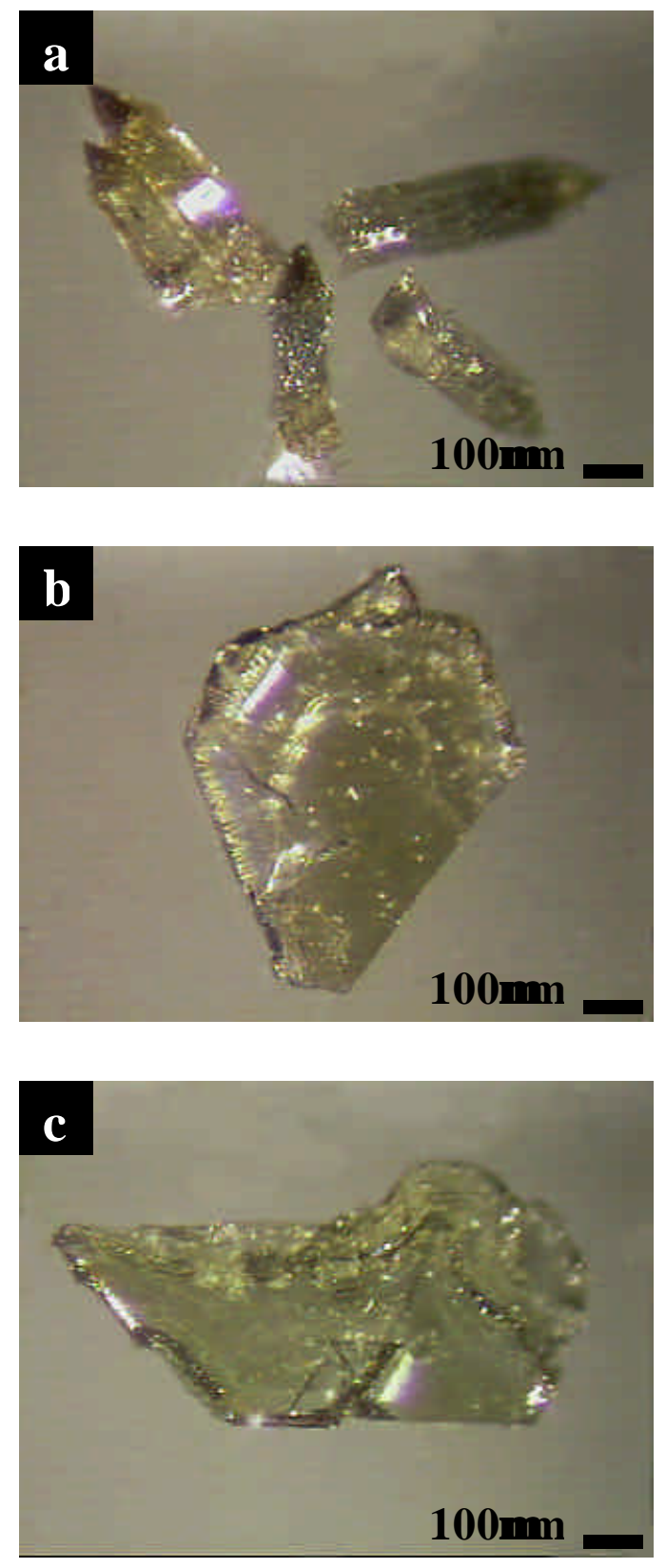

Figure 8.1 AlN crystals grown at (a) $1370^{\circ} \mathrm{C}$, (b) \& (c) $1400^{\circ} \mathrm{C}$ and 430Torr, $100 \mathrm{sccm}$ of $\mathrm{NH}_{3}$ for $4 \mathrm{hrs}$. 

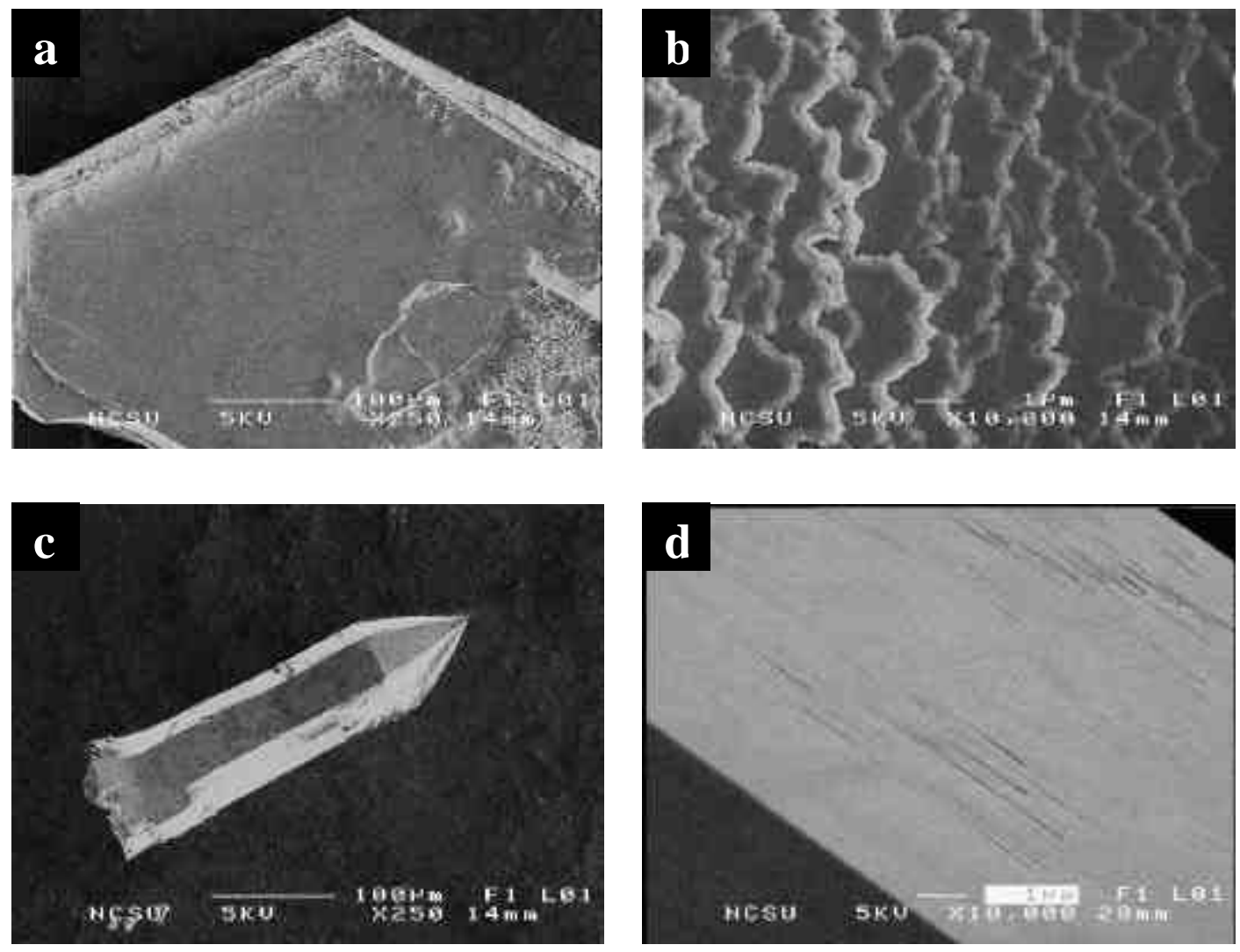

Figure 8.2. SEM micrographs of (a),(b) the c-face of an AlN platelet and (c),(d) the a-face of an AlN needle. 

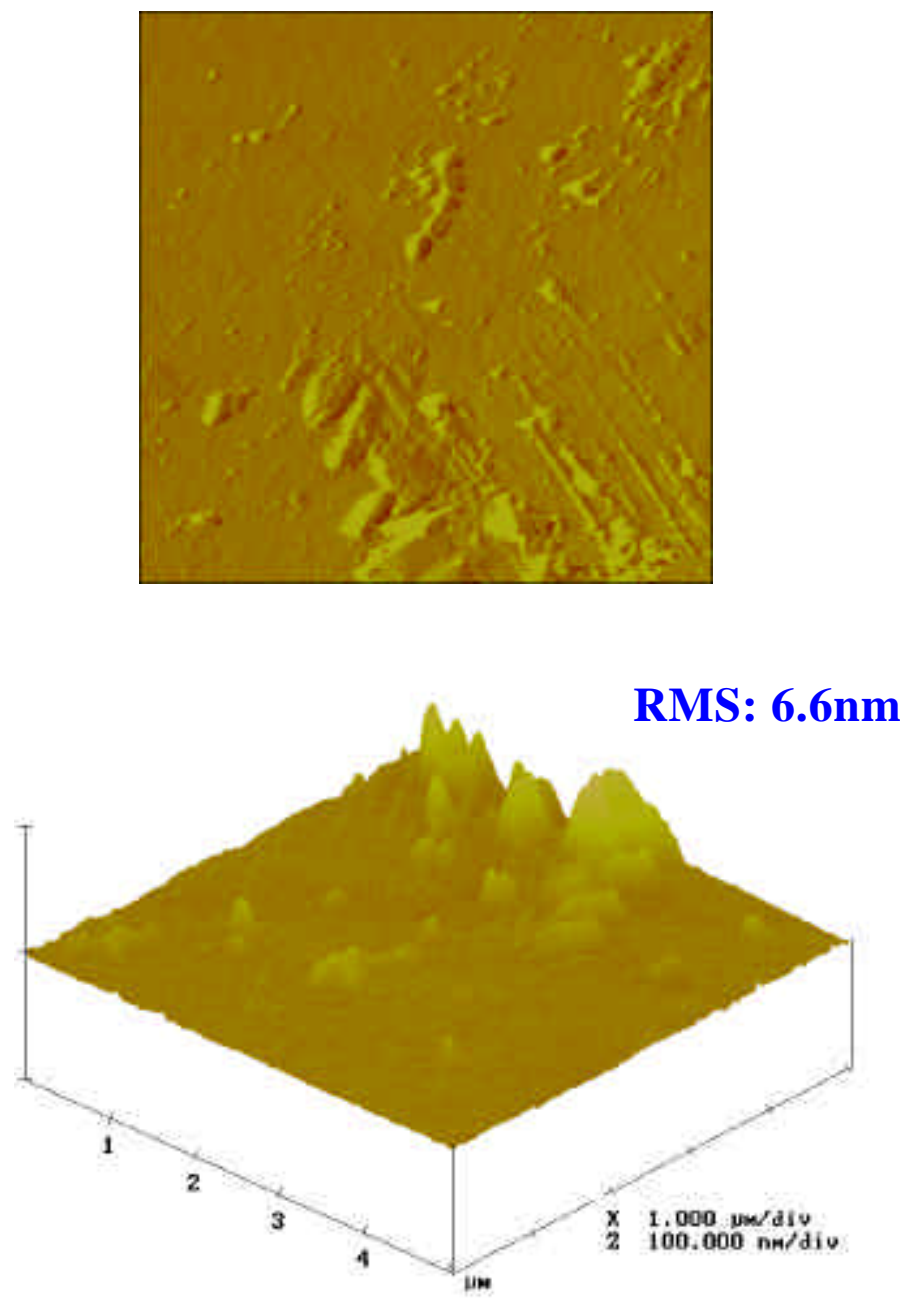

Figure 8.3 AFM images of the c-face of the AlN platelet shown in Fig. 8.2(a). 

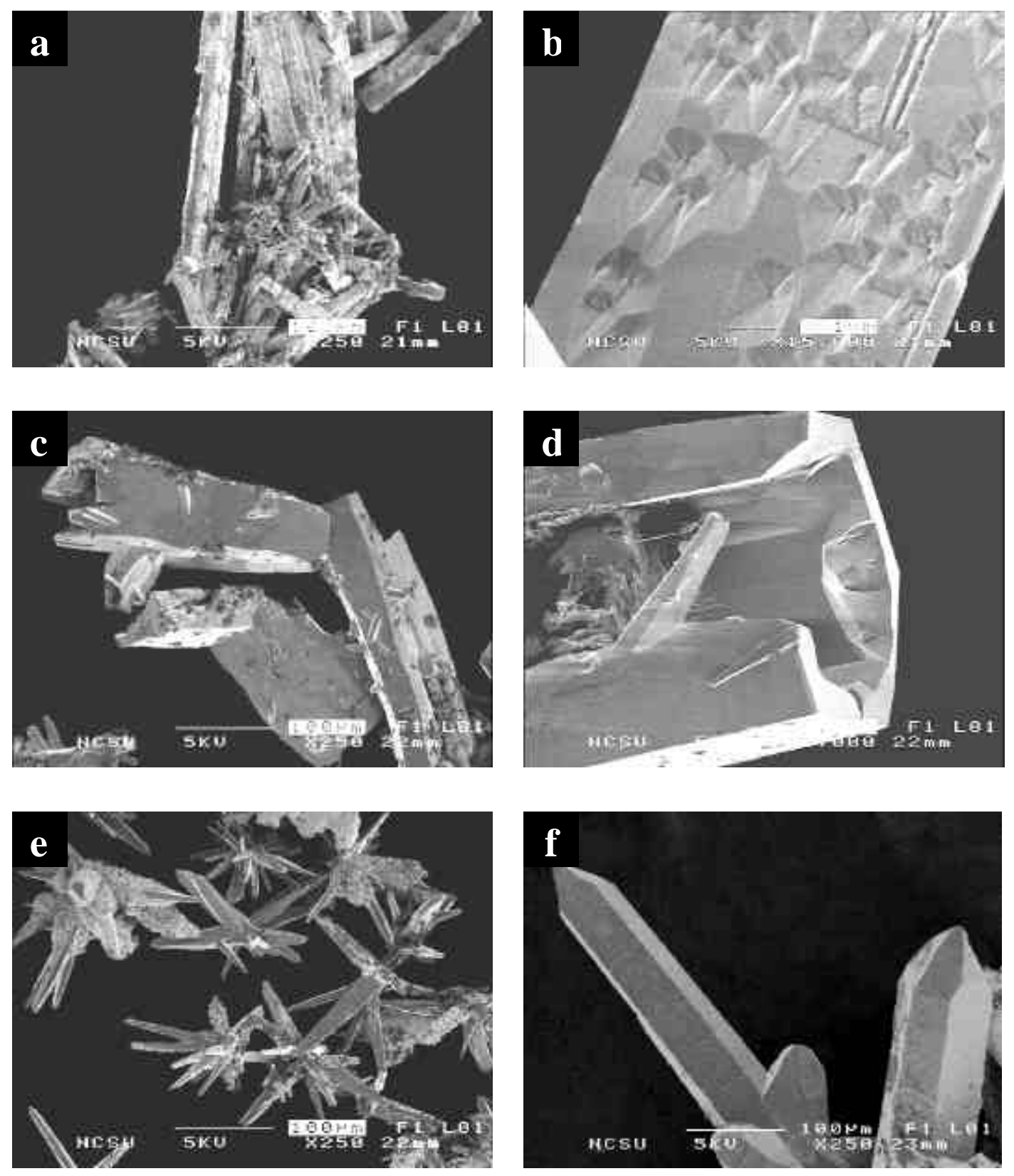

Figure 8.4 SEM micrographs of GaN crystals grown (a)at $1130^{\circ} \mathrm{C}$, (b) magnified view of the crystal in (a), (c)at $1170^{\circ} \mathrm{C}$, (d) magnified view of the crystal in (c), (e)at $1200^{\circ} \mathrm{C}$ and (f) pure GaN crystals grown at $1130^{\circ} \mathrm{C}$ and 430Torr for $2 \mathrm{hrs}$. 


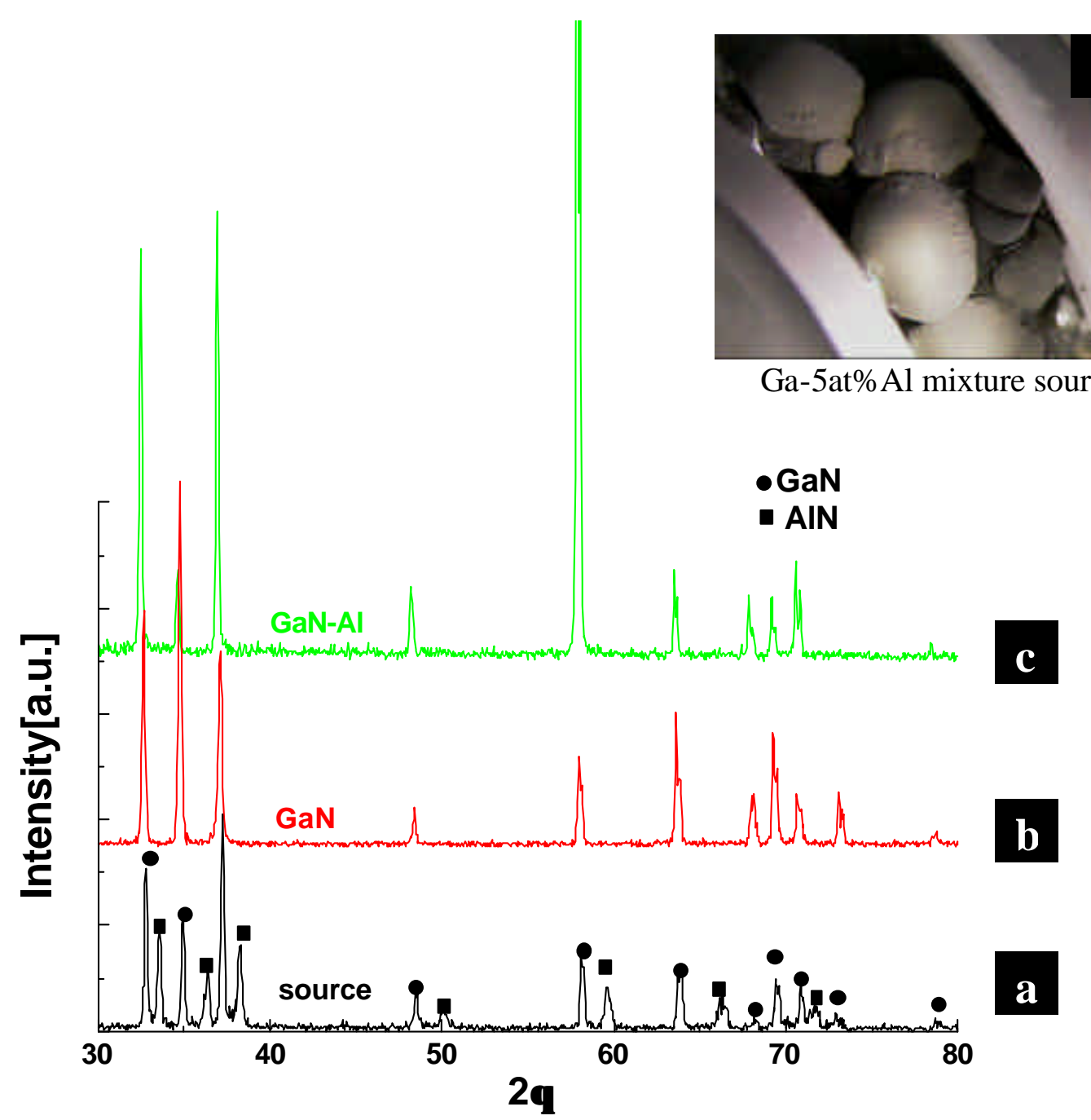

Figure 8.5 X-ray diffraction patterns of (a) Ga-5at\% Al source after 5 runs (b) pure GaN crystals (c) GaN crystals with $\mathrm{Al}$ addition and (d) a photograph of the $\mathrm{Ga}-\mathrm{Al}$ mixture source after a growth run. 


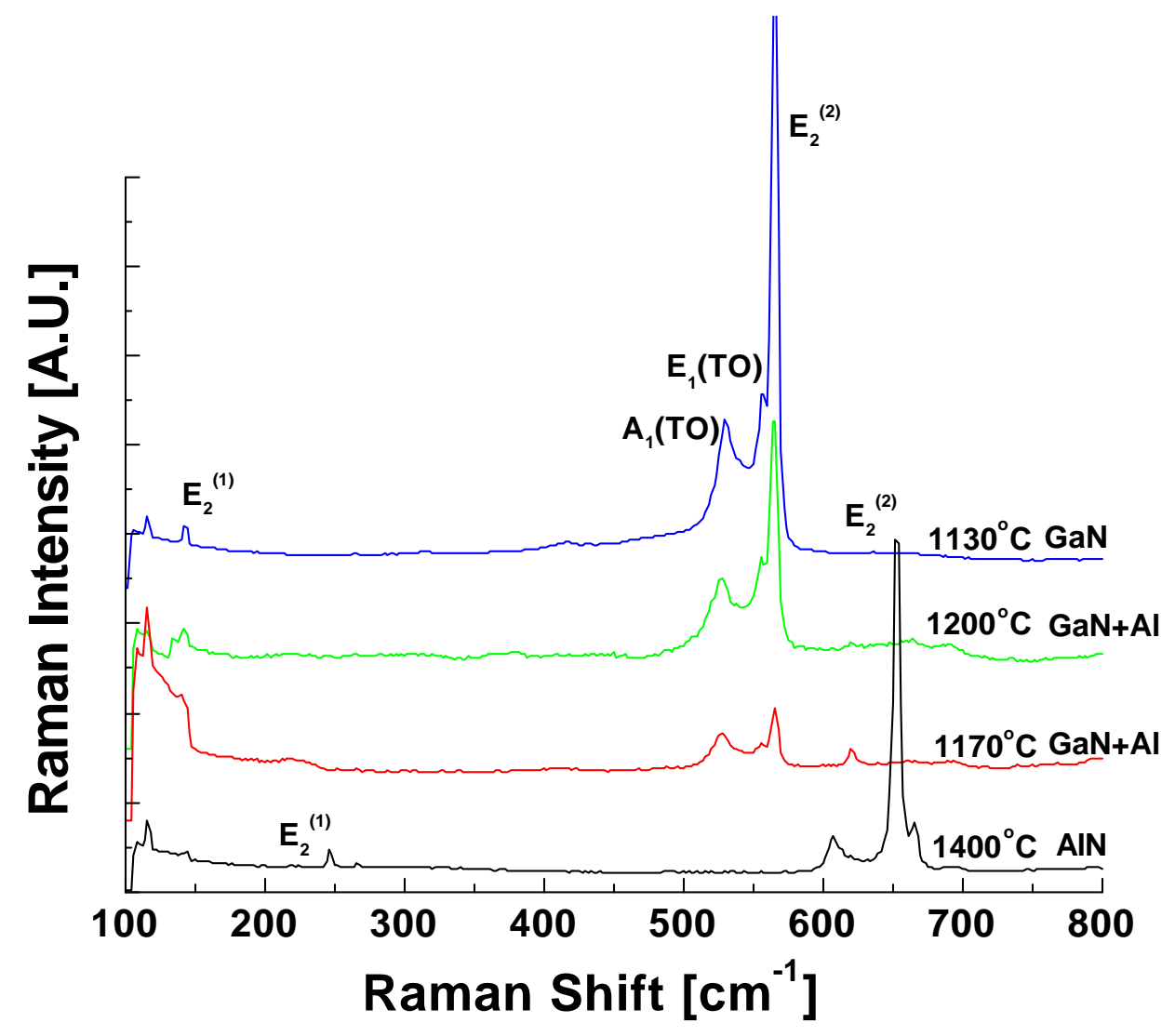

Figure 8.6 Raman spectra of GaN, AlN and GaN crystal grown with Al. 


\section{Summary}

Free-standing single crystals of bulk GaN were grown via vapor phase transport on hexagonal BN surfaces using the direct reaction of $\mathrm{Ga}$ with ammonia. A continuous supply of Ga vapor was achieved using the source temperature of $\sim 1240^{\circ} \mathrm{C}$ and ammonia flow rates $\leq 200 \mathrm{sccm}$. The number of nucleation events was reduced by using a novel nucleation technique wherein the ammonia was introduced at high temperatures. Needleand platelet-shaped single crystals of GaN grown using this high-temperature nucleation technique were larger than those grown using conventional growth processes. The high temperature nucleation technique also resulted in a cleaner template surface prior to growth and the minimization of a GaN crust on the surface of the Ga source. The optimum temperature of the substrate surface was determined to be $1130^{\circ} \mathrm{C}$, above which thermodynamic limitations governed the crystal growth in terms of crystal dimensions and surface morphology. A three-dimensional processing map for aspect ratio control was constructed with respect to ammonia flow rate and total pressure at $1130^{\circ} \mathrm{C}$ on the basis of the data obtained via the high temperature nucleation process. Low V/III ratios achieved via ammonia flow rates $\leq 75 \mathrm{sccm}$ and/or ammonia total pressures $\leq$ 430Torr favored platelet growth of $\mathrm{GaN}$ at $1130^{\circ} \mathrm{C}$. The average lateral growth rate for the platelets was $\sim 50 \mu \mathrm{m} / \mathrm{hr}$; the average vertical growth rate for the needles was $\sim 500 \mu \mathrm{m} / \mathrm{hr}$. Growth rates in all other directions for each of these two morphologies were very low. Ammonia flow rates of $\sim 60 \mathrm{sccm}$ were required for growth of platelets with excellent Raman characteristics at the $\mathrm{Ga}$ source temperature of $1260^{\circ} \mathrm{C}$. Under lateral growth 
conditions, larger needles and platelets were successfully grown via seeded growth without secondary nucleation.

Growth rate decreased at longer times and higher ammonia pressures and decomposed crystals resulted. Measurements of decomposition rate and gas phase composition analyses using mass spectrometry revealed that evaporation at low total pressures and etching by hydrogen derived from the increased decomposition of ammonia at pressures higher than 510Torr caused the cessation of growth of the seeded GaN crystals after $\sim 10 \mathrm{hrs}$. Nitrogen dilution of the $\mathrm{NH}_{3}$ suppressed the high-pressure decomposition and allowed continuous growth of the seed crystals in contrast to those grown in pure ammonia. Crystal morphology changed from needle to platelet as the nitrogen content in the nitrogen/ammonia mixture was increased. A $2 \mathrm{~mm} \times 1.5 \mathrm{~mm}$ needle and a $2.3 \mathrm{~mm} \times 1.8 \mathrm{~mm} \times 0.3 \mathrm{~mm}$ platelet of $\mathrm{GaN}$ were grown via seeded growth with minimal decomposition in a $66.7 \% \mathrm{NH}_{3}$ and $33.3 \% \mathrm{~N}_{2}$ gas mixture. The secondary nucleation problem encountered in the growth with pure ammonia due to thermodynamic propensity of $\mathrm{GaN}$ formation and in the growth at high pressure(760Torr) due to convection was alleviated by growing crystals at lower total pressure(430Torr) in an ammonia/nitrogen mixture. The excellent crystallography of these materials was confirmed by Raman spectroscopy (FWHM of $\mathrm{E}_{2}^{(2)} \sim 3 \mathrm{~cm}^{-1}$ ) and photoluminescence measurements.

The presence of Si resulted in growth of larger crystals as compared with those grown without the presence of $\mathrm{Si}$, probably due to the increased residence time of nitrogen and/or the reduced nucleation density via the formation of $\mathrm{Si}_{\mathrm{x}} \mathrm{N}_{\mathrm{y}}$ on the $\mathrm{BN}$ surface, as indicated by XPS analysis. The surface morphology of the a-face of the GaN 
crystals grown in the presence of $\mathrm{Si}$ was significantly improved relative to that of $\mathrm{GaN}$ grown without the presence of $\mathrm{Si}$ at the growth temperature of $1170^{\circ} \mathrm{C}$, while threedimensional growth was observed on the c-face. Decomposition of GaN at higher growth temperatures $\left(\sim 1170^{\circ} \mathrm{C}\right)$ was suppressed in the presence of $\mathrm{Si}$ possibly due to the increased residence time of nitrogen on the growing surface. The needle-shaped GaN crystals bound by the $\{10 \overline{1} 0\}$ and $\{0001\}$ faces and elongated in the $\langle 11 \overline{2} 0\rangle$ direction indicated that the presence of $\mathrm{Si}$ promoted the growth in this direction. Raman spectroscopy revealed that all the GaN crystals grown in the presence of Si were nearly strain free.

Needles and platelets of AlN were grown on the BN substrates at $1370^{\circ} \mathrm{C}$ and $1400^{\circ} \mathrm{C}$, respectively, via the reaction of $\mathrm{Al}$ and ammonia. Hollow crystals of $\mathrm{GaN}$, obtained using a $\mathrm{Ga}-5 \% \mathrm{Al}$ source, indicated that growth in the c-direction was promoted as compared with the crystals grown using pure Ga source. No detectable incorporation of $\mathrm{Al}$ into the GaN crystals was achieved within the detection limits of Raman spectroscopy and energy dispersive analysis. 


\section{Future Research}

In the research of this dissertation, optimum processing conditions for the growth of platelets and needles of $\mathrm{GaN}$ using a high temperature nucleation process in a dedicated crystal growth system have been determined. Seeded growth using a nitrogen/ammonia gas mixture resulted in millimeter-sized crystals. However, many problems remain concerning the stable growth of large, commercially viable $\mathrm{GaN}$ crystals.

The reason for the enhanced decomposition of $\mathrm{GaN}$ in ammonia has been determined; however, the decreased growth rate associated with the use of nitrogen dilution as an answer to this problem must be surmounted. One proposed potential solution is the use of a uniaxial open flow system to both alleviate the hydrogen etching and to increase the growth rate. At the outset, investigations regarding whether or not the hydrogen derived from the ammonia can be efficiently evacuated from such a system must be conducted. A uniaxial gas flow system would also make simpler for analysis the problems of convection and material transport and allow one to obtain meaningful kinetic data in relation to growth and decomposition. A parallel simulation study of the gas flow dynamics in the current growth system would be beneficial for understanding the transport of both material and heat. Additionally, the design of a new growth crucible such that the fluxes of $\mathrm{Ga}$ and ammonia can be more independently controlled is recommended. The use of gallium chloride as the Ga source may provide additional parameter space for growth operation, as the employment of liquid Ga source is limited, e.g., by the pressure and flow rate of the ammonia. 
Research regarding the effect of inert gases having a larger atomic weight than nitrogen on the decomposition of GaN should be conducted. Nitrogen dilution showed a significant positive effect regarding the reduction of the decomposition of $\mathrm{GaN}$ because it diluted the ammonia and bombarded the surface. The use of, e g., Ar, or $\mathrm{Kr}$ would provide atoms of increased mass and size that would physically interact with the nitrogen atoms on the GaN surface to increase their residence time and therefore limit their combination and subsequent evaporation.

The effect of $\mathrm{Si}$ on the growth of GaN crystals was indirectly investigated by placing a small piece of $\mathrm{Si}$ in the growth environment. The results indicated that the presence of $\mathrm{Si}$ has an effect on the growth of $\mathrm{GaN}$; however, it was not determined whether any Si was incorporated into the GaN. To avoid the ambiguity caused by the decreased evaporation of $\mathrm{Si}$ due to the formation of $\mathrm{Si}_{\mathrm{x}} \mathrm{N}_{\mathrm{y}}$ on the $\mathrm{Si}$ surface, growth experiments using other silicon sources such as $\mathrm{SiH}_{4}$ should be conducted. The concentration of incorporated $\mathrm{Si}$ must also be determined using secondary ion mass spectrometry. This would clarify the dependence of the surface morphology and the decomposition of the GaN crystals on the amount of incorporated Si. Utilization of the fact that $\mathrm{GaN}$ tends not to nucleate on silicon nitride at temperatures higher than $\sim 1100^{\circ} \mathrm{C}$ is another method of nucleation control by which larger GaN crystals can be grown. Shaped crystal growth should be attempted by deposition of silicon nitride on the inner wall of a mold.

The use of Ga-5at\%Al source resulted in increased the thermal stability of the crystal, which was manifested by the increase in the growth temperature $\left(\sim 1170^{\circ} \mathrm{C}\right)$ as compared with that of $\mathrm{GaN}$ without $\mathrm{Al}\left(\sim 1130^{\circ} \mathrm{C}\right)$. The presence of $\mathrm{Al}$ in the $\mathrm{GaN}$ crystals 
could not be confirmed by XPS or EDS within the detectability limit. Secondary Ion Mass Spectrometry must be employed to determine the exact amount of aluminum present in the crystal. Use of different precursors with higher Al vapor pressures, e.g., aluminum chloride, will alleviate the problem of depletion of this source material and make possible systematic research concerning the effect of the addition of $\mathrm{Al}$ on the growth of GaN.

Another proposed topic for study is the growth of $\mathrm{GaN}$ on the c-face of the $\mathrm{GaN}$ platelets. Growth on $\mathrm{GaN}$ thin films previously deposited on $\mathrm{AlN} / \mathrm{SiC}(0001)$ substrates via MOVPE resulted in three-dimensional island formation primarily due to the decomposition of the GaN films and the consequent exposure of the underlying AlN layer and/or $\mathrm{SiC}$ substrate prior to the attempted growth of the crystals at higher temperatures. More precise control of the processing variables would enable the researcher to grow in the c-direction. Comparisons via TEM of the microstructures of the GaN needles grown under lateral growth conditions and platelets grown under vertical growth conditions via seeded growth would reveal information regarding the origin of the defects and the relationship of their presence, distribution and character to growth in the different crystallographic directions. 


\section{Appendix 1: Additional Information in Support of Chapter 4 regarding the High Temperature Nucleation and Growth of GaN Crystals}

\subsection{Stability of the Ga Source}

As briefly described in Chapter 4, preliminary experiments showed that macro-size Ga droplets falling onto the substrate from other points of the reactor, i.e., ammonia gas inlet nozzle, disturbed the crystal growth. At $1130^{\circ} \mathrm{C}$, the surface morphology shown in Fig. 11.1(a), resembled a growth feature caused by secondary nucleation. The surfaces of crystals grown at $1170^{\circ} \mathrm{C}$, were rougher than those grown at $1130^{\circ} \mathrm{C}$. This is believed to have stemed both from a higher degree of wetting and a faster reaction at the higher temperature. This rough surface morphology could be a consequence of the enhanced decomposition of GaN surface as reported by Pisch et al.[1] In their study, the influence of a liquid gallium layer on the decomposition of thin $\mathrm{GaN}$ films was studied in-situ with an optical microscope to $800^{\circ} \mathrm{C}$ in $\mathrm{Ar} / \mathrm{H}_{2}$ and $\mathrm{N}_{2} / \mathrm{H}_{2}$ gas mixtures at atmosphere pressure. While a pure GaN film showed no apparent decomposition even after a 30min anneal at $800^{\circ} \mathrm{C}$, decomposition of a $\mathrm{Ga} / \mathrm{GaN}$ assembly occurred from the $\mathrm{Ga} / \mathrm{GaN}$ interface at temperatures around $720^{\circ} \mathrm{C}$; it was independent of the composition of the gas phase when liquid gallium was deposited on the surface. Enhanced decomposition in the presence of Ga metal was also reported by Schoonmaker et al.[2] Therefore, conditions for stable Ga source transport should be determined to obtain a uniform flux of Ga vapor.

Figure 11.2 shows the images of the liquid Ga surface captured during heat treatment by the $\mathrm{CCD}$ camera on the long distance microscope. The liquid Ga surface 
remained clean in pure $\mathrm{N}_{2}$ (upper right corner in Fig. 11.2) at all temperatures and nitrogen flow rates investigated because Ga does not react with molecular nitrogen under the current conditions due to the strong triple bonding of the latter. However, small GaN crystals began to form on the surface of the liquid gallium in pure ammonia at different ammonia flow rates, depending on the temperature. Increasing the ammonia flow rate above a critical value at a temperature resulted in the formation of GaN crust that completely covered the liquid Ga surface. The critical ammonia flow rates, at which vigorous reactions between $\mathrm{Ga}$ and $\mathrm{NH}_{3}$ caused $\mathrm{Ga}$ spattering, were $200 \mathrm{sccm}$ at $1100^{\circ} \mathrm{C}$, $300 \mathrm{sccm}$ at $1140^{\circ} \mathrm{C}$ and $400 \mathrm{sccm}$ at $1180^{\circ} \mathrm{C}$, respectively, as indicated in Fig. 11.2. Data points in Fig. 4.3, Chapter 4 were obtained from the above observation.

\subsection{Ga Source-to-Crystal Distance}

Initially, Ga was loaded in the bottom of the growth cell without the extra annulus-shaped container. When the cooling tube was in contact with the back of the BN substrate to control the temperature of the substrate, the wall of the $\mathrm{BN}$ pedestal also became cooled and provided the sites for nucleation of GaN crystals. Once these small crystals were formed on the sidewall, liquid Ga began to creep up the wall, since liquid Ga wets $\mathrm{GaN}$ completely under these growth conditions and eventually covered the whole BN substrate, Therefore, the Ga source had to be separated physically from the substrate using smaller BN crucible inserts. Improved thermal isolation was also achieved with this separate container by the intervening space. Subsequently, the optimum distance 
between the Ga source and the substrate for the best Ga transport was determined to be $2 \mathrm{~cm}$. The distance was defined as the length from the center of the BN substrate to the surface of the Ga source. As shown in Fig. 11.3, the crystal size increased as the distance decreased due to the reduced diffusion length. The $\mathrm{Ga}$ flux is proportional to the concentration difference and inversely proportional to the diffusion length as indicated in Fick's law[3]. Therefore, all the growth experiments were conducted for this distance.

\subsection{High Temperature Nucleation}

One of the processing steps which has not been well-studied in GaN bulk crystal growth from the gas phase is the nucleation stage. In a conventional process, $\mathrm{NH}_{3}$ is introduced at room temperature. The temperature profile for a conventional process used in this research is shown in Fig. 11.4(a). The formation of $\mathrm{GaN}$ is thermodynamically favorable during the ramp-up before the system reaches the growth temperature. This results in numerous nucleation and smaller crystals. In addition, Ga spattering that occurs at lower temperatures as a result of vigorous reaction of $\mathrm{Ga}$ with $\mathrm{NH}_{3}$, as described in the first Chapter of this Chapter, produces free $\mathrm{Ga}$ on the substrate prior to growth.

To avoid the numerous nucleation and Ga spattering, high temperature nucleation was employed, where nitrogen was used during the ramp-up and ammonia was introduced at a higher temperature. The temperature profile used in the high temperature nucleation technique is shown in Fig. 11.4(b). The total free energy change $\Delta \mathrm{G}_{\text {total }}$ involved in nucleating a spherical particle of radius $r$ is given by[4,5] 


$$
\Delta G_{\text {total }}=\frac{4}{3} \pi r^{3} \Delta G_{v}+4 \pi r^{2} \gamma
$$

where $\Delta \mathrm{G}_{\mathrm{v}}$ is the free energy change per unit volume for forming the stable condensate from the vapor and $\gamma$ is the surface energy. A graphical representation of the above equation is given in Fig. 11.5, where the contribution of both the surface and the bulk to the free energy change during nucleation are shown. For the formation of the surface, work must be carried out on the system; in the formation of the bulk, work is gained from the system. Therefore, the two terms on the right-hand side of the above equation are of opposite sign and depend differently on $r$. The total free energy change upon transformation passes through a maximum, $\Delta \mathrm{G}^{*}$. The maximum value corresponds to the critical nucleus size, $r_{c}$, which can be obtained by setting $\mathrm{d} \Delta \mathrm{G} / \mathrm{dr}=0$.

$$
r_{c 1}=-\frac{2 \gamma}{\Delta G_{v}} \propto \frac{1}{\ln \left(\frac{p}{p_{o}}\right)}
$$

where $\Omega$ is the atomic volume. For very small nuclei $\left(r<r_{c 1}\right)$, the reduction in volume free energy is much smaller than the large surface energy, which would result from its formation, thus the nucleus is unstable. The free energy of the system is decreased by allowing the nucleus to shrink. For nuclei larger than the critical nucleus size $\left(r>r_{c 1}\right)$, the energy of the system can be decreased by continued growth of the nucleus. This means that there is a free energy barrier to the nucleation, $\Delta \mathrm{G}_{1}{ }^{*}$, given by

$$
\Delta G_{1}^{*}=\frac{4}{3} \pi r_{c}^{3} \gamma
$$

The nucleation rate is simply determined by the probability of these critical nuclei overcoming this free energy barrier, which represent higher energy states of the system and is shown in Fig. 11.6, as a function of supersaturation. The size of the critical nucleus 
increases $\left(\mathrm{r}_{\mathrm{c} 1}<\mathrm{r}_{\mathrm{c} 2}\right)$ with increasing temperature and with decreasing supersaturation $\left(\mathrm{p} / \mathrm{p}_{\mathrm{o}}\right.$ $<1)[6,7]$, as shown in Fig. 11.5. Therefore, the number of supercritical nuclei decreases rapidly with temperature due to the exponential dependence of the nucleation rate on the free energy barrier, $\Delta \mathrm{G}^{*}$ and with decreasing supersaturation. Therefore, nucleation at a higher temperature results in a reduced number of nuclei as compared to the conventional process and leads to growth to a larger crystal because more incoming vapor species would be incorporated in a nucleus. In summary, the high temperature nucleation employed in the current research has the following advantages:

(1) a reduction in the nucleation density $\rightarrow$ larger crystals.

(2) minimization of a GaN crust on the liquid Ga surface and Ga spattering during $\rightarrow$ continuous Ga flux.

(3) a cleaner BN template prior to growth $\rightarrow$ reproducible data.

\subsection{Effect of the Direct Impingement of $\mathrm{NH}_{3}$ on the GaN Growth}

To examine the effect of the direct impingement of $\mathrm{NH}_{3}$ on the growth of $\mathrm{GaN}$ crystals, a thin alumina plate was placed over the BN substrate. Without the roof, very thin needle-shaped GaN crystals were grown on the BN substrate (Fig. 11.7(a)). With the roof, dark amber crystals of low aspect ratios were obtained (Fig. 11.7(b)). Upon impingement on the alumina plate, $\mathrm{NH}_{3}$ molecules tend to dissociate and a reduced amount of ammonia becomes available for the reaction with Ga vapor. Therefore, the Ga vapor under the plate is allowed to react with smaller amount of non-dissociated $\mathrm{NH}_{3}$ 
molecules. In turn, the V/III ratio becomes smaller as compared with the growth without the plate. The existence of the roof reduced the forced convection and more Ga vapor can be transported to the $\mathrm{BN}$ substrate area. This supports the postulation that low V/III ratio promotes the lateral growth of GaN crystals in the current growth system. The above experiment along with the one described in Fig. 4.5 in Chapter 4 of this thesis indicated that higher Ga flux promotes platelet growth.

\subsection{Effect of $\mathrm{NH}_{3}$ Flow Rate on the Crystal Morphology of GaN}

Figure 11.8 shows optical micrographs of the $\mathrm{GaN}$ crystals grown at $1130^{\circ} \mathrm{C}$, 430Torr, and ammonia flow rates in the range from $25 \mathrm{sccm}$ to $75 \mathrm{sccm}$. As the flow rate was increased, the thickness of the platelet increased and the width of the crystals decreased and became almost constant at the flow rate of 50sccm and higher. SEM micrographs of these crystals were given in Fig. 4.9 in Chapter 4 of this thesis. Free Ga was observed at the ammonia flow rates lower than $60 \mathrm{sccm}($ Fig. 11.8(a) and 11.8(b)), indicating that there was insufficient ammonia. The amount of free Ga decreased with increasing ammonia flow rate to $50 \mathrm{sccm}$. Free Ga was not visibly observed at $60 \mathrm{sccm}$ and crystal growth in the vertical direction began to increase at this point. The color of the crystal became transparent. It is evident that $\mathrm{GaN}$ platelets are preferred at low V/III ratios under these conditions. The nucleation density increased with increasing ammonia flow rate. As the ammonia flow rate was increased above $75 \mathrm{sccm}$, polycrystalline $\mathrm{GaN}$ powder began to appear and covered the entire substrate at $100 \mathrm{sccm}$ possibly due to the 
enhanced forced convection. Raman spectroscopy(Fig. 11.9) showed that crystals grown using ammonia flow rates $>50 \mathrm{sccm}$ exhibited only allowed modes for wurtzite structure than those grown at lower flow rates. Therefore, the minimum ammonia flow rate of $60 \mathrm{sccm}$ was required to obtain crystals with better surface morphology and Raman characteristics.

\subsection{In Situ Monitoring of the Seeded Growth}

The in situ monitoring of the crystal growth with the aid of a long distance microscope allowed us to observe the morphological change or growth instability during growth. This was very useful especially in seeded growth of GaN since the initial stage of the growth on the seed crystal was crucial to maintain a cleaner template for growth. When the surface of the seed crystal decomposed or became covered by free Ga prior to the growth, the continuous growth of the seed crystal was not possible. Therefore, the ammonia should be introduced prior to the decomposition of the seed crystal. If the temperature at which ammonia is introduced was too low, free Ga would disturb the initiation of the seeded growth due to the Ga spattering. The in situ monitoring facility enabled us to determine the temperature at which the ammonia was introduced to avoid the decomposition and Ga spattering.

A cluster of GaN needles used as a seed is shown in Fig. 11.10(a). Upon initiation

of growth by introducing ammonia, new GaN crystals began to form on the $\mathrm{BN}$ surface(Fig. 11.10(b)), but not around the seed crystals. This nucleation exclusion zone 
continued to exist throughout the growth run and did not change in size significantly(Fig. 11.10(c)-(f)) and did not change appreciably during the growth.. This indicates that most Ga vapor and $\mathrm{NH}_{3}$ molecules became incorporated into the seed crystals and the local concentrations of $\mathrm{Ga}$ and $\mathrm{NH}_{3}$ near the seed crystals were too low to induce a significant supersaturation for nucleation. Optical micrographs of the growing crystals during seeded growth of a GaN platelet is shown in Fig. 11.11. The resultant needle-shaped and platelet-like GaN crystals via seeded growth are shown in Fig. 4.11 and 4.12 in Chapter 4 of this thesis. One difficulty during the seeded growth was the control of micro Ga droplets due to the excessive condensation. Because the lateral growth conditions of $\mathrm{GaN}$ crystals employed in the current research are low V/III ratios. Therefore, the processing window is narrow and very close to the condition for the excessive Ga condensation. Any instability in the $\mathrm{Ga}$ source or temperature increase even by $5^{\circ} \mathrm{C}$ would result in the excessive condensation of Ga which in turn terminates the growth run. The processing variables including the Ga source temperature, substrate temperature, total pressure, and the ammonia flow rate must be controlled with precision.

\subsection{Growth of GaN Crystals on GaN/AIN/SiC and AIN/SiC Substrates}

On $\mathrm{SiC}(0001)$ substrates, almost no nucleation of $\mathrm{GaN}$ occurred at temperatures higher than $1100^{\circ} \mathrm{C}$. GaN films grown on SIC substrate at temperature less than $\sim 1000^{\circ} \mathrm{C}$ were partially continuous but the growth rate was significantly low $(\sim 2 \mu \mathrm{m} / \mathrm{hr})$. Then, GaN thin films deposited on $\mathrm{SiC}$ substrate using AlN buffer layer were used as a seed to 
facilitate the nucleation and grow larger crystals. The ammonia was introduced at $\sim 1050^{\circ} \mathrm{C}$ to avoid decomposition of the seed films using the high temperature nucleation technique. The introduction of ammonia at temperatures higher than $\sim 1100^{\circ} \mathrm{C}$ resulted in decomposition of the GaN thin films and randomly distributed powder-like particles remained on the thin film surface throughout the growth run. With precise control of the process, $\sim 100 \mu \mathrm{m}$ thick films were grown on $\mathrm{GaN} / \mathrm{AlN} / \mathrm{SiC}$ at $1130^{\circ} \mathrm{C}, 430 \mathrm{Torr}$, and 60sccm of $\mathrm{NH}_{3}$, as shown in Fig. 11.12(a), (b). The surface of the center area consisted of 0.5 1mm wide micro-platelets with micro-cracks, while thicker and continuous films were grown along the edge of the substrate(Fig. 11.12(c)). This may be because the stress is partially relieved near the edge of the substrate. Higher thermal stability of AlN fostered the use of $0.1 \mu \mathrm{m}$ thick AlN thin films as seed crystals. Smaller micro-platelets of 200 300 $\mu \mu$ in width were grown on AlN/SiC(0001) substrate(Fig. 11.12(d) and (e)). The latter showed more severe micro-cracks among the micro-platelets than the crystal grown on the GaN/AlN/SiC substrate. Continuous films of GaN crystals were also observed along the edge of the substrate. To use large area GaN thin films as seed crystals, control of the substrate temperature, Ga flux, and ammonia flow with precision would be required to avoid possible growth instabilities during growth. 


\subsection{References}

1. A. Pisch, R. Schmid-Fetzer, J. Crystal Growth, 187, p329(1998)

2. R. C. Schoonmaker, A. Buhl and J. Lemley, J. Phys. Chem., 69, 3455(1965)

3. D. R. Gaskell, "An Introduction to Transport Phenomena in Materials Engineering", Macmillan Publishing Company, New York, p480 (1992)

4. C. R. Barrett, W. D. Nix, and A. S. Tetelman, "The Principles of Engineering Materials", Prentice-Hall, Inc, New Jersey, p163 (1973)

5. M. M. Factor, I. Garrett, "Growth of Crystals from the vapor", John Wiley \& Sons, New York, p83 (1974)

6. M. Ohring, "The materials Science of Thin Films", Academic Press, Inc, p204(1992)

7. K. Tu, J. W. Mayer, and L. C. Feldman, "Electronic Thin Film Science", Macmillan Publishing Company, New York, p122 (1987) 


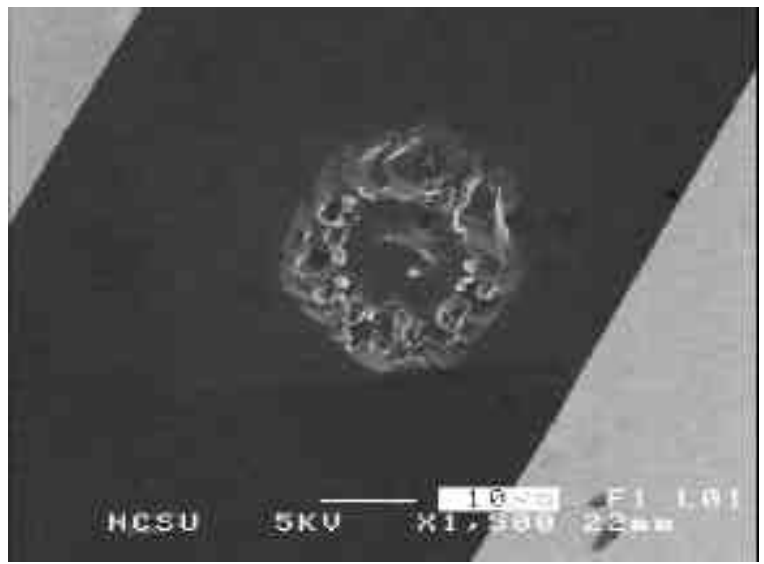

(a)

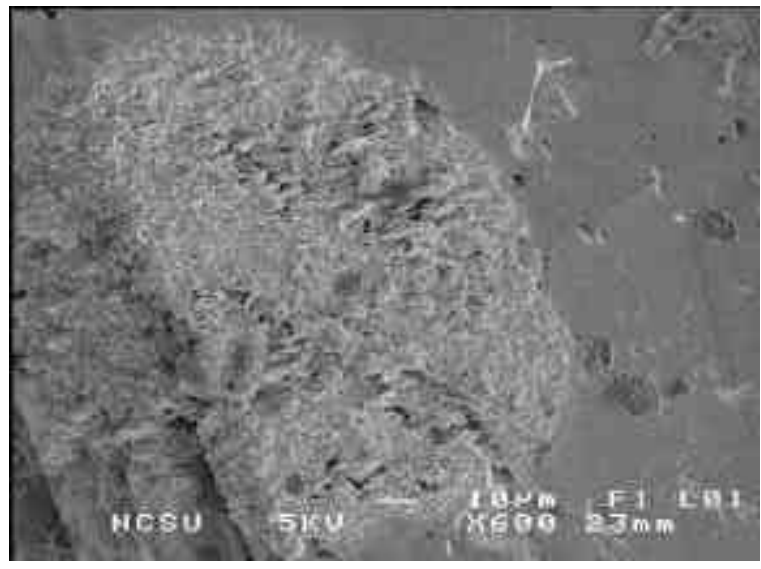

(b)

Figure 11.1 SEM micrographs of (a) the surface of a GaN crystal grown at $1130^{\circ} \mathrm{C}$, (b) a magnified view of the area (a), and (c) the surface of a crystal grown at $1170^{\circ} \mathrm{C}$ 


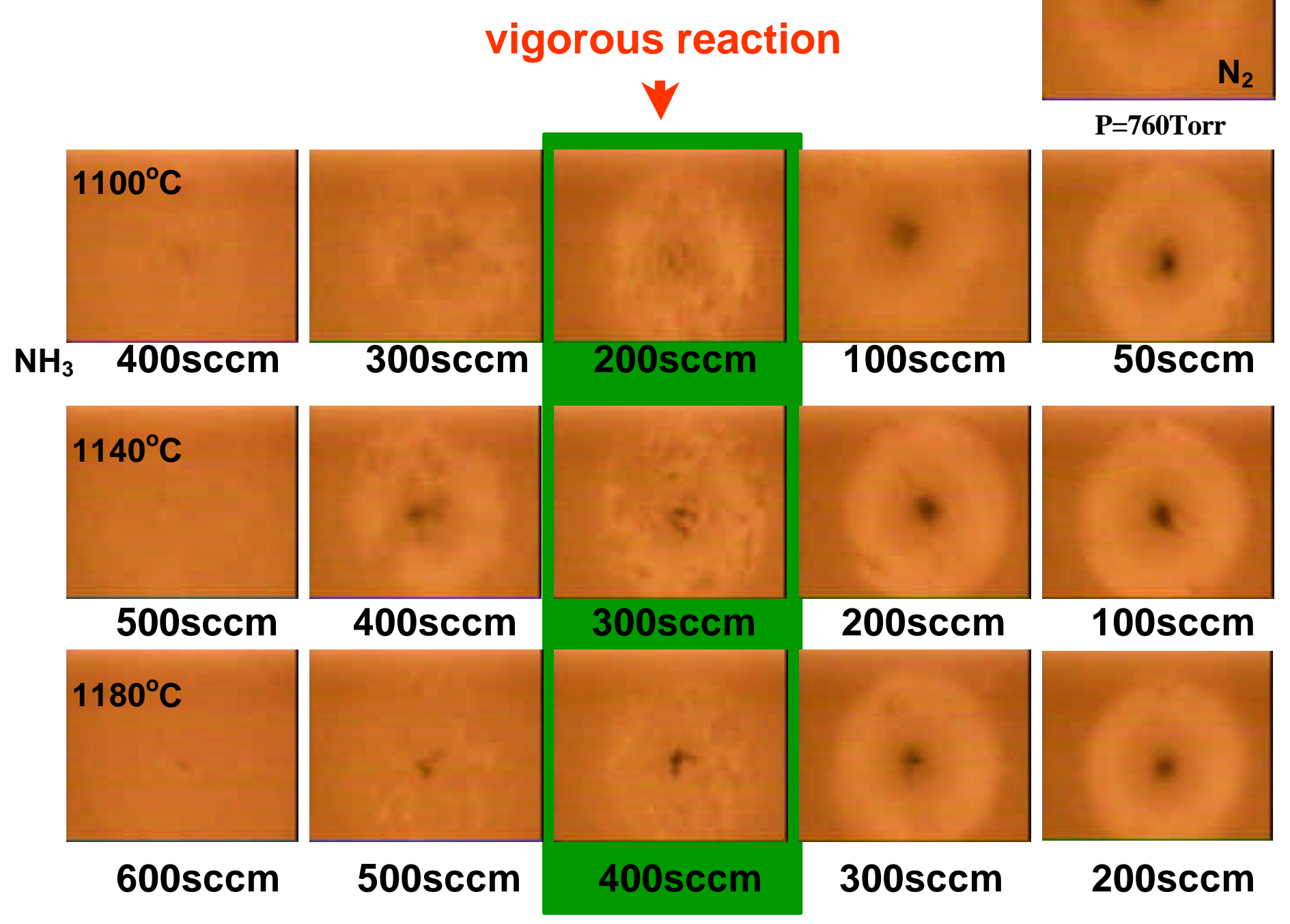

Figure 11.2 In-situ monitoring of the surface of the Ga source at different temperatures and $\mathrm{NH}_{3}$ flow rates at 760 Torr. 


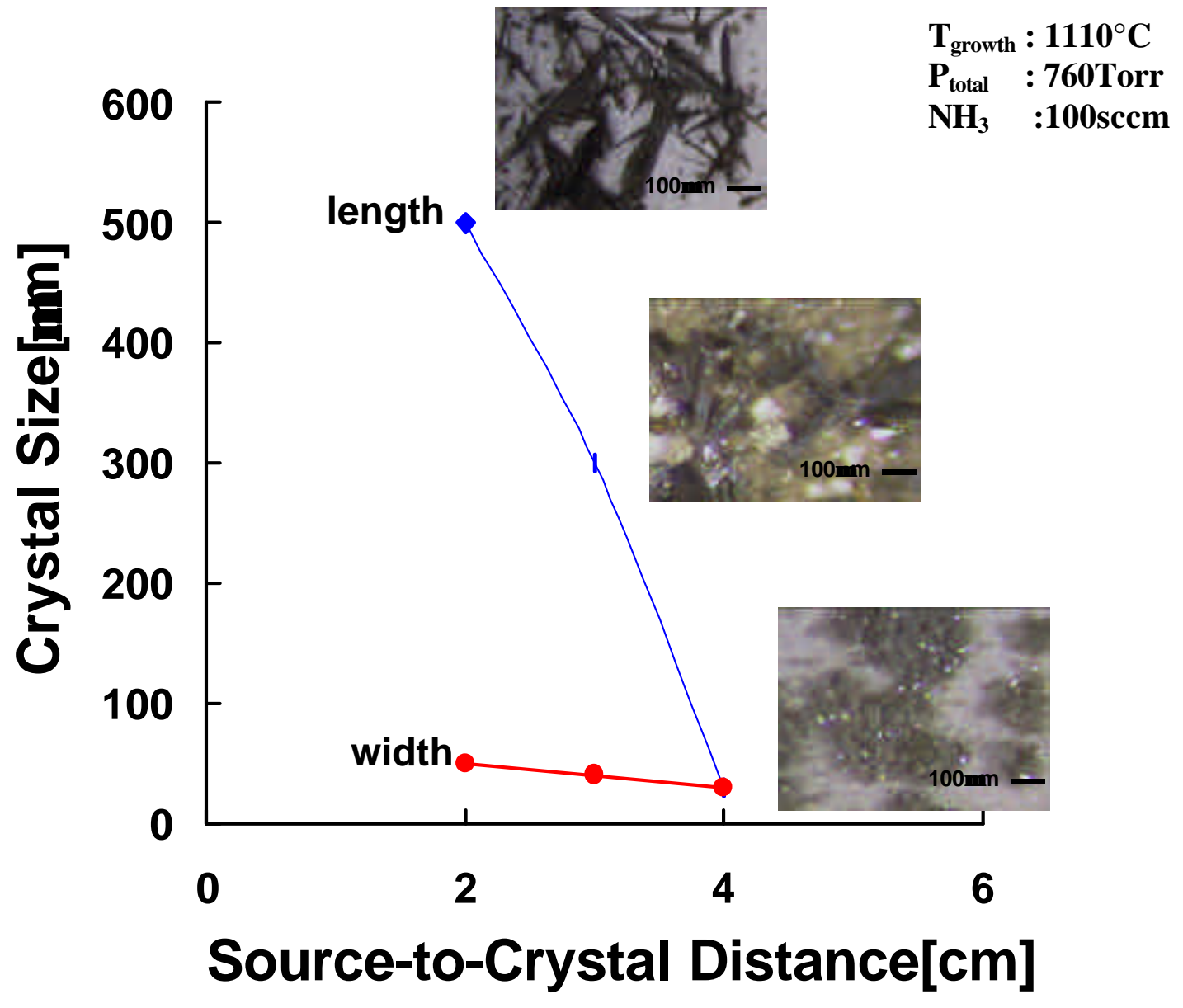

Figure 11.3 Crystal size variation as a function of source-to-crystal distance. 


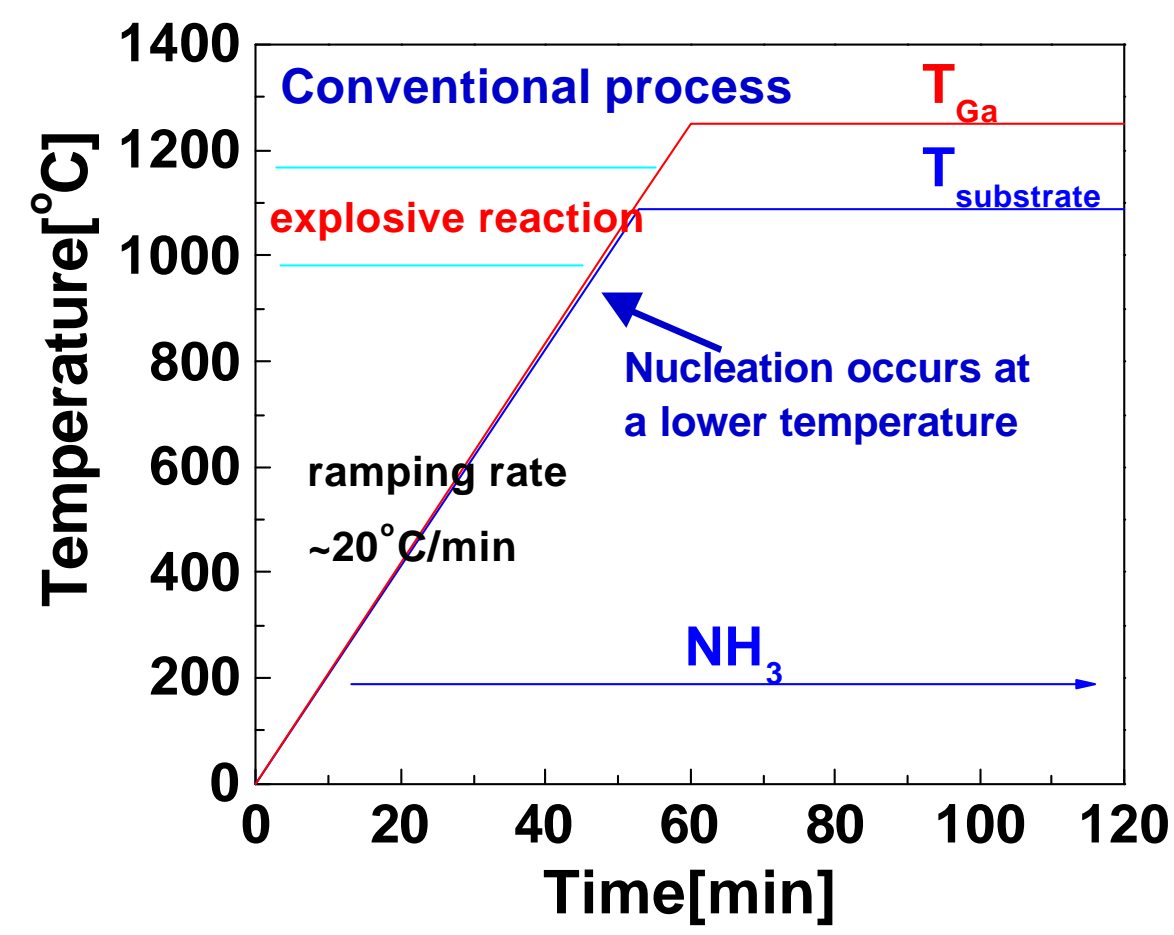

(a)

High temperature nucleation

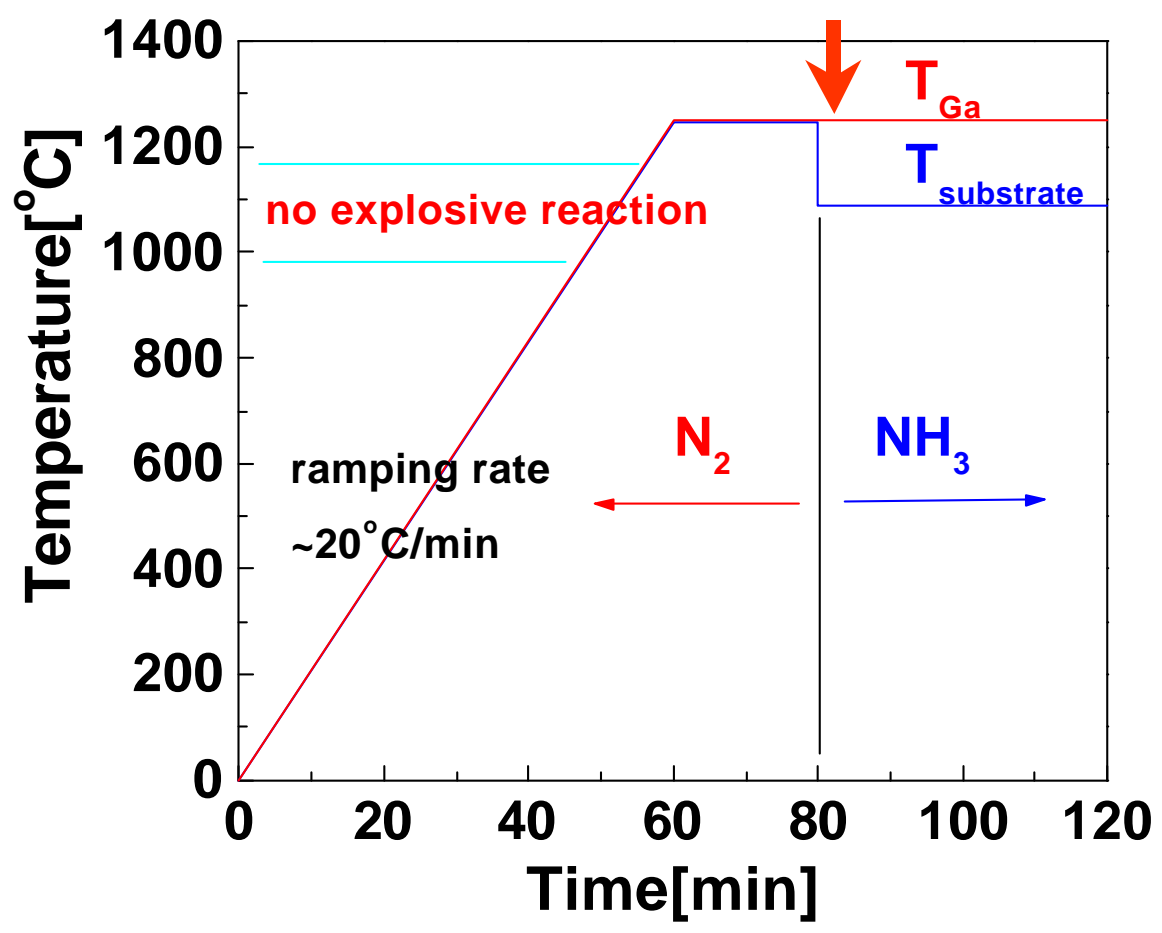

(b)

Figure 11.4 Temperature profile used in (a) the conventional process and (b) the high temperature nucleation technique. 


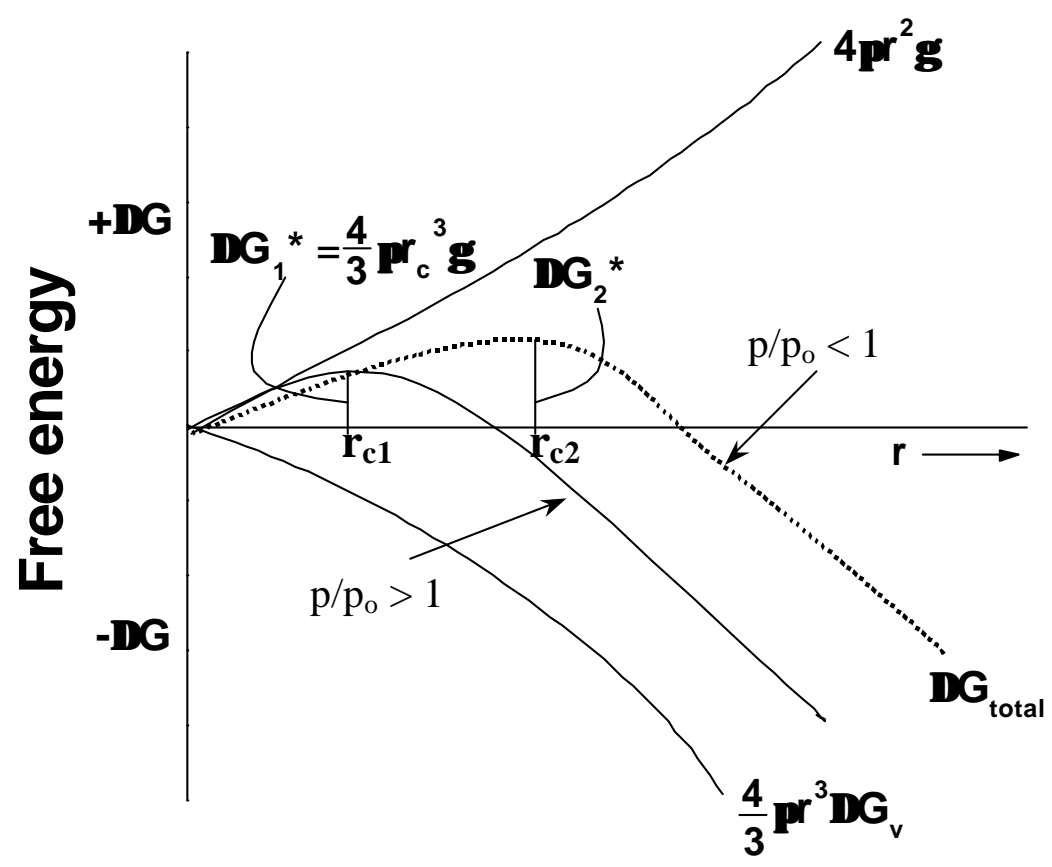

Figure 11.5 Free energy changes associated with nucleation of a spherical particle of radius r.[6]

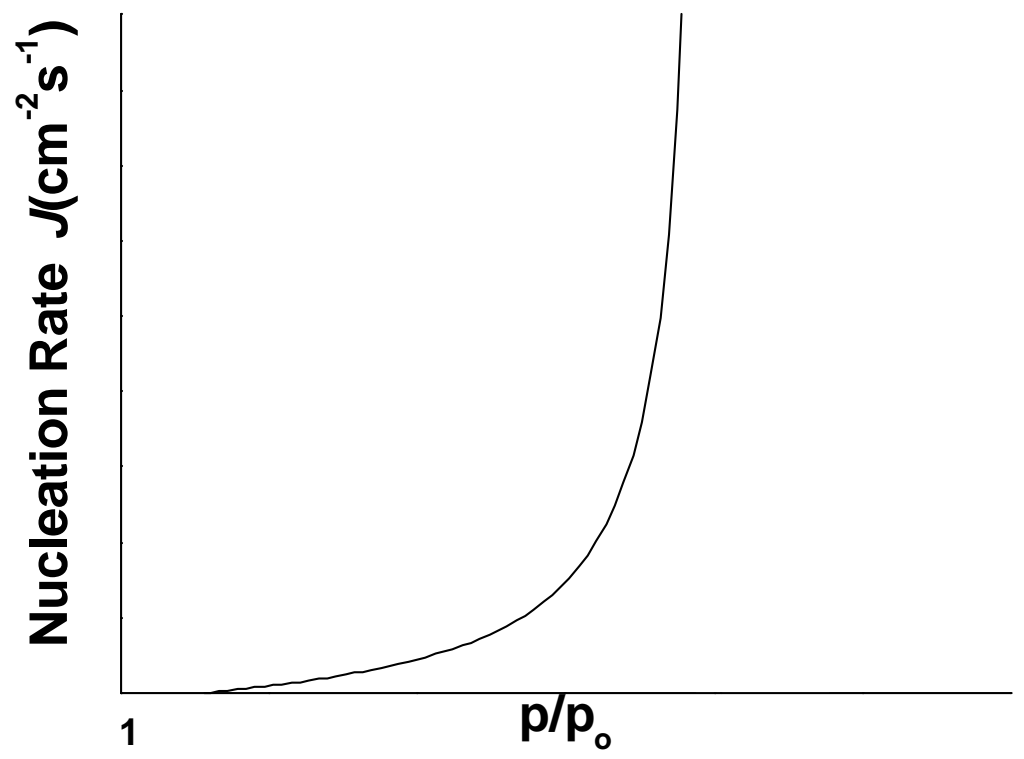

Figure 11.6 Nucleation rate $J$ as a unction of supersaturation, $p / p_{o}$ [7] 


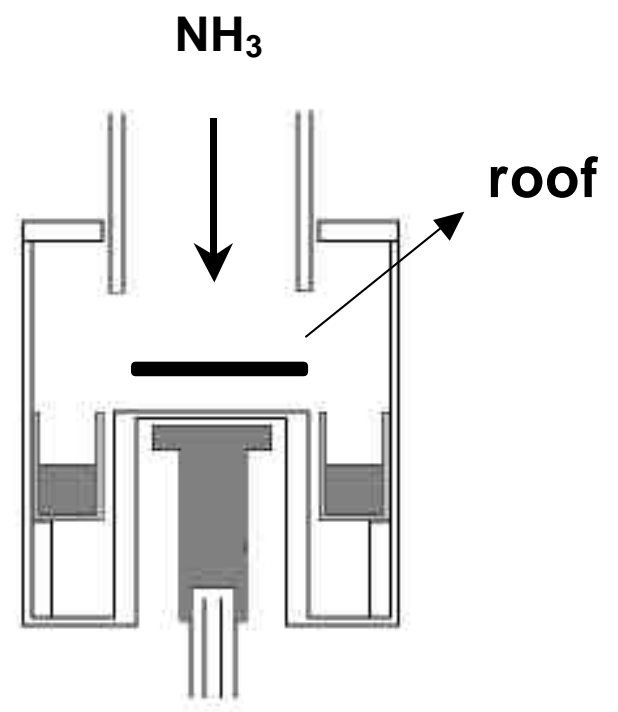

\section{Without the roof}
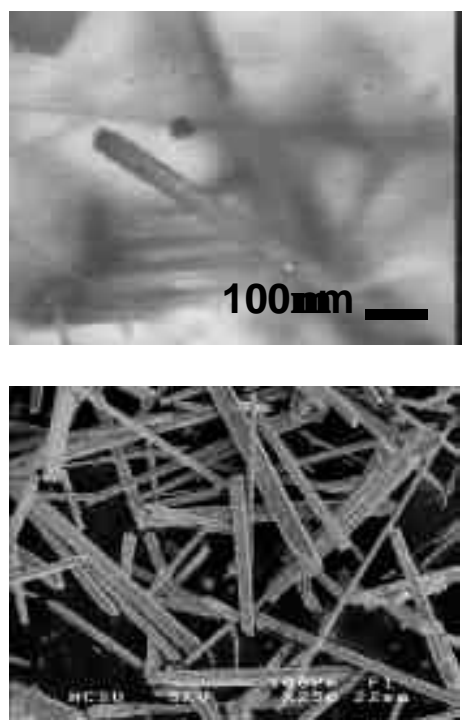

(a)
With the roof
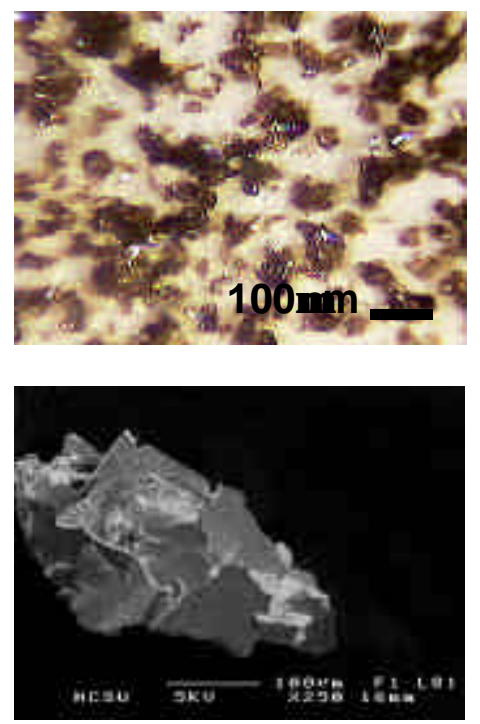

(b)

Figure 11.7 Effect of direct impingement of $\mathrm{NH}_{3}$ on the crystal growth at $1130^{\circ} \mathrm{C}$, 760Torr, $100 \mathrm{sccm}$ of $\mathrm{NH}_{3}$. 


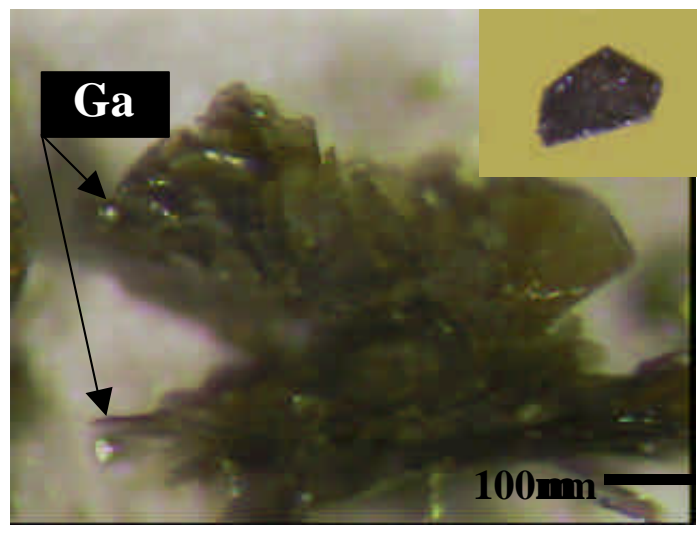

(a)

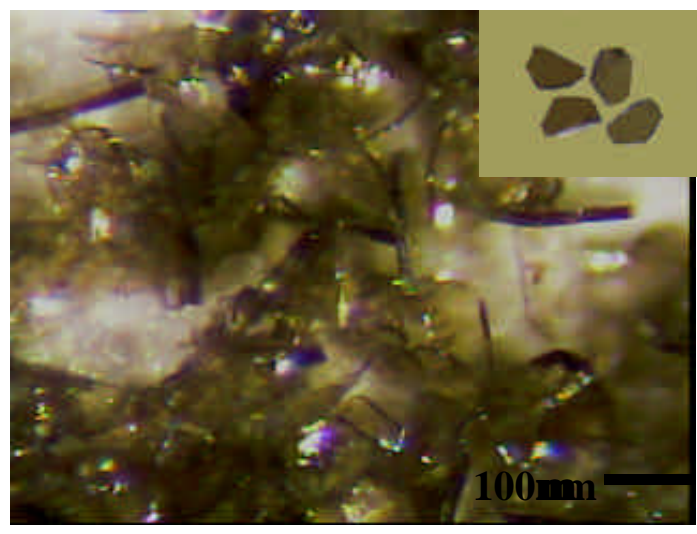

(c)

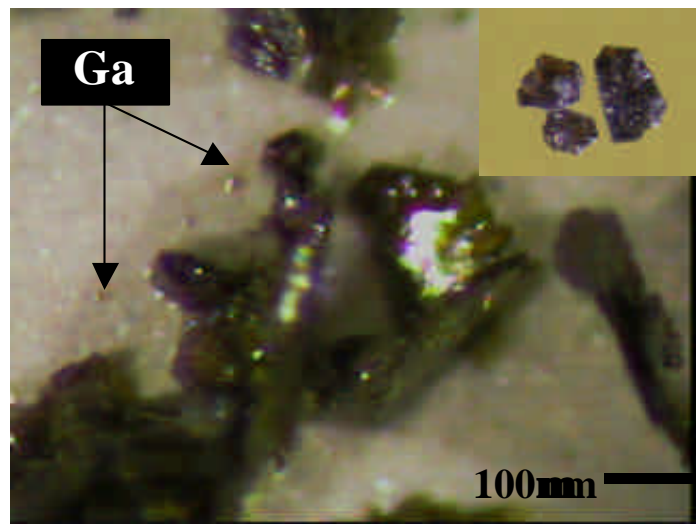

(b)

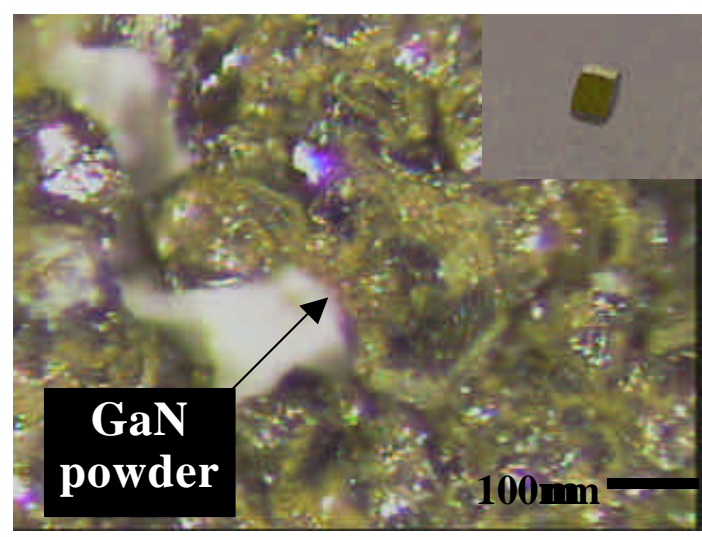

(d)

Figure 11.8 Optical micrographs of crystals grown at $1130^{\circ} \mathrm{C}, 430 \mathrm{Torr}$, and $\mathrm{NH}_{3}$ flow rate of (a) $25 \mathrm{sccm}$, (b) $40 \mathrm{sccm}$, (c) $60 \mathrm{sccm}$, (d) $75 \mathrm{sccm}$ for $2 \mathrm{hrs}$. 


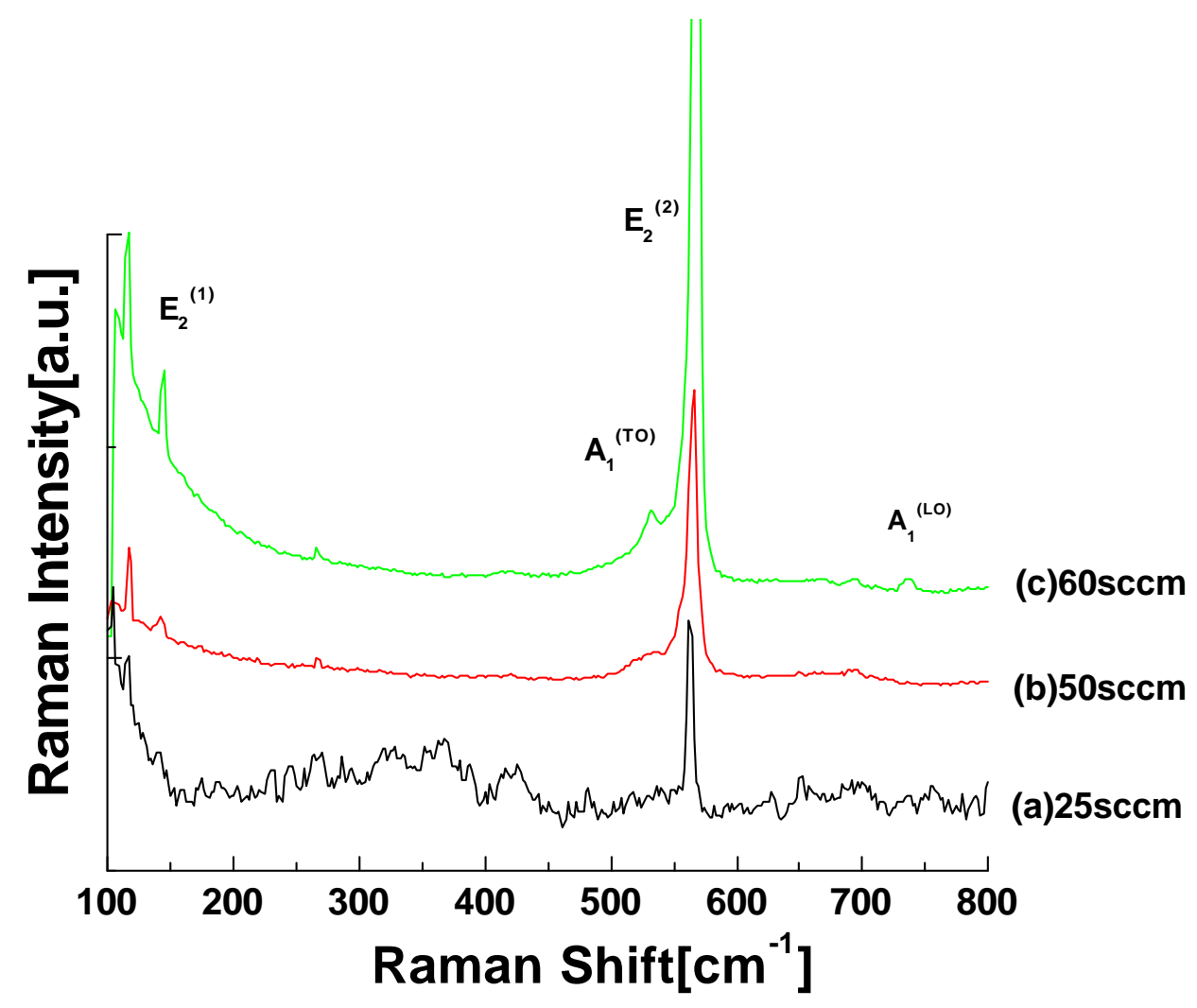

Figure 11.9 Raman spectra of the GaN platelets grown at $1130^{\circ} \mathrm{C}, 430 \mathrm{Torr}$ and (a) $25 \mathrm{sccm}$, (b) $50 \mathrm{sccm}$, and (c) $60 \mathrm{sccm}$ of $\mathrm{NH}_{3}$. 


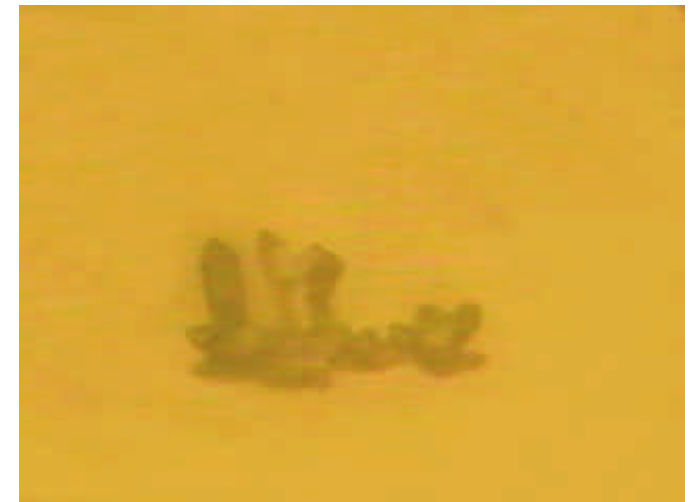

(a) seed crystal

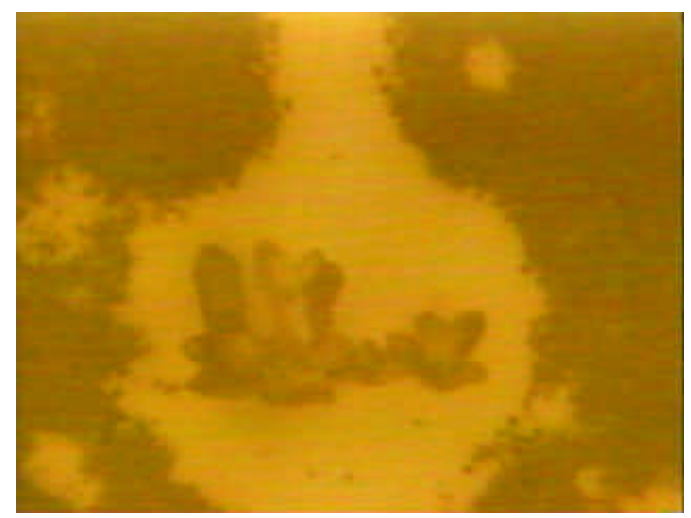

(b) $1 \mathrm{hr}$

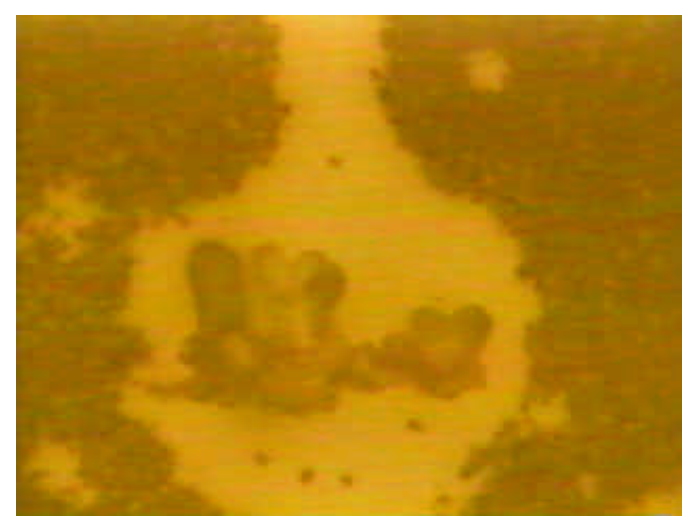

(c) $2 \mathrm{hrs}$

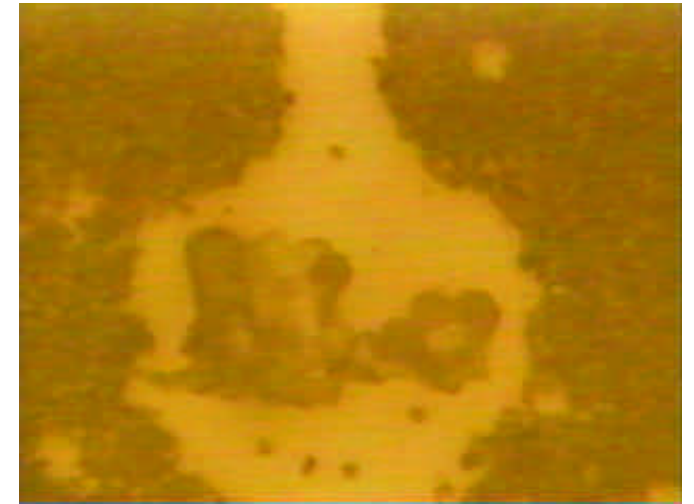

(d) $3 \mathrm{hrs}$

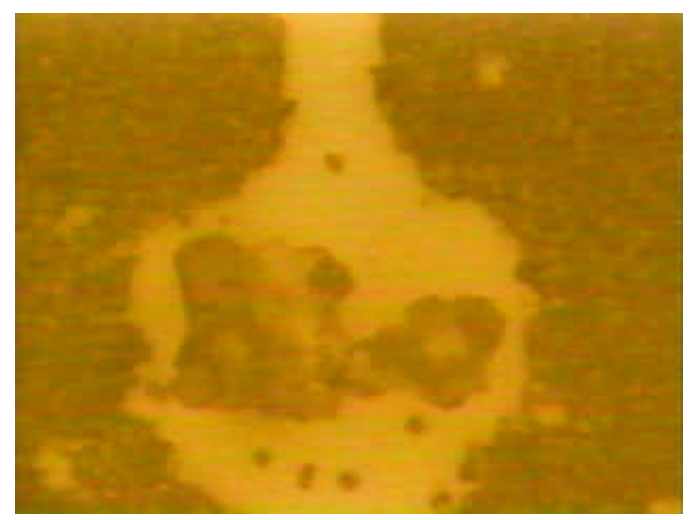

(e) $4 \mathrm{hrs}$

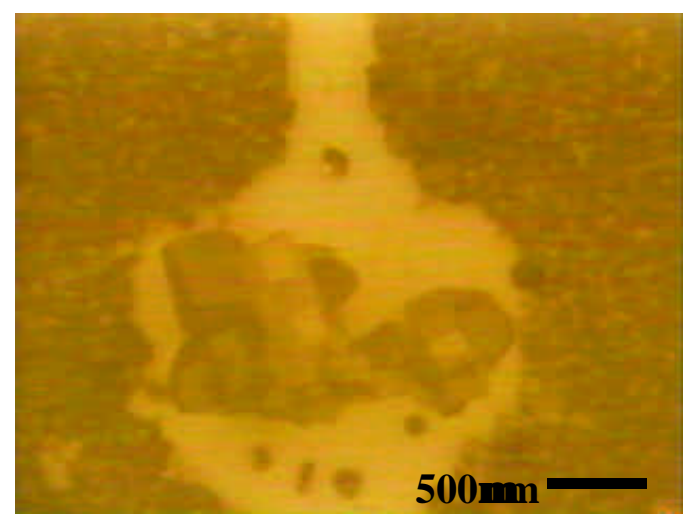

(f) $6 \mathrm{hrs}$

Figure $11.10 \mathrm{In}$ situ monitoring of the seeded growth of $\mathrm{GaN}$ needles at $1130^{\circ} \mathrm{C}, 430 \mathrm{Torr}$ and $60 \mathrm{sccm}$ of $\mathrm{NH}_{3}$. 


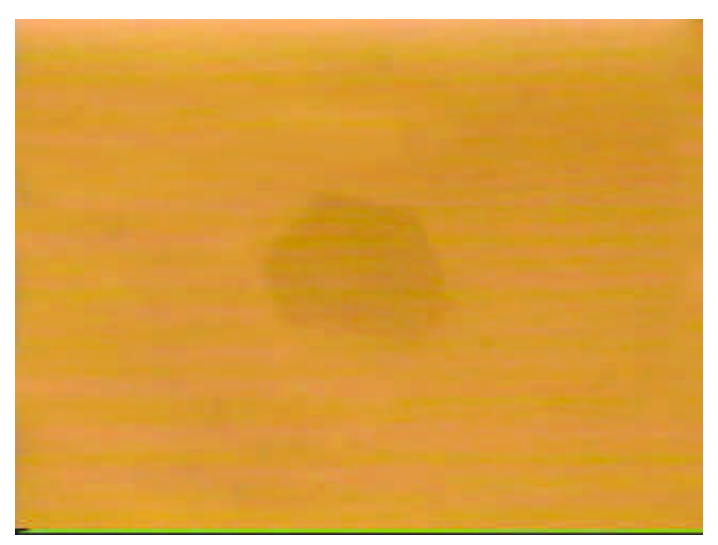

(a) seed crystal

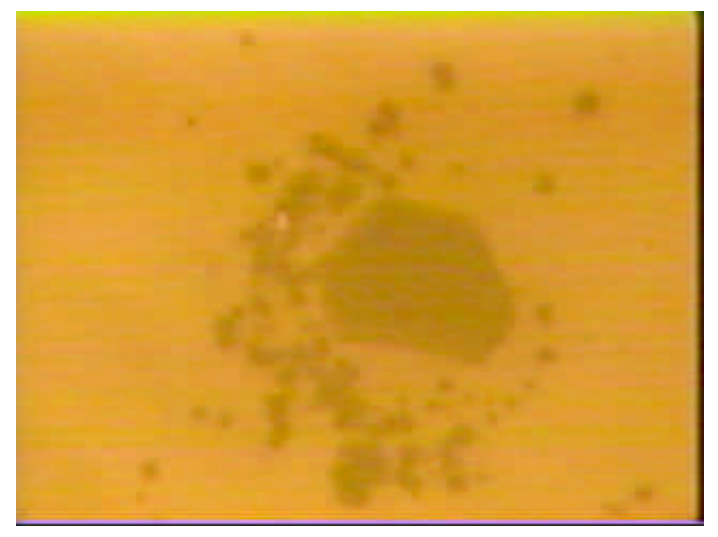

(b) $1 \mathrm{hrs}$

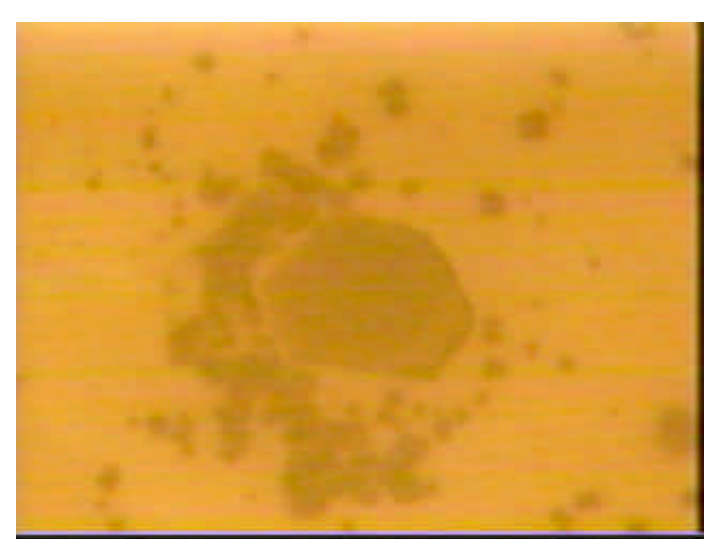

(c) $2 \mathrm{hrs}$

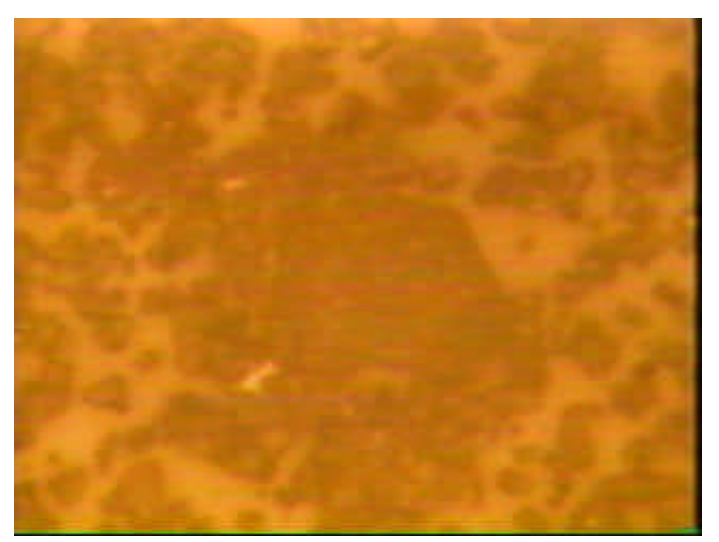

(d) $3 \mathrm{hrs}$

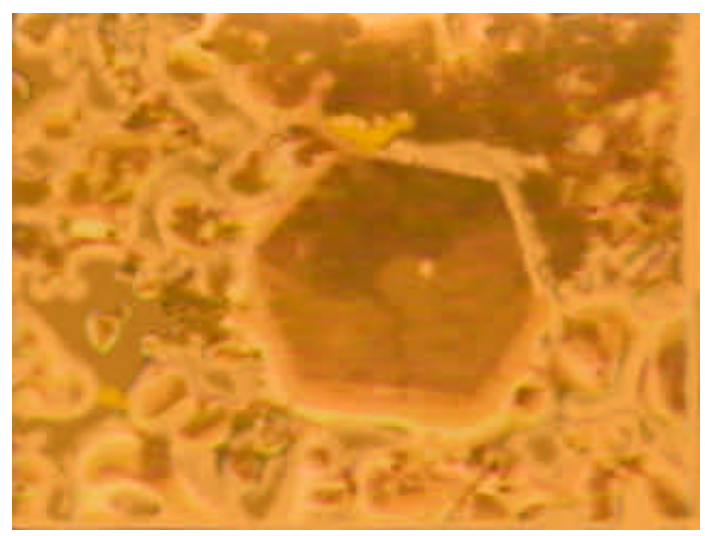

(e) $4 \mathrm{hrs}$

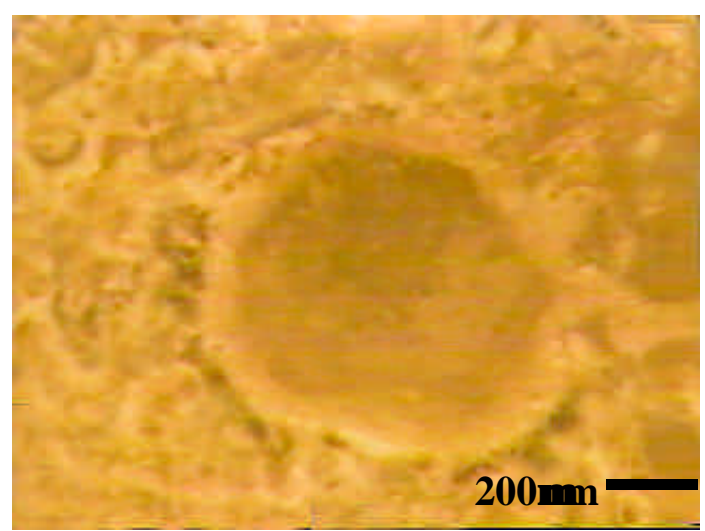

(f) $6 \mathrm{hrs}$

Figure $11.11 \mathrm{In}$ situ monitoring of the seeded growth of a $\mathrm{GaN}$ platelet at $1130^{\circ} \mathrm{C}$, 430Torr and 60sccm of $\mathrm{NH}_{3}$. 


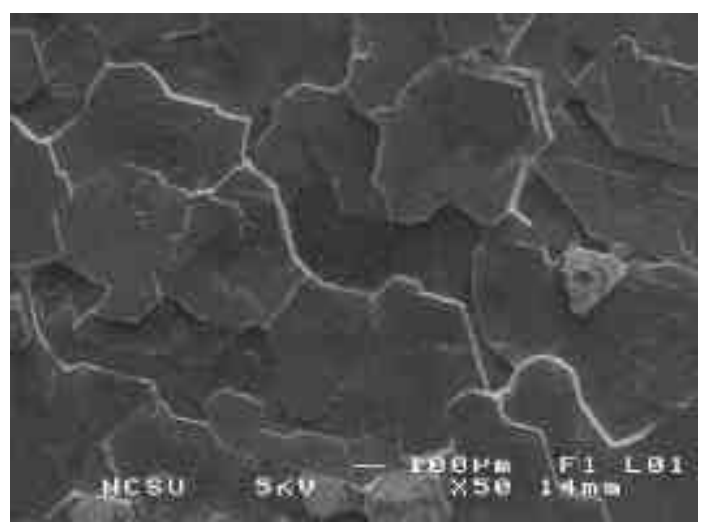

(a)

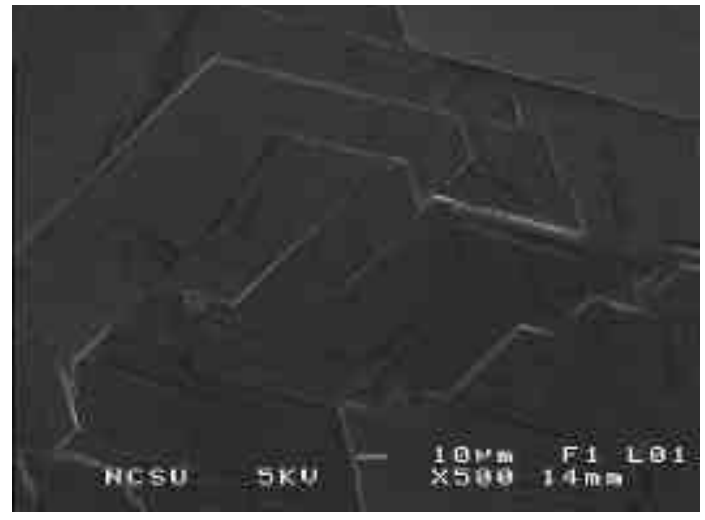

(b)

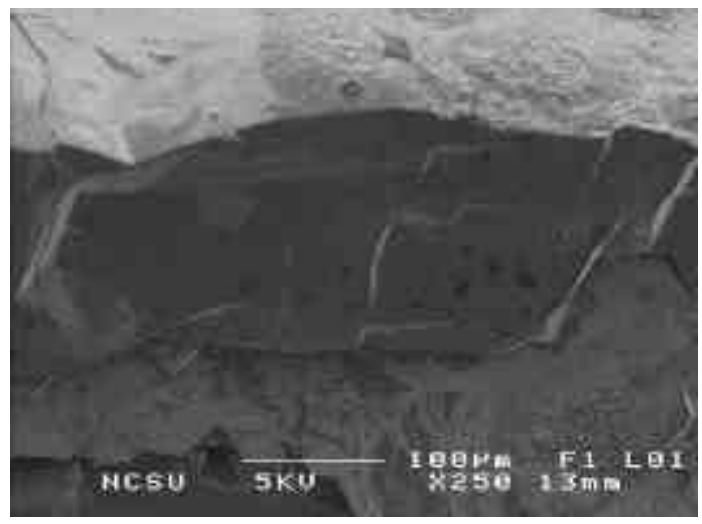

(c)

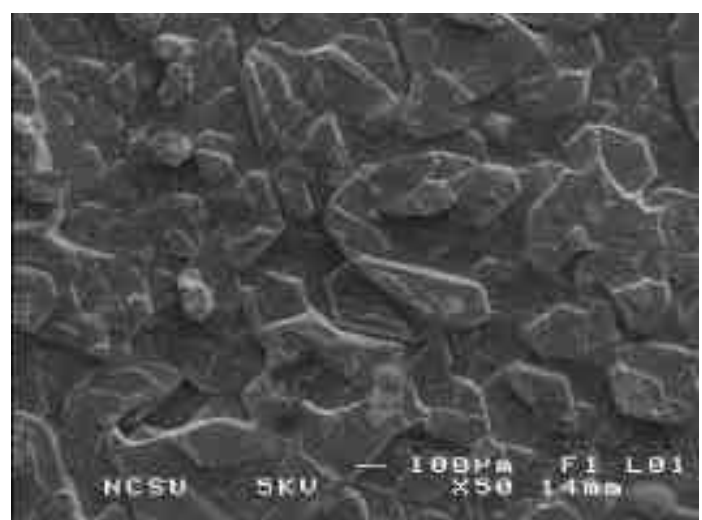

(d)

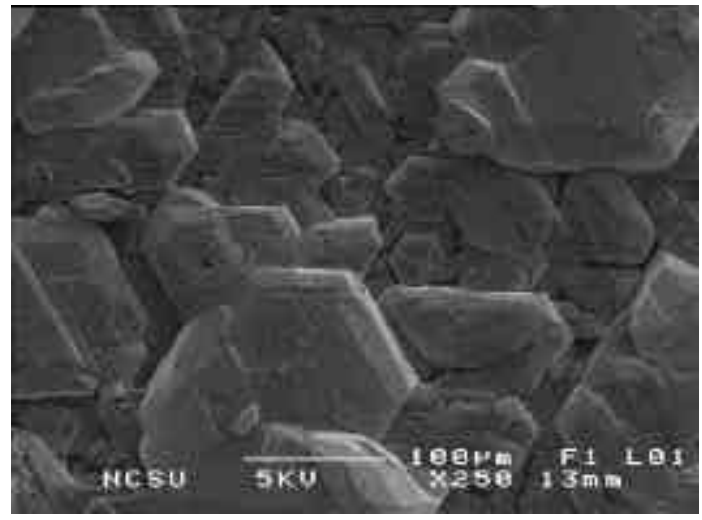

(e)

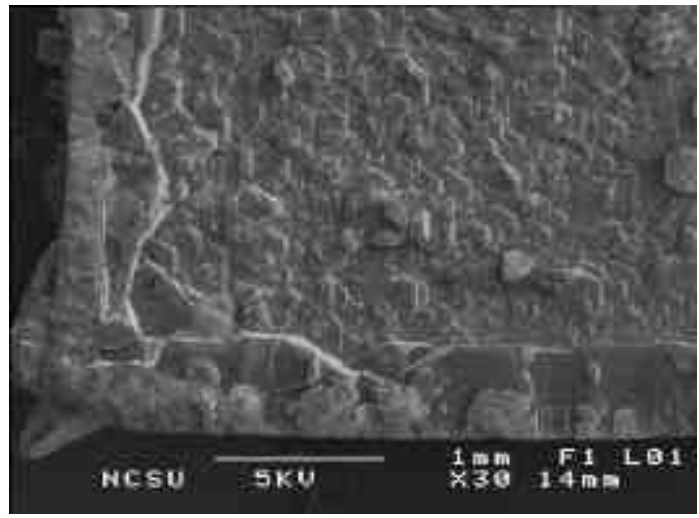

(f)

Figure 11.12 SEM micrographs of $\mathrm{GaN}$ thick films grown at $1130^{\circ} \mathrm{C}, 430 \mathrm{Torr}$, and $60 \mathrm{sccm}$ of ammonia for $6 \mathrm{hrs}$ on (a)(b)(c)GaN/AlN/SiC and (d)(e)(f) AlN/SiC substrate. 


\section{Appendix 2: GaN Growth System Operation}

\subsection{Inserting Growth Crucible in Growth Chamber}

1. Keep the butterfly valve closed during loading.(Set the butterfly valve to close on the pressure controller panel.)

2. Insert the growth crucible with $\mathrm{Ga}$, which is screwed onto the pedestal connected to the stainless steel support that is guided via four rods at the bottom part of the system.

3. Raise the bottom end cap, on which the growth crucible is screwed in place, into the reactor tube slowly and secure the bottom end cap with four screws.

4. It should be checked that the O-ring between the bottom end cap and the alumina reactor tube is secure. If the reactor chamber pressure does not go down below 20mTorr, reopen the bottom end cap and secure the O-ring again until the pressure below $20 \mathrm{~m}$ Torr is attained.

\subsection{Pump Down the Chamber after Loading the Sample}

1. Evacuate the reactor tube by opening the butterfly valve near the mechanical pump.

2. Wait until the pressure in the reactor tube reaches below $20 \mathrm{mTorr}$. If the pressure will now go below 20mTorr, reopen the bottom end cap and secure the O-ring in the bottom end cap. 
3. Close the butterfly valve. If the pressure goes up quickly upon closing the valve, check the bottom end cap to make sure there is no leak.

4. Set nitrogen flow rate at $\sim 100 \mathrm{sccm}$.

5. Open the nitrogen gas switch on the gas panel and set MFC to open on the Multigas controller and wait until the pressure reaches 760Torr.

6. Evacuate the system by opening the butterfly valve.(Purging with nitrogen facilitates faster pump down.)

7. Repeat the step 2 5 three times. This ensures the minimal residual gas in the reactor tube.

8. Set the total pressure to 760Torr and the nitrogen flow rate to $60 \mathrm{sccm}$.

9. Fill the reactor tube with nitrogen prior to ramp-up.

\subsection{Ramp-up Procedure}

1. Make sure the cooling water valve is on.(located on the wall behind the system.)

2. If the water flow rate is too low, warning light is lit on the safety control panel.

3. After making sure the reactor tube is filled with 760Torr of nitrogen, turn on both top and bottom power supplies.

4. Make all the settings in Labview as desired(i.e., top heater temperature, bottom heater temperature, ammonia flow rate, nitrogen flow rate, ramp-up rate ramp-down rate, and growth time.)

5. Execute the LabView program. 
6. When the temperature reaches the set value, switch the gas from nitrogen to ammonia of the set flow rate.

7. Raise the cooling rod to adjust the growth temperature of the $\mathrm{BN}$ substrate. When this is done, try not to unscrew the nut too much to move the cooling rod. It may introduce excess air into the reactor tube and may oxidize the thermocouple shield material. Introduction of ammonia and inserting the cooling rod must be performed in a short period of time.

8. Growth is commenced at this point.

\subsection{In situ Monitoring}

1. Turn on TV and VCR when the temperature reaches the set value.

2. Execute the frame grabber program on computer.

3. Adjust the contrast and brightness on the frame grabber.

4. Adjust the position of the long focus microscope attached on top flange of the outer chamber and the focus for best view.

5. Run VCR to tape the entire growth run.

6. Take a picture if necessary during the growth run by clicking on the icon on the frame grabber. 


\subsection{Removing the Sample}

1. Upon completion of the growth run the growth system is programmed to be cooled down to room temperature at $\sim 20^{\circ} \mathrm{C} / \mathrm{min}$. It takes about 3 hours for the system to reach room temperature from the heater temperature of $1600^{\circ} \mathrm{C}$.

2. Terminate the LabView program by clicking on the 'Stop' icon on the screen.

3. Turn off both top and bottom power supplies.

4. Turn off the ammonia flow by setting the MFC to close.

5. Evacuate the reactor tube as described previously.

6. Fill the reactor tube with nitrogen to 760Torr.

7. Unscrew the bottom end cap and lower the growth crucible.

8. Remove the growth crucible and sample the crystals

\subsection{Idling of the Growth System}

1. Keep the power supplies off.

2. Make sure all the gas valves are closed.

3. If the system is not running for a few days, it is advised to shut off the cooling water to avoid condensation of moisture on the chamber especially during summer.

4. Keep the mechanical pumps running and make sure all the valves between pumps and the chambers are closed when not in use. 


\subsection{Safety Features}

1. If the temperature of either top or bottom heater exceeds the set value $\left(1700^{\circ} \mathrm{C}\right)$, output of the power supplies is cut off and remained at zero. The set value can be adjusted on the Omega temperature controller located on the front panel. If the temperature increases above $1700^{\circ} \mathrm{C}$, the O-rings between the reactor tube and the outer chamber will be degraded.

2. If the pressure in the outer chamber exceeds $100 \mathrm{mTorr}$, the warning light is lit and the power output goes to zero. The butterfly valve will be widely open to evacuate the reactor tube to avoid the degradation of the heaters due to oxidation.

3. If the flow rate of the cooling water is too low, the warning light is on and the power supply returns to manual mode.

4. All of the above safety features were implemented to protect the graphite heaters. However, monthly check-up of these features is strongly advised in case of malfunctioning. 